Florida International University

FIU Digital Commons

FIU Electronic Theses and Dissertations

University Graduate School

$10-30-2015$

\title{
Caffeine Intake and its Association with Disease Progression, Sleep Quality and Anxiety Symptoms and Nutritional Alterations in People Living with HIV in the Miami Adult Studies on HIV Cohort
}

Venkataraghavan Ramamoorthy

Florida International University, vrama002@fiu.edu

DOI: 10.25148 /etd.FIDC000147

Follow this and additional works at: https://digitalcommons.fiu.edu/etd

Part of the Human and Clinical Nutrition Commons

\section{Recommended Citation}

Ramamoorthy, Venkataraghavan, "Caffeine Intake and its Association with Disease Progression, Sleep Quality and Anxiety Symptoms and Nutritional Alterations in People Living with HIV in the Miami Adult Studies on HIV Cohort" (2015). FIU Electronic Theses and Dissertations. 2255.

https://digitalcommons.fiu.edu/etd/2255

This work is brought to you for free and open access by the University Graduate School at FIU Digital Commons. It has been accepted for inclusion in FIU Electronic Theses and Dissertations by an authorized administrator of FIU Digital Commons. For more information, please contact dcc@fiu.edu. 


\section{FLORIDA INTERNATIONAL UNIVERSITY \\ Miami, Florida}

CAFFEINE INTAKE AND ITS ASSOCIATION WITH DISEASE PROGRESSION, SLEEP QUALITY AND ANXIETY SYMPTOMS AND NUTRITIONAL

\section{ALTERATIONS IN PEOPLE LIVING WITH HIV IN THE MIAMI ADULT STUDIES ON HIV COHORT}

A dissertation submitted in partial fulfillment of

the requirements for the degree of

DOCTOR OF PHILOSOPHY

in

DIETETICS AND NUTRITION

by

Venkataraghavan Ramamoorthy 
To: Interim Dean Mark Williams

Robert Stempel College of Public Health \& Social Work

This dissertation, written by Venkataraghavan Ramamoorthy, and entitled Caffeine Intake and its Association with Disease Progression, Sleep Quality and Anxiety Symptoms and Nutritional Alterations in People Living With HIV in the Miami Adult Studies On HIV Cohort, having been approved in respect to style and intellectual content, is referred to you for judgment.

We have read this dissertation and recommend that it be approved.

Marianna Baum

Juan Liuzzi

Florence George

Adriana Campa, Major Professor

Date of Defense: October 30, 2015

The dissertation of Venkataraghavan Ramamoorthy is approved.

Interim Dean Mark Williams

Robert Stempel College of Public Health \& Social Work

Dean Lakshmi N. Reddi

University Graduate School

Florida International University, 2015 
(C) Copyright 2015 by Venkataraghavan Ramamoorthy

All rights reserved. 


\section{DEDICATION}

I dedicate this dissertation to my parents Meenakshy R and Ramamoorthy K V, and Lord Guruvayoorappan. Without their help, timely grace, support, and unconditional love, the completion of this work would not have been possible. 


\section{ACKNOWLEDGMENTS}

I wish to extend my sincere gratitude to all people who made this dissertation possible, especially my committee members who helped me all these years. Dr. Marianna Baum, the PI of the twin studies, a special appreciation for her excellent guidance and her course Research Concept Development. Dr. Juan Liuzzi, all my admiration for his understanding and unrelenting encouragement. Dr. Florence George, my respects for her willingness to help and provide hours of unconditional support. Dr. Adriana Campa, my Major Professor, my sincere gratitude for her constructive opinions and limitless flow of ideas. Dr. Fatma G Huffman, The Chair, her support has been the beacon of hope during troubled times. I would like to thank all my fellow Ph.D. students, especially Muni Rubens and Christina Fleetwood for their immense support in the entire process of this

dissertation. Finally, I would also like to acknowledge the University Graduate School for Data and Evidence Acquisition Fellowship and Dissertation Year Fellowship. 
ABSTRACT OF THE DISSERTATION

CAFFEINE INTAKE AND ITS ASSOCIATION WITH DISEASE PROGRESSION, SLEEP QUALITY AND ANXIETY SYMPTOMS AND NUTRITIONAL

ALTERATIONS IN PEOPLE LIVING WITH HIV IN THE MIAMI ADULT STUDIES

ON HIV COHORT

by

Venkataraghavan Ramamoorthy

Florida International University, 2015

Miami, Florida

Professor Adriana Campa, Major Professor

Miami-Dade County has approximately 27,000 people living with HIV (PLWH), and the highest HIV incidence in the nation. PLWH have reported several types of sleep disturbances. Caffeine is an anorexic and lipolytic stimulant that may adversely affect sleep patterns, dietary intakes and body composition. High caffeine consumption (>250 mg. per day or the equivalent of $>4$ cups of brewed coffee) may also affect general functionality, adherence to antiretroviral treatment (ART) and HIV care. This study assess the relationship of high caffeine intake with markers of disease progression, sleep quality, insomnia, anxiety, nutritional intakes and body composition.

A convenience sample of 130 PLWH on stable ART were recruited from the Miami Adult Studies on HIV (MASH) cohort, and followed for three months. After consenting, questionnaires on Modified Caffeine Consumption (MCCQ), Pittsburg Insomnia Rating Scale (PIRS), Pittsburg Sleep Quality Index (PSQI), Generalized Anxiety Disorder-7 (GAD-7), socio-demographics, drug and medication use were 
completed. CD4 count, HIV viral load, anthropometries, and body composition measures were obtained.

Mean age was $47.89 \pm 6.37$ years, $60.8 \%$ were male and $75.4 \%$ were AfricanAmericans. Mean caffeine intake at baseline was $337.63 \pm 304.97 \mathrm{mg}$ /day (Range: 0$1498 \mathrm{mg} /$ day) and did not change significantly at 3 months. In linear regression, high caffeine consumption was associated with higher $\mathrm{CD} 4$ cell count $(\beta=1.532, \mathrm{P}=0.049)$, lower HIV viral load $(\beta=-1.067, \mathrm{P}=0.048)$, higher global PIRS $(\beta=1.776, \mathrm{P}=0.046)$, global PSQI ( $\beta=2.587, \mathrm{P}=0.038)$, and GAD-7 scores $(\beta=1.674, \mathrm{P}=0.027)$, and with lower fat mass $(\beta=-0.994, \mathrm{P}=0.042)$, energy intakes $(\beta=-1.643, \mathrm{P}=0.042)$ and fat consumption ( $\beta=-1.902, \mathrm{P}=0.044$ ), adjusting for relevant socioeconomic and disease progression variables. Over three months, these associations remained significant. The association of high caffeine with lower BMI weakened when excluding users of other anorexic and stimulant drugs such as cocaine and methamphetamine, suggesting that caffeine in combination, but not alone, may worsen their action. In summary, high caffeine consumption was associated with better measures of disease progression; but was also detrimental on sleep quality, nutritional intakes, BMI and body composition and associated with insomnia and anxiety. Large scale studies for longer time are needed to elucidate the contribution of caffeine to the well-being of PLWH. 
TABLE OF CONTENTS

CHAPTER

PAGE

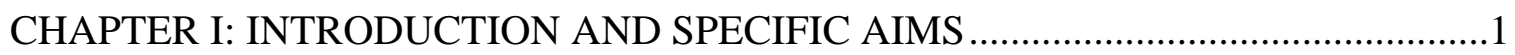

General Introduction ..............................................................................................

Justification for the Study .......................................................................................

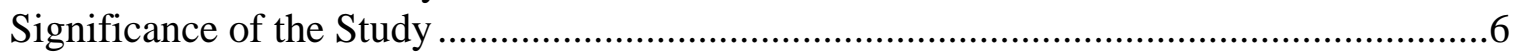

Specific Aims and Hypotheses ................................................................................

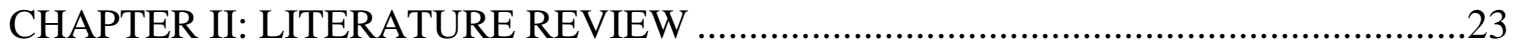

Daily Reported Caffeine use in United States ..............................................................24

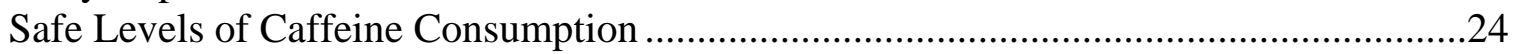

Caffeine-Biological Actions-Adenosine Receptors (A1, A2a, A2b and A3) .....................26

Caffeine and A1 Adenosine Receptors in the Central Nervous System (CNS) .................28

Caffeine Effects on A2a and A2b Adenosine Receptors ..................................................30

Biphasic Effects of Caffeine ......................................................................................31

Caffeine-Adverse Effects Outweigh Apparent Beneficial Effects ....................................33

Adverse Effects of Caffeine Withdrawal ..........................................................................35

Caffeine is Associated with Changes in CD4 levels as well as Plasma Viral Loads .........38

Caffeine Adversely Affects Sleep Quality and Precipitates Anxiety Disorders ................40

Caffeine Intake is Associated with Significant Nutritional Alterations...............................47

Caffeine Intake and its Effects on Fluid-Electrolyte Balance and Blood Pressure ............51

Caffeine is Associated with Smoking, Alcohol Consumption and Drug Abuse ...............53

Caffeine and its Metabolites and Their Collective Role in Metabolic Alterations ............56

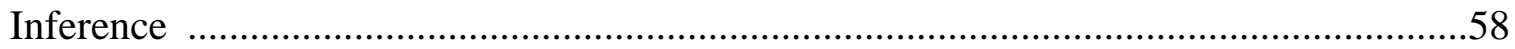

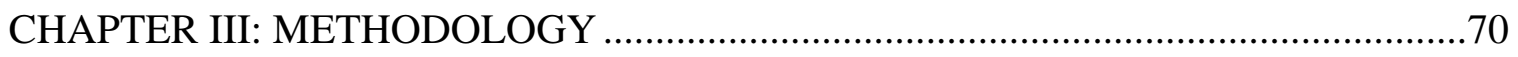

CHAPTER IV: CAFFEINE INTAKE AND ITS ASSOCIATION WITH

DISEASE PROGRESSION IN MIAMI ADULT STUDIES ON HIV

(MASH) COHORT-AN OBSERVATIONAL STUDY

CHAPTER V: CAFFEINE INTAKE AND ASSOCIATIONS WITH SLEEP

QUALITY AND GENERALIZED ANXIETY SCORES IN MIAMI ADULT

STUDIES ON HIV (MASH) COHORT—AN OBSERVATIONAL STUDY

CHAPTER VI: CAFFEINE INTAKE AND ITS ASSOCIATION WITH

NUTRITIONAL PARAMETERS IN MIAMI ADULT STUDIES OF HIV

(MASH) COHORT-AN OBSERVATIONAL STUDY

CHAPTER VII: SUMMARY AND CONCLUSIONS ……………………………......213

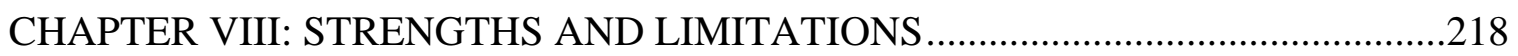


CHAPTER IX: FUTURE RESEARCH.......................................................................222

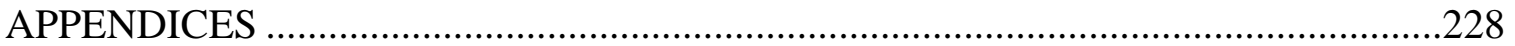

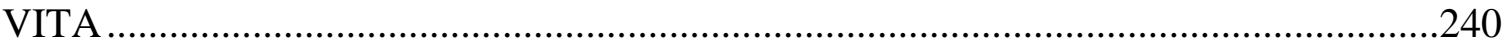




\section{LIST OF TABLES}

TABLE

PAGE

\section{CHAPTER I}

Table 1: Summary of Hypotheses and Statistical Methods

\section{CHAPTER III}

Table 1: Caffeine Intake and Viral Load using Mixed Models .71

Table 2: Outcomes and Assessments Collected During the Current Study......................81

Table 3: Assessments Variables Collected by the MASH Cohort.

\section{CHAPTER IV}

Table 1A: Baseline Demographic Characteristics of PLWH by Caffeine

Consumption Levels

Table 1B: Follow-up Demographic Characteristics of PLWH by Caffeine

Consumption Levels

Table 2: Baseline Health and Lifestyle Characteristics of PLWH by Caffeine

Consumption Levels

Table 3: Follow-up Health and Lifestyle Characteristics of PLWH by Caffeine

Consumption Levels

Table 4: Mean Caffeine Intake: Baseline and Follow-up Visit

Table 5: Linear Regression of the Effect of Caffeine Consumption on

Immunological and Virologic Markers of Disease Progression .

Table 6: Linear Mixed Model Analysis of Overtime Changes in the Effects

of Caffeine Consumption on Immunological and Virologic Markers of Disease

Progression

Table 7: Baseline: CD4 count and Viral Load Categories by Levels of Caffeine

Consumption

Table 8: Follow-up CD4 count and Viral Load Categories by Levels of Caffeine

Consumption

Table 9: Baseline Multinomial Logistic Regression of the Effect of Caffeine

Consumption Levels on CD4 and Viral Load Categorical Levels

Table 10: Overtime Multinomial Logistic Regression of the Effect of Caffeine

Consumption Levels on CD4 and Viral Load Categorical Levels

\section{CHAPTER V}

Table 1A: Baseline Demographic Characteristics of PLWH by Caffeine

Consumption Levels

Table 1B: Follow-up Demographic Characteristics of PLWH by Caffeine

Consumption Levels

Table 2: Baseline Health and Lifestyle Characteristics of PLWH by Caffeine

Consumption Levels

Table 3: Follow-up Health and Lifestyle Characteristics of PLWH by Caffeine

Consumption Levels 
Table 4: Mean Caffeine Intake: Baseline and Follow-up Visit ....................................156

Table 5: Baseline PIRS Variables by Caffeine Consumption Levels ............................156

Table 6: Follow-Up PIRS Variables by Caffeine Consumption Levels ..........................157

Table 7: Mean Scores of PIRS Variables: Baseline and Follow-Up Visit .....................157

Table 8: Baseline PSQI Variables by Caffeine Consumption Levels .............................157

Table 9: Follow-Up PSQI Variables by Caffeine Consumption Levels .........................158

Table 10: Mean Scores of PSQI Variables: Baseline and Follow-Up Visit ....................158

Table 11: Baseline GAD-7 Scores by Caffeine Consumption Levels ..........................158

Table 12: Follow-Up GAD-7 Scores by Caffeine Consumption Levels ........................159

Table 13: Mean GAD-7 Scores: Baseline and Follow-Up Visit ...................................159

Table 14: Linear Regression of the Effect of Caffeine Consumption on

PIRS Variables

Table 15: Linear Mixed Model (LMM) Analysis of Overtime Changes in

PIRS Variables due to Caffeine Consumption

Table 16: Baseline Multinomial Logistic Regression of the Effect of Caffeine

Consumption Levels on Global PIRS Score Categories

Table 17: Over Time Multinomial Logistic Regression of the Effect of Caffeine

Consumption Levels on Global PIRS Score Categories

Table 18: Linear Regression of the Effect of Caffeine Consumption on

PSQI Variables

Table 19: Linear Mixed Model (LMM) Analysis of Overtime Changes in

PSQI Variables due to Caffeine Consumption

Table 20: Baseline Multinomial Logistic Regression of the Effect of Caffeine

Consumption Levels on Global PSQI Score Categories

Table 21: Over Time Multinomial Logistic Regression of the Effect of Caffeine

Consumption Levels on Global PSQI Score Categories

Table 22: Linear Regression of the Effect of Caffeine Consumption on

GAD-7 Scores

Table 23: Linear Mixed Model (LMM) Analysis of Over Time Changes in

GAD-7 Scores due to Caffeine Consumption

Table 24: Baseline Multinomial Logistic Regression of the Effect of Caffeine

Consumption Levels on GAD-7 Score Categories

Table 25: Over Time Multinomial Logistic Regression of the Effect of Caffeine

Consumption Levels on GAD-7 Score Categories

Table 26: Linear Regression Analysis of the Effect of Global PIRS,

Global PSQI and GAD-7 Scores on Immunological and Virologic Markers

of Disease Progression ....

Table 27: Linear Mixed Model Analysis of Over Time Changes in

Immunological and Virologic Markers of Disease Progression due to

Global PIRS, Global PSQI and GAD-7 Scores

\section{CHAPTER VI}

Table 1A: Baseline Demographic Characteristics of PLWH by Caffeine

Consumption Levels 
Table 1B: Follow-up Demographic Characteristics of PLWH by Caffeine

Consumption Levels

Table 2: Baseline Health and Lifestyle Characteristics of PLWH by Caffeine

Consumption Levels

Table 3: Follow-up Health and Lifestyle Characteristics of PLWH by Caffeine

Consumption Levels

Table 4: Mean Caffeine Intake: Baseline and Follow-up Visit

196

Table 5: Baseline: Mean Nutrient Intakes by Levels of Caffeine Consumption 197

Table 6: Follow-up: Mean Nutrient Intakes by Levels of Caffeine Consumption

Table 7: Differences in Mean Nutrient Intake between Baseline and

Follow-Up Visit

Table 8: Baseline, PLWH with Nutrient Intakes below Daily Values (DV) by

Levels of Caffeine Consumption

Table 9: Follow-Up, PLWH with Nutrient Intakes below Daily Values (DV) by

Levels of Caffeine Consumption .201

Table 10: Linear Regression of the Effect of Caffeine Consumption on Body

Composition Measures and Nutritional Indicators

Table 11: Linear Mixed Model (LMM) Analysis of Over Time Changes in

Body Composition Measures and Nutritional Indicators due to Caffeine

Consumption

Table 12: Linear Regression of the Effect of Caffeine Consumption on

Macronutrient Consumption

Table 13: Linear Mixed Model (LMM) Analysis of Over Time Changes

in Macronutrient Consumption due to Caffeine Consumption

Table 14: Linear Regression of the Effect of Body Composition Measures

and Macronutrient Intake on CD4 Cell Count...

Table 15: Linear Regression of the Effect of Body Composition Measures and

Macronutrient Intake on HIV Viral Load

Table 16: . Linear Mixed Model (LMM) Analysis of Over Time Changes

in CD4 Cell Counts due to changes in Body Composition Measures and

Macronutrient intakes

Table 17: . Linear Mixed Model (LMM) Analysis of Over Time Changes in

HIV Viral Load due to changes in Body Composition Measures and

Macronutrient intakes 


\section{ABBREVIATIONS AND ACRONYMS}

AGAHLS

AIDS

ANS

ARAS

ART

AUC

AUDIT

BEE

BHCC

BIA

BMD

BMI

BMR

CAAA

CBC

cAMP

CD4

CD8

CD69

CDC

CFFT

CI
Amsterdam Growth and Health Longitudinal Study

Acquired Immune Deficiency Syndrome

Autonomic Nervous System

Ascending Reticular Activation System

Anti-Retroviral Therapy

Area Under the Curve

Alcohol Use Disorders Identification Test

Basal Energy Expenditure

Borinquen Health Care Center

Bioelectrical Impedance

Bone Mineral Density

Body Mass Index

Basal Metabolic Rate

Cellular Antioxidant Activity Assay

Complete Blood Count

Cyclic Adenosine Mono Phosphate

Cluster of Differentiation 4

Cluster of Differentiation 8

Cluster of Differentiation 69

Center for Disease Control and Prevention

Critical Flicker Fusion Threshold

Confidence Interval 


\begin{tabular}{ll} 
CNS & Central Nervous System \\
CRP & C-Reactive Protein \\
DNA & Deoxy Ribonucleic Acid \\
DRI & Dietary Reference Intakes \\
DRV & Daily Reference Values \\
DSM-V & Diagnostic and Statistical Manual of Mental Disorders, 5th Edition \\
DV & Daily Values \\
ESR & Electron Spin Resonance \\
ESR & Erythrocyte Sedimentation Rate \\
FFA & Free Fatty Acid \\
FFQ & Food Frequency Questionnaire \\
FIU & Florida International University \\
FM & Fat Mass \\
FSQ & Hood Security Questionnaire \\
GABA & Highly Active Anti-Retroviral Therapy \\
GAD-7 & Gamma-Aminobutyric Acid \\
GRAS & Generalized Anxiety Disorder 7 \\
HAART & Generally Recognized as Safe \\
HAT & Hepatitis C Virus \\
HER & Hidvification of Disease \\
\hline
\end{tabular}




\begin{tabular}{|c|c|}
\hline $\mathrm{IL}$ & Interleukin \\
\hline IRB & Institutional Review Board \\
\hline IUI & International Unit \\
\hline LBM & Lean Body Mass \\
\hline LDL & Low Density Lipoprotein \\
\hline LMM & Linear Mixed Models \\
\hline MASH & Miami Adult Studies on HIV \\
\hline MCCQ & Modified Caffeine Consumption Questionnaire \\
\hline MSA & Muscle Sympathetic Activity \\
\hline NE & Norepinephrine \\
\hline NHANES & National Health and Nutrition Examination Survey \\
\hline $\mathrm{NIH}$ & National Institute of Health \\
\hline NRTI & Nucleotide Reverse Transcriptase Inhibitors \\
\hline NNRTI & Non Nucleotide Reverse Transcriptase Inhibitors \\
\hline PNS & Peripheral Nervous System \\
\hline OGTT & Oral Glucose Tolerance \\
\hline OR & Odds Ratio \\
\hline ORAC & Oxygen Radical Absorbance Capacity \\
\hline PCR & Polymerase Chain Reaction \\
\hline PI & Principal Investigator \\
\hline PI & Protease Inhibitor \\
\hline PIRS & Pittsburg Insomnia Rating Scale \\
\hline PLWH & People Living With HIV \\
\hline
\end{tabular}




\begin{tabular}{|c|c|}
\hline PSQI & Pittsburg Sleep Quality Index \\
\hline REE & Resting Energy Expenditures \\
\hline REML & Restricted Maximum Likelihood \\
\hline RCT & Randomized Controlled Trial \\
\hline RDA & Recommended Dietary Allowance \\
\hline RDI & Reference Daily Intakes \\
\hline RNR & Resting Metabolic Rate \\
\hline RNA & Ribonucleic Acid \\
\hline RT-PCR & Reverse Transcriptase-Polymerase Chain Reaction \\
\hline SD & Standard Deviation \\
\hline STD & Sexually Transmitted Disease \\
\hline SBP & Systolic Blood Pressure \\
\hline SSS & Stanford Sleepiness Scale \\
\hline SPSS-21 & Statistical Package for Social Sciences-21 \\
\hline STAI & State-Trait Anxiety Inventory \\
\hline TNF & Tumor Necrosis Factor \\
\hline USDA & United States Department of Agriculture \\
\hline USFDA & United States Food and Drug Administration \\
\hline VLDL & Very Low Density Lipoprotein \\
\hline vWF & von Willebrand Factor \\
\hline WBC & White Blood Cells \\
\hline WC & Waist Circumference \\
\hline WHO & World Health Organization \\
\hline
\end{tabular}




\section{CHAPTER I: INTRODUCTION AND SPECIFIC AIMS}

\section{General Introduction}

Caffeine is one of the most widely consumed psycho-active substances worldwide. ${ }^{1}$ Caffeine, a white, odorless, crystalline and bitter tasting substance was first isolated form coffee beans in the year $1820 .{ }^{1}$ Over the years a huge body of literature has accrued regarding the major sources and quantities consumed as well as the populations consuming significant levels. ${ }^{2}$ Coffee constitutes the single largest source of caffeine and contains more caffeine than all other available sources. ${ }^{2,3}$ Other significant sources include tea leaves, cocoa pods, cola nuts, yerba mate, caffeinated drinks and many prescription and over the counter medications. ${ }^{2}$ Many individual studies show that athletes, students, young adults, teenagers, and military personnel are the major populations consuming significant levels of caffeine. ${ }^{4-6}$ Some of the major methods of caffeine consumption include brewed coffee, brewed tea, carbonated soft drinks, energy drinks, energy shots, fruit drinks, fruit flavored beverages and watery beverages. ${ }^{2,3}$ Among children carbonated soft drink constitutes the largest source of caffeine consumption; whereas brewed coffee constitutes the same among adults. ${ }^{4-6}$ It is difficult to comprehensively summarize average consumption levels across different countries, cultures and ethnicities given the diversities in sources and patterns of consumption. The predicted average consumption across different coffee/tea consuming nations ranges between 80 and 400 mg per person per day. ${ }^{7}$ A survey done by Faray et al., ${ }^{3}$ estimated that $87 \%$ of Americans consumed caffeine and average consumption approximated 193 mg per day per person and ranged between $166 \mathrm{mg}$ and $336 \mathrm{mg}$ per day. In addition to caffeine there are many structurally and functionally similar xanthine-alkaloid 
compounds in coffee and caffeinated products and major ones include theophylline and theobromine. ${ }^{8}$ Tea is primarily rich in theophylline, and contains approximately $50 \mathrm{mg}$ of caffeine per $8 \mathrm{oz}$ of black tea. ${ }^{8}$ Cola-acuminata extracts present in Coca-Cola and other soft drinks contain variable amounts of caffeine ( 35 to $55 \mathrm{mg}$ in $12 \mathrm{oz}$ of soft drinks). ${ }^{8}$

Chocolate derived from cocoa pods and cocoa butter is primarily rich in theobromine, but also contains trace amounts of caffeine. ${ }^{8}$ Based on standardized caffeine content of major sources (135 mg per 8 oz of coffee, $50 \mathrm{mg}$ per $8 \mathrm{oz}$ of black tea and 35-55 mg per $12 \mathrm{oz}$ of soft drinks), it was estimated in 2014 that an average American consumes 135 mg of caffeine from coffee, $30 \mathrm{mg}$ of caffeine from tea and $50 \mathrm{mg}$ of caffeine from soft drinks per day. ${ }^{9}$ According to estimates in late eighties, $75 \%$ of total caffeine consumption came from coffee, $15 \%$ from tea and $10 \%$ from caffeinated soft drinks. Chocolates, medications and other caffeine containing products contributed very less to the average consumption levels. ${ }^{9}$ Estimates in 2014 still show the same characteristics with coffee being the highest source (66\%), tea being the second highest (20\%) and caffeinated soft drinks the third highest source (11\%), while all other sources contributed negligibly towards the total consumption. ${ }^{9}$

Caffeine shows diuretic properties and stimulates respiratory, cardiovascular and neuro-hormonal systems. ${ }^{10}$ In addition to its consumption as beverages, several therapeutic interactions have been identified. This includes its effects on a variety of medical conditions like narcolepsy, asthma, sleep apnea, migraine and cluster headaches, Parkinsonism, ADHD, fetal asphyxia and major depression states. ${ }^{11-18}$ Other conditions that affect the metabolism and elimination of caffeine include age, pregnancy, concomitant medications and liver function levels. ${ }^{19}$ The half-life of the compound varies 
between 4-11 hours under normal physiological conditions. ${ }^{19}$ In acute liver failure states caffeine can be significantly toxic as the half-life increases to as high as $90-100$ hours. ${ }^{19,20}$ Caffeine is metabolized in the liver by the cytochrome P450 oxidase enzyme systems into three major metabolites paraxanthine (80-85\%), theobromine (10-15\%) and theophylline (0-5\%). ${ }^{19}$ All these metabolites are dimethyl xanthines and have independent actions similar to the parent compound caffeine and are further metabolized through the same enzyme system in the liver and excreted through urine. ${ }^{19}$ Paraxanthine has the same potency and nearly all the physiological actions of caffeine. ${ }^{21}$ In-spite of caffeine being considered a therapeutic drug, regulatory agencies have not instituted any restriction on the sale and purchase of caffeine: neither is caffeine consumption considered any kind of recreational drug use..$^{22}$ Initial efforts to include it in the list of scheduled drugs are evident in studies done by Gilliland and Bullock, and Holtzman. ${ }^{23,24}$ Both the studies suggested that caffeine and associated xanthine alkaloids should be considered as regulated substances because of their withdrawal, tolerance, dependence and addictive potentials. ${ }^{23,24}$ The median lethal dose of caffeine was 192 milligrams per kilogram body weight as estimated in rats. ${ }^{25}$ Based on estimates from animal studies the median lethal dose for humans has been calculated to be about 150 to 200 milligrams per kilogram of body weight or roughly 80 to 100 cups of coffee for an average adult, though it would also depend upon the individual's sensitivity and genetic factors affecting caffeine metabolism ${ }^{26,27}$ or the presence of other medications and therapeutic drugs affecting the same. ${ }^{28,29}$ Given these high lethal dose values caffeine consumption is generally considered safe for all practical purposes. ${ }^{26}$ 
The current study was a prospective observational study (follow-up study) of associations between caffeine consumption and immunological and virologic markers of disease progression (CD4 counts and HIV viral loads). This study also investigated for associations between caffeine consumption and sleep derangements and anxiety symptoms through sleep quality and anxiety questionnaires. Similarly, this study investigated caffeine consumption and changes in nutrient intakes which included carbohydrate intake, protein intake and fat intake. This study also investigated the effects of caffeine on body composition measures like BMI, lean body mass (LBM), total fat mass and other nutritional status indicators like hemoglobin, hematocrit and serum albumin levels. Any adverse effect on these parameters should be considered as adverse effects on HIV disease progression as the literature specifies.

\section{Justification for the Study}

Caffeine intake is very prevalent in this population of HIV infected individuals in Miami (MASH cohort). Campa et al., ${ }^{30}$ reported that $88.79 \%$ of the population sample collected for the preliminary study 'Zinc-supplementation and its effects on disease progression in HIV infected patients' recorded some levels of consumption. The mean caffeine intake for this cohort was $115 \mathrm{mg}$ per day. ${ }^{30}$ As discussed in the literature review ahead, consumption of higher levels of caffeine leads to dependency and a variety of unpleasant physical and mental conditions including nervousness, irritability, restlessness, insomnia, headaches, and heart palpitations. These symptoms collectively known as 'caffeinism' ${ }^{31}$ was shown to have many adverse health effects in a number of studies done in vulnerable populations. ${ }^{32-35}$ 
There were significant negative associations between caffeine intake and sleep quality scores as well as generalized anxiety levels. ${ }^{36,37}$ These effects were predicted to be more pronounced in $\mathrm{HIV+}$ patients with compromised health and immune status. ${ }^{36}$ Our proposed study included PSQI and PIRS questionnaires for estimating sleep quality and GAD-7 questionnaires for subjective symptoms of anxiety. Caffeine has been recognized as a beneficial stimulant in low to moderate consumption levels (50 mg/day to 250 mg/day). Increased consumption beyond this limit, however, is associated with heightened neuronal burn-outs and lack of adequate sleep. ${ }^{36,37}$ Our study retested these hypotheses in a group of HIV positive participants who were already compromised in a number of health and socio-economic parameters.

There are very few studies about the effects of caffeine consumption on nutrient intake especially in HIV positive patients. Research shows that caffeine consumption has both positive and negative health outcomes. The positive outcomes were observed mainly in diabetic patients. Moderate caffeine intake showed benefits in patients with Type-2 diabetes and metabolic syndrome, as caffeine intake facilitates weight loss and reduction of fat mass. ${ }^{38}$ Conversely, in people living with HIV, where wasting is a serious problem, high caffeine intake could precipitate adverse health outcomes. In a study done by Kent et al. ${ }^{39}$, it was observed that administration of fat lowering agent orlistat was associated with higher viral loads compared to subjects not using this medication. Similarly another study done by Shor-Prosner et.al., ${ }^{40}$ on HIV positive participants from Miami showed that body mass index (BMI) was inversely associated with progression to AIDS as well as mortality; suggesting mild-to-moderate obesity having better immune function and better survival rates in this cohort. Loss of fat mass as well as lean body mass, have 
always been reported to have detrimental effects on HIV disease progression. Both HIV ${ }^{41}$ and caffeine ${ }^{42}$ increase fat and protein catabolism and decrease appetite, and their combined interactions have not been well studied. Based on these previous literatures, our study investigated whether caffeine was associated with changes in body composition measures, nutritional indicators and in nutrient consumption levels.

\section{Significance of the Study}

The study is particularly relevant for many reasons. This study aimed to determine the effect of caffeine consumption on disease progression in HIV positive patients. Though there are many studies on the effects of caffeine on healthy persons, ergogenics, diabetes, pregnancy, liver failure and other medical conditions, to the best of our knowledge, the literature on HIV positive participants is limited. The information obtained through this study will be helpful for development of targeted interventions for people living with HIV (PLWH). Future studies that estimate the effects of different levels of consumption as well as standardized consumption limits in this population will contribute to the development of adequate nutritional recommendations for caffeine in PLWH.

This study also looked for the effects of caffeine on sleep quality, anxiety and nutritional parameters. The majority of the participants enrolled in this study are marginalized and disempowered. Their living conditions are plagued by food scarcity, homelessness, drug abuse and criminalization. Because of these harsh living conditions they are already susceptible to a variety of anxiety states and sleep disorders as well as

poor nutrient intakes. ${ }^{43-51}$ Caffeine consumption at high levels further contributes to these conditions. Such effects will definitely increase the rate of disease progression in this 
population. Many studies have shown that adequate nutrition and sufficient sleep are inseparable components of healthy living initiatives. ${ }^{52,53}$ Educating this marginalized population about healthy living can never be accomplished without understanding their caffeine consumption, its impact on sleep quality and nutrient consumption, as well as the inter-relationships between these variables.

\section{Specific Aims and Hypotheses}

Specific aim 1: Examine the effect of caffeine on HIV disease progression

Rationale: Caffeine intake in higher than regular doses (>250 mg/day) has been associated with decreased CD4 counts (adverse effect) as well as decreased viral loads (beneficial effect). Our study looks for the net impact of caffeine over these opposing effects on disease progression.

Hypothesis 1A: HIV+ adults with caffeine intake >250 mg/day have lower CD4 cell counts compared with those who do not consume caffeine or do so in moderation ( $<250$ mg/day) measured over 3 months.

Hypothesis 1B: HIV+ adults with caffeine intake $>250 \mathrm{mg}$ /day have higher viral loads compared with those who do not consume caffeine or do so in moderation ( $<250 \mathrm{mg} /$ day) measured over 3 months.

Hypothesis 1C: Caffeine consumption as a continuous variable is associated with decreased CD4 cell counts, $\mathrm{CD} 4$ counts $<200$ cells $/ \mu \mathrm{L}$ and increased viral loads or lack of viral load control, measured over 3 months.

Instruments/Tools/Observations: Caffeine Consumption questionnaires, CD4 cell count and viral loads transcribed from medical records submitted by the participants. 
Confounding Variables: Age, gender, income, race/ethnicity, grades, time from diagnosis of HIV, drug use, alcohol consumption, smoking status, BMI, total body fat percentage.

Specific Aim 2: Examine the effect of caffeine on sleep disorders in HIV

Rationale: Caffeine intake $>250 \mathrm{mg} /$ day is associated with poor quality of sleep and increased episodes of insomnia.

Hypothesis 2A: HIV+ adults with caffeine intake $>250 \mathrm{mg} /$ day have decreased quality of sleep measured by the PSQI scores, and increased periods of insomnia measured by the PIRS over a period of 3-months.

Hypothesis 2B: Caffeine consumption as a continuous variable is associated with decreased quality of sleep measured by the PSQI scores, and increased periods of insomnia measured by the PIRS over a period of 3-months.

Instruments/Tools/Observations: Caffeine consumption questionnaires, Pittsburg Sleep Quality (PSQI) questionnaire, Pittsburg Insomnia Rating Scale (PIRS) questionnaire. Confounding Variables: Age, income, race/ethnicity, time from diagnosis of HIV, drug use, alcohol consumption, smoking status, sleep medications and types of ART medications.

Specific Aim 3: Examine the effect of Caffeine on Anxiety Symptoms Rationale: Caffeine intake $>250 \mathrm{mg} /$ day has been associated with increased anxiety and restlessness.

Specific Aim 3: Examine the effect of Caffeine on anxiety symptoms

Rationale: Caffeine intake $>250$ has been associated with increased anxiety and restlessness. 
Hypothesis 3A: HIV+ adults with caffeine intake $>250 \mathrm{mg} /$ day have increased anxiety symptoms measured by the GAD-7 scores over a period of 3-months.

Hypothesis 3B: Caffeine consumption as a continuous variable is associated with increased anxiety symptoms measured by the GAD-7 scores over a period of 3-months. Instruments/Tools/Observations: Caffeine consumption questionnaires, Generalized Anxiety Disorder-7 (GAD-7) questionnaire.

Confounding Variables: Age, income, time from diagnosis of HIV, drug use, alcohol consumption, smoking status and types of ART medications.

Specific Aim 4: Examine the effect of Caffeine on Body composition measures and nutritional indicators such as hemoglobin, hematocrit and serum albumin levels Rationale: Caffeine is associated with decreased caloric intakes as well as increased energy expenditures thereby leading to nutritional deficiency states.

Hypothesis 4A: HIV+ adults with caffeine intake $>250 \mathrm{mg} /$ day have decreased lean body mass and body fat mass estimated by Bio-impedance analysis (BIA) over a period of 3months.

Hypothesis 4B: HIV+ adults with caffeine intake $>250 \mathrm{mg} /$ day have decreased BMI estimated by BIA over a period of 3-months.

Hypothesis 4C: HIV+ adults with caffeine intake >250 mg/day have lower than normal hemoglobin measured over a period of 3-months.

Hypothesis 4D: HIV+ adults with caffeine intake $>250 \mathrm{mg} /$ day have lower than normal hematocrit measured over a period of 3-months.

Hypothesis 4E: HIV+ adults with caffeine intake $>250 \mathrm{mg} /$ day have lower than normal serum albumin levels, measured over a period of 3-months. 
Instruments/Tools/Observations: Caffeine consumption questionnaires, Bio-impedance analysis (BIA), Hemoglobin levels, Hematocrit and serum albumin levels.

Confounding Variables: Age, gender, income, time from diagnosis of HIV, drug use, alcohol consumption, smoking status and types of ART medications.

Specific Aim 5: Examine the effect of caffeine on caloric and nutrient intake and food security status

Rationale: Caffeine is associated with decreased nutrient intakes and deficiency states. Hypothesis 5A: HIV+ adults with caffeine intake $>250 \mathrm{mg} /$ day have decreased total caloric intakes estimated by 24-hour dietary recall over a period of 3-months.

Hypothesis 5B: HIV+ adults with caffeine intake $>250 \mathrm{mg} /$ day have decreased caloric intakes from proteins estimated by 24-hour dietary recall over a period of 3-months. Hypothesis 5C: HIV+ adults with caffeine intake $>250 \mathrm{mg} /$ day have decreased caloric intakes from carbohydrates estimated by 24-hour dietary recall over a period of 3months.

Hypothesis 5D: HIV+ adults with caffeine intake >250 mg/day have decreased caloric intakes from fats estimated by 24-hour dietary recall over a period of 3-months.

Instruments/Tools/Observations: Caffeine consumption questionnaires, 24-hour dietary recall, Nutribase-9 analysis reports of daily nutrient intake, food security questionnaire (FSQ).

Confounding Variables: Age, gender, income, time from diagnosis of HIV, drug use, alcohol consumption, smoking status and types of ART medications. 
Table 1: Summary of Hypotheses and Statistical Methods

\begin{tabular}{|l|l|l|l|l|}
\hline Hypotheses & $\begin{array}{l}\text { Dependent } \\
\text { Variables }\end{array}$ & $\begin{array}{l}\text { Independent } \\
\text { Variables }\end{array}$ & Control Variables & Statistical Analysis \\
\hline $\begin{array}{l}\text { Hypothesis 1A :HIV+ } \\
\text { adults with caffeine } \\
\text { intake }>250 \text { mg/d have } \\
\text { lower CD4 cell counts } \\
\text { compared with those } \\
\text { who do not consume } \\
\text { caffeine or do so in } \\
\text { moderation }(<250\end{array}$ & $\begin{array}{l}\text { CD4 count } \\
\text { square root } \\
\text { mg/day) measured over } \\
\text { a period of 3 months. }\end{array}$ & $\begin{array}{l}\text { Total Caffeine } \\
\text { intake }\end{array}$ & $\begin{array}{l}\text { age, income, race } \\
\text { ethnicity, time from } \\
\text { diagnosis of HIV, } \\
\text { drug, tobacco and } \\
\text { alcohol use, BMI and } \\
\text { total body fat percent. }\end{array}$ & $\begin{array}{l}\text { T-test and linear and logistic } \\
\text { regressions were used to } \\
\text { analyze baseline cross- } \\
\text { sectional data and Linear } \\
\text { Mixed Models were used for } \\
\text { over time changes in these } \\
\text { associations }\end{array}$ \\
\hline $\begin{array}{l}\text { Hypothesis 1B: HIV+ } \\
\text { adults with caffeine } \\
\text { intake }>250 \text { mg/d have } \\
\text { higher viral loads } \\
\text { compared with those } \\
\text { who do not consume } \\
\text { caffeine or do so in } \\
\text { moderation }(<250 \\
\text { mg/day) measured over } \\
\text { a period of } 3 \text { months. }\end{array}$ & $\begin{array}{l}\text { Log } 10 \text { viral } \\
\operatorname{load}\end{array}$ & $\begin{array}{l}\text { Total Caffeine } \\
\text { intake }\end{array}$ & $\begin{array}{l}\text { age, income, race } \\
\text { ethnicity, time from } \\
\text { diagnosis of HIV, } \\
\text { drug, tobacco and } \\
\text { alcohol use, BMI and } \\
\text { total body fat percent. }\end{array}$ & $\begin{array}{l}\text { T-test and linear and logistic } \\
\text { regressions were used to } \\
\text { analyze baseline cross- } \\
\text { sectional data and Linear } \\
\text { Mixed Models were used for } \\
\text { over time changes in these } \\
\text { associations }\end{array}$ \\
\end{tabular}




\begin{tabular}{|c|c|c|c|c|}
\hline Hypotheses & $\begin{array}{l}\text { Dependent } \\
\text { Variables }\end{array}$ & $\begin{array}{l}\text { Independent } \\
\text { Variables }\end{array}$ & Control Variables & Statistical Analysis \\
\hline $\begin{array}{l}\text { Hypothesis 1C: } \\
\text { Caffeine consumption as } \\
\text { a continuous variable is } \\
\text { associated with } \\
\text { decreased CD4 cell } \\
\text { counts, CD4 counts }<200 \\
\text { cells/ } \mu \mathrm{L} \text { and increased } \\
\text { viral loads or lack of } \\
\text { viral load control, } \\
\text { measured over a period } \\
\text { of } 3 \text { months. }\end{array}$ & $\begin{array}{l}\text { CD4 count } \\
\text { square root, } \\
\log _{10} \text { viral } \\
\text { load }\end{array}$ & $\begin{array}{l}\text { Total Caffeine } \\
\text { intake }\end{array}$ & $\begin{array}{l}\text { age, income, race } \\
\text { ethnicity, time from } \\
\text { diagnosis of HIV, } \\
\text { drug, tobacco and } \\
\text { alcohol use, BMI and } \\
\text { total body fat percent. }\end{array}$ & $\begin{array}{l}\text { Linear and logistic } \\
\text { regressions were used to } \\
\text { understand whether caffeine } \\
\text { consumption is associated } \\
\text { with changes in CD4 cell } \\
\text { counts and viral loads. } \\
\text { Linear Mixed Models were } \\
\text { used for overtime changes in } \\
\text { these relationships. }\end{array}$ \\
\hline $\begin{array}{l}\text { Hypothesis 2A: HIV+ } \\
\text { adults with caffeine } \\
\text { intake }>250 \mathrm{mg} / \mathrm{d} \text { have } \\
\text { decreased quality of } \\
\text { sleep measured by the } \\
\text { PSQI scores, and } \\
\text { increased periods of } \\
\text { insomnia measured by } \\
\text { the PIRS over a period } \\
\text { of 3-months. }\end{array}$ & $\begin{array}{l}\text { PSQI } \\
\text { variables, } \\
\text { PIRS } \\
\text { variables }\end{array}$ & $\begin{array}{l}\text { Total Caffeine } \\
\text { intake }\end{array}$ & $\begin{array}{l}\text { age, income, race } \\
\text { ethnicity, time from } \\
\text { diagnosis of HIV, } \\
\text { drug, tobacco and } \\
\text { alcohol use, sleep } \\
\text { medications and } \\
\text { types of ART } \\
\text { medication. }\end{array}$ & $\begin{array}{l}\text { T-test and linear and logistic } \\
\text { regressions were used to } \\
\text { analyze baseline cross- } \\
\text { sectional data and Linear } \\
\text { Mixed Models were used for } \\
\text { over time changes in these } \\
\text { associations.* }\end{array}$ \\
\hline
\end{tabular}




\begin{tabular}{|c|c|c|c|c|}
\hline Hypotheses & $\begin{array}{l}\text { Dependent } \\
\text { Variables }\end{array}$ & $\begin{array}{l}\text { Independent } \\
\text { Variables }\end{array}$ & Control Variables & Statistical Analysis \\
\hline $\begin{array}{l}\text { Hypothesis 2B: } \\
\text { Caffeine consumption as } \\
\text { a continuous variable is } \\
\text { associated with } \\
\text { decreased quality of } \\
\text { sleep measured by the } \\
\text { PSQI scores, and } \\
\text { increased periods of } \\
\text { insomnia measured by } \\
\text { the PIRS over a period } \\
\text { of 3-months. }\end{array}$ & $\begin{array}{l}\text { PSQI } \\
\text { variables, } \\
\text { PIRS } \\
\text { variables }\end{array}$ & $\begin{array}{l}\text { Total Caffeine } \\
\text { intake }\end{array}$ & $\begin{array}{l}\text { age, income, race } \\
\text { ethnicity, time from } \\
\text { diagnosis of HIV, } \\
\text { drug, tobacco and } \\
\text { alcohol use, sleep } \\
\text { medications and } \\
\text { types of ART } \\
\text { medication. }\end{array}$ & $\begin{array}{l}\text { Linear and logistic } \\
\text { regressions were used to } \\
\text { understand whether caffeine } \\
\text { consumption is associated } \\
\text { with changes in quality of } \\
\text { sleep measured by PSQI } \\
\text { scores and severity of } \\
\text { insomnia measured by the } \\
\text { PIRS. Linear Mixed Models } \\
\text { were used for overtime } \\
\text { changes in these } \\
\text { relationships. }\end{array}$ \\
\hline $\begin{array}{l}\text { Hypothesis 3A: HIV+ } \\
\text { adults with caffeine } \\
\text { intake }>250 \mathrm{mg} / \mathrm{d} \text { have } \\
\text { increased anxiety } \\
\text { symptoms measured by } \\
\text { the GAD-7 scores over a } \\
\text { period of 3-months. }\end{array}$ & GAD-7 scores & $\begin{array}{l}\text { Total Caffeine } \\
\text { intake }\end{array}$ & $\begin{array}{l}\text { age, income, and time } \\
\text { from diagnosis of } \\
\text { HIV, drug, tobacco } \\
\text { and alcohol use and } \\
\text { different types of } \\
\text { ART medications }\end{array}$ & $\begin{array}{l}\text { T-test and linear and logistic } \\
\text { regressions were used to } \\
\text { analyze baseline cross- } \\
\text { sectional data and Linear } \\
\text { Mixed Models were used for } \\
\text { over time changes in these } \\
\text { associations. }\end{array}$ \\
\hline
\end{tabular}




\begin{tabular}{|c|c|c|c|c|}
\hline Hypotheses & $\begin{array}{l}\text { Dependent } \\
\text { Variables }\end{array}$ & $\begin{array}{l}\text { Independent } \\
\text { Variables }\end{array}$ & Control Variables & Statistical Analysis \\
\hline $\begin{array}{l}\text { Hypothesis 3B: } \\
\text { Caffeine consumption as } \\
\text { a continuous variable is } \\
\text { associated with } \\
\text { increased anxiety } \\
\text { symptoms measured by } \\
\text { the GAD-7 scores over a } \\
\text { period of 3-months. }\end{array}$ & GAD-7 scores & $\begin{array}{l}\text { Total Caffeine } \\
\text { intake }\end{array}$ & $\begin{array}{l}\text { age, income, and time } \\
\text { from diagnosis of } \\
\text { HIV, drug, tobacco } \\
\text { and alcohol use and } \\
\text { different types of } \\
\text { ART medications }\end{array}$ & $\begin{array}{l}\text { Linear and logistic } \\
\text { regressions were used to } \\
\text { understand whether caffeine } \\
\text { consumption is associated } \\
\text { with changes in levels of } \\
\text { anxiety measured by GAD-7 } \\
\text { scores. Linear Mixed Models } \\
\text { were used for overtime } \\
\text { changes in these } \\
\text { relationships. }\end{array}$ \\
\hline $\begin{array}{l}\text { Hypothesis 4A: HIV+ } \\
\text { adults with caffeine } \\
\text { intake }>250 \mathrm{mg} / \mathrm{d} \text { have } \\
\text { decreased lean body } \\
\text { mass and body fat mass } \\
\text { estimated by Bio- } \\
\text { impedance analysis } \\
\text { (BIA) over a period of } \\
\text { 3-months. }\end{array}$ & $\begin{array}{l}\text { Lean body } \\
\text { mass(LBM), } \\
\text { fat mass }\end{array}$ & $\begin{array}{l}\text { Total Caffeine } \\
\text { intake }\end{array}$ & $\begin{array}{l}\text { age, gender, income, } \\
\text { and time from } \\
\text { diagnosis of HIV, } \\
\text { drug, tobacco and } \\
\text { alcohol use and } \\
\text { different types of } \\
\text { ART medications }\end{array}$ & $\begin{array}{l}\text { T-test and linear and logistic } \\
\text { regressions were used to } \\
\text { analyze baseline cross- } \\
\text { sectional data and Linear } \\
\text { Mixed Models were used for } \\
\text { over time changes in these } \\
\text { associations. }\end{array}$ \\
\hline
\end{tabular}




\begin{tabular}{|c|c|c|c|c|}
\hline Hypotheses & $\begin{array}{l}\text { Dependent } \\
\text { Variables }\end{array}$ & $\begin{array}{l}\text { Independent } \\
\text { Variables }\end{array}$ & Control Variables & Statistical Analysis \\
\hline $\begin{array}{l}\text { Hypothesis 4B: HIV+ } \\
\text { adults with caffeine } \\
\text { intake }>250 \mathrm{mg} / \mathrm{d} \text { have } \\
\text { decreased BMI } \\
\text { estimated by BIA over a } \\
\text { period of 3-months. }\end{array}$ & $\begin{array}{l}\text { Body mass } \\
\text { index (BMI) }\end{array}$ & $\begin{array}{l}\text { Total Caffeine } \\
\text { intake }\end{array}$ & $\begin{array}{l}\text { age, gender, income, } \\
\text { and time from } \\
\text { diagnosis of HIV, } \\
\text { drug, tobacco and } \\
\text { alcohol use and } \\
\text { different types of } \\
\text { ART medications }\end{array}$ & $\begin{array}{l}\text { T-test and linear and logistic } \\
\text { regressions were used to } \\
\text { analyze baseline cross- } \\
\text { sectional data and Linear } \\
\text { Mixed Models were used for } \\
\text { over time changes in these } \\
\text { associations. }\end{array}$ \\
\hline $\begin{array}{l}\text { Hypothesis 4C: HIV+ } \\
\text { adults with caffeine } \\
\text { intake }>250 \mathrm{mg} / \mathrm{d} \text { have } \\
\text { lower than normal } \\
\text { hemoglobin measured } \\
\text { over a period of 3- } \\
\text { months. }\end{array}$ & $\begin{array}{l}\text { Hemoglobin } \\
\text { levels }\end{array}$ & $\begin{array}{l}\text { Total Caffeine } \\
\text { intake }\end{array}$ & $\begin{array}{l}\text { age, gender, income, } \\
\text { and time from } \\
\text { diagnosis of HIV, } \\
\text { drug, tobacco and } \\
\text { alcohol use and } \\
\text { different types of } \\
\text { ART medications }\end{array}$ & $\begin{array}{l}\text { T-test and linear and logistic } \\
\text { regressions were used to } \\
\text { analyze baseline cross- } \\
\text { sectional data and Linear } \\
\text { Mixed Models were used for } \\
\text { over time changes in these } \\
\text { associations. }\end{array}$ \\
\hline $\begin{array}{l}\text { Hypothesis 4D: HIV+ } \\
\text { adults with caffeine } \\
\text { intake }>250 \mathrm{mg} / \mathrm{d} \text { have } \\
\text { lower than normal } \\
\text { hematocrit measured } \\
\text { over a period of 3- } \\
\text { months. }\end{array}$ & Hematocrit & $\begin{array}{l}\text { Total Caffeine } \\
\text { intake }\end{array}$ & $\begin{array}{l}\text { age, gender, income, } \\
\text { and time from } \\
\text { diagnosis of HIV, } \\
\text { drug, tobacco and } \\
\text { alcohol use and } \\
\text { different types of } \\
\text { ART medications }\end{array}$ & $\begin{array}{l}\text { T-test and linear and logistic } \\
\text { regressions were used to } \\
\text { analyze baseline cross- } \\
\text { sectional data and Linear } \\
\text { Mixed Models were used for } \\
\text { over time changes in these } \\
\text { associations. }\end{array}$ \\
\hline
\end{tabular}




\begin{tabular}{|c|c|c|c|c|}
\hline Hypotheses & $\begin{array}{l}\text { Dependent } \\
\text { Variables }\end{array}$ & $\begin{array}{l}\text { Independent } \\
\text { Variables }\end{array}$ & Control Variables & Statistical Analysis \\
\hline $\begin{array}{l}\text { Hypothesis 4E: HIV+ } \\
\text { adults with caffeine } \\
\text { intake > } 250 \mathrm{mg} / \mathrm{d} \text { have } \\
\text { lower than normal } \\
\text { serum albumin levels, } \\
\text { measured over a period } \\
\text { of 3-months. }\end{array}$ & $\begin{array}{l}\text { Serum } \\
\text { albumin } \\
\text { levels }\end{array}$ & $\begin{array}{l}\text { Total Caffeine } \\
\text { intake }\end{array}$ & $\begin{array}{l}\text { age, gender, income, } \\
\text { and time from } \\
\text { diagnosis of HIV, } \\
\text { drug, tobacco and } \\
\text { alcohol use and } \\
\text { different types of } \\
\text { ART medications }\end{array}$ & $\begin{array}{l}\text { T-test and linear and logistic } \\
\text { regressions were used to } \\
\text { analyze baseline cross- } \\
\text { sectional data and Linear } \\
\text { Mixed Models were used for } \\
\text { over time changes in these } \\
\text { associations. }\end{array}$ \\
\hline $\begin{array}{l}\text { Hypothesis 5A: HIV+ } \\
\text { adults with caffeine } \\
\text { intake }>250 \mathrm{mg} / \mathrm{d} \text { have } \\
\text { decreased total caloric } \\
\text { intakes estimated by } 24- \\
\text { hour dietary recall over } \\
\text { a period of 3-months. }\end{array}$ & $\begin{array}{l}\text { Total caloric } \\
\text { intake }\end{array}$ & $\begin{array}{l}\text { Total Caffeine } \\
\text { intake }\end{array}$ & $\begin{array}{l}\text { age, gender, income, } \\
\text { and time from } \\
\text { diagnosis of HIV, } \\
\text { drug, tobacco and } \\
\text { alcohol use and } \\
\text { different types of } \\
\text { ART medications }\end{array}$ & $\begin{array}{l}\text { T-test and linear and logistic } \\
\text { regressions were used to } \\
\text { analyze baseline cross- } \\
\text { sectional data and Linear } \\
\text { Mixed Models were used for } \\
\text { over time changes in these } \\
\text { associations. }\end{array}$ \\
\hline $\begin{array}{l}\text { Hypothesis 5B: HIV+ } \\
\text { adults with caffeine } \\
\text { intake }>250 \mathrm{mg} / \mathrm{d} \text { have } \\
\text { decreased caloric } \\
\text { intakes from proteins } \\
\text { estimated by 24-hour } \\
\text { dietary recall over a } \\
\text { period of 3-months. }\end{array}$ & $\begin{array}{l}\text { Calories from } \\
\text { proteins }\end{array}$ & $\begin{array}{l}\text { Total Caffeine } \\
\text { intake }\end{array}$ & $\begin{array}{l}\text { age, gender, income, } \\
\text { and time from } \\
\text { diagnosis of HIV, } \\
\text { drug, tobacco and } \\
\text { alcohol use and } \\
\text { different types of } \\
\text { ART medications }\end{array}$ & $\begin{array}{l}\text { T-test and linear and logistic } \\
\text { regressions were used to } \\
\text { analyze baseline cross- } \\
\text { sectional data and Linear } \\
\text { Mixed Models were used for } \\
\text { over time changes in these } \\
\text { associations. }\end{array}$ \\
\hline
\end{tabular}




\begin{tabular}{|c|c|c|c|c|}
\hline Hypotheses & $\begin{array}{l}\text { Dependent } \\
\text { Variables }\end{array}$ & $\begin{array}{l}\text { Independent } \\
\text { Variables }\end{array}$ & Control Variables & Statistical Analysis \\
\hline $\begin{array}{l}\text { Hypothesis 5C: HIV+ } \\
\text { adults with caffeine } \\
\text { intake }>250 \mathrm{mg} / \mathrm{d} \text { have } \\
\text { decreased caloric } \\
\text { intakes from } \\
\text { carbohydrates estimated } \\
\text { by 24-hour dietary recall } \\
\text { over a period of 3- } \\
\text { months. }\end{array}$ & $\begin{array}{l}\text { Calories from } \\
\text { carbohydrates }\end{array}$ & $\begin{array}{l}\text { Total Caffeine } \\
\text { intake }\end{array}$ & $\begin{array}{l}\text { age, gender, income, } \\
\text { and time from } \\
\text { diagnosis of HIV, } \\
\text { drug, tobacco and } \\
\text { alcohol use and } \\
\text { different types of } \\
\text { ART medications }\end{array}$ & $\begin{array}{l}\text { T-test and linear and logistic } \\
\text { regressions were used to } \\
\text { analyze baseline cross- } \\
\text { sectional data and Linear } \\
\text { Mixed Models were used for } \\
\text { over time changes in these } \\
\text { associations. }\end{array}$ \\
\hline $\begin{array}{l}\text { Hypothesis 5D: HIV+ } \\
\text { adults with caffeine } \\
\text { intake }>250 \mathrm{mg} / \mathrm{d} \text { have } \\
\text { decreased caloric } \\
\text { intakes from fats } \\
\text { estimated by 24-hour } \\
\text { dietary recall over a } \\
\text { period of 3-months. }\end{array}$ & $\begin{array}{l}\text { Calories from } \\
\text { fats }\end{array}$ & $\begin{array}{l}\text { Total Caffeine } \\
\text { intake }\end{array}$ & $\begin{array}{l}\text { age, gender, income, } \\
\text { and time from } \\
\text { diagnosis of HIV, } \\
\text { drug, tobacco and } \\
\text { alcohol use and } \\
\text { different types of } \\
\text { ART medications }\end{array}$ & $\begin{array}{l}\text { T-test and linear and logistic } \\
\text { regressions were used to } \\
\text { analyze baseline cross- } \\
\text { sectional data and Linear } \\
\text { Mixed Models were used for } \\
\text { over time changes in these } \\
\text { associations. }\end{array}$ \\
\hline
\end{tabular}




\section{References}

1. James JE. Acute and chronic effects of caffeine on performance, mood, headache, and sleep. Neuropsychobiology. 1998;38(1):32-41.

2. Knight C, Knight I, Mitchell D, Zepp J. Beverage caffeine intake in US consumers and subpopulations of interest: estimates from the Share of Intake Panel survey. Food and Chemical Toxicology. 2004;42(12):1923-1930.

3. Frary CD, Johnson RK, Wang MQ. Food sources and intakes of caffeine in the diets of persons in the United States. Journal of the American Dietetic Association. 2005;105(1):110-113.

4. Heckman M, Sherry K, Mejia D, Gonzalez E. Energy drinks: an assessment of their market size, consumer demographics, ingredient profile, functionality, and regulations in the United States. Comprehensive Reviews in Food Science and Food Safety. 2010;9(3):303-317.

5. Lieberman HR, Stavinoha T, McGraw S, White A, Hadden L, Marriott BP. Caffeine use among active duty US Army soldiers. Journal of the Academy of Nutrition and Dietetics. 2012;112(6):902-912. e904.

6. Norton TR, Lazev AB, Sullivan MJ. The "buzz" on caffeine: Patterns of caffeine use in a convenience sample of college students. Journal of Caffeine Research. 2011;1(1):35-40.

7. Daly JW, Fredholm BB. Caffeine-an atypical drug of dependence. Drug and Alcohol Dependence. 1998;51(1):199-206.

8. Spiller MA. The chemical components of coffee. Caffeine. 1998;1998:97-161.

9. Flaghorn FH, Johnson RK, Ying LF. Food sources and intakes of caffeine in the diets of persons in the United States. Journal of the American Dietetic Association. 2014;115(1):110-113.

10. Dorfman L, Jarvik M. Comparative stimulant and diuretic actions of caffeine and theobromine in man. Clinical Pharmacology and Therapeutics. 1970;11(6):869.

11. Mitler MM, Walsleben J, Sangal RB, Hirshkowitz M. Sleep latency on the maintenance of wakefulness test (MWT) for 530 patients with narcolepsy while free of psychoactive drugs. Electroencephalography and Clinical Neurophysiology. 1998;107(1):33-38.

12. Bara A, Barley E. Caffeine for asthma. The Cochrane Library. 2001. 
13. Schmidt B, Roberts RS, Davis P, et al. Caffeine therapy for apnea of prematurity. New England Journal of Medicine. 2006;354(20):2112-2121.

14. Lipton RB, Stewart WF, Ryan RE, Saper J, Silberstein S, Sheftell F. Efficacy and safety of acetaminophen, aspirin, and caffeine in alleviating migraine headache pain: three double-blind, randomized, placebo-controlled trials. Archives of Neurology. 1998;55(2):210-217.

15. Ascherio A, Zhang SM, Hernán MA, et al. Prospective study of caffeine consumption and risk of Parkinson's disease in men and women. Annals of Neurology. 2001;50(1):56-63.

16. Prediger RD, Pamplona FA, Fernandes D, Takahashi RN. Caffeine improves spatial learning deficits in an animal model of attention deficit hyperactivity disorder (ADHD)-the spontaneously hypertensive rat (SHR). The International Journal of Neuropsychopharmacology. 2005;8(04):583-594.

17. Morris MB, Weinstein L. Caffeine and the fetus: is trouble brewing. Am J Obstet Gynecol. 1981;140(6):607-610.

18. Worthington J, Fava M, Agustin C, et al. Consumption of alcohol, nicotine, and caffeine among depressed outpatients: relationship with response to treatment. Psychosomatics. 1996;37(6):518-522.

19. Thorn CF, Klein TE, Altman RB. The Pharmacogenetics and Pharmacogenomics Knowledge Base. Psychopharmacology. 1996; 147 (14): 1140-11147.

20. Verbeeck RK. Pharmacokinetics and dosage adjustment in patients with hepatic dysfunction. European journal of clinical pharmacology. 2008;64(12):1147-1161.

21. Mumford GK, Evans SM, Kaminski BJ, et al. Discriminative stimulus and subjective effects of theobromine and caffeine in humans. Psychopharmacology. 1994;115(1-2):1-8.

22. Heckman MA, Weil J, Mejia D, Gonzalez E. Caffeine (1, 3, 7-trimethylxanthine) in foods: a comprehensive review on consumption, functionality, safety, and regulatory matters. Journal of Food Science. 2010;75(3):R77-R87

23. Gilliland K, Bullock W. Caffeine: a potential drug of abuse. Advances in Alcohol \& Substance abuse. 1984;3(1-2):53-73.

24. Holtzman SG. Caffeine as a model drug of abuse. Trends in Pharmacological Sciences. 1990;11(9):355-356. 
25. Holmgren P, Nordén-Pettersson L, Ahlner J. Caffeine fatalities—four case reports. Forensic Science International. 2004;139(1):71-73.

26. Peters JM. Factors affecting caffeine toxicity: a review of the literature. The Journal of Clinical Pharmacology and the Journal of New Drugs. 1967;7(3):131141.

27. Grosso LM, Bracken MB. Caffeine metabolism, genetics, and perinatal outcomes: a review of exposure assessment considerations during pregnancy. Annals of Epidemiology. 2005;15(6):460-466.

28. Brown CR, Wilson M, Benowitz NL. Changes in rate and pattern of caffeine metabolism after cigarette abstinence. Clinical Pharmacology \& Therapeutics. 1988;43(5):488-491.

29. Bertilsson L, Carrillo J, Dahl M, et al. Clozapine disposition covaries with CYP1A2 activity determined by a caffeine test. British Journal of Clinical Pharmacology. 1994;38(5):471-473.

30. Campa A LK, Rafie C, Sales S, Baum MK. Caffeine intake and plasma zinc levels among HIV+ adult drug users in Miami. Experimental Biology 2008 FASEB Conference, San Diego, CA, April 5-9, 2008.; 2008.

31. Iancu I, Strous R. Caffeine intoxication: history, clinical features, diagnosis and treatment. Harefuah. 2006;145(2):147-151, 163-144.

32. Rogers PJ, Dernoncourt C. Regular caffeine consumption: a balance of adverse and beneficial effects for mood and psychomotor performance. Pharmacology Biochemistry and Behavior. 1998;59(4):1039-1045.

33. Hughes JR, Higgins ST, Bickel WK, et al. Caffeine self-administration, withdrawal, and adverse effects among coffee drinkers. Archives of General Psychiatry. 1991;48(7):611-617.

34. Bakker R, Steegers EA, Obradov A, Raat H, Hofman A, Jaddoe VW. Maternal caffeine intake from coffee and tea, fetal growth, and the risks of adverse birth outcomes: the Generation R Study. The American Journal of Clinical Nutrition. 2010;91(6):1691-1698.

35. Sepkowitz KA. Energy drinks and caffeine-related adverse effects. Jama. 2013;309(3):243-244.

36. Dreher HM. The effect of caffeine reduction on sleep quality and well-being in persons with HIV. Journal of Psychosomatic Research. 2003;54(3):191-198. 
37. Hedges DW, Woon FL, Hoopes SP. Caffeine-induced psychosis. CNS Spectr. 2009;14(3):127-129.

38. Greenberg J, Axen K, Schnoll R, Boozer C. Coffee, tea and diabetes: the role of weight loss and caffeine. International Journal of Obesity. 2005;29(9):1121-1129.

39. Kent SJ. Loss of control of HIV viremia associated with the fat malabsorption drug orlistat. AIDS Research and Human Retroviruses. 2012;28(9):961-962.

40. Shor-Posner G, Campa A, Zhang G, et al. When obesity is desirable: a longitudinal study of the Miami HIV-1-infected drug abusers (MIDAS) cohort. Journal of Acquired Immune Deficiency Syndromes (1999). 2000;23(1):81-88.

41. Wheeler DA, Gibert CL, Launer CA, et al. Weight Loss as a Predictor of Survival and Disease Progression in HIV Infection. JAIDS Journal of Acquired Immune Deficiency Syndromes. 1998;18(1):80-85.

42. Westerterp-Plantenga MS, Lejeune MP, Kovacs EM. Body weight loss and weight maintenance in relation to habitual caffeine intake and green tea supplementation. Obesity Research. 2005;13(7):1195-1204.

43. Rukmana D. Comparing the residential origins of homeless families and homeless individuals in Miami-Dade County, Florida. Area. 2011;43(1):96-109.

44. Schneider M, Chersich M, Neuman M, Parry C. Alcohol consumption and HIV/AIDS: the neglected interface. Addiction. 2012;107(8):1369-1371.

45. Darke S, Swift W, Hall W, Ross M. Drug use, HIV risk-taking and psychosocial correlates of benzodiazepine use among methadone maintenance clients. Drug and Alcohol Dependence. 1993;34(1):67-70.

46. Nieman RB, Fleming J, Coker RJ, Harris JW, Mitchell DM. The effect of cigarette smoking on the development of AIDS in HIV-1-seropositive individuals. Aids. 1993;7(5):705-710.

47. Metsch LR, Pereyra M, Brewer TH. Use of HIV health care in HIV-seropositive crack cocaine smokers and other active drug users. Journal of substance abuse. 2001;13(1):155-167.

48. Page JB, Chitwood DD, Smith PC, Kane N, McBride DC. Intravenous drug use and HIV infection in Miami. Medical Anthropology Quarterly. 1990;4(1):56-71.

49. Fernández MI, Bowen GS, Varga LM, et al. High rates of club drug use and risky sexual practices among Hispanic men who have sex with men in Miami, Florida. Substance Use \& Misuse. 2005;40(9-10):1347-1362. 
50. Brewer TH, Metsch LR, Zenilman JM. Use of a public sexually transmitted disease clinic by known HIV-positive adults: decreased self-reported risk behavior and increased disease incidence. Journal of Acquired Immune Deficiency Syndromes (1999). 2002;29(3):289-294.

51. Brooks R, Rotheram-Borus MJ, Bing EG, Ayala G, Henry CL. HIV and AIDS among men of color who have sex with men and men of color who have sex with men and women: an epidemiological profile. AIDS Education and Prevention. 2003;15(1 Supplement):1-6.

52. Kacanek D, Jacobson DL, Spiegelman D, Wanke C, Isaac R, Wilson IB. Incident depression symptoms are associated with poorer HAART adherence: A longitudinal analysis from the Nutrition for Healthy Living (NFHL) study. Journal of Acquired Immune Deficiency Syndromes (1999). 2010;53(2):266.

53. Chatterjee S, Price A. Healthy living with persuasive technologies: framework, issues, and challenges. Journal of the American Medical Informatics Association. 2009;16(2):171-178. 


\section{CHAPTER II: LITERATURE REVIEW}

There are many recent instances of adverse events due to caffeine abuse and a number of television and newspaper reports suggest a pandemic of caffeine overuse in United States in the current decade. ${ }^{1}$ There have also been many reports of energy drinks related deaths and concerns about rising levels of caffeine consumption especially amongst many vulnerable populations. ${ }^{1}$ In spite of such alarming rates of increased adverse events due to caffeine, the extent to which these reports are scientific and evidence-based has always been disputed and repeatedly challenged by the scientific community. ${ }^{1}$ In lieu of these conflicting evidence, concerns over safety and permissible levels of caffeine consumption needs to be addressed and researched amongst different population groups. We need to understand the reasons for peaking levels of caffeine consumption in many vulnerable populations, as well as the characteristics that place these populations at higher risk. Many studies have linked caffeine intake to various physical benefits, such as increased strength, endurance and stamina, making caffeinecontaining beverages a favorite amongst athletes and sports personnel. ${ }^{1-5}$ There are many reports which show that caffeine is associated with mental faculties like increased alertness, cognition and performance, thereby increasing its overuse potentials among students and professionals. ${ }^{1-5}$ Many studies report the advantages of consuming caffeine on increased duration and quality of work, increased working capacity at hours that interfere with the biological rhythm, as well as increased work efficiency at the cost of reducing the number of hours of sleep recommended per day. ${ }^{1-5}$ Vulnerable populations according to numerous studies include students, business personnel, athletes, night shift workers, population with chronic diseases, military personnel, geriatric population, 
frequent travelers as well as professionals in college and university settings. ${ }^{6}$ It is particularly relevant that we research caffeine consumption as a phenomenon and understand the effects in the general population before we focus on the effects in our cohort of PLWH in Miami.

\section{Daily Reported Caffeine use in United States}

Secondary analyses of NHANES data collected between 2001 and 2010 showed that the general levels and patterns of caffeine consumption have not significantly changed over the last ten years. ${ }^{6-8}$ The average recorded consumption was $200 \mathrm{mg} / \mathrm{day}$ for all the entire survey. ${ }^{6-8}$ All the age groups consumed highest amounts of caffeine through coffee and average consumption through different beverages included, $135 \mathrm{mg} /$ day form coffee, $65 \mathrm{mg} /$ day from energy drinks, $60 \mathrm{mg} /$ day form tea and $35 \mathrm{mg} /$ day from soda. .-8 $^{-6}$ Results also showed that highest caffeine consumptions (average caffeine intake recorded beyond the $90^{\text {th }}$ percentiles for the entire sample) were recorded in the age group of 50-59 years with average daily levels exceeding $500 \mathrm{mg} /$ day, and in the 50-59 years group with slightly less than $500 \mathrm{mg} /$ day. ${ }^{6-8}$ There was also a statistically significant increase of 8 mg/day of caffeine from energy drinks during the past ten years $(P<0.001) \cdot{ }^{6-8}$ Another large scale study done in US in the year 2011 with 37,604 participants showed similar caffeine consumption characteristics to the ones reported by the NHANES data. ${ }^{9}$ The largest caffeine source was coffee followed by energy drinks, tea and soda. ${ }^{9}$

\section{Safe Levels of Caffeine Consumption}

Over the last fifty years caffeine has been widely researched. Several studies have been conducted by regulatory agencies for determining the safe levels of consumption as

well as levels producing side effects and adverse effects for different populations. ${ }^{10-15}$ 
The U.S. Food and Drug Administration (USFDA) has different recommendations based upon whether caffeine is consumed through naturally available sources like coffee, tea and cocoa products or artificially added in caffeinated beverages and energy drinks. ${ }^{11,14}$ USFDA has classified natural sources as Generally Recognized as Safe (GRAS) category while artificially added caffeine has been concluded to be safe, within the current average levels of consumption (200 mg/day). ${ }^{11}$ Further research was recommended to confirm the safety limits of artificially added caffeine. ${ }^{11}$ For both naturally occurring and artificially added caffeine sources, FDA considers $400 \mathrm{mg} / \mathrm{d}$ to be generally safe and not associated with any dangerous side effects. ${ }^{10,11}$ The World Health Organization (WHO) defines caffeine overuse as daily consumption beyond $500 \mathrm{mg} / \mathrm{d} .{ }^{12,13}$ Beyond this level caffeine produces visible adverse effects collectively known as ‘caffeinism'. The World Health Organization (WHO) has also cautioned that these adverse effects could be precipitated at much lower doses depending on the physiological profiles of individuals as well as the genetic makeup of the population. ${ }^{12,13}$ The International Classification of Diseases (ICD) manual considers caffeine consumption beyond $250 \mathrm{mg} /$ day to be associated with many mental and behavioral disorders though it is inconclusive whether such effects would be uniformly applicable in the general population. ${ }^{13}$ The Diagnostic and Statistical Manual of Mental Disorders (DSM-5) considers consumption below $250 \mathrm{mg}$ /day to be generally safe and beyond this level to be associated with many adverse effects such as withdrawal, addiction, irritability and craving. ${ }^{15}$ Thus we can conclude that consumption below 250 mg/day, irrespective of the sources is generally safe and devoid of adverse effects after comparing and summarizing the recommendations of these individual regulatory bodies. 


\section{Caffeine-Biological Actions-Adenosine Receptors (A1, A2a, A2b and A3)}

Caffeine affects a number of physiological and biochemical processes. ${ }^{16}$ The main action includes the blockade of a number of related adenosine receptor family subtypes. ${ }^{16,17}$ Caffeine at plasma levels of 0.001-0.1 millimoles/ml produces significant blockade of all adenosine receptor subtypes. ${ }^{16}$ Other biochemical effects include inhibition of phosphodiesterases, blockade of GABA-A receptor subtypes, and release of intracellular calcium. ${ }^{16}$ These actions are accomplished at higher plasma levels of 0.1-10 millimoles $/ \mathrm{ml} .{ }^{16}$ A number of other interactions including ion channel blockade and enzyme inhibitions have also been reported. ${ }^{16}$ Four different adenosine receptor subsets exist in mammals, which include A1, A2a, A2b and A3. ${ }^{17}$ When considered the order of importance (in humans), in terms of relative concentrations and effects in the body, A2a receptors stand the first, $\mathrm{A} 1$ the second and $\mathrm{A} 2 \mathrm{~b}$ the third. ${ }^{17}$ At A3 receptors caffeine is a 'partial agonist' with both agonist and antagonist like actions or in practical terms 'no significant effects'. ${ }^{17}$ Caffeine is primarily an antagonist at A1, A2a \& A2b receptor subtypes. ${ }^{17}$ To be antagonized, the receptors should be already acted upon by endogenous adenosine. Caffeine has no CNS effects unless the receptors are already acted upon by endogenously produced adenosine. Under normal physiological conditions, adenosine acts on A1 and A2a receptors in both the Central Nervous System (CNS) and Peripheral Nervous System (PNS) and produces inhibition of the neuronal circuitry. ${ }^{17}$ Adenosine acts on A2b and A3 receptor during abnormal conditions like ischemia and necrosis, or during increased firing states like convulsions and seizures. ${ }^{17}$ Blockade of A1 and A2b receptor seem to be the most possible mechanism for pharmacological actions of caffeine under normal resting physiological conditions. ${ }^{17} \mathrm{~A}$ number of drugs of abuse have the 
potentials to change the endogenously and constitutionally expressed levels of adenosine. ${ }^{17}$ These endogenously expressed levels of adenosine show much 'inter species variability' between different biological species and 'intra-species variability' between different individuals. ${ }^{16}$ This is the likely mechanism for different levels of tolerance to the effects of caffeine between different individuals, as well as different life forms. ${ }^{16}$ This also accounts for the different set of responses when caffeine is co- administered with other drugs of abuse. ${ }^{16}$ This is also responsible for different sets of biphasic responses between animals and humans thereby delimiting the comparability between animal and human studies. ${ }^{18}$ Caffeine also stabilizes these receptors to the normal circadian fluctuating levels of adenosine expressed constitutionally thereby explaining the phenomenon of reinforcement. ${ }^{18}$ In addition to inhibiting adenosine, caffeine also inhibits phosphodiesterase enzymes and thereby increases the G-protein stimulation, increases adenylyl cyclase enzyme activity and increases cyclic AMP levels in the cells. ${ }^{19}$ It has not been possible to classify and isolate the effects of caffeine (e.g CNS stimulation, antidepressant, and somnolytic effects) specifically to its action on any of the individual receptor subtypes. All these actions are accomplished through various levels of receptor antagonism involving all the three receptors. ${ }^{19}$ Various 'receptor sub-type specific analogs' of adenosine have been employed to study the individual receptor subtypes. But these analogs have additional actions on many other receptor, which may or may not be related to caffeine and adenosine, thus obscuring the results. ${ }^{19}$ Research has shown there are many such dormant receptor subtypes that are not affected by endogenously produced adenosine. These receptors are species specific and hence again, animal studies do not produce comparable results. ${ }^{19}$ This is further complicated by the findings in many animal 
studies which show receptor 'up-regulations' and 'down-regulations' by caffeinated products. In a study done on mice, chronic treatment with caffeine resulted in 'upregulation' of A1-adenosine receptors, serotonin receptors, GABA-A receptors, muscarinic receptors, and $\delta$-opoid receptors..$^{20}$ Similarly it produced 'down-regulation' of $\beta$-adrenergic receptors and 'desensitization' of nicotine receptors. ${ }^{20}$ Dopamine receptors were not showing any such changes and hence the actions on dopaminergic receptors can be considered unaffected by acuteness or chronicity of caffeine consumption, in both humans and animals. ${ }^{21}$ These findings suggest that the biological effects of caffeine are complex and variable (individual to individual variability), because of the differences in the mechanism of action and variability in the types of receptors involved. Many studies on acute and chronic caffeine use fail to yield adequate test-retest reliability due to these variable levels of receptor-regulations. ${ }^{21}$

\section{Caffeine and A1 Adenosine Receptors in the Central Nervous System (CNS)}

A1 receptors are abundant in the cerebral cortex, cerebellar cortex, hippocampus, substantia nigra, and thalamic nuclei. ${ }^{22}$ These receptors are located on synaptic clefts and axo-dendritic buttons. ${ }^{22}$ When endogenous adenosine acts on these receptors it produces substantial inhibition of the release of a number of neuro-transmitters. It is not well known how these inhibitory actions are accomplished. Under normal physiological conditions adenosine produces inhibition of only certain neuronal circuits while others remain unaffected. These mechanisms too, are not fully understood. Caffeine has a dual role when it comes to antagonism of adenosine at A1 receptors. It produces reversal of the inhibition produced by Adenosine which is the most important and acute action. But in the long term these receptors are also up-regulated by chronic caffeine use. ${ }^{23} \mathrm{Up}-$ 
regulation occurs both by the process of desensitization to caffeine as well as increase in the number of constitutionally synthesized receptors. ${ }^{23}$ Caffeine also increases the rate of recycling of these receptors. ${ }^{23}$ Adenosine decreases the rate of firing of many CNS neurons with nor-adrenergic, dopaminergic, cholinergic, and glutamatergic activity through A1 receptor-mediated activation of fast potassium channels. ${ }^{24}$ Thus adenosine produces hyper-polarization of the cells and thereby inhibition of neuronal circuitry. Certain studies show that open chloride channels are also responsible for these actions. This process is known as tonic inhibition of A1 receptors by adenosine. ${ }^{24}$ This tonic inhibition is competitively antagonized by caffeine. ${ }^{24} \mathrm{~A}$ number of animal studies have documented that caffeine increases the levels of acetylcholine in the cholinergic neurons of meso-pons, hippocampus and amygdala and mesolimbic nuclei. ${ }^{25}$ These are the centers responsible for mood, aggression, locomotion, learning, memory and behavior. This acetylcholine via stimulation of nicotinic receptors in Ascending Reticular Activation System (ARAS) produces behavioral arousal. Actions of caffeine have also been recorded in nigro-straital pathways, thus enhancing jitteriness and loss of fine motor coordination skills. ${ }^{25}$ Caffeine also increases the levels of dopamine and glutamine in the cortical neurons that innervate the thalamus and striatum. ${ }^{21}$ This is responsible for locomotor stimulation and hyper-excitability states. An animal study done on mice showed that both D1 and D2 receptors are involved in the locomotor stimulatory effects of caffeine. Antagonists that blocked both D1 and D2 receptors inhibited the increased locomotor stimulation induced by caffeine. ${ }^{21}$ Selective antagonists of D2 receptors produced inhibition of rotational activity also induced by the same doses of caffeine. ${ }^{21}$ These processes are very complex and shows inter species and intra species variations. 
Irrespective of these complexities it is very convincing that caffeine produces a variety of adverse effects through antagonism of Adenosine at A1 receptors. These biochemical alterations can have serious effects in chronic disease states like HIV where brain cells are constantly attacked and destroyed the virus.

\section{Caffeine Effects on A2a and A2b Adenosine Receptors}

A2a receptors are abundant in caudate nucleus, putamen, nucleus accumbens, tuberculum olfactorium ${ }^{26}$ as well as the gabaminergic neurons of striatum. ${ }^{27}$ These nuclei are mainly associated with D1 and D2 receptor mediated release of encephalins which are natural endorphins that act as potent analgesics and mood elevators. D1 receptors are also associated with release of other neurotransmitters like substance $\mathrm{P}$ and dynorphins which have similar euphoric actions. Though both the dopaminergic receptors D1 and D2 are positively modulated by caffeine, the effects of D1 predominate. ${ }^{28}$ These A2a receptors stimulate Adenylyl cyclase, increase cyclic AMP levels, similar to A1 receptors. But strikingly, D2 receptors decrease the levels of cyclic AMP. Caffeine antagonizes the actions of endogenous adenosine at A2b receptors, thereby potentiating endogenous dopaminergic effects on D2 receptors. This decreases the levels of cyclic AMP in the neuronal cells. Thus caffeine acts as a depressant in some neuronal circuitry. ${ }^{29}$ These A2a receptors are located on the dendritic spines and are virtually absent in the synaptic buttons or clefts. ${ }^{29}$ It is well established that inhibition of adenosine at A2a receptors by caffeine, potentiate the inhibitory effects of GABA. ${ }^{29}$ Caffeine blocks the striatal A2a receptor activity tonically activated and controlled by adenosine. This would decrease the effects of endogenous dopamine on D2 receptors. ${ }^{29}$ This produces major changes in circuitry associated with reward /arousal systems. Adenosine by its action on A1 
receptors produces some levels of physiological self-antagonism to its actions on A2a receptors. ${ }^{29}$ These actions confuse the role played by caffeine both in acute and chronic doses. ${ }^{29}$ Furthermore, this self-antagonism shows inters-species and intra-species variations. ${ }^{29}$ Any findings from animal studies therefore need to be validated with human studies and no acceptable levels of homogeneity and comparability exists. Caffeine therefore has both effects; stimulating effects on certain neuronal circuitry and depressant effects on others. ${ }^{30}$ Furthermore some nuclei like striato-pallidal and striato-nigral, are inhibitory to the Globus pallidus and substantially higher concentrations of A2a receptors are found to be active in these nuclei. ${ }^{31}$ Caffeine by blocking the constitutive inhibitory effects of endogenous adenosine decreases the inhibitory effects on Globus pallidus and thereby symptomatically ameliorates the progression of Parkinson’s disease. ${ }^{31}$ But this effect is at the costs of increased activity in other neuronal circuits like those in cerebral and cerebellar cortex which leads to increased burnout damages in these neurons. Thus, we have an open question 'Whether the beneficial effects of caffeine could be at the costs of potential known or unknown side-effects?'

\section{Biphasic Effects of Caffeine}

Both human and animal studies have shown biphasic behavioral effects of caffeine. Low to moderate doses elicited a stimulatory effect described by many as desirable: high doses elicited undesirable effects like anxiety, nervousness, shakiness, jitteriness and lack of concentration. ${ }^{32}$ Very high doses have shown to induce convulsions in animal models. The cluster of undesirable effects of high and very high doses of caffeine is collectively known as 'caffeinism' ${ }^{32}$ Low doses of caffeine ( $<4$ $\mathrm{mg} / \mathrm{kg}$ body weight/day) stimulated a frenzy of motor activity in rodents. This is 
measured in terms of 'open-field locomotion activity scores' in normal mice and 'rotational activity scores' in mice with induced unilateral dopaminergic lesions. Low doses elicited 'conditioned place preference' an indicator of desirable effects in mice. ${ }^{32}$ High doses on the contrary, elicited 'place aversion' an indicator of undesirable effects. ${ }^{32}$ High doses have also shown major depression like symptoms in these animals. ${ }^{32}$ Another study suggested that high doses of caffeine produced profound suppression of motor activity in knockout mice with absent $\mathrm{A}_{2 \mathrm{~A}}$-adenosine receptor. ${ }^{33}$ This shows that the stimulatory effects are prominent until fullest saturation of these and other structurally similar receptors and once these receptors are saturated depressive effects begin to predominate. Mumford and Holtzman ${ }^{34}$ did an experiment in which the mice were trained to identify drugs with similar effects as that of caffeine upon temporary withdrawal of regularly administered doses of caffeine. The regularly administered doses were different for different groups of mice and are referred to as 'priming doses'. They were primed initially either for low or high doses of caffeine and subsequently given choices of a number of other test drugs. These experiments used extensive behavioral techniques in order to derive exact cues from rodent behaviors. Mice that were primed with low doses of caffeine chose dopaminergic drugs such as amphetamine and cocaine. Mice that were primed for high doses of caffeine chose CNS depressants which included benzodiazepine inverse agonists such as phencyclidine, pentylenetetrazole and papaverine. This study reflects the biphasic response to caffeine, where the mice primed with low doses showed euphoric effects and mice primed for high doses showed many complex effects, which were behaviorally non-routine but definitely not euphoric and tended towards coping mechanisms for depressive effects. ${ }^{34}$ These experiments cannot be generalized to human 
beings because humans show different sets of responses for both high and low doses of caffeine. Furthermore, other xanthine alkaloids like theobromine have virtually no responses in humans but are comparably active as caffeine in rodent populations. ${ }^{34} \mathrm{To}$ add to the limitations of this animal study, all sources of caffeine metabolize to three xanthine alkaloid products in the human body and the metabolic products of caffeine show many differences in types as well as levels between humans and animals. ${ }^{18}$ These three xanthine alkaloid products are also naturally present in differing concentrations in various caffeinated products. ${ }^{18}$ There are no unified cutoff points for high and low doses of caffeine in human beings, as the effects may vary from individual to individual and in the same individual from one time to another, depending on the intakes of other substances and their regular intakes. ${ }^{18}$ Paraxanthine a biological metabolite of caffeine is also as potent as caffeine in humans and this complicates the mechanisms further. ${ }^{18}$ Thus, we see that caffeine produces biphasic responses in both humans and animal models, although the exact signs and symptoms may be variable due to intra-species and interspecies biological dissimilarities. Most of these biphasic responses can elevate the levels of stress in chronic disease states such as HIV infected patients, which can further aggravate disease progression. These biphasic effects are also correlated with increased consumption of alcohol due to delay in attaining the euphoric effects, and thereby exacerbating the adverse effects of both alcohol and caffeine in combination. ${ }^{35}$

\section{Caffeine-Adverse Effects Outweigh Apparent Beneficial Effects}

A number of studies done during the early nineties have documented that caffeine increases mental and physical alertness. These effects have been wrongly interpreted as the beneficial effects of caffeine. The majority of them have been 
documented in situations of compromised alertness, like patients on benzodiazepines ${ }^{36}$ early morning shift workers ${ }^{37}$ night shift workers ${ }^{38}$ and persons on cold medications and sleep $\operatorname{loss}^{39}$. Lieberman ${ }^{40}$ stated that some of these beneficial effects can increase neuronal burnouts when administered under normal wakeful conditions. Caffeine in single bolus dose infusion of $300 \mathrm{mg} /$ day or higher, triggered acute anxiety states. ${ }^{41}$ This heightened anxiety has been described by many healthy volunteers under normal physiological conditions to increase their mental and physical capacities. A number of healthy volunteers scored better in self-rated depression questionnaires when administered $300 \mathrm{mg} / \mathrm{d}$ of caffeine per day. ${ }^{41}$ Caffeine reduces fatigue and produces increased tension and nervousness, and human physiology perceives this as a pleasurable experience. ${ }^{41}$ In a study done amongst apparently healthy volunteers, it was observed that subjects who were administered $300 \mathrm{mg} / \mathrm{d}$ of caffeine showed increases jitteriness and nervousness, and fine motor coordination scores were adversely affected. ${ }^{42}$ A number of stress related physiological and neuro-hormonal changes have also been documented and include increased levels of excitatory neuro-hormones like nor-epinephrine and epinephrine, increased calcium mobilization into the cells, increased prostaglandin antagonism and increased phosphodiesterase enzyme inhibition. ${ }^{43}$ Caffeine infusions produced better performance in both simple reaction time and choice reaction time scores; both indicators of increased stress and alertness. ${ }^{40}$ Caffeine facilitated performance in jobs involving impulsive maneuverings, and reduced performance in those involving complex cognitive skills. ${ }^{44}$ This finding is also supported by another study in which caffeine in doses of $400 \mathrm{mg} /$ day increased anxiety when paired up with a stressful task requiring increased cerebral functions. ${ }^{45}$ Though many of these early studies 
record the beneficial versus adverse effects, they used fairly large doses of caffeine ( $>400$ $\mathrm{mg}$ /day) in single administered doses and do not consider regular consumption levels of caffeine. These studied are virtually inconclusive about the long term effects of regular small to medium doses of caffeine on human behavior. Furthermore, these studies were done on apparently healthy volunteers and the health related impacts could be many folds higher in chronic disease states like HIV, and can be further adverse in those on Antiretroviral medications. Thus we can say that caffeine produces a number of adverse effects masked by perceived beneficial effects.

\section{Adverse Effects of Caffeine Withdrawal}

Caffeine withdrawal as a topic has been widely researched and there exist adequate evidences in literature on the addictive potentials and development of dependence in regular users. ${ }^{46}$ Caffeine shows all the three criteria for labeling it as a reinforcing drug, which includes dependence, tolerance and withdrawal. ${ }^{46}$ However the reinforcing potentials of caffeine are much lesser that than other psychomotor stimulants such as cocaine and amphetamines. ${ }^{46}$ Both the acute stimulating effects and undesirable withdrawal effects contribute to the reinforcing potentials, but withdrawal effects predominate in making it an additive substance. ${ }^{46}$ Many studies report the reinforcing or addictive potentials but are inconclusive whether these are physiological or psychological responses to decreasing serum caffeine levels. The most widely reported symptoms include headache, body ache and mood changes. ${ }^{46}$ In a study done by Ratcliff-Crain et al., ${ }^{47}$ it was shown that caffeine deprivation leads to increased reporting of stress and anxiety by regular caffeine consumers. This is further confirmed by another study done by Schuh et al., ${ }^{48}$ in which participants reported feelings of fatigue and decreased 
alertness on caffeine deprivation. Silverman et al., ${ }^{49}$ reported that about $52 \%$ of volunteers with low to moderate daily intakes of caffeine (mean=235 mg/day), reported moderate to severe headaches, $11 \%$ reported increased depression, $8 \%$ reported increased anxiety symptoms, $11 \%$ reported low vigor and $8 \%$ reported increased fatigue when their regular doses were acutely substituted with placebo solutions. Some studies confirm that even regular doses of caffeine ( $\leq 250 \mathrm{mg} /$ day) produces tolerance as well as ill effects of withdrawal due to habituation. ${ }^{42}$ This is very well confirmed by a double blind study done by Goldstein et al. ${ }^{42}$ in which both habitual and non-habitual caffeine consumers were challenged with overnight caffeine deprivation. Habitual caffeine consumers reported higher rates of caffeine withdrawal symptoms than non- habitual caffeine consumers, which included decreased alertness, decreased feeling of content and wellbeing, increased sleepiness, irritability and mild to moderate headaches. ${ }^{42}$ Consequent to the caffeine deprivation test, the participants were randomly divided into three groups and each group received single dose pills of either $0 \mathrm{mg}$ (placebo), $150 \mathrm{mg}$ or $300 \mathrm{mg}$ of caffeine with approximately equal number of habitual and non-habitual consumers in each of the three groups. This study showed that habitual caffeine consumers showed significant reversal of the negative symptoms of caffeine withdrawal, within minutes after administration of 150 or $300 \mathrm{mg}$ of caffeine, but non-habitual consumers did not show such responses. This study confirms the re-enforcing potentials of caffeine. ${ }^{42}$ With regards to the beneficial effects such as increased cognitive acuity, increased wakefulness and increased sense of well-being, both habitual and non-habitual consumers showed no significant differences for both $150 \mathrm{mg}$ and $300 \mathrm{mg}$ doses; on the contrary, the non-habitual consumers reported higher rates of negative symptoms such as 
nervousness, jitteriness and increased gastric acidity. ${ }^{42}$ Strikingly, non-habitual consumers who were administered placebo pills $(0 \mathrm{mg})$ also reported equivalent increase in negative symptoms such as nervousness, jitteriness and increased gastric acidity, indicating the role of placebo responses in these individuals. ${ }^{42}$ Habitual consumers who received $0 \mathrm{mg}$ of caffeine did not show significant reversal of negative symptoms indicating the existence of physiological mechanisms for caffeine withdrawal and reinforcements. ${ }^{42}$ This study very well documents the addictive potentials of caffeine. This also shows that both physiological and psychological mechanisms are involved in withdrawal reactions. A number of other possibilities should have been considered in analyzing these responses, which include the preexisting differences in personalities, possibilities of mood disorders in these volunteers, the number of hours of sleep, and the number of hours of caffeine deprivation. These factors were not adequately considered in the study and hence the conclusions are not entirely reliable. Another study done by Bruce et al., ${ }^{50}$ showed that negative symptoms of caffeine withdrawal like tiredness, drowsiness, anger and depression successively increased and peaked in volunteers deprived of caffeine for 24 hours, and beyond this time interval these effects started to subside, and by the end of 7 days were completely resolved. Thus we can see that caffeine withdrawal and dependence are associated with time elapsed since consumption of habitual doses of caffeine. ${ }^{50}$ Furthermore it can be inferred that caffeine withdrawal symptoms occur regularly in caffeine addicted individuals and force them to consume regular or higher doses to overcome these symptoms. ${ }^{42}$ Caffeine withdrawal also facilitates increasing doses in a vicious cycle. These increasing doses of caffeine would lead to marginal weight loss even in normal subjects due to serially increasing levels of 
consumption. ${ }^{51}$ Such addictive and withdrawal effects can have increased adverse effects on HIV positive patients who are already compromised in a variety of health related parameters.

\section{Caffeine is Associated with Changes in CD4 levels as well as Plasma Viral Loads}

A study was done amongst HIV infected clinically stable (except for oral Candidiasis in some participants) patients in order to quantify the variations in CD4 cell counts that could be ascribed to laboratory and physiological factors. There was $15 \%$ reduction in CD4 counts due to laboratory factors (alcohol, caffeine and tobacco) after controlling for factors like age, gender, ART compliance, presence of opportunistic infections and measurement errors. ${ }^{52}$ Though caffeine was considered one of the laboratory factors in this study, it was clustered with many other factors like exercise, tobacco and alcohol consumption. ${ }^{52}$ In addition, this study recruited a small sample size of 30 participants and results are not generalizable. ${ }^{52}$ Another study was done amongst clinically stable HIV positive individuals to establish the effects of caffeine consumption on CD4 and CD8 cell counts after exercise (cycling for about 90 minutes). The participants were asked to abstain from consumption of caffeine for 60 hours prior to the experiment. Half of the subjects were administered $6 \mathrm{mg} / \mathrm{kg} /$ day of caffeine, while the remaining subjects were administered placebo before the exercise. There was 54\% decrease in circulating CD4 cell counts and 55\% decrease in circulating CD8 cell counts post exercise in subjects administered caffeine when compared to placebo after controlling for factors like fluid input levels, age, gender, BMI, lean body mass and fluid output levels. ${ }^{53}$ This study also reports that post exercise plasma catecholamine levels were significantly higher in those administered caffeine when compared to placebo 
indicating increased stress levels in participants administered caffeine. ${ }^{53}$ This study also reported that caffeine produced alterations in lymphocyte subset trafficking as well as expression of CD69 molecules which are important intermediate steps in generating and recruiting inflammatory cells. ${ }^{53}$ Through this process caffeine decreased production and recruitment of inflammatory cells to the targeted areas of inflammation which included decreased circulating CD4 and CD8 cells. ${ }^{53}$

In contrast to the findings that caffeine intake produces adverse effects on HIV disease progression; an in-vitro tissue culture study showed that caffeine suppresses replication of infectious HIV-1 strains in cultures of human peripheral mononuclear cells. Caffeine in 100 millimoles/ml concentrations exerted these effects by inhibiting the integration step of the HIV-1 viral replication cycle. This study also shows that other methyl-xanthines like theophylline, theobromine, and paraxanthine, in 100 millimoles/ml doses act through the same process to inhibit HIV-1 viral replication. They observed a 9fold reduction in HIV-1 p24 antigen values in samples treated with caffeine, theobromine, paraxanthine or theophylline when compared to control solutions. ${ }^{54}$ These analysis were controlled for confounding factors like solvents (Water vs $0.1 \% \mathrm{NaCl}$ solution) used for different xanthine compounds, rate of growth of human peripheral mononuclear cells, differences in viral replications per unit time for different HIV-1 strains as well as the differences in reagents used for the experiment. ${ }^{54}$ Adjustments were also made to account for variations in reverse transcriptase-polymerase chain reaction procedures (RT-PCR), southern blotting assays for HIV gag sequences, as well as the primer-probes SK38, SK39, and SK19. ${ }^{54}$ In another tissue culture study it was found that caffeine in doses of $10 \mu \mathrm{gm} /$ liter significantly inhibited retroviral transduction of dividing 
Human Neuronal Precursor (hNT-2) cells thereby blocking post integration repair of HIV-1 viral strains. These effects have been postulated to a cellular target- 'The Ataxia Telangiectasia-Mutated And Rad3-Related (ATR) kinase'. ${ }^{55}$ Caffeine inhibits viral DNA repair at the DNA damage-activated checkpoints. ${ }^{55}$ These results were adjusted for different dosages of retinoic acid used for maturation of hNT-2 cells, different levels of Nocodazole used for cell cycle arrest, differences in HIV-1vectors like vpr, vif, vpu, and nef genes, as well as differences in western blot procedures for detecting levels of PCNA (Proliferating Cell Nuclear Antigen) proteins and viral integrase. ${ }^{55}$

In summary, we can say that here are very few studies that document the direct effect of caffeine on CD4 cells and viral load. The studies investigating viral loads are tissue culture in-vitro studies. Furthermore, these effects are opposing one another in terms of disease progression as caffeine inhibits viral replication as well as decreases the number of CD4 cells. Therefore a question remains-whether caffeine is beneficial to HIV infected individuals due to decreased viral replications or harmful due to depletions in CD4 cell counts.

\section{Caffeine Adversely Affects Sleep Quality and Precipitates Anxiety Disorders}

In a study done amongst pre-AIDS seropositive men and women, it was observed that increasing psychological distress scores were associated with increasing viral load and lowering CD4 cells after controlling for age, medication use and HIV symptomatology. ${ }^{56}$ In an animal study, it was observed that even mild acute stressors produced increased plasma corticosterone levels and a significant decrease in the numbers and percentages of all circulating lymphocytes, and these changes were rapidly reversed upon removal of the stressors. ${ }^{57}$ Oral administration of $480 \mathrm{mg}$ of caffeine 
provoked acute stress responses like panic attacks and heightened anxiety levels in a sample of regular non HIV subjects with various forms of anxiety disorders, recruited in a randomized double-blind experiment conducted on two occasions 7 days apart. ${ }^{58}$ General stress levels estimated by the number of anxiety symptoms and panic attacks, were substantially higher in subjects administered $480 \mathrm{mg}$ of caffeine when compared to control solutions after adjusting for gender, age, educational level, marital status, occupation, different sources of caffeine and previous psychiatric treatments if any. Four hundred and eighty mg of caffeine on each of the two test dates precipitated panic attacks in $60.7 \%$ all of the participants in experimental arm of the study while none of the participants in control arm showed any such symptoms. This study concluded that higher doses of caffeine precipitated anxiety and panic attacks even in regular non-HIV volunteers with some levels of anxiety disorders. ${ }^{58}$ According to a review paper, caffeine in higher than regular levels (>250 mg/day) worsened mental stress and precipitated acute events in healthy subjects after controlling for many covariates such as sedative medications, presence or absence of psychiatric symptoms, age, gender, lifestyle factors, exercise and alternative therapies. ${ }^{59}$ In a case report, it was also observed that chronic caffeine consumption in doses of $400 \mathrm{mg} /$ day precipitated delusions and paranoia in a schizophrenic patient undergoing treatment, with symptoms controlled through medications. Lowering the doses of caffeine serially to end with the eventual cessation of caffeine caused the delusions and paranoia to subside completely. This case study shows the effects of caffeine in increasing neuronal excitability and stress, however the study was very limited because the patient is a single isolated case with psychiatric abnormalities. ${ }^{60}$ In a study that investigated the effects of day-long consumption of tea, 
coffee and water on cognitive and psychomotor performance, and of sleep quality at night, it was observed that caffeine in doses of 35 to $150 \mathrm{mg} /$ day, irrespective of sources, significantly decreased the initial Critical Flicker Fusion Threshold (CFFT) which signifies higher levels of neuronal excitability after controlling for age, BMI, exercise, gender, body composition measures and lifestyle factors. ${ }^{61}$ This study also reports that the caffeine in coffee produced significantly greater sleep disturbances than in tea, in the form of altered sleep patterns after controlling for several cognitive and psychomotor adverse effects for both the beverages and dose adjustments for different levels of caffeine in both the beverages. ${ }^{61}$

In a cross-sectional survey conducted in 1514 men and 1528 women, men who consumed more than $200 \mathrm{mg} / \mathrm{d}$ of caffeine had 50\% higher interleukin 6 (IL-6), 30\% higher C-reactive protein (CRP), 28\% higher tumor necrosis factor- $\alpha(\mathrm{TNF}-\alpha)$ and 3\% higher white blood cell (WBC) counts . Women who consumed greater than $200 \mathrm{mg} / \mathrm{d}$ of caffeine similarly showed 54\% higher IL-6, 38\% higher CRP, 28\% higher TNF- $\alpha$ and $4 \%$ higher WBC counts. ${ }^{62}$ These findings were significant even after controlling for interactions between caffeine consumption and age, sex, smoking, body mass index, physical activity, and other covariates. This study shows that caffeine consumption and related physiological stress is associated with increased inflammatory states and thereby wasteful immune functions.

HIV patients already report deteriorated sleep quality, increased periods of insomnia and post morning sleepiness, cognitive impairments, and increased tiredness. ${ }^{63-}$ ${ }^{67}$ In a study done amongst HIV positive participants it was found that sleep quality measured by the Pittsburgh Sleep Quality Index (PSQI) was significantly poorer after 
adjusting for underlying pathologies and medications(over-the-counter drugs, vitamins and herbal products, and mood-altering substance). ${ }^{65}$ Another study was done to examine the correlates of sleep quality in HIV-infected persons using the 'Symptom Experience Dimension' of the revised 'UCSF Symptom Management conceptual model'. According to this study the variables significantly related to sleep quality included employment status, trait anxiety, general well-being, length of time living with HIV disease, depressive symptoms, state anxiety, severity of symptoms, daytime sleepiness, and functional status of the participants. ${ }^{66}$ The length of time living with HIV disease was significantly associated with poor sleep quality measured by the PSQI after controlling for other covariates mentioned above. ${ }^{66}$ Another study done amongst 146 clinically stable HIV positive participants showed that physical pain, stress and social support variables were significantly associated with deteriorated sleep quality after controlling for covariates like age, sex, marital status, compliance with ART, other medications, concurrent drug use, alcohol and tobacco use as well as income. ${ }^{68}$ Similarly, a study done amongst clinically stable HIV positive patients shows that that higher sleep quality measured by the Pittsburgh Sleep Quality Index (PSQI) and Pittsburg Insomnia Rating Scale (PIRS) was associated with better cognitive performance on tasks of attention, frontal/executive function, and psychomotor/motor speed after controlling for the effects of medications, alcohol consumption and drug abuse ${ }^{67}$ However this study also reports that more than $40 \%$ of the participants were chronically and severely sleep deprived. ${ }^{67}$ In addition, another study done on injection drug users reported that general well-being scores estimated by the HIV Assessment Tool (HAT) and the State-Trait Anxiety Inventory(STAI), was significantly associated with sleep quality measured by Pittsburg 
sleep quality index (PSQI) after controlling for age, gender ethnicity, injection drug use, employment status, income, sleep medications, day time dysfunction and alcohol consumption. ${ }^{64}$

\section{Side Effects of Caffeine in Non-sleep-deprived Volunteers}

In a study done on non-sleep-deprived volunteers, caffeine was administered in doses of $0,100,200,400$, and $600 \mathrm{mg}$ and the biological effects were measured four hours after this administered dose. ${ }^{69}$ This study found a dose dependent increase in subjective symptoms of jitteriness, nervousness and shakiness with increasing dosages after controlling for many co-factors like age, gender, number of hours of sleep and physiological and psychological stressors. Even the lowest dose of $100 \mathrm{mg}$ showed statistically significant differences when compared to placebo for ratings in subjective distress scores. There was also a statistically significant as well as dose dependent increase in the ratings for "dislike effects" for caffeine doses of $400 \mathrm{mg}$ and $600 \mathrm{mg}$ after controlling for the same co-factors mentioned earlier. ${ }^{69}$ Another study was done in a group of non-sleep-deprived volunteers who were habitual smokers and drug users. ${ }^{70}$ This study looked for the side effects of $0 \mathrm{mg}$ (placebo), 200, 400 and $800 \mathrm{mg}$ doses of caffeine on ratings of subjective distress scores. There was a dose dependent increase in tension-anxiety ratings and this increase was statistically significant for all the doses of caffeine when compared to placebo. In addition there was also a statistically significant increase in scales associated dysphoric and somatic symptoms in participants administered $800 \mathrm{mg}$ doses when compared to placebo. There was also a significant increase in ratings for drug induced euphoria in the participants administered $800 \mathrm{mg}$ doses. Although this study controlled for many covariates, such as stress, hours of sleep, 
age and physiological impairments, changes in subjective assessments could have been affected by other drugs like nicotine and amphetamines which were prevalent in this cohort. The study included only six subjects and a repeated-measures design was used. There would have been many carryover effects affecting the results of the study. The subjects were not restricted from smoking after caffeine consumption, and the subjective symptoms could have been due to both nicotine and caffeine. Irrespective of the limitations of these studies, we can infer that caffeine is associated with many subjective sensations of anxiety, distress and discomfort which could affect sleep quality as well as wellbeing even in non-sleep-deprived participants. ${ }^{69,70}$

\section{Side Effects of Caffeine in Sleep-Deprived Volunteers}

There are many recent studies that have mixed findings about the impact of caffeine on performance and alertness in sleep-deprived volunteers. Sizeable amounts of caffeine consumption are directed to overcoming the subjective effects of tiredness and irritability due to insufficient sleep. In a study conducted amongst fifty healthy, nonsmoking males between the ages of 18 and 32 years, caffeine was administered in doses of 150, 300, or $600 \mathrm{mg}$ after 48 hours of sleep deprivation. ${ }^{71}$ Mental alertness was measured through Stanford Sleepiness Scale (SSS), and Visual Analog Scale (VAS). Caffeine even in low doses of $150 \mathrm{mg} /$ day produced reversal of sleep deprivation-induced lack of alertness measured through SSS and VAS. In this study the highest doses of 600 mg/day produced complete reversal of sleepiness and the values of SSS and VAS were close to fully rested physiological conditions with recommended number of hours of sleep. Thus, this study reports the benefits of caffeine consumption in terms of increased alertness during physiologically challenged condition such as sleep deprivation. However 
this study also suggests that these subjective feelings of increased alertness could be at the cost of many health related parameters such as impaired immune functions, impaired cognition and other indicators of healthy living. ${ }^{71}$ In the same study, it was also reported that there was a dose dependent increase in frequency of sleepiness, anxiousness, irritability, jitteriness, talkativeness, increased heart rate, headache, sweatiness, stomach discomfort and other subjective symptoms. ${ }^{71}$ However, the doses at which these subjective symptoms started to appear was not clearly mentioned in this study. ${ }^{71}$ In another study to test the efficacy of modafinil versus caffeine on fifty sleep deprived volunteers, it was found that $600 \mathrm{mg}$ doses of caffeine produced increased subjective symptoms of palpitations, irritability and nausea following 41 hours of forceful sleep deprivation. ${ }^{6}$ In the same study it was also observed that 2 volunteers vomited approximately after two hours of administration of $600 \mathrm{mg}$ of caffeine. ${ }^{6}$ In the same study, caffeine in doses beyond $100 \mathrm{mg}$ was associated with increased blood pressure tracings, though the increase was not significant. (Approximately 1mm Hg per 100 mg increase in doses of caffeine). ${ }^{6}$ Thus we can summarize that, though many studies discussed the adverse effects of caffeine in sleep deprived volunteers, none of them reported any hospitalizations or other adverse events beyond subjective symptoms. However, it should also be noted that the majority of these studies employed a convenient sample of healthy volunteers, and that adverse events due to the administered doses of caffeine were criteria for discontinuation of study participation. Furthermore these studies did not look for the adverse effects of chronic levels of caffeine consumption.

In addition, caffeine intake affects sleep quality as demonstrated in a study done amongst $88 \mathrm{HIV}$ positive participants. ${ }^{72}$ In this study sleep quality was measured by the 
Revised Pittsburg Sleep Quality Index (R-PSQI). Mean caffeine intake of the entire sample was $476 \mathrm{mg} /$ day, which was 2.4 times the national US consumption average of $200 \mathrm{mg}$ caffeine/day. This study showed that subjects having higher caffeine consumption levels (>400 mg/day) showed decreased sleep quality index scores. ${ }^{72}$ Within one month subjects who reduced their baseline caffeine consumption by $90 \%$ or higher, showed significant improvements in sleep quality index scores after controlling for other covariates like liver function tests, CD4 cell counts, viral loads, smoking, alcohol consumption and recreational drug use. However this study had several limitations because the average caffeine intake of the sample was very high, sample size was small, and this study did not look for dose-based adverse effects of caffeine.

Thus, we see that caffeine consumption could be responsible for decreased sleep quality, altered sleep patterns as well as increasing stress levels and anxiety symptoms. All these factors could be responsible for accelerated disease progression in PLWH. Our study aims at understanding whether such mechanisms would have existed in our population of HIV positive participants from Miami-Dade County. We also aim at estimating the share of caffeine in adverse effects on sleep quality and anxiety symptoms, after controlling for covariates such as age, gender, drug abuse, alcohol consumption, tobacco use and types of ART, as well as explore the effects of moderate ( $<250 \mathrm{mg} /$ day) and high (>250 mg/day) doses of caffeine on these outcome variables.

\section{Caffeine Intake is Associated with Significant Nutritional Alterations}

A long-term follow-up study from 1980 to 1998, that recruited 1333 males and

4085 females having type -2 diabetes, showed that there was a strong association between increased caffeine consumption ( $>4$ cups/day which is approximately $>240 \mathrm{mg}$ 
caffeine/day) and weight loss (approximately $5.5 \mathrm{~kg} /$ year) and this weight loss produced significant reduction in risk factors for diabetic complications after controlling for age, weight status, insulin administration, anti-diabetic drugs, physical activity and lifestyle factors. ${ }^{73}$ Further analysis also revealed that there was decreased risk for diabetes in those who lost weight, and that there was a positive dose-response relationship between caffeine intake and weight loss when caffeine was considered as a continuous variable. ${ }^{73}$ In a systematic review of twenty studies on the protective effects of caffeine in diabetes, twelve studies reported that the protective effects were due to weight loss induced by caffeine. ${ }^{74}$ This review also mentions an estimated 100kcal/day increased energy expenditure due to habitual consumption of 6 cups of coffee ( $400 \mathrm{mg}$ caffeine/d).${ }^{74}$ This review states that caffeine is the primary, and possibly the sole, ingredient responsible for the negative energy balance observed in several studies. ${ }^{74}$ Eight studies of these twenty studies also reported a dose-response relationship between caffeine intake and weight loss. ${ }^{74}$ Caffeine intake is also associated with decreased feeding in animal models. In a vertebrate study on Wistar rats, it was observed that rats administered $1 \mathrm{gm} /$ liter caffeine solutions in their drinking water for forty days showed significant aversions to palatable rat foods, when compared to the rats administered $0.3 \mathrm{~g} /$ liter caffeine solutions or plain water control solutions after controlling for baseline weights and feeding behaviors. ${ }^{75}$ This study also showed that such effects were more profound in the female rats, when compared male rats, after controlling for the differences in catecholamine levels, baseline weights, and baseline calorie consumption levels, in all groups of animals. ${ }^{75}$ In another study done in young healthy women, caffeine was responsible for increasing basal energy expenditures (BEE), even in the presence of genetic abnormalities predisposing to 
decreased BEE. The Arg allele in the beta-3 adrenergic receptor gene (beta-3-AR) is a marker for obesity-related traits, and mutations in this gene make an individual susceptible to decreased BEE. ${ }^{76}$ In a group of women showing beta-3-AR Trp64Arg abnormalities, and consequently decreased basal energy expenditures, an average early morning dose of caffeine (4 mg/kg body weight/day) produced significant increase in energy expenditures, measured through indirect open-circuit calorimetric studies at four intervals during the day, after controlling for age; physical activity; height; blood pressure; dietary intakes of fat, proteins, carbohydrates, cholesterol, fiber; BMI; and lifestyle factors. ${ }^{76}$ This study showed that caffeine, independent of genetic predispositions to gain weight, increased resting energy expenditure leading to significant weight loss. However, the study was limited because it included a convenient sample of healthy young women with an average age of $21 \pm 1$ years, and men and subjects from other age groups are not included. ${ }^{76}$

Jones et al. ${ }^{77}$ showed that increased fat mass was associated with lower rates of disease progression, and fat loss produced faster progression to CD4 counts less than 200 cells $/ \mu 1 .{ }^{77}$ The HIV Epidemiology Research (HER) Initiative enrolled 871 HIV positive women for an observational study of three years. Cross sectional analysis, survival analysis and longitudinal analysis were done on the data obtained from this cohort. All five study outcomes, (which included CD4 cell count and viral load; time to first occurrence of CD4 cell count $\leq 200$ cells $/ \mathrm{mm}^{3}$; first occurrence of CD4 cell count $\leq 100$ cells $/ \mathrm{mm}^{3}$; first occurrence of other Infection/malignancy; and HIV-related death), were significantly delayed in women who were in the obese group (BMI $\left.\geq 35 \mathrm{~kg} / \mathrm{m}^{2}\right)$ after controlling for ART status, BMI changes, baseline CD4 cell counts, attrition due to death 
and progression to AIDS, age and lifestyle factors. ${ }^{77}$ This study established the need to prevent weight loss; especially loss of fat mass in HIV positive patients.

Deficiencies of several essential micronutrients in HIV-infection have been reported to accentuate disease progression and mortality risks. ${ }^{78}$ Several altered metabolic pathways are responsible for such nutrient depletions in these patients. One such pathway is chronic anti-oxidant depletion, including a drastic depletion of cysteine from the glutathione pool, and a progressive decline in serum selenium levels. ${ }^{79}$ There is significant correlation between caffeine intake and depletion of antioxidants, although this relationship is controversial, with some studies reporting an anti-oxidant effect ${ }^{80}$ while others reporting a pro-oxidant effect for caffeine itself. ${ }^{81}$ In a laboratory study done with chemical equivalents of naturally produced biological oxidative species, it was observed through Electron Spin Resonance (ESR) trapping that caffeine, in concentrations of $1 \mathrm{mmols} / \mathrm{L}$, acted as an antioxidant with efficient free radical scavenging rates of $5.9 \times 10^{9} \mathrm{M}^{-1} \mathrm{sec}^{-1}$, which is comparable to the scores of other naturally occurring antioxidants such as vitamin C, vitamin E, Selenium, and Zinc. ${ }^{80}$ However this study is a measure of reductive behavior of the chemical named 1,3,7trimethylxanthine (caffeine) and may or may not correlate with the biological effects of caffeine. ${ }^{80}$ Such disclaimers about the antioxidant capacities of caffeine and other xanthine alkaloids in living animals and humans, in spite of laboratory evidences for antioxidant effects, was also reported in recent study done by Tsoi et al., ${ }^{82}$ where he recommends better technologies such as Oxygen Radical Absorbance Capacity (ORAC) and Cellular Antioxidant Activity Assay (CAAA), for comparing biological versus laboratory antioxidant capacities of caffeine and other xanthine compounds. Caffeine 
consumption in higher than normal doses (>250 $\mathrm{mg} /$ day) has also been reported to lower the plasma levels of antioxidant trace elements such as zinc and selenium after controlling for dietary intakes, age, physical activity, smoking, alcohol use and drug use. ${ }^{26}$ This relationship also shows a dose-response, with lower caffeine consumption associated with decreased depletion of antioxidant elements. ${ }^{26}$ Thus, the net effect of caffeine on total antioxidant status has not been elucidated, and remains questionable.

In summary, we see that caffeine can accentuate weight loss which may be useful for diabetic patients as shown in several studies, but extremely detrimental to PLWH. It also produces nutritional changes such as lower serum selenium levels and decreased plasma zinc levels. However, the effects on total antioxidant capacity in PLWH are controversial and need further research.

\section{Caffeine Intake and its Effects on Fluid-Electrolyte Balance and Blood Pressure}

Caffeine and other methyl -xanthene compounds have significant diuretic properties. Consumers are often cautioned to avoid these beverages when their fluidelectrolyte balance is jeopardized due to various medical conditions. Acute ingestion of caffeine in doses of $250-300 \mathrm{mg}$ (equivalent to 2-3 cups of coffee or 5-8 cups of tea) is associated with short-term stimulation of urine output. But these effects are observed only in subjects deprived of caffeine for few days before the study. There is profound tolerance to these effects in regular and frequent coffee drinkers. As such there is no concrete relationship between caffeine intake in regular doses $(\leq 250 \mathrm{mg} / \mathrm{d})$ and fluid losses in excess of the volume ingested under normal physiological conditions. ${ }^{83}$ But this is not the same for stressful or non-physiological states. Recreation enthusiasts and athletes are often advised to decrease the consumption of coffee or caffeine containing 
carbonated drinks to avoid dehydration, electrolyte imbalance, and potential complications. ${ }^{84} \mathrm{~A}$ number of contrary evidences also exist. One study supports that caffeine intake is associated with only $0.03 \%$ higher diuretic capacity than plain water itself and hence it is advisable to administer caffeinated beverages to athletes ${ }^{85}$ Thus there is no general consensus as to whether caffeine produces or does not produce dehydration and electrolyte imbalance. Furthermore tolerance to caffeine reduces the likelihood of any serious fluid electrolyte imbalance. ${ }^{84}$ Abstaining from caffeine has a protective effect on hypertension. Caffeine, even in moderate doses (250 mg/day) produces small elevation in blood pressure (8-10 mm hg). Many other substances present in brewed coffee like poly-phenols and soluble fibers may reverse the adverse effects of pure caffeine. ${ }^{86}$ Coffee and caffeine containing beverages produce similar increases in Muscle Sympathetic Activity (MSA) Scores and blood-pressure in non-habitual coffee drinkers; but in habitual coffee drinkers there is no comparable increase in blood pressure even when there is MSA activation. ${ }^{84}$ This could be attributed to the homeostatic mechanisms of the cardio-vascular system. This can also be attributed to ingredients other than caffeine, such as poly-phenols and chlorogenic acids and hunic acid, but the mechanism still remains unclear. ${ }^{84}$ In a study done amongst hypertensive patients, it was observed that caffeine through 'acute presser response' significantly increased both systolic and diastolic blood pressure levels. ${ }^{87}$ This study concludes with a word of caution for hypertensive patients to restrict their caffeine consumption. It also states that the hemodynamic effects of chronic caffeine consumption should be studied through prospective longitudinal studies. This report also proposes the inhibition of phosphodiesterases as the probable mechanism for these responses ${ }^{87}$ Thus, we see that 
caffeine definitely has some role in altering the fluid-electrolyte balance and systemic blood pressure tracings, though not clinically significant to produce visible adverse effects. Partly, this phenomenon is due to the increased tolerance of the body to the diuretic effects of caffeine. Some other constituents of coffee, other than caffeine, can also be suspected, but the mechanism remains unclear. But it is definite that caffeine can have adverse effects in HIV infected patients, because of their already jeopardized fluidelectrolyte balance, which is secondary to nutritional inadequacies and intermittent diarrheal episodes.

\section{Caffeine is Associated with Smoking, Alcohol Consumption and Drug Abuse}

A British study consisting of 376 young adults suggested that estimated daily caffeine consumption increased with age, and was associated with increased smoking and greater alcohol consumption. ${ }^{88}$ This study, however, does not show any correlation between caffeine consumption and drug abuse.$^{88}$ Other studies have also shown that caffeine intake is higher in smokers than in nonsmokers. A secondary analysis of data from adults who participated in the Second National Health and Nutrition Examination Survey showed that subjects who ingested caffeine from tea had lower alcohol consumption..$^{89}$ In comparison to this, the subjects who ingested caffeine from coffee and caffeinated beverages were more likely to be heavy alcohol consumers and chain smokers ${ }^{89}$ There was also a positive correlation between income and caffeine intake; caffeine intake and alcohol consumption, and caffeine intake and smoking. ${ }^{89}$ Smokers were much more likely to drink caffeinated coffee, and a significant dose-response relationship between caffeine intake and smoking was observed. ${ }^{89}$ These studies also show a definite linear relationship between caffeine intake and alcohol consumption. ${ }^{89}$ 
The relationship between caffeinated beverages, alcohol consumption and smoking, was also researched in a group of chronic alcoholics from Israel. There was a significant linear relationship between caffeine intake and alcohol consumption \& smoking. ${ }^{90}$ In addition, the subgroup of subjects with a family history of alcoholism revealed significant correlations between alcohol and caffeine consumption, between alcohol intake and smoking, as well as caffeine use and smoking. ${ }^{90}$ The subjects without a family history of alcoholism also showed similar linear relationships between alcohol and caffeine use, but no relationship between caffeine intake and smoking. ${ }^{90} \mathrm{~A}$ review article on the relationships between caffeine, alcohol and drugs of abuse concluded that many studies show positive correlations between caffeine consumption, alcohol intake and drugs of abuse such as cocaine, amphetamines and marijuana. ${ }^{91}$ In a Sardinian study, conducted amongst patients with bipolar disorders, it was observed that smoking, alcohol consumption and illicit drug abuse synergistically increased the levels of stress in subjects consuming high amounts of caffeine, and the collective effects of these factors increased suicidal tendencies. ${ }^{92} \mathrm{~A}$ study assessing the combined biological influence of coffee, smoking, and alcohol showed that caffeine consumption from coffee showed inverse correlations with biological markers of heavy drinking, after controlling for baseline alcohol consumption levels, the number of cigarettes smoked per day, as well as number of years of smoking. ${ }^{93}$ This study shows that in addition to adverse health effects, these addictive substances also show associations with nutritional deficiencies such as vitamin B12 depletion and anemic states. ${ }^{93}$ Alcohol intake can be indirectly measured through a number of markers. $\gamma$-Glutamyltransferase is one such widely used marker. Coffee intake was significantly $(P<0.01)$ and negatively related to $\gamma$-Glutamyltransferase 
activity. This study contradicts other studies presented earlier in this section, and shows that caffeine consumption reduces alcohol intake. ${ }^{94}$ Caffeine also influences the actions of other dependence producing drugs such cocaine and amphetamines. ${ }^{95}$ An animal study conducted in rats showed that there are significant interactions between caffeine and cocaine on many behavioral paradigms related to drug abuse. ${ }^{95}$ Caffeine was responsible for reinstating cocaine consumption behavior in rats that were forced to abstain from cocaine after initial priming. In this study, rats were administered either normal saline, cocaine in different doses $(5.0,10.0$, or $20.0 \mathrm{mg} / \mathrm{kg})$ through foods and caffeine in different doses (5.0, 10.0, 20.0, $40.0 \mathrm{mg} / \mathrm{kg})$ through injections. There was a dosedependent increase in cocaine consumption behaviors with increasing doses of injected caffeine. ${ }^{95}$ This study confirms that caffeine can modulate the drug seeking tendencies and provoke drug reinstating response to dopaminergic drugs such as cocaine and amphetamines ${ }^{95}$ Caffeine affects the dopaminergic reward circuitry, and hence, it is responsible for altering the addictive potentials of many dopaminergic drugs. ${ }^{95}$ In another study conducted on cocaine addicted individuals, it was found that caffeine consumption was significantly higher in cocaine dependent individuals when compared to matched controls. ${ }^{96}$ The same study also found that habitual caffeine consumption was associated with lower cocaine use within the cocaine dependent group, and that caffeine deprivation tends to increase the abuse of cocaine in these individuals. ${ }^{96}$ In summary, we can say that caffeine intake shows significant associations with alcohol, tobacco and drug use levels, patterns and behaviors. There could be many behavioral, physiological and genetic mechanisms responsible for these observations. Through these mechanisms, caffeine consumption can have a number of adverse effects in these HIV-infected subjects, among 
whom drug use, alcohol and smoking are frequent. Drug abuse, along with alcohol consumption and smoking, can quickly and synergistically deteriorate their health status and contribute to HIV disease progression. Because of these interactions, we have decided to control for tobacco, drug and alcohol use in all our analysis related to the adverse effects of caffeine on several health related parameters.

\section{Caffeine and its Metabolites and Their Collective Role in Metabolic Alterations}

Cardiovascular diseases and diabetes are a major health problem in HIV infected patients. A large number of these diseases can be traced back to their roots in metabolic syndrome. A longitudinal study done by Balk et al., ${ }^{97}$ examined the relationship between caffeine consumption and the components of the metabolic syndrome. This study used the data from “Amsterdam Growth and Health Longitudinal Study (AGAHLS)” for analyzing these associations. All the earlier studies on the benefits of caffeine in metabolic syndrome are challenged by this study, as the study shows no significant improvements in any of the parameters used to assess the severity of metabolic syndrome. ${ }^{97}$ This study questions the very benefits of caffeine in metabolic syndrome, and rather discusses the adverse effects. All the analyses were adjusted for other confounding variables such as physical activity, energy intake, alcohol consumption, smoking behavior etc., thus, eliminating many confounders clouding the validity of these observations. ${ }^{97}$ Coffee is a complex mixture of cholrogenic acid, cafestol, kahweol, diterpines and caffeine. ${ }^{98}$ These other components significantly alter the serum levels of both healthy and non-healthy lipids. These components are implicated in increasing several risk factors associated with cardiovascular health such as blood pressure and plasma homocysteine levels. ${ }^{98}$ High consumption of unfiltered coffee such as French 
press and boiled house brew have been reported to increase the levels of LDL and VLDL fractions of serum lipid profile. ${ }^{99}$ People with hypertensive disorders, children, adolescents, and the elderly are at the highest risks for these adverse effects. There is compelling evidence to decrease caffeine consumption in pregnant women and women of reproductive age groups. Caffeine is also associated with several cases of spontaneous abortions, sudden fetal death syndromes and impaired fetal growth. ${ }^{100}$ A recent study has established the existence of genetic polymorphisms in the process of metabolism and actions of caffeine. ${ }^{101}$ Thus, caffeine may be beneficial to certain sets of genetically privileged individuals. But in individuals with genetic weakness, caffeine could exacerbate the adverse effects. Diterpines present in caffeine have been strongly associated with adverse cardiac events. ${ }^{102}$ Caffeine is also associated with increased levels of fibrinogen and C-reactive proteins, both individually potent and significant risk factors for a number complications such as stroke, myocardial infarction, diabetes, renal disorders, and thrombo-embolic sequels. ${ }^{103}$ Habitual caffeine consumption is also associated with accelerating the adverse effects of mental stress on vascular inflammatory response as evidenced by a dietary study done amongst eighty-five healthy non-smoking men with various levels of caffeine consumption. ${ }^{104}$ This study found that caffeine was positively associated with baseline systolic blood pressure, increased heart rate and increased inflammatory markers such as C-reactive protein (CRP) and Von Willebrand factor antigen (vWF), after controlling for age, body mass index and consumption of tea, red wine, fruit, vegetables, oily fish and dietary supplements. ${ }^{104}$ These adverse effects could be more pronounced in HIV positive subjects who experience dyslipidemias due to ART medications. Such adverse effects could also affect their general health status. 


\section{Inference}

In summary, evidence to date indicates that caffeine intake is associated with depletion of circulating CD4 cells. It is also associated with weight loss and wasting. It is implicated for altered sleep patterns , decreased intervals of sleep, decreased sleep quality scores, decreased perceptional wellbeing scores, increased neuronal excitability and increased plasma levels of inflammatory markers such as interleukein-6, C-reactive proteins and tumor necrosis factor- $\alpha$. All these factors can have a bearing in hastening disease progression in HIV infected patients. Moderate caffeine intake produces small elevations in blood pressure. Caffeine also produces minor non-significant electrolyte imbalances in healthy subjects. This, however, can have accentuated effects in HIV infected patients, because of their already jeopardized fluid-electrolyte balance secondary to nutritional inadequacies and intermittent diarrheal episodes. Caffeine intake is associated with increased smoking, greater alcohol consumption and increased recreational drug abuse. Drugs along with alcohol consumption and smoking can synergistically deteriorate the health status of HIV-positive patients. Chronic caffeine consumption may have irreversible effects on palatability and food consumption. There exists strong evidences for caffeine producing significant weight loss. There is significant correlation between caffeine intake and depletion of antioxidants. It reduces the plasma levels of anti-oxidant trace elements like selenium and zinc. Such weight changes, loss of appetite and antioxidant depletion can have adverse effects on the health status of these HIV infected patients. Caffeine produces many metabolic alterations like increased levels of LDL and VLDL fractions of serum lipid profile, increased plasma homocysteine levels, increased fibrinogen and C-reactive protein, all signifying increased stressful 
states and chronic inflammation. These markers of chronic inflammation are already aggravated in HIV infected patients due to the disease as well as the medications. Caffeine can accentuate these adverse effects. It is associated with altered dopaminergic neurotransmission and consequent heightened neuronal excitability and potential loss of brain cells due to neuronal burnouts. Caffeine also precipitates fluid and electrolyte imbalances. Our proposed study aims at elucidating the net combined effects of these adverse reactions of caffeine consumption on HIV disease progression in PLWH. 


\section{References}

1. Cook DB, Davis JM. Mental energy: defining the science. Nutrition Reviews. 2006;64(s3):S1-S1.

2. Lara B, Gonzalez-Millán C, Salinero JJ, et al. Caffeine-containing energy drink improves physical performance in female soccer players. Amino Acids. 2014;46(5):1385-1392.

3. Eckerson JM, Bull AJ, Baechle TR, et al. Acute ingestion of sugar-free red bull energy drink has no effect on upper body strength and muscular endurance in resistance trained men. The Journal of Strength \& Conditioning Research. 2013;27(8):2248-2254.

4. Schubert MM, Astorino TA. The effects of caffeinated "energy shots" on time trial performance. Nutrients. 2013;5(6):2062-2075.

5. Del Coso J, Portillo J, Muñoz G, Abián-Vicén J, Gonzalez-Millán C, MuñozGuerra J. Caffeine-containing energy drink improves sprint performance during an international rugby sevens competition. Amino Acids. 2013;44(6):1511-1519.

6. Wesensten NJ. Legitimacy of concerns about caffeine and energy drink consumption. Nutrition Reviews. 2014;72(suppl 1):78-86.

7. Heckman MA, Weil J, Mejia D, Gonzalez E. Caffeine (1, 3, 7-trimethylxanthine) in Foods: A Comprehensive Review on Consumption, Functionality, Safety, and Regulatory Matters. Journal of Food Science. 2010;75(3):R77-R87.

8. Pankevich D, Pray L, Yaktine AL. Caffeine in Food and Dietary Supplements: Examining Safety: Workshop Summary. National Academies Press; 2014.

9. Mitchell DC, Knight CA, Hockenberry J, Teplansky R, Hartman TJ. Beverage caffeine intakes in the US. Food and Chemical Toxicology. 2014;63:136-142.

10. United States Food and Drug Administration. FDA to investigate caffeine. http://www.fda.gov/downloads/ForConsumers/ConsumerUpdates/UCM350642.p df. Acessed September 22013.

11. United States Food and Drug Administration. Database of Select Committee on GRAS Substances (SCOG) Reviews: Caffeine. 2006; http://www.accessdata.fda.gov/scripts/fcn/fcnDetailNavigation.cfm?rpt=sco gsListing\&id=42. Accessed Spetember 12, 2014. 
12. World Health Organization. Mental and behavioural disorders F15. International Statistical Classification of Diseases and Related Health Problems. 2010;Chapter 5(Mental and behavioural disorders due to use of other stimulants, including caffeine.).

13. World Health Organization. Lexicon of alcohol and drug terms published by the World Health Organization. September 22013.

14. United States Food and Drug Administration. FDA to investigate added caffeine. 2013; http://www.fda.gov/downloads/ForConsumers/ConsumerUpdates/UCM350 740.pdf. Accessed October 20, 2014.

15. American Psychiatric Association. Diagnostic and Statistical Manual of Mental Disorders. Vol Fifth ed2013.

16. Daly JW, Fredholm BB. Caffeine-an atypical drug of dependence. Drug and alcohol dependence. 1998;51(1):199-206.

17. Klotz K-N, Hessling J, Hegler J, et al. Comparative pharmacology of human adenosine receptor subtypes-characterization of stably transfected receptors in CHO cells. Naunyn-Schmiedeberg's Archives of Pharmacology. 1997;357(1):1-9.

18. James JE. Caffeine, health and commercial interests. Addiction. 1994;89(12):1595-1599.

19. Nikodijević O, Sarges R, Daly JW, Jacobson KA. Behavioral effects of A1-and A2-selective adenosine agonists and antagonists: evidence for synergism and antagonism. Journal of Pharmacology and Experimental Therapeutics. 1991;259(1):286-294.

20. Shi D, Nikodijević O, Jacobson K, Daly J. Effects of chronic caffeine on adenosine, dopamine and acetylcholine systems in mice. Archives Internationales de Pharmacodynamie et de Therapie. 1994;328(3):261.

21. Garrett BE, Griffiths RR. The role of dopamine in the behavioral effects of caffeine in animals and humans. Pharmacology Biochemistry and Behavior. 1997;57(3):533-541.

22. Rivkees SA, Price SL, Zhou FC. Immunohistochemical detection of $A<\mathrm{sub}>$ $1</$ sub $>$ adenosine receptors in rat brain with emphasis on localization in the hippocampal formation, cerebral cortex, cerebellum, and basal ganglia. Brain Research. 1995;677(2):193-203. 
23. Fredholm BB, Arslan G, Halldner L, Kull B, Schulte G, Wasserman W. Structure and function of adenosine receptors and their genes. Naunyn-Schmiedeberg's Archives of Pharmacology. 2000;362(4-5):364-374.

24. Carter AJ, O'Connor WT, Carter MJ, Ungerstedt U. Caffeine enhances acetylcholine release in the hippocampus in vivo by a selective interaction with adenosine A1 receptors. Journal of Pharmacology and Experimental Therapeutics. 1995;273(2):637-642.

25. Dixon AK, Widdowson L, Richardson PJ. Desensitisation of the adenosine A1 receptor by the A2A receptor in the rat striatum. Journal of neurochemistry. 1997;69(1):315-321.

26. Ongini E, Fredholm BB. Pharmacology of adenosine $A<\operatorname{sub}>2 A</$ sub $>$ receptors. Trends in Pharmacological Sciences. 1996;17(10):364-372.

27. Svenningsson P, Le Moine C, Kull B, Sunahara R, Bloch B, Fredholm B. Cellular expression of adenosine $\mathrm{A}<\mathrm{sub}>2 \mathrm{~A}</$ sub $>$ receptor messenger RNA in the rat central nervous system with special reference to dopamine innervated areas. Neuroscience. 1997;80(4):1171-1185.

28. Hettinger BD, Lee A, Linden J, Rosin DL. Ultrastructural localization of adenosine A2A receptors suggests multiple cellular sites for modulation of GABAergic neurons in rat striatum. Journal of Comparative Neurology. 2001;431(3):331-346.

29. Mori A, Shindou T, Ichimura M, Nonaka H, Kase H. The role of adenosine A2a receptors in regulating GABAergic synaptic transmission in striatal medium spiny neurons. The Basal Ganglia V: Springer; 1996:119-122.

30. Mayfield RD, Larson G, Orona RA, Zahniser NR. Opposing actions of adenosine A2a and dopamine D2 receptor activation on GABA release in the basal ganglia: evidence for an A2a/D2 receptor interaction in globus pallidus. Synapse. 1996;22(2):132-138.

31. Svenningsson P, Nomikos GG, Fredholm BB. Biphasic changes in locomotor behavior and in expression of mRNA for NGFI-A and NGFI-B in rat striatum following acute caffeine administration. The Journal of Neuroscience. 1995;15(11):7612-7624.

32. Brockwell NT, Eikelboom R, Beninger RJ. Caffeine-induced place and taste conditioning: production of dose-dependent preference and aversion. Pharmacology Biochemistry and Behavior. 1991;38(3):513-517. 
33. Ledent C, Vaugeois J-M, Schiffmann SN, et al. Aggressiveness, hypoalgesia and high blood pressure in mice lacking the adenosine A2a receptor. Nature. 1997;388(6643):674-678.

34. Mumford GK, Holtzman SG. Qualitative differences in the discriminative stimulus effects of low and high doses of caffeine in the rat. Journal of Pharmacology and Experimental Therapeutics. 1991;258(3):857-865.

35. Howland J, Rohsenow DJ, Arnedt JT, et al. The acute effects of caffeinated versus non-caffeinated alcoholic beverage on driving performance and attention/reaction time. Addiction. 2011;106(2):335-341.

36. Johnson LC, Freeman CR, Spinweber CL, Gomez SA. Subjective and objective measures of sleepiness: effect of benzodiazepine and caffeine on their relationship. Psychophysiology. 1991;28(1):65-71.

37. Smith A, Kendrick A, Maben A. Effects of breakfast and caffeine on performance and mood in the late morning and after lunch. Neuropsychobiology. 1992;26(4):198-204.

38. Smith A, Maben A, Brockman P. Effects of evening meals and caffeine on cognitive performance, mood and cardiovascular functioning. Appetite. 1994;22(1):57-65.

39. Bonnet $\mathrm{MH}$, Gomez S, Wirth O, Arand DL. The use of caffeine versus prophylatic naps in sustained performance. Sleep: Journal of Sleep Research \& Sleep Medicine. 1995.

40. Lieberman HR, Wurtman RJ, Emde GG, Coviella IG. The effects of caffeine and aspirin on mood and performance. Journal of Clinical Psychopharmacology. 1987;7(5):315-320.

41. Loke WH. Effects of caffeine on mood and memory. Physiology \& Behavior. 1988;44(3):367-372.

42. Goldstein A, Kaizer S, Whitby O. Psychotropic effects of caffeine in man. IV. Quantitative and qualitative differences associated with habituation to coffee. Clin Pharmacol Ther. 1969;10(4):489-497.

43. Snyder SH, Sklar P. Psychiatric progress: Behavioral and molecular actions of caffeine: Focus on adenosine. Journal of Psychiatric Research. 1984;18(2):91106. 
44. Humphreys MS, Revelle W. Personality, motivation, and performance: a theory of the relationship between individual differences and information processing. Psychological Review. 1984;91(2):153.

45. Shanahan M, Hughes R. Potentiation of performance-induced anxiety by caffeine in coffee. Psychological Reports. 1986;59(1):83-86.

46. Griffiths R, Mumford G. Caffeine reinforcement, discrimination, tolerance and physical dependence in laboratory animals and humans. Pharmacological Aspects of Drug Dependence: Springer; 1996:315-341.

47. Ratliff-Crain J, O'Keeffe MK, Baum A. Cardiovascular reactivity, mood, and task performance in deprived and nondeprived coffee drinkers. Health Psychology. 1989;8(4):427.

48. Schuh KJ, Griffiths RR. Caffeine reinforcement: the role of withdrawal. Psychopharmacology. 1997;130(4):320-326.

49. Silverman K, Evans SM, Strain EC, Griffiths RR. Withdrawal syndrome after the double-blind cessation of caffeine consumption. New England Journal of Medicine. 1992;327(16):1109-1114.

50. Bruce M, Scott N, Shine P, Lader M. Anxiogenic effects of caffeine in patients with anxiety disorders. Archives of General Psychiatry. 1992;49(11):867-869.

51. Lopez-Garcia E, van Dam RM, Rajpathak S, Willett WC, Manson JE, Hu FB. Changes in caffeine intake and long-term weight change in men and women. The American Journal of Clinical Nutrition. 2006;83(3):674-680.

52. Raboud J, Haley L, Montaner J, Murphy C, Januszewska M, Schechter M. Quantification of the variation due to laboratory and physiologic sources in CD4 lymphocyte counts of clinically stable HIV-infected individuals. Journal of Acquired Immune Deficiency Syndromes and Human Retrovirology. 1995;10:S67.

53. Bishop NC, Fitzgerald C, Porter PJ, Scanlon GA, Smith AC. Effect of caffeine ingestion on lymphocyte counts and subset activation in vivo following strenuous cycling. European Journal of Applied Physiology. 2005;93(5-6):606-613.

54. Nunnari G, Argyris E, Fang J, Mehlman KE, Pomerantz RJ, Daniel R. Inhibition of HIV-1 replication by caffeine and caffeine-related methylxanthines. Virology. 2005;335(2):177-184.

55. Daniel R, Marusich E, Argyris E, Zhao RY, Skalka AM, Pomerantz RJ. Caffeine inhibits human immunodeficiency virus type 1 transduction of nondividing cells. Journal of virology. 2005;79(4):2058-2065. 
56. Motivala SJ, Hurwitz BE, Llabre MM, et al. Psychological distress is associated with decreased memory helper T-cell and B-cell counts in pre-AIDS HIV seropositive men and women but only in those with low viral load. Psychosomatic Medicine. 2003;65(4):627-635.

57. Dhabhar FS, Miller AH, McEwen BS, Spencer RL. Effects of stress on immune cell distribution. Dynamics and hormonal mechanisms. The Journal of Immunology. 1995;154(10):5511-5527.

58. Nardi AE, Lopes FL, Freire RC, et al. Panic disorder and social anxiety disorder subtypes in a caffeine challenge test. Psychiatry Research. 2009;169(2):149-153.

59. Broderick P, Benjamín AB. Caffeine and psychiatric symptoms: a review. The Journal of the Oklahoma State Medical Association. 2004;97(12):538-542.

60. Hedges DW, Woon FL, Hoopes SP. Caffeine-induced psychosis. CNS Spectrums: The International Journal of Neuropsychiatric Medicine. 2009;14(3).

61. Hindmarch I, Rigney U, Stanley N, Quinlan P, Rycroft J, Lane J. A naturalistic investigation of the effects of day-long consumption of tea, coffee and water on alertness, sleep onset and sleep quality. Psychopharmacology. 2000;149(3):203216.

62. Zampelas A, Panagiotakos DB, Pitsavos C, Chrysohoou C, Stefanadis C. Associations between coffee consumption and inflammatory markers in healthy persons: the ATTICA study. The American Journal of Clinical Nutrition. 2004;80(4):862-867.

63. Cohen FL, Ferrans CE, Vizgirda V, Kunkle V, Cloninger L. Sleep in men and women infected with human immunodeficiency virus. Holistic Nursing Practice. 1996;10(4):33-43.

64. Nokes KM, Kendrew J. Sleep quality in people with HIV disease. Journal of the Association of Nurses in AIDS Care. 1996;7(3):43-50.

65. Nokes KM, Chidekel JH, Kendrew J. Exploring the complexity of sleep disturbances in persons with HIV/AIDS. Journal of the Association of Nurses in AIDS Care. 1999;10(3):22-29.

66. Nokes KM, Kendrew J. Correlates of sleep quality in persons with HIV disease. Journal of the Association of Nurses in AIDS Care. 2001;12(1):17-22.

67. Gamaldo CE, Gamaldo A, Creighton J, et al. Evaluating sleep and cognition in HIV. JAIDS Journal of Acquired Immune Deficiency Syndromes. 2013;63(5):609616. 
68. Vosvick M, Gore-Felton C, Ashton E, et al. Sleep disturbances among HIVpositive adults: the role of pain, stress, and social support. Journal of

Psychosomatic Research. 2004;57(5):459-463.

69. Griffiths RR, Woodson PP. Reinforcing effects of caffeine in humans. Journal of Pharmacology and Experimental Therapeutics. 1988;246(1):21-29.

70. Wesensten N, Belenky G, Kautz MA, Thorne DR, Reichardt RM, Balkin TJ. Maintaining alertness and performance during sleep deprivation: modafinil versus caffeine. Psychopharmacology. 2002;159(3):238-247.

71. Penetar D, McCann U, Thorne D, et al. Caffeine reversal of sleep deprivation effects on alertness and mood. Psychopharmacology. 1993;112(2-3):359-365.

72. Dreher HM. The effect of caffeine reduction on sleep quality and well-being in persons with HIV. Journal of Psychosomatic Research. 2003;54(3):191-198.

73. Salazar-Martinez E, Willett WC, Ascherio A, et al. Coffee consumption and risk for type 2 diabetes mellitus. Annals of Internal Medicine. 2004;140(1):1-8.

74. Greenberg JA, Boozer CN, Geliebter A. Coffee, diabetes, and weight control. The American Journal of Clinical Nutrition. 2006;84(4):682-693.

75. Pettenuzzo LF, Noschang C, von Pozzer Toigo E, Fachin A, Vendite D, Dalmaz C. Effects of chronic administration of caffeine and stress on feeding behavior of rats. Physiology \& Behavior. 2008;95(3):295-301.

76. Hamada T, Kotani K, Higashi A, et al. Lack of Association of the Trp64Arg Polymorphism of $\beta$ 3-Adrenergic Receptor Gene with Energy Expenditure in Response to Caffeine Among Young Healthy Women. The Tohoku Journal of Experimental Medicine. 2008;214(4):365-370.

77. Jones CY, Hogan JW, Snyder B, et al. Overweight and human immunodeficiency virus (HIV) progression in women: associations HIV disease progression and changes in body mass index in women in the HIV epidemiology research study cohort. Clinical Infectious Diseases. 2003;37(Supplement 2):S69-S80.

78. Baum MK, Shor-Posner G, Campa A. Zinc status in human immunodeficiency virus infection. The Journal of Nutrition. 2000;130(5):1421S-1423S.

79. Taylor EW. The oxidative stress-induced niacin sink (OSINS) model for HIV pathogenesis. Toxicology. 2010;278(1):124-130.

80. Shi X, Dalal N, Jain A. Antioxidant behaviour of caffeine: efficient scavenging of hydroxyl radicals. Food and Chemical Toxicology. 1991;29(1):1-6. 
81. Lee BL, Wong D, Benowitz NL, Sullam PM. Altered patterns of drug metabolism in patients with acquired immunodeficiency syndrome. Clinical Pharmacology \& Therapeutics. 1993;53(5):529-535.

82. Tsoi B, Yi R-N, Cao L-F, et al. Comparing antioxidant capacity of purine alkaloids: A new, efficient trio for screening and discovering potential antioxidants in vitro and in vivo. Food Chemistry. 2015;176:411-419.

83. Maughan RJ, Griffin J. Caffeine ingestion and fluid balance: a review. Journal of Human Nutrition and Dietetics. 2003;16(6):411-420.

84. Corti R, Binggeli C, Sudano I, et al. Coffee acutely increases sympathetic nerve activity and blood pressure independently of caffeine content role of habitual versus nonhabitual drinking. Circulation. 2002;106(23):2935-2940.

85. Wemple R, Lamb D, McKeever K. Caffeine vs caffeine-free sports drinks: effects on urine production at rest and during prolonged exercise. International Journal of Sports Medicine. 1997(18):40-46.

86. Geleijnse JM. Habitual coffee consumption and blood pressure: an epidemiological perspective. Vascular Health and Risk Management. 2008;4(5):963.

87. Nurminen M-L, Niittynen L, Korpela R, Vapaatalo H. Coffee, caffeine and blood pressure: a critical review. European Journal of Clinical Nutrition. 1999;53(11):831-839.

88. Hewlett P, Smith A. Correlates of daily caffeine consumption. Appetite. 2006;46(1):97-99.

89. Klesges RC, Ray JW, Klesges LM. Caffeinated coffee and tea intake and its relationship to cigarette smoking: an analysis of the Second National Health and Nutrition Examination Survey (NHANES II). Journal of Substance Abuse. 1994;6(4):407-418.

90. Amit Z, Weiss S, Smith BR, Markevitch S. Use of caffeine-based products and tobacco in relation to the consumption of alcohol. European Addiction Research. 2003;10(1):22-28.

91. Istvan J, Matarazzo JD. Tobacco, alcohol, and caffeine use: a review of their interrelationships. Psychological Bulletin. 1984;95(2):301.

92. Baethge C, Tondo L, Lepri B, Baldessarini RJ. Coffee and cigarette use: association with suicidal acts in 352 Sardinian bipolar disorder patients. Bipolar Disorders. 2009;11(5):494-503. 
93. Aubin H-J, Laureaux C, Zerah F, et al. Joint influence of alcohol, tobacco, and coffee on biological markers of heavy drinking in alcoholics. Biological Psychiatry. 1998;44(7):638-643.

94. Poikolainen K, Vartiainen E. Determinants of $\gamma$-Glutamyltransferase: positive interaction with alcohol and body mass index, negative association with coffee. American Journal of Epidemiology. 1997;146(12):1019-1024.

95. Worley CM, Valadez A, Schenk S. Reinstatement of extinguished cocaine-taking behavior by cocaine and caffeine. Pharmacology Biochemistry and Behavior. 1994;48(1):217-221.

96. Budney AJ, Higgins ST, Hughes JR, Bickel WK. Nicotine and caffeine use in cocaine-dependent individuals. Journal of Substance Abuse. 1993;5(2):117-130.

97. Balk L, Hoekstra T, Twisk J. Relationship between long-term coffee consumption and components of the metabolic syndrome: the Amsterdam Growth and Health Longitudinal Study. European Journal of Epidemiology. 2009;24(4):203-209.

98. Ranheim T, Halvorsen B. Coffee consumption and human health-beneficial or detrimental?-Mechanisms for effects of coffee consumption on different risk factors for cardiovascular disease and type 2 diabetes mellitus. Molecular Nutrition \& Food Research. 2005;49(3):274-284.

99. van Dam RM. Coffee consumption and risk of type 2 diabetes, cardiovascular diseases, and cancer. Applied Physiology, Nutrition, and Metabolism. 2008;33(6):1269-1283.

100. Higdon JV, Frei B. Coffee and health: a review of recent human research. Critical Reviews in Food Science and Nutrition. 2006;46(2):101-123.

101. Grosso LM, Bracken MB. Caffeine metabolism, genetics, and perinatal outcomes: a review of exposure assessment considerations during pregnancy. Annals of Epidemiology. 2005;15(6):460-466.

102. Cornelis MC, El-Sohemy A. Coffee, caffeine, and coronary heart disease. Current Opinion in Lipidology. 2007;18(1):13-19.

103. Rodrigues IM, Klein LC. Boiled or Filtered Coffee? Toxicological Reviews. 2006;25(1):55-69.

104. Hamer M, Williams ED, Vuononvirta R, Gibson EL, Steptoe A. Association between coffee consumption and markers of inflammation and cardiovascular function during mental stress. Journal of Hypertension. 2006;24(11):2191-2197. 


\section{CHAPTER III: METHODOLOGY}

\section{Preliminary Study}

A preliminary study was conducted to understand the relationship between caffeine consumption and CD4 cell counts and viral loads in $231 \mathrm{HIV}$ positive participants. ${ }^{1}$ This study was a secondary analysis of data collected by the parent study “Zinc-supplementation and HIV disease progression in HIV infected adults in Miami” also known as the Zinc study. ${ }^{1,2}$ For this study, HIV positive adults were recruited between March, 2002 and December, 2005 from several outreach sites in Miami-Dade County. The procedures included an informed consent, medical history, physical examination, blood collection for various disease related parameters; several standardized and validated questionnaires and standardized 24-hr dietary recalls using NUTRIBASE-7 diet-analysis program. Participants were eligible, if HIV infection was documented, had low plasma zinc levels $(<0.75 \mu \mathrm{g} / \mathrm{ml})$, were $\geq 18$ years, and did not have history of endocrine or psychiatric disorders; women were excluded if pregnant or had intention to become pregnant. Participants with plasma zinc levels $\leq 0.35 \mu \mathrm{g} / \mathrm{ml}$ at any time during the study were excluded for scientific and ethical reasons. HIV-viral load, complete blood counts and chemistries were monitored at baseline and every 6 months and any abnormal value communicated to the primary care physician. The study protocol was approved by the Florida International University (FIU) Internal Review Board. For this analysis only the baseline measures were used for $231 \mathrm{HIV}+$ adults. About $78 \%$ were AfricanAmerican, $62 \%$ received ART and $73.2 \%$ were men. The mean age was $42.7 \pm 7.0$ years. The mean caffeine intake was $115 \mathrm{mg} /$ day and about 10\% recorded zero mg caffeine intakes in the past month. There was a positive correlation between caffeine intake and 
viral load $(\mathrm{r}=0.3, \mathrm{p}<0.008)$ in patients who were not on ART $(\mathrm{N}=87)$, but no relationship was found in those on ART $(\mathrm{N}=144)$. This association also showed a dose response relationship which strengthened after controlling for several associated variables like age, drug use, smoking and alcohol consumption $(\beta=739, \mathrm{p}=0.004)$. This study served as a preliminary data to calculate sample size and for the current observational study on the effects of caffeine consumption on potential risk factors for HIV disease progression.

Figure 1: Regression Analysis Scatter Plot with Line of Fit for Caffeine Intake and HIV Viral Load

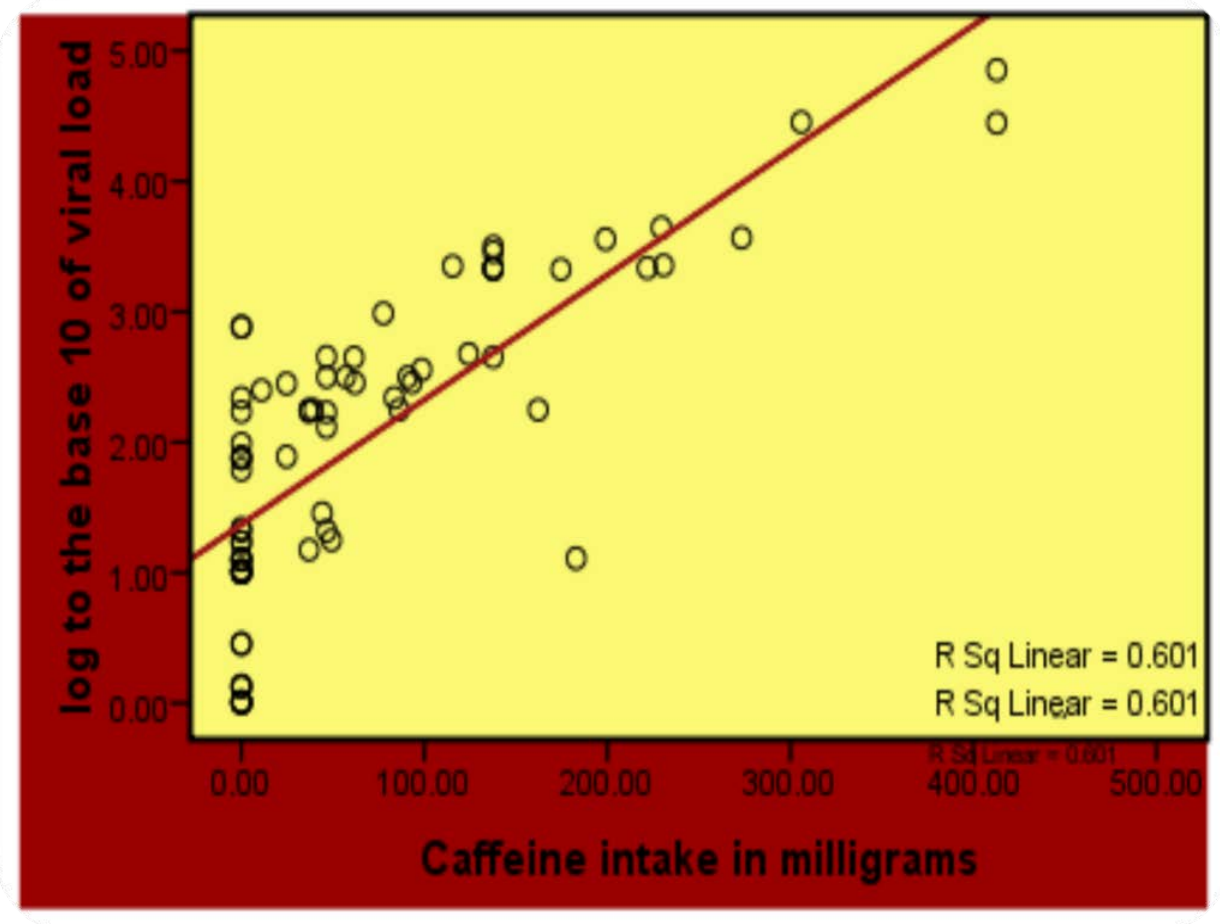

Table 1: Caffeine Intake and Viral Load using Mixed Models

\begin{tabular}{|l|l|l|}
\hline Variable & \multicolumn{2}{|l|}{ Coefficients } \\
\hline Viral Load* & $\beta=739$ & $P=0.004$ \\
\hline
\end{tabular}

*Controlled for age, drug use, smoking and alcohol consumption 


\section{Overview of the Current Study}

The current study was a prospective observational study (follow-up study) of data collected over a period of three months. It also included secondary analysis of relevant variables collected from the Miami Adult Studies on HIV (MASH) cohort which included a total of 803 HIV positive and 78 uninfected participants followed from 2002 to 2014, for two NIH sponsored grant studies, co-infection study and alcohol study, described elsewhere in this chapter. It included a baseline visit and a follow-up visit at three months. This study collected data from February to June of 2014. One hundred and thirty HIV+ adults (sample size calculations given in page 28) were recruited from the participants who were already enrolled in the MASH cohort. This study was approved by the Florida International University Institutional Review Board. The initial screening included detailed explanation of the current study as well as obtaining informed voluntary written consent for participation. To obtain a study sample of 130 patients (65 consuming $\leq 250 \mathrm{mg}$ /day and 65 consuming $>250 \mathrm{mg} /$ day of caffeine) a total of 150 patients were screened. Outreach personnel from the parent grants collaborated in scheduling of appointments and establishing contacts with the participants. All data collected during the baseline and 3-month visits were used for data analysis and inferences.

\section{Parent Studies}

At the time of recruitment from MASH, there were two active NIH sponsored studies for which we had already screened more than 800 HIV positive participants. These two studies were 'HIV and HIV/HCV co-infection, Disease Progression, Oxidative Stress and Antioxidants' also known as Co-infection study and 'Alcohol \& Antiretrovirals in HIV infection, Oxidative Stress and Liver Disease’ also known as 
Alcohol study. Co-infection study looked for the adverse effects of HCV co-infection on oxidative stress and plasma levels of antioxidant micronutrients as well as the net effects of these variables on HIV disease progression. The "Alcohol study” similarly examined the effects of alcohol consumption on oxidative stress, mitochondrial DNA damage and hepatocellular injury as well as the combined effects on HIV disease progression. The majority of the participants in both the studies were receiving antiretroviral therapy (ART). They were interviewed every three months at Borinquen Health Center, and at the semiannual and annual visits blood and urine were collected for laboratory values. Both the studies had stringent eligibility criteria, meticulous recruitment and retention protocols and safety and confidentiality procedures.

\section{Inclusion Criteria for Co-Infection Study}

1) HIV/HCV co-infected or HIV mono-infected participants with HBV infection ruled out and documented in the medical chart. HIV mono-infected participants will have qualitative HCV-RNA analysis by PCR to rule out HCV infection also documented in the medical chart

2) Identified from the Borinquen Healthcare Center

3) HIV/HCV co-infected patients determined with biopsy or another accepted noninvasive method of staging to be either F0-F5 fibrosis grading or its equivalence

4) Age 40-60 years

5) $\quad$ BMI $>18$, but $<40 \mathrm{~kg} / \mathrm{m} 2$

6) Compliant, as determined by regular visits to the clinic and adherence to treatment

7) Free of significant active psychiatric conditions 
8) Free of co-morbid diseases (uncontrolled diabetes, symptomatic cardiovascular disease)

9) Willingness to provide consent for a second biopsy if clinically indicated

10) Signature on a consent form

11) Willingness to participate in a study for 4 years (monthly contact with the clinic for follow-up, assessment visits at baseline and every 3 months thereafter for 48 months)

12) English speaking

\section{Exclusion Criteria for Co-Infection Study}

1) HBV infection

2) $\quad$ BMI $<18$, or $>40 \mathrm{~kg} / \mathrm{m} 2$

3) Chronic inflammatory diseases

4) Age $<40$, or $>60$ years

5) Elevated liver enzymes $>$ than grade 2 according to ATCG criteria, in HIV monoinfected participants

6) Ishak score F6 or end stage liver disease defined by clinical criteria of hepatic encephalopathy, esophageal varices, ascites, or hepatocellular carcinoma

7) Receiving HCV treatment

8) Pregnancy or the intent to become pregnant. Although the proposed study is observational, CD4 cell count increases in pregnancy, and pregnant women need to be referred to the obstetrics clinics where they are given micronutrient supplementation, which may confound the micronutrient and the oxidative stress findings 


\section{Inclusion Criteria for Alcohol Study}

1) HIV status documented in the medical chart

2) HIV-positive adults identified from the Borinquen clinics where the participants are followed medically and we will have access to their medical charts with written permission of the participant

3) ART naïve or treatment experienced

4) For Groups 1 and 2, CD4 cell count <350, initiating ART and achieving undetectable HIV viral load within 6 months, just prior to baseline. The ART will be a tenofovir based regimen

5) For Groups 3 and 4 (CD4 cell count $>450$, and viral load < 50,000), not yet eligible for ART

6) For Group 5 (85 HIV-negative participants) participants will have a documented seronegative test in the last year

7) Willing to respond to questionnaires on alcohol use pattern, frequency and type of beverages consumed

8) Age $18-60$ years old

9) $\mathrm{BMI}>18$, but $<40 \mathrm{~kg} / \mathrm{m} 2$ to control for malnutrition or obesity

10) Compliant, as determined by regular visits to the clinic and adherence to treatment

11) Controlled co-morbid diseases (diabetes, symptomatic cardiovascular disease, hyperlipidemia, and metabolic syndrome). Free of HBV and HCV (as confirmed by test results)

12) Free of heavy tobacco smoking (defined as $>20$ cigarettes/day) 
13) Signature on a consent form

14) Willingness to participate in a study for 2 years (monthly contact with the clinic for follow-up, assessment visits at baseline and every 3 months thereafter)

\section{Exclusion Criteria for Alcohol Study}

1) HBV and HCV infected as confirmed by testing or medical records

2) $\quad \mathrm{BMI}<18$, or $>40 \mathrm{~kg} / \mathrm{m} 2$

3) Chronic inflammatory diseases

4) Pregnancy or the intent to become pregnant. Although the proposed study is observational, CD4 cell count increases in pregnancy. Pregnant women will be referred to the obstetrics clinics

\section{Additional Inclusion Criteria for The Current Study}

1) Enrolled in the MASH cohort

2) History of ART

3) Willing to participate in a study that is at least 3 months duration Additional exclusion criteria for the current study

1) Any major cardiovascular abnormalities or implanted pacemakers

2) Any morbid medical conditions such as uncontrolled hypertension, anemia, malabsorption syndromes or AIDS defining opportunistic infections during the course of the study

\section{Characteristics of the MASH Cohort}

For the two NIH grant sponsored studies, co-infection study and alcohol study, a total of $803 \mathrm{HIV}$ positive and 78 uninfected participants were followed from 2002 to 2014, for a period of twelve years. This constituted the Miami Adult Studies on HIV 
(MASH) cohort and included a specimen repository and database for a number of clinical, laboratory, socio-demographic, substance abuse and behavioral data collected at regular intervals during the studies. The mean age of the cohort was $45.13 \pm 7.9$ years. Of these participants, 74.73\% were African American, 6.8\% were non-Hispanic White, 19.92\% were Hispanic, and $1.55 \%$ belonged to other races. Males constituted $68.95 \%$ of all participants. The mean family income for the entire cohort was $439 \pm 638.4 \$$ per month. The average time from diagnosis of HIV was $12.2 \pm 8.7$ years. About $33.62 \%$ reported adequate control over disease progression represented by undetectable HIV viral loads, while $23.4 \%$ reported inadequate control over disease progression represented by CD4 counts less than 200 cells per microliter. About $54.41 \%$ of the cohort reported some form of recreational drug use. The mean CD4 cell count for the entire cohort was 470.81 \pm 444.81 cells per microliter. The mean $\log _{10}$ HIV viral load was $3.23 \pm 1.33$ copies of HIV viral RNA.

\section{Human Subjects and Institutional Review Board (IRB)}

This study was approved by the Institutional Review Board at Florida International University. According to the eligibility criteria of the parent studies, all the participants recruited for the current study were under standard medical care prior to the recruitment, as well as during the entire period of the study. All the data collected were entered into a de-identified database where visits were linked only by a coded ID. All the software used for data storage and retrieval procedures were password protected to ensure safety and confidentiality. 


\section{Recruitment of Study Subjects}

All the study participants were recruited from the MASH cohort followed at the FIU-Borinquen Research Clinic. Participants were a consecutive convenience sample of 130 people (65 consuming $\leq 250 \mathrm{mg} /$ day and 65 consuming $>250 \mathrm{mg} /$ day of caffeine)

living with HIV (PLWH). We recruited participants from both genders and major racial and ethnic characteristics. To ensure compliance with the current study, the participants were provided incentives such as reimbursement for their time and effort, nutritional education and counseling.

\section{Initial Screening and Enrollment}

During the screening, participants were explained the details of the study and the eligibility criteria; if they were eligible and willing to participate, they were enrolled in the study. The participants were also assured confidentiality of the data obtained from them, as well as voluntary withdrawal from the study without any penalization. The consent forms are currently maintained at FIU in a locked cabinet only accessible to investigators for audit purposes.

\section{Pilot Testing of the Questionnaires, Logistics and Instruments}

Though all the questionnaires and instruments used in the current study were already validated in original studies and publications, we additionally pilot tested all questionnaires and instruments in a subset of 15 participants to assess the understanding of the questions by the participants. We evaluated the wording, understandability and schematic and grammatical layout of the administered questionnaires, and develop an efficient clinic logistic to administer them. No changes to the questionnaires and logistics were made throughout the duration of the study. 


\section{Baseline and 3-month Visits}

All eligible participants were screened and enrolled into the study and the baseline visits were scheduled at their earliest convenience, including the dates when the participants were screened for the current study. The baseline visits included the Caffeine Consumption Questionnaire (CCQ), Pittsburg Insomnia Rating Scale (PIRS) questionnaire, Pittsburg Sleep Quality Index (PSQI) questionnaire and Generalized Anxiety Disorder-7(GAD-7) questionnaire. Participants were interviewed at the threemonth visits with the same set of questionnaires and assessments. At the end of the study we followed all the study termination procedures enlisted in the Good Clinical Practice protocol. We also ensured that the data collected did not include any personal identifiers and were transported safely to a secure storage location within the premises of Florida International University ensuring their confidentiality.

\section{Compliance}

Compliance with the assigned schedule of visits and eligibility requirements was closely monitored. A variety of factors such as non-compliance to ART medications, inappropriate nutritional practices, self-supplementations, self-medications and types and frequency of substance abuse were assessed every three months in the MASH cohort. We tried to overcome potential barriers to compliance through meticulous efforts such as calling and reminding the participants a month and a week before the scheduled visit, reimbursing costs for their time spent with us, reducing wait time through organized appointments, and provisions for free parking through collaborations with the administration at Borinquen Health Care Center. We also tried to achieve higher compliance by assuring that the participants were interviewed by the same staff on every 
successive visit, and by trying to contact the participants for rescheduling on the same day, third day, a week, a month and two months after no show for the scheduled visits. During the visits, we established rapport before asking uncomfortable questions such as the reasons for their missing appointments, failure to follow study requirements, as well as other factors affecting compliance, so as to understand and take necessary steps to maximize compliance for the study. For those participants who did not show up for the 3month visit, we also searched the incarceration records and vital statistics. In-spite of these efforts to ensure compliance with follow-up visits, when we had missing values, we imputed them during the analysis of data.

\section{Safety Monitoring}

The majority of the safety-monitoring procedures were already in place in the MASH cohort when we collected data for the current study. Viral loads and CD4 counts were scrupulously monitored for signs of disease progression beyond healthy levels. Though there were no adverse events recorded during the current study, as this was not an intervention study, all protocols were in place for prompt intervention and resolution of adverse events. In case of adverse events severe enough to warrant prompt medical attention, we also had provisions for referrals to the nearby hospitals and emergency services. The MASH cohort was already monitored for signs of medical illness or nutritional deficiencies during follow-up visits of the parent studies.

\section{Outcomes and Assessments}

The primary outcomes of the study were changes in the markers of HIV disease progression which included changes in CD4 counts and viral loads. The outcomes collected during the current study included variables gathered from Caffeine 
Consumption Questionnaire (CCQ), Pittsburg Insomnia Rating Scale (PIRS) questionnaire, Pittsburg Sleep Quality Index (PSQI) questionnaire and Generalized Anxiety Disorder-7(GAD-7) questionnaire. Several variables such as age, gender, race/ethnicity, education, income, smoking, alcohol consumption, drug use, ART medications, CD4 counts, plasma viral load, 24-hour dietary intakes, body mass index (BMI), lean body mass (LBM), total fat mass, hemoglobin, hematocrit, serum albumin levels, and food security questionnaire (FSQ) scores were collected as part of the MASH cohort requirements and were used for secondary analysis in the current study. The following table provides a brief description of variables collected during the study as well as variables transcribed from the MASH cohort.

Table 2: Outcomes and Assessments Collected During the Current Study

\begin{tabular}{|l|l|l|}
\hline Assessments & Visits \\
\cline { 2 - 3 } & Baseline & 3-month \\
\hline Caffeine Consumption Questionnaire (CCQ) & $\checkmark$ & $\checkmark$ \\
\hline Pittsburg Insomnia Rating Scale (PIRS) questionnaire & $\checkmark$ & $\checkmark$ \\
\hline Pittsburg Sleep Quality Index (PSQI) questionnaire & $\checkmark$ & $\checkmark$ \\
\hline Generalized Anxiety Disorder-7(GAD-7) questionnaire & $\checkmark$ & $\checkmark$ \\
\hline
\end{tabular}

Caffeine Consumption Questionnaire (Appendix-1): We used the Modified Caffeine Consumption Questionnaire (MCCQ) developed by Preston et al in the year 1998. ${ }^{3}$ This questionnaire is easy to understand, compact, organized and reported adequate compliance, validity and reliability. ${ }^{3}$ This questionnaire was field tested and validated in many large scale studies and adequately reflected average daily caffeine consumption levels. ${ }^{4}$ It includes a total of 21 sources of caffeine classified in to three groups, 'beverages', 'over the counter medications' and 'prescription medications'. This 
questionnaire also included 'total caffeine consumption per day' by adding these individual sources. Caffeine consumption was analyzed both as a continuous variable and a categorical variable. Caffeine categories included low ( $\leq 250 \mathrm{mg} /$ day) and high $(>250$ mg/day) based on previous studies ${ }^{5}$ and recommendations by regulatory bodies like World Health Organization (WHO) ${ }^{6,7}$, International Classification of Diseases (ICD) manual $^{13}$ and The Diagnostic and Statistical Manual of Mental Disorders (DSM-V). ${ }^{8}$ The Pittsburg Insomnia Rating Scale (PIRS): The PIRS (Appendix-1) is a 66-item self-report questionnaire that measures the subjective levels of insomnia experienced over the past seven days. ${ }^{9}$ This questionnaire consists of four components: Distress Score; Sleep Parameter Score; Quality of Life Sore; and Total Insomnia Score. The 'Distress Score' equals the total of first 46 questions each rated on a 0-3 scale and higher scores indicate increased levels of subjective distress symptoms experienced by the participants. Similarly, the 'Sleep Parameter Score' totals questions 47 to 56 each rated on a 0-3 scale and higher scores signify poor sleep quality. The ‘Quality of Life Score’ adds questions 57 to 65 and higher scores signify poor quality of life. The 'The Global PIRS Score' sums all the 65 questions and higher scores represent increased subjective reports of insomnia. The original study of the questionnaire also recommends scores 0-50 as 'No Insomnia', scores 51-100 as 'Moderate Insomnia' and scores greater than 100 as 'Severe Insomnia'. ${ }^{9}$ The questionnaire also contains an 'Overall Sleep Quality’ estimator with scores from $0 \%$ to $100 \%$, and serves as a simplified summary of overall sleep. In opposition to the other components and the global score, increasing scores in 'Overall Sleep Quality’ signify lower levels of insomnia. The PIRS questionnaire showed excellent internal consistency, test-retest reliability and discriminative validity in a mixed 
sample of 456 normal adult participants between 18 and 85 years in the original study. The original study also reported a Cronbach's alpha coefficient of 0.88 indicating high internal consistency and an intra-class correlation of 0.89 indicating good test-retest reliability. ${ }^{9}$ The original study also reported a sensitivity of $83.4 \%$ and a specificity of 88.6\% for the questionnaire. ${ }^{9}$ In the present study the global PIRS scores were analyzed as both continuous and categorical variables. The global PIRS score categories included: $\leq 50$ (No Insomnia), 51-100 (Moderate Insomnia), and >100(Severe Insomnia) as recommended in the original study. ${ }^{9}$

The Pittsburg Sleep Quality Index Questionnaire (PSQI):The PSQI (Appendix-1) is a 19-item self-report questionnaire that measures self-reported quality of sleep over the past 30 days. ${ }^{10}$ This questionnaire includes seven individual components: Sleep Duration; Sleep Disturbance; Sleep Latency; Days Dysfunction due to Sleepiness; Sleep Efficiency; Overall Sleep Quality; and Need Meds to Sleep. Each component is rated on a 0-3 scale with higher scores signifying worsening outcomes. 'Sleep Duration' is calculated using question 4 and represents the total number hours slept per day. 'Sleep Disturbance' is calculated by summarizing individual scores in questions $5 \mathrm{~b}$ to $5 \mathrm{j}$ and represents various factors like bad dreams, pain, breathing problems etc. that have impaired the quality of sleep. 'Sleep Latency' represents the total time spent awake on bed trying to sleep each day and is calculated using the questions 2 and 5 with necessary re-coding. 'Days Dysfunction due to Sleepiness' is calculated from questions 8 and 9 and represents daily problems related to sleep, such as having trouble staying awake or having enough enthusiasm to get things done. 'Sleep Efficiency' is calculated from questions 1 and 3 and represents the ratio of actual number of hours of sleep, given the number of hours 
spent in bed. 'Overall Sleep Quality’ is calculated from question 6 and represents general sleep quality over the past month. 'Need Meds to Sleep' is calculated from question 7 and represents use of sleep medications over the past month. These seven component scores are added to obtain a global PSQI score which ranges from 0 to 21 and higher scores represent worsening sleep quality. According to the original study a global PSQI score of 5 or greater represents poor sleep quality. ${ }^{10}$ However other studies recommend scores 0-5 as good sleep quality, 6-10 as poor sleep quality and greater than 10 as worst sleep quality. ${ }^{11,12}$ This questionnaire had good internal consistency, test-retest reliability, and discriminative validity in the original study with a sample of 168 participants aged 19 to 83 years. ${ }^{10}$ The original study also reported a Cronbach's alpha coefficient of 0.83 indicating high internal consistency and an intra-class correlation of 0.85 indicating good test-retest reliability. ${ }^{10,13}$ The original study also reported a sensitivity of $89.6 \%$ and a specificity of $86.5 \%$ for the questionnaire. ${ }^{10,13}$ In the current study the global PSQI scores were analyzed as both continuous and categorical variables. The global PSQI score categories included: $\leq 5$ (Good Sleep Quality), 6-10 (Poor Sleep Quality), and >10 (Worst Sleep Quality). ${ }^{23,24}$

\section{The Generalized Anxiety Disorder-7 (GAD-7) Questionnaire: The GAD-7}

(Appendix-1) is a 7-item self-reported questionnaire for screening and evaluating the severity of generalized anxiety symptoms over the past two weeks. ${ }^{14}$ Although primarily developed for measuring generalized anxiety disorder, studies have also reported good sensitivity and specificity for many other anxiety and panic disorders. ${ }^{15}$ There are seven questions about anxiety symptoms each rated on a 0-3 scale representing the options 'not at all', 'several days' , 'more than half the days', and 'nearly every day'. The total scores 
range from 0 to 21 and higher scores represent greater anxiety levels. GAD-7 had shown good internal consistency, test-retest reliability, and discriminative validity in the original study of 2470 participants aged 19 to 95 years. ${ }^{14}$ The original study of this questionnaire reported a Cronbach's alpha coefficient of 0.92 indicating very high internal consistency and an intra-class correlation of 0.83 indicating good test-retest reliability. ${ }^{14}$ The original study also reported a sensitivity of $89 \%$ and a specificity of $82 \%$ for the questionnaire. ${ }^{14}$ In the current study the GAD-7 scores were analyzed as both continuous and categorical variables. The GAD-7 score categories included: $\leq 5$ (Minimal Anxiety), 6-10 (Mild Anxiety), 11-15 (Moderate Anxiety) and >15 (Severe Anxiety) as recommended in the original study. ${ }^{14}$

Table 3: Assessments Variables Collected by the MASH Cohort

\begin{tabular}{|l|l|l|}
\hline Assessments & Visits \\
\cline { 2 - 3 } & Baseline & 3-month \\
\hline Demographic and Socioeconomic information & $\checkmark$ & $\times$ \\
\hline 24-hour dietary recall & $\checkmark$ & $\checkmark$ \\
\hline Bio-impedance analysis (BIA) & $\checkmark$ & $\checkmark$ \\
\hline CD4 cell count & $\checkmark$ & $\checkmark$ \\
\hline Viral loads & $\checkmark$ & $\checkmark$ \\
\hline Alcohol, tobacco, and illicit drugs & $\checkmark$ & $\checkmark$ \\
\hline Food Security Questionnaire (FSQ) & $\checkmark$ & $\checkmark$ \\
\hline Hemoglobin & $\checkmark$ & $\checkmark$ \\
\hline Hematocrit & $\checkmark$ & $\checkmark$ \\
\hline Serum Albumin levels & $\checkmark$ & $\checkmark$ \\
\hline
\end{tabular}

Demographic and socioeconomic information: The parent studies collected demographic and socioeconomic information for all participants. Information used for the present study included age, gender, race/ethnicity, education and income levels. A 
number of health and lifestyle related factors like tobacco use, alcohol consumption, drug use and types of antiretroviral (ART) medications were also transcribed from the MASH cohort data.

24-hour dietary recall: All research personnel in the parent studies were trained to obtain 24-hour dietary recalls which were used to estimate dietary and nutrient consumption by the participants. During each visit participants were queried about foods and beverages consumed on the day prior to the visit. All details including cooking methods, amount consumed, additional ingredients and seasonings and food brands were recorded to ensure the comprehensiveness of the obtained information. We also used props like food models and measuring cups to ensure accuracy of the amounts and volumes recalled as well as providing cues for better recall of consumed foods. We used Nutribase Professional Software Version 9 (Cybersoft Inc, 2011), into which all the collected information were entered to obtain estimation of several nutrients consumed by the participants.

Bio-impedance analysis (BIA): In the parent studies after screening the participants, height was recorded immediately using a stadiometer, calibrated according to the instruction manual. Height was recorded to the nearest 0.5 inch after removing shoes, socks and other footwear. Height was recorded only once to ensure that it was uniform and there were no minor variations during every successive visit. Weight was measured every visit to the nearest $0.1 \mathrm{lbs}$. using a standard weighing machine which was calibrated and maintained throughout the study and the participants were requested to remove, their watches, shoes, mobile phones or other heavy materials possessed by them. The data so obtained along with age were entered into the bio-impedance machine (Biodynamics- 
$450)^{16}$ to obtain several body composition measures such as, body cell mass, extracellular mass, lean body mass (LBM), fat mass, body mass index (BMI) and intracellular and extracellular fluid levels. In addition we also obtained the waist-to-hip ratio using a nonstretchable tape to measure the waist and hip circumference at the narrowest levels of the waist and widest levels of the hip.

CD4 counts and viral load: The BHCC provides a variety of comprehensive health services for HIV/AIDS patients which include quarterly check-up visits, laboratory services, nutritional counseling and emergency services. Based on requests from their primary health care physicians or their HIV/ STD consultant at BHCC, CD4 counts, viral loads and other clinical variables are measured every six months for all HIV infected patients. The parent grant collected and documented these reports after appropriate medical release forms signed by the participants. The parent grants also paid a compensation of \$15 every six month to motivate participants towards timely submission of medical records and lab reports which included CD4 counts and viral load. We took meticulous efforts to ensure that lab reports submitted by the participants were timely and done within the interval between two six monthly follow-up visits in the parent study. The CD4 counts and viral loads were analyzed as both continuous and categorical variables. In analyses where CD4 counts and viral load were used as continuous variables they were transformed into CD4 square root and $\log _{10}$ viral load to ensure normal distribution and better model fit criteria. In analysis where CD4 counts and viral loads were used as categorical variables both the variables were divided into three groups of adequate control on disease progression (CD4 count $>500$ and viral load $<75$ copies of HIV RNA); moderate control over disease progression (CD4 count between 200-499 and 
viral load between 76-9999 copies of HIV RNA); and inadequate control over disease progression (CD4 count <200 and viral load >10,000 copies of HIV RNA), based on immunological and viroloigc stratification of HIV disease progression by the World Health Organization (WHO). ${ }^{17,18}$

Alcohol, tobacco, and illicit drugs: A trained interviewer administered alcohol, tobacco, and drug abuse questionnaires. The alcohol use questionnaires include information on frequency and type of alcohol use over time collected by the Lifetime Alcohol History $(\mathrm{LAH}),{ }^{19}$ and history of alcohol binging and prolonged heavy exposure utilizing the validated and standardized Alcohol Use Disorders Identification Test (AUDIT). ${ }^{19}$ Hemoglobin, hematocrit and serum albumin:_Two chemistry panels and complete blood counts (CBC) from visits that tallied closest to the baseline and 3-month visit of the current study were transcribed form the laboratory reports of blood samples collected from the MASH cohort for the two parent studies. We obtained nutritional indicators like hemoglobin; hematocrit and serum albumin form these lab reports.

\section{Data Collection for the Study}

To reduce observer bias, we used standardized procedures with uniform protocols. All equipment, questionnaires and instruments were calibrated according to the instructions in user's manual and the requirements of the MASH cohort. We also assured that these procedures were done prior to the commencement of the study to reduce wait time, as well as the time taken to administer the questionnaires and assessments. Each visit lasted approximately 30 minutes and was primarily devoted towards answering and filling out the forms and questionnaires. Participant responses were recorded and maintained in the paper based research charts for each study visit. Every chart included a 
checklist of activities and the questionnaires were arranged according to the specific aims

of the current study. The consent forms were maintained separately to ensure better levels of confidentiality as well as availability for audit purposes. All the research charts were quality assured at least twice during the course of the study to avoid missing data and non-rectifiable errors.

\section{Sample Size Calculation}

G-Power is a common software used for power analysis in social and behavioral research. ${ }^{20}$ G-Power 3 has incorporated several improvements over previous versions and is adapted to run on several interfaces like Windows XP, Windows Vista, and Mac OS X 10.4. This software covers many different statistical tests of the $\mathrm{t}, \mathrm{F}$ and $\chi^{2}$ categories. ${ }^{20}$ G-Power 3 provides improved effect size calculations and graphic options, supports both distribution-based and design-based input models. This software comes handy in several types of power analysis with adjustments according to the study designs and sample size limitations. ${ }^{20}$ Hypothesis $1 \mathrm{~A}$ was used for calculating the sample size for the study. The input parameters for the sample size calculations included a two tailed t-tests to determine difference between two independent means or two group means. The effect size was set at 0.5 . Cohen et al., ${ }^{21}$ has described three effect sizes: 0.3 for strong associations, 0.5 for moderate associations, and 0.8 for strong associations. Considering the associations between caffeine and CD4 cells to be moderate as evident in the preliminary study, we had decided 0.5 as the effect size. We set the probability of alpha error at 0.05 and statistical power levels at 0.80 i.e. 80 percentage. We obtained an actual power of 0.801 for a total sample size of 128 participants for the study. We rounded this 
figure to 130 participants (65 consuming $\leq 250 \mathrm{mg} /$ day and 65 consuming $>250 \mathrm{mg} /$ day of caffeine) for the study.

\section{Statistical Methods Used in the Study}

SPSS-21 for windows was used for analyzing the relationship between caffeine intake and outcome variables in the study. Standard statistical methods were used to calculate the rates, describe the demographic characteristics and show basic summary statistics. Caffeine intake was analyzed as a as a categorical variable by splitting into two groups of $<250 \mathrm{mg}$ (low intake) and $>250 \mathrm{mg}$ (high intake) based on the studies that classify the dosage based adverse effects of caffeine. ${ }^{4-8,22}$ T-tests and chi-square tests were used for significant differences between the two caffeine groups with respect to all the outcome variables in the study. Multinomial logistic regressions were used to estimate the associations between different levels of caffeine consumption and several categorical outcome variables. Linear Mixed Models were used for over time changes in these associations. Caffeine intake was also considered as a continuous variable for several analyses. Correlation analyses were used to find significant associations between caffeine intake and several continuous outcome variables. Correlation matrices helped to understand the existence of these associations. Linear regressions were used to analyze baseline cross-sectional data and report the strength and predictability of the associations between caffeine intake and continuous outcome variables. Linear Mixed Models were used for overtime changes in these associations. The results were considered significant for $\mathrm{p}<0.05$ 


\section{Quality Control}

We took several steps to ensure that data collected during the study were accurate and free from errors. All the procedures were done according to the 'Good Clinical Practice' protocols for quality control. We meticulously strived to ensure that there was no breach of protocol and we had adequate procedures to resolve them and take effective measures if we found any such occurrences. The Doctoral Candidate, Dr. Ramamoorthy's responsibilities included monitoring every visit along with immediate perusal of all the data collected in charts as well as data entered into the software programs. He was also assisted by other staff members in quality assurance procedures. The PI, Dr. Marianna Baum, $\mathrm{PhD}$, and the committee members were constantly consulted to discuss logistic issues as well as sufficient supply of binders, folders, forms, questionnaire, copies and other supplies. The gathered data were regularly monitored through standardized procedures to ensure validity as well as reliability. All activities done during each week were discussed in weekly meetings to get feedback on the progress of the project as well as technical issues. A weekly review of performance, protocol compliance, and recommendations was done by the major professor, Dr. Adriana Campa, $\mathrm{PhD}$, during the entire period of data collection and data entry. The security and confidentiality of data were ascertained through scrupulous and meticulous coding procedures. An elaborate system of patient identification numbers and study identification numbers were already in place for the parent study and were used for the current project. The data form charts were entered into databases by trained personnel with sufficient experience in data entry and retrieval procedures. All the working steps were intermittently scrutinized to ensure adequate quality control. The confidentiality and security of the data was further 
strengthened by assigning appropriate password protections and accessibility codes for all the software used in the current study. All the instruments, logistics as well as the questionnaires were pilot tested to ensure the continuation of established standards of the parent study. To the best of our knowledge we took adequate steps to ensure the validity as well as reliability of the data collected during the current study as well as secondary analysis variables from the parent studies.

\section{Proposed Benefits of the Study}

This prospective study would serve as the basis for further large clinical trials for understanding the effects of caffeine consumption on disease progression levels. Several other factors that could not be covered in this study can be progressively determined, measured and analyzed. These researches can further help in instituting studies on standardized dietary recommendations on the consumption of coffee and other caffeine containing beverages in HIV infected patients. This can alleviate the already immunocompromised states in these patients, contribute to immune recuperation and bring significant changes in their general wellbeing. 


\section{References}

1. Campa A LK, Rafie C, Sales S, Baum MK. Caffeine intake and plasma zinc levels among HIV+ adult drug users in Miami. Experimental Biology 2008 FASEB Conference, San Diego, CA, April 5-9, 2008.; 2008.

2. Baum MK, Lai S, Sales S, Page JB, Campa A. Randomized, controlled clinical trial of zinc supplementation to prevent immunological failure in HIV-infected adults. Clinical Infectious Diseases. 2010;50(12):1653-1660.

3. Preston JD, O'Neal JH, Talaga MC. Consumer's Guide to Psychiatric Drugs. New Harbinger Publications, Inc; 1998.

4. United States Food And Drug Administration. FDA to investigate caffeine. 2013; http://www.fda.gov/downloads/ForConsumers/ConsumerUpdates/UCM350 740.pdf. Accessed October 20, 2014.

5. United States Food And Drug Administration. FDA to investigate added caffeine. 2013; http://www.fda.gov/downloads/ForConsumers/ConsumerUpdates/UCM350 643.pdf. Accessed September 2, 2014.

6. World Health Organization. Lexicon of alcohol and drug terms published by the World Health Organization. Accessed September 22013.

7. World Health Organization. Mental and behavioural disorders F15. International Statistical Classification of Diseases and Related Health Problems. 2010;Chapter 5(Mental and behavioural disorders due to use of other stimulants, including caffeine.).

8. American Psychiatric Association. Diagnostic and Statistical Manual of Mental Disorders. Vol Fifth ed2013.

9. Moul D, Pilkonis P, Miewald J, Carey T, Buysse D. Preliminary study of the testretest reliability and concurrent validities of the Pittsburgh Insomnia Rating Scale (PIRS). Paper presented at: Sleep2002.

10. Buysse DJ, Reynolds CF, Monk TH, Berman SR, Kupfer DJ. The Pittsburgh Sleep Quality Index: a new instrument for psychiatric practice and research. Psychiatry Research. 1989;28(2):193-213.

11. Carpenter JS, Andrykowski MA. Psychometric evaluation of the Pittsburgh sleep quality index. Journal of Psychosomatic Research. 1998;45(1):5-13. 
12. Fichtenberg NL, Putnam SH, Mann NR, Zafonte RD, Millard AE. Insomnia screening in postacute traumatic brain injury: utility and validity of the Pittsburgh Sleep Quality Index. American Journal of Physical Medicine \& Rehabilitation. 2001;80(5):339-345.

13. Backhaus J, Junghanns K, Broocks A, Riemann D, Hohagen F. Test-retest reliability and validity of the Pittsburgh Sleep Quality Index in primary insomnia. Journal of Psychosomatic Research. 2002;53(3):737-740.

14. Spitzer RL, Kroenke K, Williams JB, Löwe B. A brief measure for assessing generalized anxiety disorder: the GAD-7. Archives of Internal Medicine. 2006;166(10):1092-1097.

15. Kroenke K, Spitzer RL, Williams JB, Monahan PO, Löwe B. Anxiety disorders in primary care: prevalence, impairment, comorbidity, and detection. Annals of Internal Medicine. 2007;146(5):317-325.

16. Biodynamics Corporation. BIA 450 bioimpedance analyzer. 2010; http://www.biodyncorp.com/product/450/450.html, May, 2015.

17. World Health Organization. Who Case Definitions of HIV for Surveillance and Revised Clinical Staging and Immunological Classification of HIV-Related Disease in Adults and Children.

2007; http://www.who.int/hiv/pub/guidelines/WHO\%20HIV\%20Staging.pdf. Accessed September 30, 2014.

18. United States Department of Health and Human Services. Panel on antiretroviral guidelines for adults and adolescents: Guidelines for the use of antiretroviral agents in HIV-1 infected adults and adolescents.

2011; http://aidsinfo.nih.gov/contentfiles/lvguidelines/adultandadolescentgl.pdf. Accessed September 12, 2014.

19. Saunders JB, Aasland OG, Babor TF, de la Fuente JR, Grant M. Development of the alcohol use disorders identification test (AUDIT): WHO collaborative project on early detection of persons with harmful alcohol consumption-II. Addiction. 1993;88(6):791-804.

20. Faul F, Erdfelder E, Lang A-G, Buchner A. G* Power 3: A flexible statistical power analysis program for the social, behavioral, and biomedical sciences. Behavior research methods. 2007;39(2):175-191.

21. Cohen J. Statistical Power Analysis for the Behavioral Sciences. Academic press; 2013. 
22. United States Food and Drug Administration. Database of Select Committee on GRAS Substances (SCOG) Reviews: Caffeine.

2006; http://www.accessdata.fda.gov/scripts/fcn/fcnDetailNavigation.cfm?rpt=sco gsListing\&id=42. Accessed Spetember 12, 2014. 


\title{
CHAPTER IV: CAFFEINE INTAKE AND ITS ASSOCIATION WITH DISEASE PROGRESSION IN MIAMI ADULT STUDIES ON HIV (MASH) COHORT - AN OBSERVATIONAL STUDY
}

\begin{abstract}
Introduction: In the year 2013, Miami-Dade County reported about 26,760 people living with HIV (PLWH). Though there are many studies on adverse health effects of alcohol, recreational drugs and tobacco use in this population, similar studies about caffeine consumption are few. In this study we investigated for the effects of caffeine on immunological and virologic markers of disease progression.

Methods: A convenience sample of 130 consecutive, clinically stable HIV-positive participants on ART, (65 consuming $\leq 250 \mathrm{mg} /$ day and 65 consuming $>250 \mathrm{mg} /$ day of caffeine) were recruited from the Miami Adult Studies on HIV (MASH) cohort. This prospective study included a baseline and a follow-up visit after 3 months. After obtaining written consent, the Modified Caffeine Consumption Questionnaire (MCCQ), CD4 cell count, HIV viral load, demographics, anthropometries, Body Mass Index (BMI), bio impedance measures, substance abuse and types of ART were obtained. Data were sequentially entered in secure databases and analyzed using SPSS-21 for windows. T-tests and chi-square tests were used to describe demographics and health and lifestyle characteristics of the participants. Linear regressions were used to analyze baseline data for relationships between caffeine consumption and parameters of HIV disease progression. Linear Mixed Models were used to understand the effect of caffeine consumption on these parameters over time.
\end{abstract}


Results: The mean age of the cohort was $47.89 \pm 6.37$ years, $60.8 \%$ were male and 75.4\% were African-Americans. All participants were on ART during both the visits. Mean caffeine intake at baseline was $161.26 \pm 194.95 \mathrm{mg} /$ day (3-8 cups of coffee) (Range: $0 \mathrm{mg}$-1498 mg/day) and did not change significantly at the 3-month follow-up visit. Linear regression analysis showed significant associations between higher caffeine consumption and higher CD4 cell count $(\beta=1.532, P=0.049)$ and lower HIV viral load $(\beta=-1.067, P=0.048)$, after adjusting for age, gender, education, income, and time from diagnosis of HIV, drug use, smoking status, alcohol use and different types of ART medications. Linear mixed model analysis showed that higher caffeine consumption was associated with higher CD4 cell count $(\beta=1.720, P=0.042)$ and lower HIV viral load $(\beta=-$ 1.389, $P=0.033$ ), in a dose-response manner, after adjusting for the same covariates. Conclusion: Higher caffeine consumption was associated with higher CD4 cell counts and lower HIV viral loads indicating beneficial effects on HIV disease progression. Future studies examining bio-chemical effects of caffeine on CD4 cell counts and viral replication are needed to shed light on the mechanisms of these potential beneficial effects. Keywords: Caffeine, HIV infection, CD4 cell count, HIVviral load. 


\section{INTRODUCTION}

HIV/AIDS is a leading cause of morbidity and mortality worldwide. ${ }^{1}$ According to CDC estimates in 2013, about 1.2 million people were living with HIV/AIDS in United States. $^{2}$ In Miami-Dade County, there were 26,760 people living with HIV/AIDS (PLWH), in the same year. ${ }^{3}$ In the year 2013, it was also estimated that one in 99 MiamiDade resident was living with HIV infection which included one in 36 African American, one in 123 White, and one in 163 Hispanic. ${ }^{4}$ HIV/AIDS has also successively been in the list of ten leading causes of death among African Americans in Florida. ${ }^{5}$ This epidemiological evidence shows that Miami-Dade County and the State of Florida suffer increased burden of the disease compared to the national average.

Antiretroviral therapy (ART) has significantly improved survival rates and decreased morbidity and mortality in PLWH and constitutes the single most effective strategy to prevent HIV-1 transmission rates. ${ }^{6}$ Combination ART has decreased the numbers of patient entering health-care centers from 75,486 in the year 2000 to 24,780 in the year 2010. ${ }^{15}$ The estimated cumulative survival benefits of combination ART therapy was 2,813,892 years between the years 2000 and $2010 .^{15}$ Due to recent improvements in availability and accessibility of combination ART medications, currently, HIV/AIDS constitutes a chronic disease with decreasing incidence, increasing prevalence and 97\% decrease in progression to AIDS and death as of the year 2014. ${ }^{16}$

Many factors contribute to faster HIV disease progression, such as homelessness, illegal commercial sex, drug abuse, alcohol addiction and criminalization of the disease which contribute to barriers in access to effective ART and compliance with the medications. ${ }^{17-21}$ Most of the PLWH live in marginalized neighborhoods with limited 
resources. ${ }^{22}$ Though the majority of the MASH cohort, from which our participants were recruited, receive social security benefits and some forms of food assistance, many of them experience poverty and some experience food insecurity ${ }^{23}$ Food insecurity, poverty and poor living conditions are associated with accelerated disease progression and poor health outcomes, as reported in other studies..$^{24,25}$ There is a large body of literature on associations of alcohol, ${ }^{26}$ illicit drugs ${ }^{27}$ and tobacco use ${ }^{28}$ with a variety of health related outcomes in this population. However, there are very few studies that relate caffeine consumption to health related outcomes in HIV infected populations.

In a study done by Raboud et al., ${ }^{29} \mathrm{CD} 4$ cell counts were significantly lower in consumers of moderate amounts of caffeine ( $<250 \mathrm{mg} /$ day) compared to non-consumers (0 mg/day). Another study done among clinically stable HIV positive individuals showed that administration of caffeine ( $<250 \mathrm{mg} /$ day) decreased CD4 cell counts by $54 \%$ and CD8 cell counts by 55\% compared to placebo $(0 \mathrm{mg} / \mathrm{d}) .{ }^{30} \mathrm{In}$ contrast, an in-vitro study showed that caffeine suppressed replication of infectious HIV-1 strains in cultures of human peripheral mononuclear cells. ${ }^{31}$ This study demonstrated greater than 9-fold reductions in HIV-1 p24 antigen values in samples treated with caffeine or caffeine metabolites such as theobromine, paraxanthine or theophylline when compared to control solutions. ${ }^{31}$ Similar findings were reported in another tissue culture study where caffeine in concentrations of $10 \mu \mathrm{gm} /$ liter significantly inhibited retroviral transduction of dividing Human neuronal precursor (hNT-2) cells, thereby, blocking post integration repair of HIV-1 viral strains and inhibiting viral replication cycles. ${ }^{32}$ These effects have been hypothesized to be related to a cellular target: the ataxia telangiectasia-mutated Rad3-related (ATR) kinase. ${ }^{32}$ 
Studies in HIV-seronegative populations have implicated caffeine use in a variety of health problems. High caffeine intake ( $>400 \mathrm{mg} /$ day) adversely affected the quality of sleep and general well-being scores in healthy subjects, ${ }^{33,34}$ and precipitated anxiety disorders in apparently healthy volunteers. ${ }^{35}$ High caffeine intake (480 mg/day), adversely affected gabaminergic (inhibitory) neurotransmission, exacerbated mental stress, and produced irreversible psychological derangements in apparently healthy participants with anxiety disorders controlled through medications. ${ }^{36,37}$ Caffeine intake ( $<250 \mathrm{mg}$ /day) was also associated with nutritional losses such as cysteine-depletion and decreased plasma levels of anti-oxidant trace elements such as zinc and selenium thereby increasing susceptibility to oxidative damage of neuronal cells. ${ }^{38,39}$ Caffeine in doses of $300 \mathrm{mg} /$ day was also associated with irregularities in blood pressure tracings and cardiac function tests in susceptible populations. ${ }^{40,41}$

Excessive caffeine intakes were also associated with higher levels of inflammation. In a cross-sectional survey conducted in 1514 men and 1528 women, men who consumed more than $200 \mathrm{mg} /$ day of caffeine had 50\% higher interleukin 6 (IL-6), $30 \%$ higher C-reactive protein (CRP), 28\% higher tumor necrosis factor- $\alpha$ (TNF- $\alpha$ ) and 3\% higher white blood cell (WBC) counts. Similarly women who consumed more than $200 \mathrm{mg} /$ day of caffeine reported 54\% higher IL-6, 38\% higher CRP, 28\% higher TNF- $\alpha$ and $4 \%$ higher WBC counts. ${ }^{42}$

Caffeine ( $<250 \mathrm{mg} /$ day) was associated with moderate weight loss in many groups of healthy volunteers. ${ }^{43,44}$ This could be detrimental to HIV-infected patients because higher body weight and fat-mass are associated with higher CD4 cell counts, lower viral load and better health outcomes in participants receiving ART. ${ }^{45-47}$ 
Since studies have found associations between excessive caffeine consumption and many adverse effects in non-HIV infected populations, it is possible that some of these effects may be more pronounced in HIV infected subjects, who are already compromised in a variety of health related parameters. There are very few studies that document the associations of caffeine and CD4 cells and HIV viral load. Existing studies on the effects of caffeine on viral loads are in-vitro studies conducted in tissue cultures, while the ones investigating CD4 counts have several shortcomings, including small sample sizes and inadequate control for several variables associated with HIV disease progression. Furthermore, some studies show adverse associations between caffeine and immunological markers but potentially beneficial associations with virologic markers. Therefore, a question remains on whether caffeine is beneficial or detrimental to PLWH. The specific aim of this study was to investigate the immunological (CD4 cell counts) and virologic (HIV viral load) measures of disease progression in association with caffeine consumption in a group of PLWH on stable ART.

\section{METHODS}

\section{Study Design and Setting}

The present study recruited a convenience sample of 130 participants ( 65 consuming $\leq$ $250 \mathrm{mg} /$ day and 65 consuming > $250 \mathrm{mg} /$ day of caffeine) from the MASH cohort, which consisted of $803 \mathrm{HIV}$ positive and 78 uninfected participants, followed for more than 10 years at the FIU research clinic in the Borinquen Health Care Center (BHCC). The BHCC provides comprehensive range of health and social services to a culturally diverse low income community. The recruitment for the present study took place from February to July 2014. The present study included a baseline and 3-month follow-up visits, and 
participants received $\$ 5$ as partial reimbursement for their time and efforts, for each of the two visits. The initial screening included detailed explanation of the study as well as obtaining informed voluntary written consent for participation. In order to obtain a study sample of 128 participants as estimated in our sample size calculations, we screened a total of 150 subjects, enrolled 130 participants and excluded 20 ineligible participants. The present study also included secondary analysis of relevant variables collected for the MASH cohort studies. Data collected during the baseline and 3-month visits were used for the analyses of descriptive and inferential statistics. The inclusion and exclusion criteria for the MASH cohort are presented in "Chapter 3: Methodology” and applicable to our current study. The additional inclusion criteria for participants in the present study were: enrollment in the MASH cohort; receiving ART; and willingness to participate in a study with two visits, a baseline and one follow-up visit at 3 months. The exclusion criteria were: cardiovascular abnormalities or implanted pacemakers; morbid medical conditions such as uncontrolled hypertension, anemia, chronic inflammatory diseases or mal-absorption syndromes. The Institutional Review Board at Florida International University approved the study protocol and research procedures.

\section{Measures}

The questionnaires used in the present study were previously field tested and validated in several large scale studies. ${ }^{48-51}$ However, we pre-tested these questionnaires on 15 participants from the MASH cohort to ascertain their applicability and we determined that revisions were not necessary for the questionnaires. 
Caffeine consumption questionnaire: We used the Modified Caffeine Consumption Questionnaire (MCCQ) developed by Preston et al in the year $1998 .{ }^{52}$ This questionnaire is easy to understand, compact, organized and reports adequate compliance, validity and reliability. ${ }^{52}$ This questionnaire was field tested and validated in several large scale studies and adequately reflected average daily caffeine consumption levels. ${ }^{48}$ It includes a total of 21 sources of caffeine classified in to three groups, 'Beverages', 'Over the counter medications' and 'Prescription medications'. This questionnaire also included ‘Total caffeine consumption per day’ by adding these individual sources. Caffeine consumption was analyzed both as a continuous variable and a categorical variable.

For both naturally occurring and artificially added caffeine sources, FDA considers $400 \mathrm{mg} / \mathrm{d}$ to be generally safe and not associated with any dangerous side effects. ${ }^{53,54}$ The World Health Organization (WHO) defines caffeine overuse as daily consumption beyond $500 \mathrm{mg} / \mathrm{d} \cdot{ }^{55,56}$ Beyond this level caffeine produces visible adverse effects collectively known as ‘caffeinism'. The World Health Organization (WHO) has also cautioned that these adverse effects could be precipitated at much lower doses depending on the physiological profiles of individuals as well as the genetic makeup of the population..$^{55,56}$ The International Classification of Diseases (ICD) manual considers caffeine consumption above $250 \mathrm{mg} /$ day to be associated with many mental and behavioral disorders though it is inconclusive whether such effects would be uniformly applicable in the general population. ${ }^{13}$ The Diagnostic and Statistical Manual of Mental Disorders (DSM-5) considers consumption below $250 \mathrm{mg} /$ day to be generally safe and above this level to be associated with many adverse effects such as withdrawal, addiction, irritability and craving. ${ }^{57}$ Summarizing these cutoffs, we concluded that caffeine 
consumption below $250 \mathrm{mg} /$ day that is equivalent to 4 cups of coffee, irrespective of the sources is generally safe and not associated with adverse effects. In this study, caffeine categories included low ( $\leq 250 \mathrm{mg} /$ day, within safe levels) and high (>250 mg/day, beyond safe levels) based on these recommendations.

CD4 counts and viral load: The BHCC provides a variety of comprehensive health services for HIV/AIDS patients which include quarterly check-up visits, laboratory services, nutritional counseling and emergency services. Based on requests from their primary health care physicians or their HIV/ STD consultant at BHCC, CD4 counts, viral loads and other clinical variables are measured every six months for all PLWH. The MASH cohort studies collected and documented these reports after appropriate medical release forms were signed by the participants. The CD4 counts and viral loads were analyzed as both continuous and categorical variables using clinically meaningful cutoff points. In analyses where CD4 counts and viral load were considered as continuous variables, they were transformed into CD4 square root and $\log _{10} \mathrm{HIV}$ viral load to ensure normal distribution and better model fit criteria. In analysis where CD4 counts and HIV viral loads were considered as categorical variables both variables were divided into three groups with clinically meaningful cutoff points based on immunological and virologic stratification of HIV disease progression by the World Health Organization (WHO). ${ }^{58,59}$ CD4 cell counts were stratified as $>500$ cells $/ \mu \mathrm{L}, \leq 500$ and $>200$ cells $/ \mu \mathrm{L}$, and $\leq 200 \mu \mathrm{L}$ .${ }^{58,59} \mathrm{HIV}$ viral load was stratified as undetectable HIV viral load <21; between 21 and 9,999 copies/mL, considered moderately controlled HIV viral load; and >10,000 copies/mL, considered uncontrolled viral load, based on the clinical cutoffs recommended by the World Health Organization. ${ }^{50,51}$ 


\section{Control Variables}

Demographic and socioeconomic information: Demographic and socioeconomic information used in this study were collected by the MASH studies. Information used for the current study included age, gender, ethnicity, education and income levels. A number of health and lifestyle related factors such as tobacco use, alcohol consumption, and illicit drug use were also gathered from the MASH data repository. All these variables were adjusted in our analysis based on studies associating these variables with HIV disease progression. $^{26-28}$

Bio-impedance analysis (BIA): In the MASH cohort studies, after screening the participants, height was recorded immediately using a stadiometer, calibrated according to the instructions in user manual. Height was recorded to the nearest 0.5 inch after removing shoes, socks and other footwear. Height was recorded only once to ensure that it was uniform and there were no minor variations during every successive visit. Weight was measured every visit to the nearest $0.1 \mathrm{lbs}$. using a standard weighing machine which was calibrated and maintained throughout the study and the participants were requested to remove their watches, shoes, mobile phones or other heavy materials. The data so obtained along with age were entered into the bio-impedance machine (Biodynamics$450)^{60}$ to obtain body cell mass, extracellular mass, lean body mass (LBM), fat mass, body mass index (BMI) and intracellular and extracellular fluid levels. In addition we also obtained the waist-to-hip ratio using a non-stretchable tape to measure the waist and hip circumference at the narrowest levels of the waist and widest levels of the hip. While estimating the effects of caffeine on immunological and virologic markers of HIV disease progression, we adjusted for BMI and fat mass, based on studies associating these 
variables to better immunological and virologic profiles. ${ }^{45,61-63}$

ART medications: All participants enrolled in the study were on some form of ART. Information about different types of antiretroviral medications prescribed by their physicians was obtained during the MASH cohort visits. All analyses were adjusted for these variables because all antiretroviral medications have profound effects on markers of HIV disease progression.

\section{Statistical Analysis}

Field data were collected in paper based questionnaires and later entered into RedCap database, imported into SPSS version 21 for Windows (Armonk, NY: IBM Corp) and merged into a single dataset for analysis. Descriptive statistics were used to understand the population characteristics and were expressed in terms of means, standard deviations and percentages. The characteristics of the population were shown for all the participants and separated based on low and high intakes of caffeine using the cutoff points: $>250 \mathrm{mg} /$ day for high intake; and $\leq 250 \mathrm{mg} /$ day for low or no intake. T-tests and chi square tests were used to describe differences in demographics, health and lifestyle characteristics and CD4 and viral load categories with respect to low and high levels of caffeine consumption. Paired sample t-tests were used to measure differences in levels of caffeine consumption between baseline and the follow-up visit for major sources, as well as total levels of caffeine consumption. Linear regression was used to estimate the strength of association between caffeine consumption and markers of HIV disease progression, CD4 counts and viral load. Assumptions of linear regression were followed prior to analyses. Linear mixed models (LMM) were used to determine over time changes in the strength of these associations. For parameter estimation in LMM models, 
Restricted Maximum Likelihood (REML) was used. Multinomial logistic regressions were used to determine the associations between high and low caffeine intake groups with respect to different levels of disease progression (different categories of CD4 counts and viral load). For liner and logistic regressions, as well as linear mixed model analysis, we initially used crude models and subsequently adjusted for associated covariates already described in Methodology. These covariates were also tested for significant associations with the outcome variables using bivariate analysis before being incorporated into the models. To increase the validity of the models, multicollinearity among covariates was tested prior to the analyses. Adjusted models included non-missing values for all independent variables included in the models. Statistical significance was set at $P<0.05$ for all the analyses.

\section{RESULTS}

\section{Demographic and Socio-economic Characteristics}

A total of 130 participants were included in the study and 79 (60.8\%) were men. The mean age was $47.89 \pm$ SD 6.37 years. Most of the participants were African Americans (75.4\%), Hispanics constituted 16.9\%, Whites constituted 5.4\% and other races constituted 4.6 percent. About $24 \%$ of the participants had college education, while 45.4\% were high school graduates and 30.8\% had some form of primary education. All participants had incomes under the level of poverty and the mean income was $\$ 495.91 \pm$ 465.887. There were no significant differences in any socio-demographic variables between low and high levels of caffeine consumption in both baseline and follow-up visits (Table-1A, 1B). 


\section{Health/lifestyle Characteristics}

Sixty one percent of the participants reported smoking within the past six weeks of their scheduled baseline visits, $57.9 \%$ reported alcohol use and $48.2 \%$ tested positive for illicit drug use. Similarly, 63.2\% reported smoking, 60.3\% reported alcohol use and 65.8\% tested positive for illicit drug use during the follow-up visit.

All participants were on ART during both the visits. Antiretroviral therapy took many forms, $58.5 \%$ were on NRTI, $13.1 \%$ were on NNRTI and $47.7 \%$ were on PI in several combinations, $26.2 \%$ of the participants were using a one-pill multi-drug combination such as Atripla, Truvada and Combivir during the baseline visit. At the 3month visit, $63.8 \%$ were on NRTI, $13.8 \%$ were on NNRTI and $47.7 \%$ were on PI, and 25.4\% were on a one-pill multi-drug combination during the follow-up visit. There were no significant differences in the distribution of these variables between low and high levels of caffeine consumption in both baseline and follow-up visits (Tables 2 and 3).

\section{Caffeine Consumption}

Total caffeine consumption was $337.63 \pm 304.97 \mathrm{mg} /$ day at baseline (Range: 0 1,498 mg/day), and $281.04 \pm 260.85 \mathrm{mg} /$ day (Range: 0-1,175 mg/day) at the 3-months follow-up. Coffee constituted the largest source of caffeine and mean consumption levels were $161.26 \pm 194.95 \mathrm{mg} /$ day at baseline, and $190.40 \pm 205.03 \mathrm{mg} /$ day at follow-up. Caffeinated soft drinks constituted the second largest source of caffeine and mean consumption levels were $63.23 \pm 92.98 \mathrm{mg} /$ day at baseline, and $29.66 \pm 83.78 \mathrm{mg} / \mathrm{day}$ at follow-up. There were no significant differences between baseline and follow-up visits with respect to total caffeine consumption or caffeine from most of the sources. However, there was significant decrease in consumption of caffeinated soft drinks (63.23 \pm 92.98 
vs. $29.66 \pm 83.78, P<0.00001$ ), energy drinks (46.32 \pm 134.42 vs. $9.61 \pm 65.32, P=0.005$ )

and hot cocoa $(1.03 \pm 5.00$ vs. $0.00 \pm 0.00, P=0.020)$ from the baseline to the follow-up visits (Table-4). For all other sources of caffeine in the questionnaire, except the ones enlisted in Table 4, participants reported none to negligible levels of consumption at both the visits.

\section{Caffeine Consumption and Immunological And Virologic Markers of HIV Disease Progression}

Caffeine intake was significantly associated with CD4 cell count $(\beta=1.532$, $P=0.049)$ and $\log _{10}$ viral load $(\beta=-1.067, P=0.048)$ after adjusting for age, gender, race/ethnicity, education, income, and time from diagnosis of HIV, drug use, smoking status, alcohol use, different types of ART medications, BMI and total fat mass (Table-5). Linear mixed model analysis for the effect of caffeine intake on changes in parameters of HIV disease progression between the two study visits, showed higher CD4 cell count $(\beta=1.720, P=0.042)$ and lower $\log _{10} \mathrm{HIV}$ viral load $(\beta=-1.389, P=0.033)$ with increasing caffeine consumption, in a dose-response manner, after adjusting for the same covariates (Table-6).

Multinomial logistic regression showed that the odds of having CD4 counts < 200 cells $/ \mathrm{mm}^{3}$ were $69 \%$ higher in participants who consumed less than $250 \mathrm{mg}$ of caffeine per day when compared to participants who consumed greater than $250 \mathrm{mg}$, after adjusting for the same covariates (OR=1.690, 95\% CI: $1.123-3.879, P=0.047)$. Similarly the odds of having CD4 counts 200-499 cells $/ \mathrm{mm}^{3}$ were 53\% higher in participants who consumed less than 250 mg of caffeine per day when compared to participants who consumed greater than $250 \mathrm{mg}$, after adjusting for the same covariates (OR=1.537, 95\% 
CI: 0.522 -5.136, $P=0.198)$. The odds of presenting HIV viral loads greater than 10,000 copies of HIV viral RNA $/ \mathrm{mm}^{3}$ were $93 \%$ higher in in participants who consumed less than $250 \mathrm{mg}$ of caffeine per day when compared to participants who consumed greater than $250 \mathrm{mg}$ after adjusting for covariates (OR=1.933, 95\%CI: $1.254-6.192, P=0.048)$. However caffeine consumption did not affect the odds of presenting HIV viral loads 219,999 copies of HIV viral RNA/mm³ (OR=0.964, 95\%CI: $0.317-3.444, P=0.437$ ). To summarize, the participants who consumed less caffeine had lower CD4 and higher viral loads. All the significant odds continued overtime and retained significant when associations over the three month period were considered (Table 7, 8, 9 and 10).

\section{DISCUSSION}

The characteristics of our population were epidemiologically similar to those described by others in Miami-Dade County. ${ }^{64,65}$ More than half of the participants were consuming alcohol and smoking cigarettes, and 48.2\% used illicit drugs confirmed by urine toxicology, therefore, we adjusted for these variables in the analyses, to evaluate the independent effect of caffeine. The apparent beneficial effects of high consumption of caffeine on HIV disease progression was unexpected, although there is evidence from in-

vitro studies on caffeine decreasing the replication of the HIV virus in tissue cultures. ${ }^{31,32}$ In our study, only after adjusting for other relevant variables affecting HIV disease progression, caffeine consumption became significantly associated with both immunological and virologic markers of disease progression. This suggests a complex and moderate impact of caffeine on parameters of HIV disease progression. Our findings need to be confirmed by larger studies, as they could be incidental findings. Furthermore, there are very few studies that explore the relationship between caffeine and HIV disease 
progression, and there is lack of scientific consensus on this topic, probably due to the general acceptance of caffeine as a safe consumer product. ${ }^{53}$

A study conducted by Raboud et al. ${ }^{29}$ among clinically stable HIV-infected patients showed significant reductions in CD4 counts among caffeine consumers compared to non-consumers, after adjusting for age, gender, medications, presence of opportunistic infections (oral candidiasis) and potential measurement errors. However, this study had several limitations and differences from our study. The study was conducted before the advent of combined ART; caffeine consumption was considered a categorical variable with subjects either reporting or not reporting caffeine consumption; and the study had a small sample size of 30 participants, which limited its external validity. ${ }^{29}$ Because of these shortcomings, this study could have missed the beneficial effects of caffeine. Furthermore, the findings in our study could be more relevant because of the larger sample size and adjustments for several covariates that have significant confounding effects on immunological and virologic parameters.

Bishop et al., ${ }^{30}$ conducted a study in clinically stable PLWH to establish the effects of caffeine consumption and exercise on CD4 and CD8 cell counts. The participants were asked to abstain from consumption of caffeine for 60 hours prior to the experiment. Half of the subjects were administered $350 \mathrm{mg} /$ day of caffeine, while the remaining subjects were administered placebo. There was 54\% decrease in circulating CD4 cell counts and 55\% decrease in circulating CD8 cell counts post exercise in subjects administered caffeine compared to the placebo group, after adjusting for factors such as age, gender, BMI, lean body mass and fluid input and output levels. ${ }^{30}$ This study also reports that post exercise plasma catecholamine levels were significantly higher in those administered 
caffeine when compared to placebo. ${ }^{30}$ This study hypothesized that caffeine produced alterations in lymphocyte subset trafficking as well as expression of CD69 molecules which are important intermediate steps in generating and recruiting inflammatory cells. ${ }^{30}$ Through this process, caffeine decreased production and recruitment of inflammatory cells to the targeted areas of inflammation which included decreased circulating CD4 and CD8 cells. ${ }^{30}$ It is not clear whether these results were produced by caffeine itself or the stress hormones such as catecholamines that are associated with exercise and caffeine consumption. ${ }^{66-69}$

Our study found mostly beneficial effects of caffeine consumption. The beneficial findings in our study are supported by two in-vitro studies. The first in-vitro study showed that caffeine suppressed replication of infectious HIV-1 strains in cultures of human peripheral mononuclear cells. ${ }^{31}$ Caffeine in 100 millimolar concentrations exerted these effects by inhibiting the integration step of the HIV-1 viral replication cycle. This study also showed that other methyl-xanthines such as theophylline, theobromine, and paraxanthine, in 100 millimolar doses act through the same processes to inhibit HIV-1 replication. They observed a 9-fold reduction in HIV-1 p24 antigen values in samples treated with caffeine, theobromine, paraxanthine or theophylline when compared to control solutions. ${ }^{31}$ The second in-vitro study found that caffeine in concentrations of $10 \mu \mathrm{gm} /$ liter significantly inhibited retroviral transduction of dividing human Neuronal Precursor (hNT-2) cells thereby blocking post integration repair of HIV1 viral strains. These effects have been postulated to a cellular target- 'the ataxia telangiectasia-mutated and Rad3-related (ATR) kinase' ${ }^{32}$ Caffeine inhibits viral DNA repair at the DNA damage-activated checkpoints, thereby inhibiting viral replication 
cycle. $^{32}$ Our study observed an inverse association between caffeine consumption and viral load which might be ascribable to these mechanisms.

Nevertheless, we should also note that tissue culture studies and studies on human beings are not comparable. Many confounders associated with the lifestyle, dietary and other confounding factors could have influenced the findings in our study. Our sample size was also very limited due to the feasibility and constraints of the study settings. Large scale studies with controlled intake of nutrients and health and lifestyle factors and adequate sample size should be planned in the future to ascertain the findings in our study.

\section{Acknowledgements}

I would like to thank Dr. Marianna Baum for providing access to the MASH cohort data repository, as well as for the collaboration of her research group and my major professor Dr. Adriana Campa for the advice on the intellectual content of this manuscript. I am grateful for the support provided by Florida International University Graduate School, in the form of Data and Evidence Acquisition Fellowship and Doctoral Year Fellowship. Overall, I am very grateful to the FIU-Borinquen team, who collaborated enthusiastically with this project, and especially for the generosity of our participants who gave us their time and efforts. 
Table 1A: Baseline Demographic Characteristics of PLWH by Caffeine Consumption Levels

\begin{tabular}{|c|c|c|c|c|}
\hline \multirow[b]{2}{*}{ Variables } & \multicolumn{4}{|c|}{ Baseline } \\
\hline & Total & $\begin{array}{c}\text { Low } \\
\text { caffeine } \\
\text { intake } \\
(\leq 250 \\
\text { mg/d) }\end{array}$ & $\begin{array}{c}\text { High } \\
\text { caffeine } \\
\text { intake } \\
(>250 \\
\text { mg/d) }\end{array}$ & $P$-value \\
\hline $\begin{array}{l}\text { Age in years } \\
\text { (Mean } \pm \text { SD) }\end{array}$ & $47.89 \pm 6.37$ & $47.57 \pm 6.81$ & $48.00 \pm 6.15$ & 0.706 \\
\hline $\begin{array}{r}\text { Gender, N (\%) } \\
\text { Male } \\
\text { Female }\end{array}$ & $\begin{array}{l}79(60.8 \%) \\
51(39.2 \%)\end{array}$ & $\begin{array}{l}40 \text { (61.5\%) } \\
25 \text { (38.5\%) }\end{array}$ & $\begin{array}{l}39(60.0 \%) \\
26(40.0 \%)\end{array}$ & 0.857 \\
\hline $\begin{array}{r}\text { Ethnicity, } \mathrm{N}(\%) \\
\text { White } \\
\text { Hispanic } \\
\text { Black } \\
\text { Other } \\
\end{array}$ & $\begin{array}{l}7(5.4 \%) \\
22(16.9 \%) \\
98(75.4 \%) \\
3(2.3 \%) \\
\end{array}$ & $\begin{array}{l}3(4.6 \%) \\
7(10.8 \%) \\
55(84.6 \%) \\
0(0.0 \%) \\
\end{array}$ & $\begin{array}{l}4(6.2 \%) \\
15(23.1 \%) \\
43(66.2 \%) \\
3(4.6 \%) \\
\end{array}$ & 0.057 \\
\hline $\begin{array}{rr}\text { Education in } & \\
\text { years, N (\%) } & <12 \\
& 12 \\
& >12 \\
\end{array}$ & $\begin{array}{l}40(30.8 \%) \\
59(45.4 \%) \\
31(23.8 \%) \\
\end{array}$ & $\begin{array}{l}24(36.9 \%) \\
29(44.6 \%) \\
12(18.5 \%) \\
\end{array}$ & $\begin{array}{l}16(24.6 \%) \\
30(46.2 \%) \\
19(29.2 \%) \\
\end{array}$ & 0.202 \\
\hline $\begin{array}{l}\text { Income in dollars } \\
\text { per month }\end{array}$ & $\begin{array}{l}495.91 \pm \\
465.887\end{array}$ & $\begin{array}{l}464.00 \pm \\
419.667\end{array}$ & $\begin{array}{l}527.34 \pm \\
508.637\end{array}$ & 0.442 \\
\hline
\end{tabular}

Note: $P$-values corresponds to $\chi^{2}$ tests for categorical variables and t-test for continuous variables 
Table 1B: Follow-up Demographic Characteristics of PLWH by Caffeine Consumption Levels

\begin{tabular}{|c|c|c|c|c|}
\hline \multirow[b]{2}{*}{ Variables } & \multicolumn{4}{|c|}{ Follow-up } \\
\hline & Total & $\begin{array}{l}\text { Low } \\
\text { caffeine } \\
\text { intake } \\
(\leq 250 \\
\mathbf{m g} / \mathbf{d})\end{array}$ & $\begin{array}{c}\text { High } \\
\text { caffeine } \\
\text { intake } \\
(>250 \\
\text { mg/d) }\end{array}$ & $P$-value \\
\hline $\begin{array}{l}\text { Age in years } \\
\text { (Mean } \pm \text { SD) }\end{array}$ & $47.89 \pm 6.37$ & $46.63 \pm 7.33$ & $48.87 \pm 5.38$ & 0.490 \\
\hline $\begin{array}{r}\text { Gender, N (\%) } \\
\text { Male } \\
\text { Female }\end{array}$ & $\begin{array}{l}79(60.8 \%) \\
51(39.2 \%)\end{array}$ & $\begin{array}{l}43(68.3 \%) \\
20(31.7 \%)\end{array}$ & $\begin{array}{l}36(53.7 \%) \\
31(46.3 \%)\end{array}$ & 0.090 \\
\hline $\begin{array}{r}\text { Ethnicity, } \mathrm{N}(\%) \\
\text { White } \\
\text { Hispanic } \\
\text { Black } \\
\text { Other }\end{array}$ & $\begin{array}{l}7(5.4 \%) \\
22(16.9 \%) \\
98(75.4 \%) \\
3(2.3 \%)\end{array}$ & $\begin{array}{l}4(6.3 \%) \\
9(14.3 \%) \\
50(79.4 \%) \\
0(0.0 \%)\end{array}$ & $\begin{array}{l}3(4.5 \%) \\
13(19.4 \%) \\
48(71.6 \%) \\
3(4.6 \%)\end{array}$ & 0.285 \\
\hline $\begin{array}{l}\text { Education in } \\
\text { years, } \mathrm{N}(\%) \\
\\
<12 \\
12 \\
>12 \\
\end{array}$ & $\begin{array}{l}40(30.8 \%) \\
59(45.4 \%) \\
31(23.8 \%)\end{array}$ & $\begin{array}{l}21(33.3 \%) \\
29(46.0 \%) \\
13(20.6 \%)\end{array}$ & $\begin{array}{l}19(28.4 \%) \\
30(44.8 \%) \\
18(26.9 \%)\end{array}$ & 0.670 \\
\hline $\begin{array}{l}\text { Income in dollars } \\
\text { per month }\end{array}$ & $\begin{array}{l}495.91 \pm \\
465.887\end{array}$ & $\begin{array}{l}498.80 \pm \\
511.708\end{array}$ & $\begin{array}{l}492.89 \pm \\
416.619\end{array}$ & 0.943 \\
\hline
\end{tabular}

Note: $P$-values corresponds to $\chi^{2}$ tests for categorical variables and t-test for continuous variables 
Table 2: Baseline Health and Lifestyle Characteristics of PLWH by Caffeine Consumption Levels

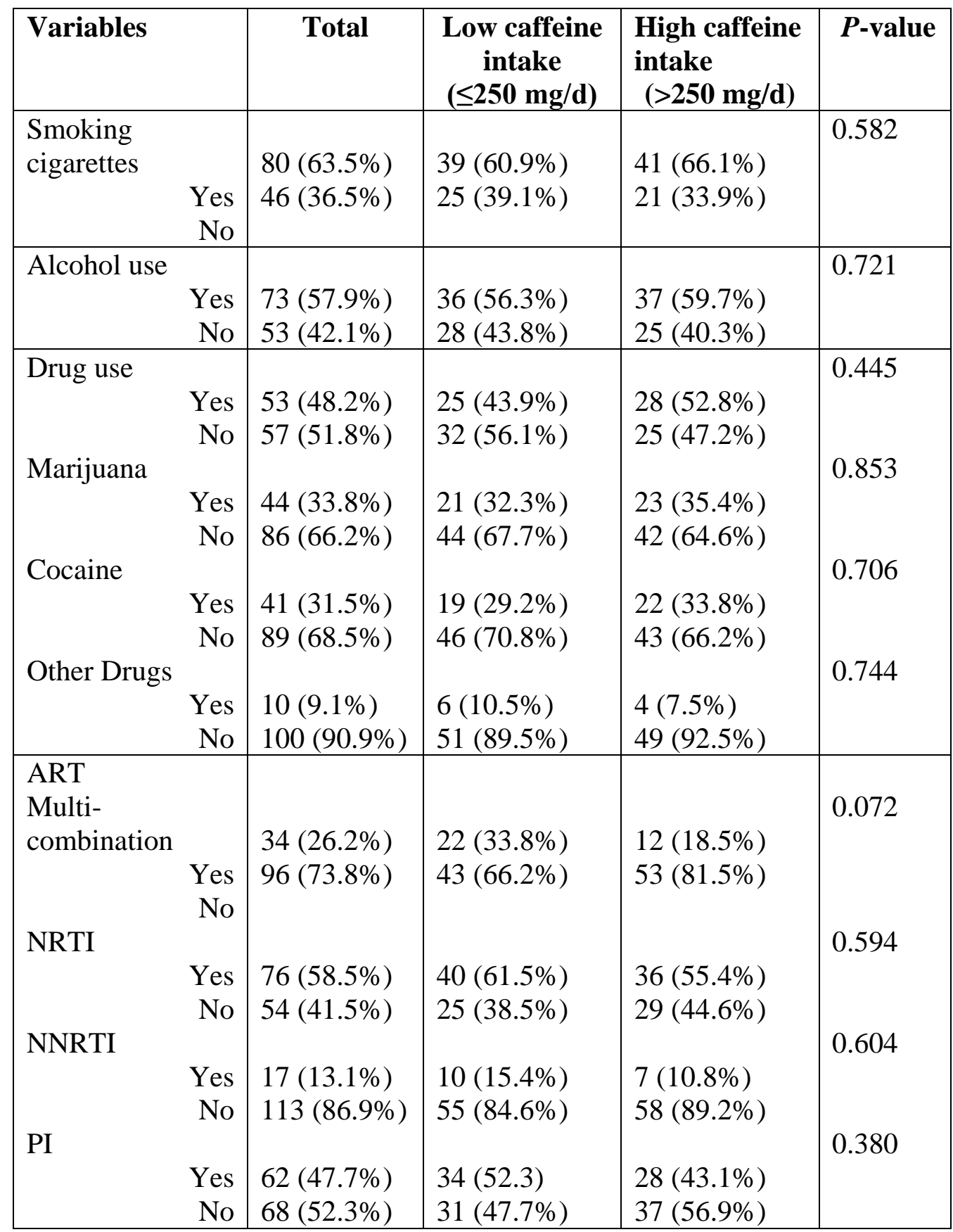

All variables reported as $\mathrm{N}(\%)$

Note: $P$-values correspond to $\chi^{2}$ tests for all variables

ART: Antiretroviral therapy. 
Table 3: Follow-up Health and Lifestyle Characteristics of PLWH by Caffeine Consumption Levels

\begin{tabular}{|c|c|c|c|c|}
\hline Variables & Total & $\begin{array}{l}\text { Low caffeine } \\
\text { intake } \\
(\leq 250 \mathrm{mg} / \mathrm{d})\end{array}$ & $\begin{array}{c}\text { High caffeine } \\
\text { intake } \\
(>250 \mathrm{mg} / \mathrm{d})\end{array}$ & $\begin{array}{c}P \text { - } \\
\text { value }\end{array}$ \\
\hline $\begin{array}{lr}\text { Smoking } & \\
\text { cigarettes } & \\
& \text { Yes } \\
& \text { No }\end{array}$ & $\begin{array}{l}79(63.2 \%) \\
46(36.8 \%)\end{array}$ & $\begin{array}{l}41(68.3 \%) \\
19(31.7 \%)\end{array}$ & $\begin{array}{l}38(58.5 \%) \\
27(41.5 \%)\end{array}$ & 0.271 \\
\hline $\begin{array}{r}\text { Alcohol use } \\
\text { Yes } \\
\text { No }\end{array}$ & $\begin{array}{l}76(60.3 \%) \\
50(39.7 \%)\end{array}$ & $\begin{array}{l}34(56.7 \%) \\
26(43.3 \%)\end{array}$ & $\begin{array}{l}42(63.6 \%) \\
24(36.4 \%)\end{array}$ & 0.469 \\
\hline $\begin{array}{rr}\text { Drug use } & \\
& \text { Yes } \\
& \text { No } \\
\end{array}$ & $\begin{array}{l}79(65.8 \%) \\
41(34.2 \%)\end{array}$ & $\begin{array}{l}45(75.0 \%) \\
15(25.0 \%)\end{array}$ & $\begin{array}{l}34(56.7 \%) \\
26(43.3 \%)\end{array}$ & 0.054 \\
\hline $\begin{array}{lr}\text { Marijuana } & \\
& \text { Yes } \\
\text { Nocaine } & \\
& \text { Yes } \\
\text { No } & \\
\text { Other drugs } & \text { Yes } \\
\text { No }\end{array}$ & $\begin{array}{l}67(55.8 \%) \\
53(44.2 \%) \\
48(40.0 \%) \\
72(60.0 \%) \\
13(10.9 \%) \\
106(89.1 \%)\end{array}$ & $\begin{array}{l}38(63.3 \%) \\
22(36.7 \%) \\
29(48.3 \%) \\
31(51.7 \%) \\
6(10.0 \%) \\
54(90.0 \%)\end{array}$ & $\begin{array}{l}29(48.3 \%) \\
31(51.7 \%) \\
19(31.7 \%) \\
41(68.3 \%) \\
7(11.9 \%) \\
52(88.1 \%)\end{array}$ & $\begin{array}{l}0.141 \\
0.093\end{array}$ \\
\hline $\begin{array}{l}\text { ART } \\
\text { Multi- } \\
\text { combination } \\
\\
\quad \text { Yes } \\
\\
\text { No }\end{array}$ & $\begin{array}{l}33(25.4 \%) \\
97(74.6 \%)\end{array}$ & $\begin{array}{l}20(31.7 \%) \\
43(68.3 \%)\end{array}$ & $\begin{array}{l}13(19.4 \%) \\
54(80.6 \%)\end{array}$ & 0.113 \\
\hline $\begin{array}{ll}\text { NRTI } & \\
& \text { Yes } \\
& \text { No }\end{array}$ & $\begin{array}{l}83(63.8 \%) \\
47(36.2 \%)\end{array}$ & $\begin{array}{l}40(63.5 \%) \\
23(36.5 \%)\end{array}$ & $\begin{array}{l}43(64.2 \%) \\
24(35.8 \%)\end{array}$ & 1.000 \\
\hline $\begin{array}{l}\text { Yes } \\
\text { No } \\
\text { Yes } \\
\text { No }\end{array}$ & $\begin{array}{l}18(13.8 \%) \\
112(86.2 \%) \\
62(47.7 \%) \\
68(52.3 \%)\end{array}$ & $\begin{array}{l}9(14.3 \%) \\
54(85.7 \%) \\
28(44.4 \%) \\
35(55.6 \%)\end{array}$ & $\begin{array}{l}9(13.4 \%) \\
58(86.6 \%) \\
34(50.7 \%) \\
33(49.3 \%)\end{array}$ & 0.488 \\
\hline
\end{tabular}

All variables reported as $\mathrm{N}(\%)$

Note: $P$-values correspond to $\chi^{2}$ tests all variables.

ART: Antiretroviral therapy. 
Table 4: Mean Caffeine Intake: Baseline and Follow-up Visit

\begin{tabular}{|l|l|l|l|}
\hline Food source & \multicolumn{1}{|c|}{ Baseline } & \multicolumn{1}{c|}{ Follow-up } & \multicolumn{1}{c|}{ P-value } \\
\hline Coffee & $161.26 \pm 194.95$ & $190.40 \pm 205.03$ & 0.206 \\
\hline $\begin{array}{l}\text { De-Caffeinated } \\
\text { coffee }\end{array}$ & $0.83 \pm 9.21$ & $0.03 \pm 0.43$ & 0.329 \\
\hline Expresso & $14.40 \pm 64.35$ & $13.92 \pm 57.82$ & 0.942 \\
\hline Tea & $34.70 \pm 64.32$ & $31.58 \pm 59.36$ & 0.640 \\
\hline Green tea & $7.34 \pm 62.93$ & $4.20 \pm 21.62$ & 0.594 \\
\hline Energy drinks & $46.32 \pm 134.42$ & $9.61 \pm 65.32$ & $0.005^{*}$ \\
\hline Hot cocoa & $1.03 \pm 5.00$ & $0.00 \pm 0.00$ & $0.020^{*}$ \\
\hline $\begin{array}{l}\text { Caffeinated soft } \\
\text { drinks }\end{array}$ & $63.23 \pm 92.98$ & $29.66 \pm 83.78$ & $<0.0001^{*}$ \\
\hline $\begin{array}{l}\text { Chocolate candy } \\
\text { bars }\end{array}$ & $3.69 \pm 13.81$ & $2.00 \pm 17.93$ & 0.402 \\
\hline Anacin & $0.24 \pm 2.80$ & $0.00 \pm 0.00$ & 0.319 \\
\hline $\begin{array}{l}\text { Appetite control } \\
\text { pills }\end{array}$ & $4.61 \pm 39.10$ & $0.00 \pm 0.00$ & 0.181 \\
\hline Total & $337.63 \pm 304.97$ & $281.04 \pm 260.85$ & 0.890 \\
\hline
\end{tabular}

All variables reported as mean $\pm \mathrm{SD}$

Note: $P$-values correspond to t-tests for all variables

*Significant

Table 5: Linear Regression of the Effect of Caffeine Consumption on Immunological and Virologic Markers of Disease Progression

\begin{tabular}{|c|c|c|c|c|c|c|}
\hline Disease & \multicolumn{3}{|c|}{ Unadjusted } & \multicolumn{3}{|c|}{ Adjusted $^{\dagger}$} \\
\hline & Beta & SE & $P$-value & Beta & SE & $P$-value \\
\hline CD4 square root $^{a}$ & 1.215 & 0.099 & 0.465 & 1.532 & 0.241 & 0.049* \\
\hline $\log _{10}$ Viral load ${ }^{b}$ & -1.023 & 0.043 & 0.588 & -1.067 & 0.081 & $0.048 *$ \\
\hline
\end{tabular}

${ }^{a}$ Model $\mathrm{R}^{2}=0.135, \mathrm{~F}(17)=15.313, P=.047$.

${ }^{\mathrm{b}}$ Model $\mathrm{R}^{2}=0.174, \mathrm{~F}(17)=16.379, P=.047$.

${ }^{\dagger}$ Model adjusted for age, income, race/ethnicity, time from diagnosis of HIV, drug use, alcohol consumption, smoking status, BMI, total body fat percentage.

*Significant 
Table 6: Linear Mixed Model Analysis of Overtime Changes in the Effects of Caffeine Consumption on Immunological and Virologic Markers of Disease Progression

\begin{tabular}{|c|c|c|c|c|c|c|}
\hline Disease progression & \multicolumn{3}{|c|}{ Unadjusted } & \multicolumn{3}{|c|}{ Adjusted $^{\dagger}$} \\
\hline & Beta & SE & $P$-value & Beta & SE & $P$-value \\
\hline CD4 square root ${ }^{a}$ & 0.900 & 0.3011 & 0.402 & 1.720 & 0.901 & $0.042 *$ \\
\hline $\log _{10}$ Viral load ${ }^{b}$ & -0.9774 & 0.8002 & 0.777 & -1.389 & 0.786 & $0.033 *$ \\
\hline
\end{tabular}

a'Model: -2 Restricted Log Likelihood = 1055.823; Akaike's Information Criteria (AIC) = 1059.823; Schwarz’s Bayesian Criteria $(\mathrm{BIC})=1065.910$.

bModel: -2 Restricted Log Likelihood = 2597.274; Akaike's Information Criteria (AIC) = 2601.274; Schwarz’s Bayesian Criteria $(\mathrm{BIC})=2607.36$.

${ }^{\dagger}$ Model adjusted for age, income, race/ethnicity, time from diagnosis of HIV, drug use, alcohol consumption, smoking status, BMI, total body fat percentage.

*Significant

Table 7: Baseline: CD4 count and Viral Load Categories by Levels of Caffeine Consumption $\dagger$

\begin{tabular}{|c|c|c|c|c|}
\hline Variables & Total & $\begin{array}{l}\text { Low caffeine } \\
\text { intake } \\
(\leq 250 \mathrm{mg} / \mathrm{d})\end{array}$ & $\begin{array}{c}\text { High caffeine } \\
\text { intake } \\
(>250 \mathrm{mg} / \mathrm{d})\end{array}$ & $P$-value \\
\hline $\begin{array}{r}\text { CD4 count } \\
\leq 199^{\mathrm{a}} \\
200-499^{\mathrm{b}} \\
\geq 500^{\mathrm{c}}\end{array}$ & $\begin{array}{l}15(13.0 \%) \\
53(46.1 \%) \\
47(40.9 \%)\end{array}$ & $\begin{array}{l}8(13.8 \%) \\
25(43.1 \%) \\
25(43.1 \%)\end{array}$ & $\begin{array}{l}7(12.3 \%) \\
28(49.1 \%) \\
22(38.6 \%)\end{array}$ & 0.811 \\
\hline $\begin{array}{r}\text { HIV viral load } \\
\leq 21^{\mathrm{c}} \\
21-9999^{\mathrm{b}} \\
\geq 10000^{\mathrm{a}}\end{array}$ & $\begin{array}{l}32(28.6 \%) \\
55(49.1 \%) \\
25(22.3 \%)\end{array}$ & $\begin{array}{l}16(28.6 \%) \\
27(50.0 \%) \\
13(21.4 \%)\end{array}$ & $\begin{array}{l}16(28.6 \%) \\
28(50.0 \%) \\
12(21.4 \%)\end{array}$ & 0.971 \\
\hline
\end{tabular}

All variables reported as $\mathrm{N}(\%)$

Note: $P$-values correspond to $\chi^{2}$ tests for all variables.

${ }^{a}$ Inadequate control over disease progression

${ }^{\mathrm{b}}$ Moderate control over disease progression

${ }^{\mathrm{c}}$ Adequate control over disease progression

†World Health Organization. Who Case Definitions of HIV for Surveillance and Revised Clinical Staging and Immunological Classification of HIV-Related Disease in Adults and Children. 2007; http://www.who.int/hiv/pub/guidelines/WHO\%20HIV\%20Staging.pdf. Accessed September 30, 2014. 
Table 8: Follow-up CD4 count and Viral Load Categories by Levels of Caffeine Consumption $\dagger$

\begin{tabular}{|c|c|c|c|c|}
\hline Variables & Total & $\begin{array}{l}\text { Low caffeine } \\
\text { intake } \\
(\leq 250 \mathrm{mg} / \mathrm{d})\end{array}$ & $\begin{array}{c}\text { High caffeine } \\
\text { intake } \\
(>250 \mathrm{mg} / \mathrm{d})\end{array}$ & $P$-value \\
\hline $\begin{array}{r}\text { CD4 count }^{43,44} \\
\leq 199^{\mathrm{a}} \\
200-499^{\mathrm{b}} \\
\geq 500^{\mathrm{c}}\end{array}$ & $\begin{array}{l}17(15.5 \%) \\
41(37.3 \%) \\
52(47.3 \%)\end{array}$ & $\begin{array}{l}6(11.1 \%) \\
27(50.0 \%) \\
21(38.9 \%)\end{array}$ & $\begin{array}{l}11(19.6 \%) \\
14(25.0 \%) \\
31(55.4 \%)\end{array}$ & $0.024 *$ \\
\hline $\begin{array}{l}\text { HIV viral } \\
\text { load }^{43,44} \leq 21^{\mathrm{c}} \\
21-9999^{\mathrm{b}} \\
\geq 10000^{\mathrm{a}}\end{array}$ & $\begin{array}{l}34(31.5 \%) \\
50(46.3 \%) \\
24(22.2 \%)\end{array}$ & $\begin{array}{l}18(34.0 \%) \\
22(41.5 \%) \\
13(24.5 \%)\end{array}$ & $\begin{array}{l}16(29.1 \%) \\
28(50.9 \%) \\
11(20.0 \%)\end{array}$ & 0.616 \\
\hline
\end{tabular}

All variables reported as $\mathrm{N}(\%)$

Note: $P$-values correspond to $\chi^{2}$ tests for all variables.

${ }^{a}$ Inadequate control over disease progression

${ }^{\mathrm{b}}$ Moderate control over disease progression

${ }^{\mathrm{c}}$ Adequate control over disease progression

*Significant

†World Health Organization. Who Case Definitions of HIV for Surveillance and Revised Clinical Staging and Immunological Classification of HIV-Related Disease in Adults and Children. 2007; http://www.who.int/hiv/pub/guidelines/WHO\%20HIV\%20Staging.pdf. Accessed September 30, 2014. 
Table 9: Baseline Multinomial Logistic Regression of the Effect of Caffeine Consumption Levels on CD4 and Viral Load Categorical Levels

\begin{tabular}{|c|c|c|c|c|c|c|}
\hline & \multicolumn{3}{|c|}{ Unadjusted } & \multicolumn{3}{|c|}{ Adjusted $^{\dagger}$} \\
\hline & OR & $95 \% \mathrm{CI}$ & $\begin{array}{c}P \text { - } \\
\text { value }\end{array}$ & OR & $95 \% \mathrm{CI}$ & $\begin{array}{c}P \text { - } \\
\text { value }\end{array}$ \\
\hline $\begin{array}{l}\text { Caffeine } \\
\text { intake }\end{array}$ & \multicolumn{6}{|c|}{ CD4 count $>500$ versus $\leq 199$ (High risk for disease progression) } \\
\hline $\begin{array}{l}\text { High } \\
\text { Low }\end{array}$ & $\begin{array}{c}\text { Ref } \\
0.994\end{array}$ & $\begin{array}{c}\text { Ref } \\
(0.310-3.188)\end{array}$ & 0.992 & $\begin{array}{c}\text { Ref } \\
1.690\end{array}$ & $\begin{array}{c}\text { Ref } \\
(1.123-3.879)\end{array}$ & $0.047 *$ \\
\hline & \multicolumn{6}{|c|}{$\begin{array}{l}\text { CD4 count }>500 \text { versus } 200-499 \text { (Moderate risk for disease } \\
\text { progression) }\end{array}$} \\
\hline $\begin{array}{l}\text { High } \\
\text { Low }\end{array}$ & $\begin{array}{l}\text { Ref } \\
1.237\end{array}$ & $\begin{array}{c}\text { Ref } \\
(0.579-2.795)\end{array}$ & 0.548 & $\begin{array}{c}\text { Ref } \\
1.537\end{array}$ & $\begin{array}{c}\text { Ref } \\
(0.522-5.136)\end{array}$ & 0.198 \\
\hline & \multicolumn{6}{|c|}{$\begin{array}{l}\text { HIV viral load } \leq 21 \text { and } 21-9999 \text { (Moderate risk for disease } \\
\text { progression) }\end{array}$} \\
\hline $\begin{array}{l}\text { High } \\
\text { Low }\end{array}$ & $\begin{array}{c}\text { Ref } \\
0.874\end{array}$ & $\begin{array}{c}\text { Ref } \\
(0.367-2.079)\end{array}$ & 0.761 & $\begin{array}{c}\text { Ref } \\
0.964\end{array}$ & $\begin{array}{c}\text { Ref } \\
(0.317-3.444)\end{array}$ & 0.437 \\
\hline & \multicolumn{6}{|c|}{ HIV viral load $\leq 21$ and $\geq \mathbf{1 0 0 0 0}$ (High risk for disease progression) } \\
\hline $\begin{array}{l}\text { High } \\
\text { Low }\end{array}$ & $\begin{array}{c}\text { Ref } \\
0.857\end{array}$ & $\begin{array}{c}\text { Ref } \\
(0.332-2.214)\end{array}$ & 0.750 & $\begin{array}{c}\text { Ref } \\
1.933 \\
\end{array}$ & $\begin{array}{c}\text { Ref } \\
(1.254-6.192) \\
\end{array}$ & $0.048 *$ \\
\hline
\end{tabular}

$\mathrm{R}^{2}=0.213$ (Cox and Snell), 0.219 (Nagelkerke). $\chi^{2}(36)=47.638, P=0.029$

${ }^{\dagger}$ Model adjusted for age, income, race/ethnicity, time from diagnosis of HIV, drug use, alcohol consumption, smoking status, BMI, total body fat percentage.

*Significant 
Table 10: Overtime Multinomial Logistic Regression of the Effect of Caffeine Consumption Levels on CD4 and Viral Load Categorical Levels

\begin{tabular}{|c|c|c|c|c|c|c|}
\hline & \multicolumn{3}{|c|}{ Unadjusted } & \multicolumn{3}{|c|}{ Adjusted $^{\dagger}$} \\
\hline $\begin{array}{l}\text { Caffein } \\
\text { e intake }\end{array}$ & OR & $95 \% \mathrm{CI}$ & $\begin{array}{c}P- \\
\text { value }\end{array}$ & $\overline{\text { OR }}$ & $95 \% \mathrm{CI}$ & $\begin{array}{c}P \text { - } \\
\text { value }\end{array}$ \\
\hline & \multicolumn{6}{|c|}{ CD4 count $>500$ versus $\leq 199$ (High risk for disease progression) } \\
\hline $\begin{array}{l}\text { High } \\
\text { Low }\end{array}$ & $\begin{array}{c}\text { Ref } \\
1.242\end{array}$ & $\begin{array}{c}\text { Ref } \\
(0.398-3.878)\end{array}$ & 0.709 & $\begin{array}{c}\text { Ref } \\
1.876\end{array}$ & $\begin{array}{c}\text { Ref } \\
(1.216-8.763)\end{array}$ & $0.047 *$ \\
\hline & \multicolumn{6}{|c|}{$\begin{array}{l}\text { CD4 count }>500 \text { versus 200-499 (Moderate risk for disease } \\
\text { progression) }\end{array}$} \\
\hline $\begin{array}{l}\text { High } \\
\text { Low }\end{array}$ & $\begin{array}{c}\text { Ref } \\
0.351\end{array}$ & $\begin{array}{c}\text { Ref } \\
(0.150-1.822)\end{array}$ & 0.159 & $\begin{array}{c}\text { Ref } \\
1.375\end{array}$ & $\begin{array}{c}\text { Ref } \\
(0.094-2.500)\end{array}$ & 0.066 \\
\hline & \multicolumn{6}{|c|}{$\begin{array}{l}\text { HIV viral load } \leq 21 \text { and 21-9999 (Moderate risk for disease } \\
\text { progression) }\end{array}$} \\
\hline $\begin{array}{l}\text { High } \\
\text { Low }\end{array}$ & $\begin{array}{c}\text { Ref } \\
1.057\end{array}$ & $\begin{array}{c}\text { Ref } \\
(0.772-4.470)\end{array}$ & 0.167 & $\begin{array}{c}\text { Ref } \\
1.186\end{array}$ & $\begin{array}{c}\text { Ref } \\
(0.288-4.878)\end{array}$ & 0.113 \\
\hline & \multicolumn{6}{|c|}{ HIV viral load $\leq 21$ and $\geq 10000$ (High risk for disease progression) } \\
\hline $\begin{array}{l}\text { High } \\
\text { Low }\end{array}$ & $\begin{array}{c}\text { Ref } \\
1.300\end{array}$ & $\begin{array}{c}\text { Ref } \\
(0.274-5.674)\end{array}$ & 0.900 & $\begin{array}{c}\text { Ref } \\
1.863\end{array}$ & $\begin{array}{c}\text { Ref } \\
(1.217-7.894)\end{array}$ & $0.048 *$ \\
\hline
\end{tabular}

$\mathrm{R}^{2}=0.216$ (Cox and Snell), 0.215 (Nagelkerke). $\chi^{2}(36)=45.478, P=0.020$

${ }^{\dagger}$ Model adjusted for age, income, race/ethnicity, time from diagnosis of HIV, drug use, alcohol consumption, smoking status, BMI, total body fat percentage.

*Significant 


\section{References}

1. Beyrer C, Karim QA. The changing epidemiology of HIV in 2013. Current Opinion in HIV and AIDS. 2013;8(4):306-310.

2. CDC. HIV/AIDS Fact Sheet.

2014; http://www.cdc.gov/hiv/statistics/basics/ataglance.html. Accessed December 12, 2014.

3. Care Resources. HIV/AIDS Fact sheet.

2014; http://www.careresource.org/hivaids/statistics/. Accessed December 25, 2014.

4. $\quad$ Federal Department of Health.

2013; http://miamidade.floridahealth.gov/downloads/2013-12.pdf. Accessed September 14, 2014.

5. Florida Department of Health. HIV Disease: United States vs Florida. 2014; http://www.floridahealth.gov/diseases-andconditions/aids/surveillance/_documents/fact-sheet/2014/2014-us-vs-fl-factsheet.pdf. Accessed December 20, 2014.

6. May M, Boulle A, Phiri S, et al. Prognosis of patients with HIV-1 infection starting antiretroviral therapy in sub-Saharan Africa: a collaborative analysis of scale-up programmes. The Lancet. 2010;376(9739):449-457.

7. Walensky RP, Paltiel AD, Losina E, et al. The survival benefits of AIDS treatment in the United States. Journal of Infectious Diseases. 2006;194(1):11-19.

8. Graham N, Zeger S, Park L, et al. Effect of zidovudine and Pneumocystis carinii pneumonia prophylaxis on progression of HIV-1 infection to AIDS. The Multicenter AIDS Cohort Study. Lancet. 1991;338(8762):265-269.

9. Karakousis PC, Moore RD, Chaisson RE. Mycobacterium avium complex in patients with HIV infection in the era of highly active antiretroviral therapy. The Lancet Infectious Diseases. 2004;4(9):557-565.

10. Moore RD, Chaisson RE. Natural history of opportunistic disease in an HIVinfected urban clinical cohort. Annals of Internal Medicine. 1996;124(7):633-642.

11. Hammer SM, Squires KE, Hughes MD, et al. A controlled trial of two nucleoside analogues plus indinavir in persons with human immunodeficiency virus infection and CD4 cell counts of 200 per cubic millimeter or less. New England Journal of Medicine. 1997;337(11):725-733. 
12. Gulick RM, Mellors JW, Havlir D, et al. Treatment with indinavir, zidovudine, and lamivudine in adults with human immunodeficiency virus infection and prior antiretroviral therapy. New England Journal of Medicine. 1997;337(11):734-739.

13. Infection PoCPfToH. Guidelines for the use of antiretroviral agents in HIVinfected adults and adolescents, January 28, 2000. HIV Clinical Trials. 2015.

14. Hawkins T. Understanding and managing the adverse effects of antiretroviral therapy. Antiviral Research. 2010;85(1):201-209.

15. Montagnier L. 25 years after HIV discovery: prospects for cure and vaccine. Virology. 2010;397(2):248-254.

16. Passaes CP, Sáez-Cirión A. HIV cure research: Advances and prospects. Virology. 2014;454:340-352.

17. Metsch LR, Pereyra M, Brewer TH. Use of HIV health care in HIV-seropositive crack cocaine smokers and other active drug users. Journal of Substance Abuse. 2001;13(1):155-167.

18. Page JB, Chitwood DD, Smith PC, Kane N, McBride DC. Intravenous drug use and HIV infection in Miami. Medical Anthropology Quarterly. 1990;4(1):56-71.

19. Fernández MI, Bowen GS, Varga LM, et al. High rates of club drug use and risky sexual practices among Hispanic men who have sex with men in Miami, Florida. Substance Use \& Misuse. 2005;40(9-10):1347-1362.

20. Brewer TH, Metsch LR, Zenilman JM. Use of a public sexually transmitted disease clinic by known HIV-positive adults: decreased self-reported risk behavior and increased disease incidence. Journal of Acquired Immune Deficiency Syndromes (1999). 2002;29(3):289-294.

21. Brooks R, Rotheram-Borus MJ, Bing EG, Ayala G, Henry CL. HIV and AIDS among men of color who have sex with men and men of color who have sex with men and women: an epidemiological profile. AIDS Education and Prevention. 2003;15(1 Supplement):1-6.

22. Rukmana D. Comparing the residential origins of homeless families and homeless individuals in Miami-Dade County, Florida. Area. 2011;43(1):96-109.

23. Hatsu I, Huffman F, Johnson P, Baum M, Thomlison B, Campa A. Association of Supplemental Nutrition Assistance Program (SNAP) with food security and nutrition status among persons living with HIV. European Journal of Nutrition and Food Safety. 2015;5(4):229-241. 
24. Weiser SD, Fernandes KA, Brandson EK, et al. The association between food insecurity and mortality among HIV-infected individuals on HAART. Journal of Acquired Immune Deficiency Syndromes. 2009;52(3):342.

25. Wang EA, McGinnis KA, Fiellin DA, et al. Food insecurity is associated with poor virologic response among HIV-infected patients receiving antiretroviral medications. Journal of General Internal Medicine. 2011;26(9):1012-1018.

26. Schneider M, Chersich M, Neuman M, Parry C. Alcohol consumption and HIV/AIDS: the neglected interface. Addiction. 2012;107(8):1369-1371.

27. Darke S, Swift W, Hall W, Ross M. Drug use, HIV risk-taking and psychosocial correlates of benzodiazepine use among methadone maintenance clients. Drug and Alcohol Dependence. 1993;34(1):67-70.

28. Nieman RB, Fleming J, Coker RJ, Harris JW, Mitchell DM. The effect of cigarette smoking on the development of AIDS in HIV-1-seropositive individuals. Aids. 1993;7(5):705-710.

29. Raboud J, Haley L, Montaner J, Murphy C, Januszewska M, Schechter M. Quantification of the variation due to laboratory and physiologic sources in CD4 lymphocyte counts of clinically stable HIV-infected individuals. Journal of Acquired Immune Deficiency Syndromes and Human Retrovirology. 1995;10:S67.

30. Bishop NC, Fitzgerald C, Porter PJ, Scanlon GA, Smith AC. Effect of caffeine ingestion on lymphocyte counts and subset activation in vivo following strenuous cycling. European Journal of Applied Physiology. 2005;93(5-6):606-613.

31. Nunnari G, Argyris E, Fang J, Mehlman KE, Pomerantz RJ, Daniel R. Inhibition of HIV-1 replication by caffeine and caffeine-related methylxanthines. Virology. 2005;335(2):177-184.

32. Daniel R, Marusich E, Argyris E, Zhao RY, Skalka AM, Pomerantz RJ. Caffeine inhibits human immunodeficiency virus type 1 transduction of nondividing cells. Journal of Virology. 2005;79(4):2058-2065.

33. Dreher HM. The effect of caffeine reduction on sleep quality and well-being in persons with HIV. Journal of Psychosomatic Research. 2003;54(3):191-198.

34. Nokes KM, Kendrew J. Sleep quality in people with HIV disease. Journal of the Association of Nurses in AIDS Care. 1996;7(3):43-50.

35. Nardi AE, Lopes FL, Freire RC, et al. Panic disorder and social anxiety disorder subtypes in a caffeine challenge test. Psychiatry Research. 2009;169(2):149-153. 
36. Hedges DW, Woon FL, Hoopes SP. Caffeine-induced psychosis. CNS Spectr. 2009;14(3):127-129.

37. Lee BL, Wong D, Benowitz NL, Sullam PM. Altered patterns of drug metabolism in patients with acquired immunodeficiency syndrome. Clinical Pharmacology \& Therapeutics. 1993;53(5):529-535.

38. Baum MK, Shor-Posner G, Campa A. Zinc status in human immunodeficiency virus infection. The Journal of Nutrition. 2000;130(5):1421S-1423S.

39. Taylor EW. The oxidative stress-induced niacin sink (OSINS) model for HIV pathogenesis. Toxicology. 2010;278(1):124-130.

40. Geleijnse JM. Habitual coffee consumption and blood pressure: an epidemiological perspective. Vascular Health and Risk Management. 2008;4(5):963.

41. Maughan R, Griffin J. Caffeine ingestion and fluid balance: a review. Journal of Human Nutrition and Dietetics. 2003;16(6):411-420.

42. Zampelas A, Panagiotakos DB, Pitsavos C, Chrysohoou C, Stefanadis C. Associations between coffee consumption and inflammatory markers in healthy persons: the ATTICA study. The American Journal of Clinical Nutrition. 2004;80(4):862-867.

43. Balk L, Hoekstra T, Twisk J. Relationship between long-term coffee consumption and components of the metabolic syndrome: the Amsterdam Growth and Health Longitudinal Study. European Journal of Epidemiology. 2009;24(4):203-209.

44. Greenberg J, Axen K, Schnoll R, Boozer C. Coffee, tea and diabetes: the role of weight loss and caffeine. International Journal of Obesity. 2005;29(9):1121-1129.

45. Jones CY, Hogan JW, Snyder B, et al. Overweight and human immunodeficiency virus (HIV) progression in women: associations HIV disease progression and changes in body mass index in women in the HIV epidemiology research study cohort. Clinical Infectious Diseases. 2003;37(Supplement 2):S69-S80.

46. Blashill AJ, Mayer KH, Crane HM, Grasso C, Safren SA. Body mass index, immune status, and virological control in HIV-infected men who have sex with men. Journal of the International Association of Providers of AIDS Care (JIAPAC). 2013;12(5):319-324.

47. Koethe JR, Jenkins CA, Shepherd BE, Stinnette SE, Sterling TR. An optimal body mass index range associated with improved immune reconstitution among 
HIV-infected adults initiating antiretroviral therapy. Clinical infectious diseases. 2011;53(9):952-960.

48. United States Food and Drug Administration. FDA to investigate added caffeine. 2013; http://www.fda.gov/downloads/ForConsumers/ConsumerUpdates/UCM350 740.pdf. Accessed October 20, 2014.

49. Moul D, Pilkonis P, Miewald J, Carey T, Buysse D. Preliminary study of the testretest reliability and concurrent validities of the Pittsburgh Insomnia Rating Scale (PIRS). Paper presented at: Sleep2002.

50. Buysse DJ, Reynolds CF, Monk TH, Berman SR, Kupfer DJ. The Pittsburgh Sleep Quality Index: a new instrument for psychiatric practice and research. Psychiatry Research. 1989;28(2):193-213.

51. Spitzer RL, Kroenke K, Williams JB, Löwe B. A brief measure for assessing generalized anxiety disorder: the GAD-7. Archives of Internal Medicine. 2006;166(10):1092-1097.

52. Preston JD, O'Neal JH, Talaga MC. Consumer's Guide to Psychiatric Drugs. New Harbinger Publications, Inc; 1998.

53. United States Food and Drug Administration. Database of Select Committee on GRAS Substances (SCOG) Reviews: Caffeine. 2006; http://www.accessdata.fda.gov/scripts/fcn/fcnDetailNavigation.cfm?rpt=sco gsListing\&id=42. Accessed Spetember 12, 2014.

54. United States Food and Drug Administration. FDA to investigate added caffeine. http://www.fda.gov/downloads/ForConsumers/ConsumerUpdates/UCM 350740.pdf. Accessed September 22014.

55. World Health Organization. Lexicon of alcohol and drug terms published by the World Health Organization. September 22013.

56. World Health Organization. Mental and behavioural disorders F15. International Statistical Classification of Diseases and Related Health Problems. 2010;Chapter 5(Mental and behavioural disorders due to use of other stimulants, including caffeine.).

57. American Psychiatric Association. Diagnostic and Statistical Manual of Mental Disorders. Vol Fifth ed2013.

58. World Health Organization. Who Case Definitions of HIV for Surveillance and Revised Clinical Staging and Immunological Classification of HIV-Related Disease in Adults and Children. 
2007; http://www.who.int/hiv/pub/guidelines/WHO\%20HIV\%20Staging.pdf. Accessed September 30, 2014.

59. United States Department of Health and Human Services. Panel on antiretroviral guidelines for adults and adolescents: Guidelines for the use of antiretroviral agents in HIV-1 infected adults and adolescents.

2011; http://aidsinfo.nih.gov/contentfiles/lvguidelines/adultandadolescentgl.pdf. Accessed September 12, 2014.

60. Biodynamics Corporation. BIA 450 bioimpedance analyzer. 2010; http://www.biodyncorp.com/product/450/450.html, May, 2015.

61. Shor-Posner G, Campa A, Zhang G, et al. When obesity is desirable: a longitudinal study of the Miami HIV-1-infected drug abusers (MIDAS) cohort. Journal of Acquired Immune Deficiency Syndromes (1999). 2000;23(1):81-88.

62. Kent SJ. Loss of control of HIV viremia associated with the fat malabsorption drug orlistat. AIDS Research and Human Retroviruses. 2012;28(9):961-962.

63. Langford SE, Ananworanich J, Cooper DA. Predictors of disease progression in HIV infection: a review. AIDS Research and Therapy. 2007;4(1):11.

64. Moss T, Martin CW, Klausner JD, Brown BJ. Integration of Screening for Syphilis, Hepatitis C, and Other Sexually Transmitted Infections with HIV Testing in a Community-Based HIV Prevention Program in Miami, Florida. LGBT Health. 2014;1(2):82-85.

65. Wawrzyniak AJ, Rodríguez AE, Falcon AE, et al. Association of Individual and Systemic Barriers to Optimal Medical Care in People Living With HIV/AIDS in Miami-Dade County. JAIDS Journal of Acquired Immune Deficiency Syndromes. 2015;69:S63-S72.

66. Elenkov IJ, Chrousos GP. Stress hormones, Th1/Th2 patterns, pro/antiinflammatory cytokines and susceptibility to disease. Trends in Endocrinology \& Metabolism. 1999;10(9):359-368.

67. Cruess DG, Antoni MH, Kumar M, et al. Cognitive-behavioral stress management buffers decreases in dehydroepiandrosterone sulfate (DHEA-S) and increases in the cortisol/DHEA-S ratio and reduces mood disturbance and perceived stress among HIV-seropositive men. Psychoneuroendocrinology. 1999;24(5):537-549.

68. Marketon JIW, Glaser R. Stress hormones and immune function. Cellular Immunology. 2008;252(1):16-26. 
69. King SL, Hegadoren KM. Stress hormones: how do they measure up? Biological Research for Nursing. 2002;4(2):92-103. 
CHAPTER-V: CAFFEINE INTAKE AND ASSOCIATIONS WITH SLEEP QUALITY AND GENERALIZED ANXIETY SCORES IN MIAMI ADULT STUDIES ON HIV (MASH) COHORT—AN OBSERVATIONAL STUDY ABSTRACT

Introduction: People living with HIV (PLWH) report deteriorated sleep quality, increased periods of insomnia, post morning sleepiness, cognitive impairment, and chronic fatigue. Caffeine consumption adversely affects sleep quality and anxiety symptoms in many vulnerable populations. Although there are many studies on caffeine consumption and sleep and anxiety symptoms in HIV non-infected populations, inadequate information is available in PLWH.

Methods: We examined caffeine intake and sleep quality, insomnia levels, and anxiety symptoms in a convenience sample of 130 clinically stable HIV positive participants (65 consuming $\leq 250 \mathrm{mg} /$ day and 65 consuming $>250 \mathrm{mg} /$ day of caffeine) recruited from the Miami Adult Studies on HIV (MASH) cohort. This study included a baseline and a follow-up visit at 3 month. After obtaining written informed consent, caffeine consumption, sleep quality, insomnia levels and anxiety symptoms were determined using Modified Caffeine Consumption Questionnaire (MCCQ), Pittsburg Insomnia Rating Scale (PIRS), Pittsburg Sleep Quality Index (PSQI) and Generalized Anxiety Disorder-7 (GAD-7) questionnaires. Information on demographics, anthropometries, body composition measures, substance abuse and antiretroviral therapy (ART) were collected from the MASH cohort database. T-tests and chi-square were used to describe demographics and health and lifestyle characteristics. Linear regressions were used to analyze baseline data for relationships between caffeine consumption, insomnia, sleep 
quality and anxiety symptoms. Linear Mixed Models were used to understand the effect of caffeine consumption on these parameters over time.

Results: The mean age of the cohort was $47.89 \pm 6.37$ years, $60.8 \%$ were male participants and $75.4 \%$ were African-Americans. All participants were on ART throughout this study. Mean caffeine intake at baseline was $161.26 \pm 194.95 \mathrm{mg} /$ day (3-8 cups of coffee) (Range: $0 \mathrm{mg}-1498 \mathrm{mg} /$ day) and did not change significantly at 3-month follow-up visit. Linear regressions showed significant associations between higher caffeine consumption and higher global PIRS scores $(\beta=1.776, P=0.046)$, higher global PSQI scores ( $\beta=2.587, P=0.038)$ and higher GAD-7 scores $(\beta=1.674, P=0.027)$ after adjusting for associated covariates. Linear mixed model analysis showed that higher caffeine consumption was associated with higher global PIRS scores $(\beta=1.678, P=0.047)$, higher global PSQI scores $(\beta=2.594, P=0.006)$ and higher GAD-7 scores $(\beta=0.937$, $P=0.048)$, in a dose-response manner, after adjusting for covariates.

Conclusion: Higher caffeine consumption was associated with higher levels of insomnia, poor sleep quality and higher levels of anxiety symptoms in PLWH. Although our previous studies have suggested a benefit of higher caffeine consumption on markers of HIV disease progression, in vulnerable patients, high doses of caffeine can aggravate existing psychological conditions. Effective interventions to reduce caffeine intake in this population need to be developed and tested in future large scale studies.

Keywords: Modified Caffeine Consumption Questionnaire (MCCQ), HIV infection, Pittsburg Insomnia Rating Scale (PIRS), Pittsburg Sleep Quality Index (PSQI) and Generalized Anxiety Disorder-7 (GAD-7) 


\section{INTRODUCTION}

According to the 2013 CDC estimates, about 1.2 million people were living with HIV/AIDS (PLWH) in United States. In Miami-Dade County, there were 26,760 PLWH. ${ }^{1}$ PLWH report deteriorated sleep quality, increased periods of insomnia, post morning sleepiness, cognitive impairments, and chronic fatigue. ${ }^{2-6}$ Sleep quality measured by the Pittsburgh Sleep Quality Index (PSQI) was significantly lower in PLWH, when compared to the general population, after adjusting for other co-morbidities and over-the-counter sleep medications. ${ }^{4}$ In another study among clinically stable PLWH, it was found that poor sleep quality and increased psychological distress scores were associated with lower CD4 cell counts and higher HIV viral load after adjusting for the effects of ART. ${ }^{7}$ In a study conducted to identify the correlates of sleep quality in PLWH, using the "Symptom Experience Dimension” of the revised "UCSF Symptom Management Conceptual Model”, the variables significantly affecting sleep quality were trait and state anxiety scores, general well-being scores, length of time living with HIV disease and diagnosis of clinical depression. ${ }^{5}$ The length of time living with HIV disease strongly correlated with worst sleep quality measured by the Pittsburg Sleep Quality Index (PSQI) questionnaire after adjusting for other predictor variables mentioned above. $^{5}$ Another study done among 146 clinically stable PLWH showed that stress levels measured by State and Trait Anxiety (STA) Questionnaires were significantly associated with deteriorated sleep quality, after adjusting for covariates such as age, sex, ART, other medications, substance use and income. ${ }^{8}$ Similarly, better sleep quality, measured by the PSQI and Pittsburg Insomnia Rating Scale (PIRS) was associated with better cognitive performance on tasks of attention, frontal/executive functions, and psychomotor/motor 
speeds in PLWH, after adjusting for medications, alcohol consumption and drug use. ${ }^{6}$ Additionally this study reported that more than one third of the PLWH participants were chronically and severely sleep deprived. ${ }^{6}$

In a study that investigated the effects of caffeine on cognitive and psychomotor performance and sleep quality at night, in HIV non-infected participants, it was observed that caffeine in doses of $250 \mathrm{mg} /$ day, irrespective of sources, significantly decreased the initial critical flicker fusion threshold (CFFT) scores which signifies higher levels of neuronal excitability after adjusting for age, BMI, exercise, gender, body composition measures and lifestyle factors. ${ }^{9}$ In a randomized double-blind study of 72 HIV noninfected participants with various forms of anxiety disorders, oral administration of 480 mg/day of caffeine provoked acute stress responses measured through State and Trait Anxiety Questionnaires. ${ }^{10}$ General stress levels estimated by the State and Trait Anxiety Questionnaires, were substantially higher in subjects administered $480 \mathrm{mg} /$ day of caffeine when compared to control solutions after adjusting for gender, age, educational level, occupation and anxiolytic medications. Four hundred and eighty mg of caffeine precipitated panic attacks in $60.7 \%$ all of the participants in the experimental arm of the study. This study concluded that higher doses of caffeine (480 mg/day) precipitated anxiety and panic attacks even in HIV non-infected volunteers. ${ }^{10}$

Caffeine intake also affected sleep quality as reported by a study conducted among 88 HIV-positive participants. ${ }^{11}$ In this study, sleep quality was measured by the Revised Pittsburg Sleep Quality Index (RPSQI) Questionnaire. Mean caffeine intake of the sample was $476 \mathrm{mg} /$ day or 2.4 times the US consumption average of $200 \mathrm{mg} / \mathrm{day}$. It was found that subjects having high levels of caffeine consumption (>400 mg/day) 
reported poor PSQI scores. ${ }^{11}$ Within one month, subjects who reduced their baseline caffeine consumption by $90 \%$ or higher, showed significant improvements in PSQI scores after adjusting for covariates such as sleep medications, other co-morbidities and substance use.

In summary, the literature shows that caffeine consumption is associated with compromised sleep quality, altered sleep patterns, increased periods of insomnia, and increased stress and anxiety symptoms. All these parameters could produce adverse effects on disease progression in PLWH. ${ }^{7}$ The specific aim of the current study was to explore whether caffeine consumption affected sleep quality, insomnia levels and anxiety symptoms in a convenience sample of 130 participants (65 consuming $\leq 250 \mathrm{mg} /$ day and 65 consuming > $250 \mathrm{mg} /$ day of caffeine) recruited from the Miami Adult Studies of HIV (MASH) cohort. We also observed for the effects of sleep quality, insomnia and anxiety symptoms on immunological and virologic markers of HIV disease progression.

\section{METHODS}

\section{Study Design and Setting}

The present study recruited a convenience sample of 130 participants (65 consuming $\leq$ $250 \mathrm{mg} /$ day and 65 consuming > $250 \mathrm{mg} /$ day of caffeine) from the MASH cohort, which consisted of $803 \mathrm{HIV}$ positive and 78 uninfected participants, followed for more than 10 years at the FIU research clinic in the Borinquen Health Care Center (BHCC). The BHCC provides comprehensive range of health and social services to a culturally diverse low income community. The recruitment for the present study took place from February to July 2014. The present study included a baseline and 3-month follow-up visits, and participants received $\$ 5$ as partial reimbursement for their time and efforts, for each of 
the two visits. The initial screening included detailed explanation of the study as well as obtaining informed voluntary written consent for participation. In order to obtain a study sample of 128 participants as estimated in our sample size calculations, we screened a total of 150 subjects, enrolled 130 participants and excluded 20 ineligible participants. The present study also included secondary analysis of relevant variables collected for the MASH cohort studies. Data collected during the baseline and 3-month visits were used for the analyses of descriptive and inferential statistics. The inclusion and exclusion criteria for the MASH cohort are presented in "Chapter 3: Methodology” and applicable to our current study. The additional inclusion criteria for participants in the present study were: enrollment in the MASH cohort; receiving ART; and willingness to participate in a study with two visits, a baseline and one follow-up visit at 3 months. The exclusion criteria were: cardiovascular abnormalities or implanted pacemakers; morbid medical conditions such as uncontrolled hypertension, anemia, chronic inflammatory diseases or mal-absorption syndromes. The Institutional Review Board at Florida International University approved the study protocol and research procedures.

\section{Measures}

The questionnaires used in the present study were previously field tested and validated in several large scale studies. ${ }^{12-15}$ However, we pre-tested these questionnaires on 15 participants from the MASH cohort to ascertain their applicability and we determined that revisions were not necessary for the questionnaires.

Caffeine consumption questionnaire: We used the Modified Caffeine Consumption Questionnaire (MCCQ) developed by Preston et al. in the year 1998. ${ }^{16}$ This questionnaire is easy to understand, compact, organized and reported adequate compliance, validity and 
reliability. ${ }^{16}$ This questionnaire was field tested and validated in many large scale studies and adequately reflected average daily caffeine consumption levels. ${ }^{12}$ It includes a total of 21 sources of caffeine classified in to three groups, 'Beverages', 'Over the counter medications' and 'Prescription medications'. This questionnaire also included 'Total caffeine consumption per day’ by adding these individual sources. Caffeine consumption was analyzed both as a continuous variable and a categorical variable.

For both naturally occurring and artificially added caffeine sources, FDA considers $400 \mathrm{mg} /$ day (7 cups of Coffee) to be generally safe and not associated with any dangerous side effects. ${ }^{17,18}$ The World Health Organization (WHO) defines caffeine overuse as daily consumption beyond $500 \mathrm{mg} / \mathrm{d} .{ }^{19,20}$ Beyond this level caffeine produces visible adverse effects collectively known as 'Caffeinism'. The World Health Organization (WHO) has also cautioned that these adverse effects could be precipitated at much lower doses depending on the physiological profiles of individuals as well as the genetic makeup of the population. ${ }^{19,20}$ The International Classification of Diseases (ICD) manual considers caffeine consumption above $250 \mathrm{mg}$ /day to be associated with many mental and behavioral disorders though it is inconclusive whether such effects would be uniformly applicable in the general population. ${ }^{13}$ The Diagnostic and Statistical Manual of Mental Disorders (DSM-5) considers consumption below $250 \mathrm{mg} /$ day to be generally safe and above this level to be associated with many adverse effects such as withdrawal, addiction, irritability and craving. ${ }^{21}$ Summarizing these cutoffs, we concluded that caffeine consumption below $250 \mathrm{mg} /$ day that is equivalent to 4 cups of coffee, irrespective of the sources is generally safe and not associated with adverse effects. In 
this study, caffeine categories included low ( $\leq 250 \mathrm{mg} /$ day, within safe levels) and high ( $>250 \mathrm{mg} /$ day, beyond safe levels) based on these recommendations.

The Pittsburg Insomnia Rating Scale (PIRS): The PIRS is a 66-item self-report questionnaire that measures the subjective levels of insomnia experienced over the past seven days. ${ }^{13}$ This questionnaire consists of four components: Distress Score; Sleep Parameter Score; Quality of Life Score; and Total Insomnia Score. The 'Distress Score' equals the total of first 46 questions each rated on a 0-3 scale and higher scores indicate increased levels of subjective distress symptoms experienced by the participants. Similarly, the 'Sleep Parameter Score' totals questions 47 to 56, each rated on a 0-3 scale and higher scores signify poor sleep quality. The 'Quality of Life Sore’ sums questions 57 to 65, and higher scores signify poor quality of life. The 'The Global PIRS Score' sums all the 65 questions and higher scores represent increased subjective reports of insomnia. The original study validating the questionnaire ${ }^{13}$ also recommends scores 0-50 as 'No Insomnia', scores 51-100 as 'Moderate Insomnia' and scores greater than 100 as 'Severe Insomnia'. ${ }^{13}$ The PIRS questionnaire showed excellent internal consistency, testretest reliability and discriminative validity in a mixed sample of 456 normal adult participants between 18 and 85 years in the original study. The original study also reported a Cronbach's alpha coefficient of 0.88 indicating high internal consistency and an intra-class correlation of 0.89 indicating good test-retest reliability. ${ }^{13}$ The original study also reported a sensitivity of $83.4 \%$ and a specificity of $88.6 \%$ for the questionnaire. ${ }^{13}$ In the present study the global PIRS scores were analyzed as both continuous and categorical variables. The global PIRS score categories included: $\leq 50$ (No 
Insomnia), 51-100 (Moderate Insomnia), and >100(Severe Insomnia) as recommended in the original study. ${ }^{13}$

The Pittsburg Sleep Quality Index questionnaire (PSQI): The PSQI is a 19-item selfreport questionnaire that measures self-reported quality of sleep over the past 30 days. ${ }^{14}$ This questionnaire includes seven individual components: Sleep Duration; Sleep Disturbance; Sleep Latency; Days Dysfunction due to Sleepiness; Sleep Efficiency; Overall Sleep Quality; and Need Meds to Sleep. Each component is rated on a 0-3 scale, with higher scores signifying worsening outcomes. ‘Sleep Duration’ is calculated using question 4 and represents the total number hours slept per day. 'Sleep Disturbance' is calculated by summarizing individual scores in questions $5 \mathrm{~b}$ to $5 \mathrm{j}$ and represents various factors like bad dreams, pain, breathing problems etc. that have impaired the quality of sleep. 'Sleep Latency’ represents the total time spent awake on bed trying to sleep each day and is calculated using the questions 2 and 5 with necessary re-coding. 'Days Dysfunction due to Sleepiness' is calculated from questions 8 and 9 and represents daily problems related to sleep, such as having trouble staying awake or having enough enthusiasm to get things done. 'Sleep Efficiency' is calculated from questions 1 and 3 and represents the ratio of actual number of hours of sleep, given the number of hours spent in bed. 'Overall Sleep Quality’ is calculated from question 6 and represents general sleep quality over the past month. 'Need Meds to Sleep' is calculated from question 7 and represents use of sleep medications over the past month. These seven component scores are added to obtain a global PSQI score which ranges from 0 to 21 and higher scores represent worsening sleep quality. According to the original study a global PSQI score of 5 or greater represents poor sleep quality. ${ }^{14}$ However other studies recommend 
scores 0-5 as good sleep quality, 6-10 as poor sleep quality and greater than 10 as worst sleep quality. ${ }^{22,23}$ This questionnaire had good internal consistency, test-retest reliability, and discriminative validity in the original study with a sample of 168 participants aged 19 to 83 years. ${ }^{14}$ The original study also reported a Cronbach's alpha coefficient of 0.83 indicating high internal consistency and an intra-class correlation of 0.85 indicating good test-retest reliability. ${ }^{14,24}$ The original study also reported a sensitivity of $89.6 \%$ and a specificity of $86.5 \%$ for the questionnaire. ${ }^{14,24}$ In the current study the global PSQI scores were analyzed as both continuous and categorical variables. The global PSQI score categories included: $\leq 5$ (Good Sleep Quality), 6-10 (Poor Sleep Quality), and >10 (Worst Sleep Quality). ${ }^{23,24}$

The Generalized Anxiety Disorder-7 (GAD-7) questionnaire: The GAD-7 is a 7-item self-reported questionnaire for screening and evaluating the severity of generalized anxiety symptoms over the past two weeks. ${ }^{15}$ Although primarily developed for measuring generalized anxiety disorder, studies have also reported good sensitivity and specificity for many other anxiety and panic disorders. ${ }^{25}$ There are seven questions about anxiety symptoms each rated on a 0-3 scale representing the options 'not at all', 'several days' , 'more than half the days', and 'nearly every day'. The total scores range from 0 to 21 and higher scores represent greater anxiety levels. GAD-7 had shown good internal consistency, test-retest reliability, and discriminative validity in the original study of 2470 participants aged 19 to 95 years. ${ }^{15}$ The original study of this questionnaire reported a Cronbach's alpha coefficient of 0.92 indicating very high internal consistency and an intra-class correlation of 0.83 indicating good test-retest reliability. ${ }^{15}$ The original study also reported a sensitivity of $89 \%$ and a specificity of $82 \%$ for the questionnaire. ${ }^{15}$ In the 
current study, the GAD-7 scores were analyzed as both continuous and categorical variables. The GAD-7 score categories included: $\leq 5$ (Minimal Anxiety), 6-10 (Mild Anxiety), 11-15 (Moderate Anxiety) and >15 (Severe Anxiety), as recommended in the original study. ${ }^{15}$

Immunological and virologic variables: CD4 counts, viral loads and other clinical variables are determined for the participants' healthcare visits by their primary health care physicians. The MASH cohort studies collected and documented these reports after appropriate medical release forms were signed by the participants. The MASH studies also paid a compensation of $\$ 15$ every six months to motivate participants towards timely submission of medical records and lab reports, which included CD4 counts and viral load. In the current chapter, CD4 counts and viral loads were analyzed as continuous variables and transformed into CD4 square root and $\log _{10}$ viral load to ensure normal distribution and better model fit criteria.

\section{Control Variables}

Demographic and socioeconomic information: Demographic and socioeconomic information used in this study were collected by the MASH studies. Information used for the current study included age, gender, ethnicity, education and income levels. A number of health and lifestyle related factors such as tobacco use, alcohol consumption and illicit drug use were also gathered from the MASH data repository. These controlled variables were selected based on studies associating them with sleep quality and anxiety disorders. ${ }^{13-16,25-27}$

ART medications: We obtained information about types of the antiretroviral medications prescribed and administered by their physicians during the MASH cohort visits. We 
adjusted the analyses for these variables because some of the antiretroviral medications are associated with sleep and anxiety disorders. ${ }^{26-28}$

\section{Statistical Analysis}

Field data were collected in paper based questionnaires and later entered into RedCap database, then imported into SPSS version 21 for Windows (Armonk, NY: IBM Corp) and merged into a single dataset for analysis. Descriptive statistics were used to understand the population characteristics and were expressed in terms of means, standard deviations and percentages. The characteristics of the population were shown for all the participants and separated based on low and high intakes of caffeine using the cutoff points: $>250 \mathrm{mg} /$ day for high intake; and $\leq 250 \mathrm{mg} /$ day for low or no intake as described in the Methods section above. ${ }^{17,18,19,20}$ T-tests and chi square tests were used to describe differences in demographics, health and lifestyle characteristics, and individual components and global scores of PIRS, PSQI and GAD-7 questionnaires, with respect to low and high levels of caffeine consumption. Paired sample t-tests were used to measure differences in levels of caffeine consumption as well as the individual components and global scores of PIRS, PSQI and GAD-7 questionnaires, between the baseline and 3month visits. Linear regression was used to estimate the strength of association between caffeine consumption and the individual components and global scores of PIRS, PSQI and GAD-7 questionnaires. Assumptions of linear regression were followed prior to analyses. Linear mixed models (LMM) were used to determine the overtime changes in the strength of these associations. For parameter estimation in LMM models restricted maximum likelihood (REML) was used. Multinomial logistic regressions were used to determine the associations between high and low caffeine intake groups with respect to 
different categories of global scores of PIRS, PSQI and GAD-7 questionnaires. Linear Regression was also used to estimate the strength of association between global scores of PIRS, PSQI and GAD-7 questionnaires and the markers of HIV disease progression (CD4 counts and viral load). Linear Mixed Models were used to estimate the changes over time in the strength of these associations. For Linear and Logistic Regressions and Linear Mixed Model analysis, we initially used crude models and subsequently adjusted for the covariates already described in the methodology. These covariates were also tested for significant associations with the outcome variables using bivariate analysis before being incorporated into the models. To increase the validity of the models, multicollinearity among covariates was tested prior to the analyses. Adjusted models included non-missing values for all independent variables included in the models. Statistical significance was set at $P<0.05$ for all the analyses.

\section{RESULTS}

\section{Demographic and Socio-economic Characteristics}

A total of 130 participants were included in the study and 79 (60.8\%) were men. The mean age was $47.89 \pm 6.37$ years. Most of the participants were African Americans (75.4\%), Hispanics constituted 16.9\%, Whites constituted 5.4\% and other races constituted 4.6 percent. About $24 \%$ of the participants had college education, while $45.4 \%$ were high school graduates and $30.8 \%$ has some form of primary education. All participants had incomes under the level of poverty and the mean income was $\$ 495.91 \pm$ 465.887. There were no significant differences in any socio-demographic variables between low and high levels of caffeine consumption in both baseline and follow-up visits (Table-1A, 1B). 


\section{Health/lifestyle Characteristics}

Sixty one percent of the participants reported smoking within the past six weeks of their scheduled baseline visits, $57.9 \%$ reported alcohol use and $48.2 \%$ tested positive for illicit drug use. Similarly, 63.2\% reported smoking, 60.3\% reported alcohol use and 65.8\% tested positive for illicit drug use during the follow-up visit.

All participants were on ART during both visits. Antiretroviral therapy took many forms, $58.5 \%$ were on NRTI, $13.1 \%$ were on NNRTI and $47.7 \%$ were on PI in several combinations, $26.2 \%$ of the participants were using a one-pill multi-drug combination such as Atripla, Truvada and Combivir during the baseline visit. At the 3-month visit, 63.8\% were on NRTI, $13.8 \%$ were on NNRTI and $47.7 \%$ were on PI, and $25.4 \%$ were on a one-pill multi-drug combination during the follow-up visit. There were no significant differences in the distribution of these variables between low and high levels of caffeine consumption in both baseline and follow-up visits (Tables 2 and 3).

\section{Caffeine Consumption from Different Sources}

Total caffeine consumption was $337.63 \pm 304.97 \mathrm{mg} /$ day at baseline (Range: 0 1,498 mg/day), and $281.04 \pm 260.85 \mathrm{mg} /$ day (Range: 0-1,175 mg/day) at the 3-months follow-up. Coffee constituted the largest source of caffeine and mean consumption levels were $161.26 \pm 194.95 \mathrm{mg} /$ day at baseline, and $190.40 \pm 205.03 \mathrm{mg} /$ day at follow-up. Caffeinated soft drinks constituted the second largest source of caffeine and mean consumption levels were $63.23 \pm 92.98 \mathrm{mg} /$ day at baseline, and $29.66 \pm 83.78 \mathrm{mg} / \mathrm{day}$ at follow-up. There were no significant differences between baseline and follow-up visits with respect to total caffeine consumption or caffeine from most of the sources. However, there was significant decrease in consumption of caffeinated soft drinks (63.23 \pm 92.98 
vs. $29.66 \pm 83.78, P<0.00001$ ), energy drinks (46.32 \pm 134.42 vs. $9.61 \pm 65.32, P=0.005$ ) and hot cocoa ( $1.03 \pm 5.00$ vs. $0.00 \pm 0.00, P=0.020)$ from the baseline to the follow-up visits (Table-4). For all other sources of caffeine in the questionnaire, except the ones enlisted in Table 4, participants reported none to negligible levels of consumption at both the visits.

\section{The Individual Components and Global PIRS, PSQI and GAD-7 Scores}

Independent sample t-tests showed that most of the individual components and global scores of PIRS, PSQI and GAD-7 questionnaires did not differ significantly between the groups who consumed $<250 \mathrm{mg}$ of caffeine per day versus $\geq 250 \mathrm{mg} / \mathrm{day}$, in the baseline as well as 3-month follow-up visit. However, 'Distress Score’ (31.44 \pm 23.92 vs $72.33 \pm 28.75, P=0.002)$, ‘The Global PIRS Scores’ ( $45.89 \pm 133.13$ vs $105.75 \pm$ 41.12, $P=0.002)$, 'Days Dysfunction due to Sleepiness’ ( $0.60 \pm 0.63$ vs $1.89 \pm 0.85$, $P=0.002)$, and ‘Overall Sleep Quality Derangements’ (0.58 \pm 0.63 vs $1.74 \pm 0.85$, $P=0.002$ ), were significantly higher in those who consumed $\geq 250 \mathrm{mg} /$ day when compared to those who consumed $<250 \mathrm{mg}$ of caffeine per day (Tables 5, 6,8,9, 11,12).

Paired sample t-tests comparing the baseline and 3-month visits also showed that most of the individual components and global scores of PIRS, PSQI and GAD-7 questionnaires did not differ significantly between the visits. 'Sleep Disturbance’ (1.55 \pm 0.74 vs $1.32 \pm 0.83, P=0.019)$, 'Sleep Latency’ ( $1.54 \pm 1.05$ vs $1.16 \pm 0.89, P=0.001)$, 'Sleep Efficiency’ ( $0.68 \pm 0.96$ vs $0.19 \pm 0.53, P<0.001)$ and ‘Global PSQI’ $(7.98 \pm 5.59$ vs $6.61 \pm 4.87, P=0.031$ ), however, were significantly higher during the baseline visit when compared to follow-up visits (Tables 7, 9, 10, and 13). 


\section{Relationship between Caffeine Intake and PIRS Variables}

Caffeine consumption as a continuous variable was significantly associated with

Distress Score $(\beta=1.506, P=0.048)$, Quality of Life Score $(\beta=1.784, P=0.001)$, and global PIRS Score ( $\beta=1.776, P=0.046)$, after adjusting for age, gender, race/ethnicity, education, income, and time from diagnosis of HIV, drug use, smoking status, alcohol use, different types of ART medications and use of sleep medications (Table 14). Linear Mixed Model analysis for the effect of caffeine intake on changes in these scores, between the two study visits, showed significantly increased Distress Score $(\beta=1.347, P=0.036)$, Quality of Life Sore $(\beta=1.767, P=0.006)$ and Global PIRS Score $(\beta=1.678, P=0.047)$, with increasing caffeine consumption, in a dose-response manner, after adjusting for the same covariates (Table 15). Multinomial logistic regressions showed that the odds of having moderate insomnia were 9 times higher in participants consuming $>250 \mathrm{mg}$ of caffeine per day, when compared to participants consuming $\leq 250 \mathrm{mg}$ per day, after adjusting for the same covariates (OR=9.321, 95\%CI: $3.324-21.402, P=0.018)$. Similarly, the odds of having severe insomnia were 17 times higher in participants consuming $>250 \mathrm{mg}$ of caffeine per day, when compared to participants consuming $\leq 250 \mathrm{mg}$ per day, after adjusting for the same covariates (OR=17.9558, 95\%CI: 10.153 -94.512, $P=0.003$ ). These odds also increased in significance, when changes over the three month period were considered (Table 16 and 17).

\section{Relationship between Caffeine Intake and PSQI Variables}

Caffeine intake as a continuous variable was significantly associated with Sleep Duration $(\beta=1.199, P=0.049)$, Days Dysfunction due to Sleepiness $(\beta=1.250, P=0.043)$, Overall Sleep Quality $(\beta=2.248, P=0.001)$, and Global PSQI scores $(\beta=2.587, P=0.038)$, 
after adjusting for covariates such as age, gender, race/ethnicity, education, income, and time from diagnosis of HIV, drug use, smoking status, alcohol use and different types of ART medications (Table 18). Linear Mixed Model analysis for the effect of caffeine intake on changes in these scores, between the two study visits, showed significantly worse domains of "Sleep Duration" ( $\beta=1.345, P=0.042)$, "Sleep Disturbance" ( $\beta=1,505$, $P=0.032)$, "Sleep Latency" ( $\beta=1.323, P=0.023)$, "Days Dysfunction Due to Sleepiness" ( $\beta=1.353, P=0.036)$, "Sleep Efficiency" ( $\beta=1.212, P=0.025)$, "Need Meds to Sleep" ( $\beta=1.494, P=0.049$ ) and "Global PSQI Scores" ( $\beta=2.594, P=0.0006)$, with increasing caffeine consumption, in a dose-response manner, after adjusting for the same covariates (Table 19).

Multinomial logistic regressions showed that the odds of having poor sleep quality was 18 times higher in participants consuming > $250 \mathrm{mg}$ of caffeine per day when compared to participants consuming $\leq 250 \mathrm{mg}$ per day after adjusting for the same covariates (OR=18.659, 95\%CI: 8.016 -165.741, $P=0.013$ ). Similarly the odds of having extremely low sleep quality was 19 times higher in participants consuming >250 mg of caffeine per day when compared to participants consuming $\leq 250 \mathrm{mg}$ per day after adjusting for the same covariates (OR=19.060, 95\%CI: 16.906 -186.786, $P=0.008)$. When changes over the three month period were considered, the odd ratios for these variables became more significant (Table 20 and 21).

\section{Relationship between Caffeine Intake and GAD-7 Variables}

Caffeine intake as a continuous variable was significantly associated with GAD-7 Score $(\beta=1.674, \mathrm{p}=0.027)$, after adjusting for covariates such as age, gender, race/ethnicity, education, income, and time from diagnosis of HIV, drug use, smoking 
status, alcohol use, different types of ART medications and use of sleep medications (Table 22). Linear mixed model analysis for the effect of caffeine intake on changes in GAD-7 scores, between the two study visits, showed significantly increased scores ( $\beta=0.937, P=0.048$ ) with increasing caffeine consumption, in a dose-response manner, after adjusting for the same covariates (Table 23). Multinomial logistic regressions showed that the odds of having mild anxiety was 5 times higher in participants consuming $>250 \mathrm{mg}$ of caffeine per day, when compared to participants consuming $\leq 250$ mg per day after adjusting for the same covariates. (OR=5.107, 95\%CI: 1.568 -33.499, $P=0.027)$. Similarly the odds of having moderate anxiety was 6 times greater $(\mathrm{OR}=$ 6.091, 95\%CI: 2.333 -35.841, $P=0.002$ ) and the odds of having severe anxiety was 17 times greater (OR=17.185, 95\%CI: $5.185-88.185, P=0.001)$ in participants consuming $>250 \mathrm{mg}$ of caffeine per day, when compared to participants consuming $\leq 250 \mathrm{mg}$ per day after adjusting for the same covariates. These odds also increased in significance, when changes over the three month period were considered (Tables 24 and 25).

\section{Relationship between Global PIRS, Global PSQI, GAD-7 and Immunological and Virologic Markers of Disease Progression}

Linear regression showed that global PIRS scores were significantly associated with lower CD4 cell counts ( $\beta=-1.202, P=0.015)$ after adjusting for time from diagnosis of HIV, drug use, smoking status, alcohol use and different types of ART medications. Similarly global PSQI scores $(\beta=-1.149, P=0.036)$ and GAD-7 scores $(\beta=-1.122$, $P=0.031$ ) were significantly associated with lower CD4 cell counts after adjusting for the same covariates (Table 26). 
Linear regression showed that global PIRS scores was significantly associated with higher HIV viral load $(\beta=1.949, \mathrm{P}=0.045)$ after adjusting for time from diagnosis of HIV, drug use, smoking status, alcohol use and different types of ART medications. Similarly global PSQI scores $(\beta=1.988, P=0.031)$ and GAD-7 scores $(\beta=1.269, P=0.029)$ were significantly associated with higher HIV viral load after adjusting for the same covariates (Table 26). However, linear mixed model analysis showed that these associations diminished and lost insignificance overtime (Table 27).

\section{DISCUSSION}

The characteristics of our population were epidemiologically similar to those described by others in Miami-Dade County. ${ }^{29,30}$ More than half of the participants were consuming alcohol and smoking cigarettes, and $48.2 \%$ had a positive urine toxicology result for illicit drugs.

The relationship between caffeine consumption and sleep quality, insomnia and anxiety scores, were also expected, as caffeine consumption has been associated with poor sleep quality and worsening anxiety symptoms in other studies on non-HIV infected participants. ${ }^{31-34}$ There are also studies stating that HIV infected patients have deteriorated sleep quality, increased periods of insomnia, post morning sleepiness, cognitive impairments, increased anxiety symptoms and tiredness. ${ }^{2-6,35-38}$ However, studies associating caffeine consumption to these adverse effects are rare in HIV positive populations. Currently, only one study on HIV positive patients reports adverse effects of caffeine consumption on sleep quality and general wellbeing. ${ }^{11}$ This study, however, was limited due to its small sample size $(\mathrm{N}=88)$ and very high mean caffeine consumption levels (476 mg/day), which was about 2.4 times the average consumption in United 
States. Though many studies have associated caffeine intake with impaired sleep quality in HIV non-infected populations, ${ }^{4,539-43}$ our study is the among the few that investigated the association between high caffeine consumption and sleep quality and anxiety symptoms in a population of clinically stable PLWH.

We found that caffeine intake adversely affected many parameters of sleep and anxiety measured by PIRS, PSQI and GAD-7 questionnaires, adjusting for income, years since diagnosis of HIV, substance abuse and ART. Our analyses were adjusted by these variables because the literature reported their associations with poor sleep quality. ${ }^{44-47}$ Our findings suggest that the adverse effects of caffeine on sleep and anxiety levels were mild but compounded by medication side effects, cocaine and amphetamine use, which have stronger effects on sleep disturbances and anxiety.

We also found that worsening sleep and anxiety scores measured through PIRS, PSQI and GAD-7 questionnaires were associated with lower CD4 counts and higher HIV viral load after adjusting for the covariates associated with HIV disease progression. ${ }^{48-50}$ Similar findings are also reported in another study in PLWH, where poor sleep quality and worsening psychological distress scores were associated with lower CD4 cell counts and higher HIV viral loads. ${ }^{7}$ Nevertheless, comparability with our study is limited, because this study used a sample of PLWH beginning to show symptoms of AIDS, whereas, our participants were clinically stable HIV positive participants receiving ART. The deleterious effects of poor sleep quality and higher psychological distress scores on HIV disease progression, would have been more prominent in PLWH who were beginning to show symptoms of AIDS, compared to our stable HIV positive participants receiving ART, because recovery of the immune function and controlled viral loads are 
only attained with ART. ${ }^{51}$ Our study findings are unique because we explored the adverse effects of sleep loss and anxiety symptoms in the absence of advanced HIV disease progression.

In spite of the findings in this study, we have to acknowledge some of its limitations. The current study enrolled a convenience sample of $130 \mathrm{PLWH}$, thus the results may not be generalizable. Participating in the baseline could also have influenced the outcomes in the follow-up visit, as the participants could have been affected by an “Interpersonal Expectancy Bias,” 52 by which they would have responded what they believed the investigators wanted to hear or the investigators would have recorded what they wanted to report.

Furthermore, the survey instruments used in the study do not measure the outcomes within the same time frame. PIRS measured insomnia levels over the past one month, GAD-7 measured anxiety symptoms over the past two weeks, PSQI measured sleep quality over the past week and MCCQ measured caffeine consumption over the past 24 hours. Furthermore these instruments are self-reported measures and susceptible to memory and recall biases.

Large scale studies should be done with controlled dietary and lifestyle factors, as well as controlled study settings, to overcome the limitations of our study. Though, our findings showed that caffeine intake adversely affected sleep quality and anxiety symptoms, and, in turn, adversely affected HIV disease progression, these findings should be confirmed by such large scale studies. 


\section{Acknowledgements}

I would like to thank Dr. Marianna Baum for providing access to the MASH cohort data repository, as well as for the collaboration of her research group and my major professor Dr. Adriana Campa for the advice on the intellectual content of this manuscript. I am grateful for the support provided by Florida International University Graduate School, in the form of Data and Evidence Acquisition Fellowship and Doctoral Year Fellowship. Overall, I am very grateful to the FIU-Borinquen team, who collaborated enthusiastically with this project, and especially for the generosity of our participants who gave us their time and efforts. I also convey my sincere thanks to the Institute of Sleep Medicine, University of Pittsburg, for allowing me to reprint PIRS and PSQI questionnaires for this study. 
Table 1A: Baseline Demographic Characteristics of PLWH by Caffeine Consumption Levels

\begin{tabular}{|c|c|c|c|c|}
\hline \multirow[b]{2}{*}{ Variables } & \multicolumn{4}{|c|}{ Baseline } \\
\hline & Total & $\begin{array}{c}\text { Low } \\
\text { caffeine } \\
\text { intake } \\
(\leq 250 \\
\text { mg/d) }\end{array}$ & $\begin{array}{c}\text { High } \\
\text { caffeine } \\
\text { intake } \\
(>250 \\
\text { mg/d) }\end{array}$ & $P$-value \\
\hline $\begin{array}{l}\text { Age in years } \\
\text { (Mean } \pm \text { SD) }\end{array}$ & $47.89 \pm 6.37$ & $47.57 \pm 6.81$ & $48.00 \pm 6.15$ & 0.706 \\
\hline $\begin{array}{r}\text { Gender, N (\%) } \\
\text { Male } \\
\text { Female } \\
\end{array}$ & $\begin{array}{l}79(60.8 \%) \\
51(39.2 \%)\end{array}$ & $\begin{array}{l}40(61.5 \%) \\
25(38.5 \%)\end{array}$ & $\begin{array}{l}39(60.0 \%) \\
26(40.0 \%)\end{array}$ & 0.857 \\
\hline $\begin{array}{r}\text { Ethnicity, } \mathrm{N}(\%) \\
\text { White } \\
\text { Hispanic } \\
\text { Black } \\
\text { Other } \\
\end{array}$ & $\begin{array}{l}7(5.4 \%) \\
22(16.9 \%) \\
98(75.4 \%) \\
3(2.3 \%) \\
\end{array}$ & $\begin{array}{l}3(4.6 \%) \\
7(10.8 \%) \\
55(84.6 \%) \\
0(0.0 \%) \\
\end{array}$ & $\begin{array}{l}4(6.2 \%) \\
15(23.1 \%) \\
43(66.2 \%) \\
3(4.6 \%) \\
\end{array}$ & 0.057 \\
\hline $\begin{array}{l}\text { Education in years, } \\
\mathrm{N}(\%) \\
\\
<12 \\
12 \\
>12 \\
\end{array}$ & $\begin{array}{l}40(30.8 \%) \\
59(45.4 \%) \\
31(23.8 \%)\end{array}$ & $\begin{array}{l}24(36.9 \%) \\
29(44.6 \%) \\
12(18.5 \%)\end{array}$ & $\begin{array}{l}16(24.6 \%) \\
30(46.2 \%) \\
19(29.2 \%)\end{array}$ & 0.202 \\
\hline $\begin{array}{l}\text { Income in dollars } \\
\text { per month }\end{array}$ & $\begin{array}{l}495.91 \pm \\
465.887\end{array}$ & $\begin{array}{l}464.00 \pm \\
419.667\end{array}$ & $\begin{array}{l}527.34 \pm \\
508.637\end{array}$ & 0.442 \\
\hline
\end{tabular}

Note: $P$-values corresponds to $\chi^{2}$ tests for categorical variables and t-test for continuous variables 
Table 1B: Follow-up Demographic Characteristics of PLWH by Caffeine Consumption Levels

\begin{tabular}{|c|c|c|c|c|}
\hline \multirow[b]{2}{*}{ Variables } & \multicolumn{4}{|c|}{ Follow-up } \\
\hline & Total & $\begin{array}{l}\text { Low } \\
\text { caffeine } \\
\text { intake } \\
(\leq 250 \\
\text { mg/d) }\end{array}$ & $\begin{array}{c}\text { High } \\
\text { caffeine } \\
\text { intake } \\
(>250 \\
\text { mg/d) }\end{array}$ & $P$-value \\
\hline $\begin{array}{l}\text { Age in years } \\
\text { (Mean } \pm \text { SD) }\end{array}$ & $47.89 \pm 6.37$ & $46.63 \pm 7.33$ & $48.87 \pm 5.38$ & 0.490 \\
\hline $\begin{array}{r}\text { Gender, N (\%) } \\
\text { Male } \\
\text { Female }\end{array}$ & $\begin{array}{l}79(60.8 \%) \\
51(39.2 \%)\end{array}$ & $\begin{array}{l}43(68.3 \%) \\
20(31.7 \%)\end{array}$ & $\begin{array}{l}36 \text { (53.7\%) } \\
31(46.3 \%)\end{array}$ & 0.090 \\
\hline $\begin{array}{r}\text { Ethnicity, } \mathrm{N}(\%) \\
\text { White } \\
\text { Hispanic } \\
\text { Black } \\
\text { Other }\end{array}$ & $\begin{array}{l}7(5.4 \%) \\
22(16.9 \%) \\
98(75.4 \%) \\
3(2.3 \%)\end{array}$ & $\begin{array}{l}4(6.3 \%) \\
9(14.3 \%) \\
50(79.4 \%) \\
0(0.0 \%)\end{array}$ & \begin{tabular}{|l}
$3(4.5 \%)$ \\
$13(19.4 \%)$ \\
$48(71.6 \%)$ \\
$3(4.6 \%)$
\end{tabular} & 0.285 \\
\hline $\begin{array}{l}\text { Education in years, } \\
\mathrm{N}(\%) \\
\\
<12 \\
12 \\
>12 \\
\end{array}$ & $\begin{array}{l}40(30.8 \%) \\
59(45.4 \%) \\
31(23.8 \%)\end{array}$ & $\begin{array}{l}21(33.3 \%) \\
29(46.0 \%) \\
13(20.6 \%) \\
\end{array}$ & $\begin{array}{l}19(28.4 \%) \\
30(44.8 \%) \\
18(26.9 \%) \\
\end{array}$ & 0.670 \\
\hline $\begin{array}{l}\text { Income in dollars } \\
\text { per month }\end{array}$ & $\begin{array}{l}495.91 \pm \\
465.887\end{array}$ & $\begin{array}{l}498.80 \pm \\
511.708\end{array}$ & $\begin{array}{l}492.89 \pm \\
416.619\end{array}$ & 0.943 \\
\hline
\end{tabular}

Note: $P$-values corresponds to $\chi^{2}$ tests for categorical variables and t-test for continuous variables 
Table 2: Baseline Health and Lifestyle Characteristics of PLWH by Caffeine Consumption Levels

\begin{tabular}{|c|c|c|c|c|}
\hline Variables & Total & $\begin{array}{c}\text { Low caffeine } \\
\text { intake } \\
(\leq 250 \mathrm{mg} / \mathrm{d})\end{array}$ & $\begin{array}{l}\text { High caffeine } \\
\text { intake } \\
(>250 \mathrm{mg} / \mathrm{d}) \\
\end{array}$ & $\begin{array}{c}P \text { - } \\
\text { value }\end{array}$ \\
\hline $\begin{array}{l}\text { Smoking } \\
\text { cigarettes }\end{array}$ & $\begin{array}{l}80(63.5 \%) \\
46(36.5 \%)\end{array}$ & $\begin{array}{l}39(60.9 \%) \\
25(39.1 \%)\end{array}$ & $\begin{array}{l}41(66.1 \%) \\
21(33.9 \%)\end{array}$ & 0.582 \\
\hline Alcohol use & $\begin{array}{l}73(57.9 \%) \\
53(42.1 \%)\end{array}$ & $\begin{array}{l}36(56.3 \%) \\
28(43.8 \%)\end{array}$ & $\begin{array}{l}37(59.7 \%) \\
25(40.3 \%)\end{array}$ & 0.721 \\
\hline Drug use & $\begin{array}{l}53(48.2 \%) \\
57(51.8 \%)\end{array}$ & $\begin{array}{l}25(43.9 \%) \\
32(56.1 \%)\end{array}$ & $\begin{array}{l}28(52.8 \%) \\
25(47.2 \%)\end{array}$ & 0.445 \\
\hline Marijuana & $\begin{array}{l}44(33.8 \%) \\
86(66.2 \%)\end{array}$ & $\begin{array}{l}21(32.3 \%) \\
44(67.7 \%)\end{array}$ & $\begin{array}{l}23(35.4 \%) \\
42(64.6 \%)\end{array}$ & 0.853 \\
\hline Cocaine & $\begin{array}{l}41(31.5 \%) \\
89(68.5 \%)\end{array}$ & $\begin{array}{l}19(29.2 \%) \\
46(70.8 \%)\end{array}$ & $\begin{array}{l}22(33.8 \%) \\
43(66.2 \%)\end{array}$ & 0.706 \\
\hline Other Drugs & $\begin{array}{l}10(9.1 \%) \\
100(90.9 \%)\end{array}$ & $\begin{array}{l}6(10.5 \%) \\
51(89.5 \%)\end{array}$ & $\begin{array}{l}4(7.5 \%) \\
49(92.5 \%)\end{array}$ & 0.744 \\
\hline $\begin{array}{l}\text { ART } \\
\text { Multi-combination } \\
\text { Yes } \\
\text { No }\end{array}$ & $\begin{array}{l}34(26.2 \%) \\
96(73.8 \%)\end{array}$ & $\begin{array}{l}22(33.8 \%) \\
43(66.2 \%)\end{array}$ & $\begin{array}{l}12(18.5 \%) \\
53(81.5 \%)\end{array}$ & 0.072 \\
\hline $\begin{array}{r}\text { Yes } \\
\text { No }\end{array}$ & $\begin{array}{l}76(58.5 \%) \\
54(41.5 \%)\end{array}$ & $\begin{array}{l}40(61.5 \%) \\
25(38.5 \%)\end{array}$ & $\begin{array}{l}36(55.4 \%) \\
29(44.6 \%)\end{array}$ & 0.594 \\
\hline $\begin{array}{r}\text { Yes } \\
\text { No } \\
\text { Yes } \\
\text { No }\end{array}$ & $\begin{array}{l}17(13.1 \%) \\
113(86.9 \%) \\
62(47.7 \%) \\
68(52.3 \%) \\
\end{array}$ & $\begin{array}{l}10(15.4 \%) \\
55(84.6 \%) \\
34(52.3) \\
31(47.7 \%)\end{array}$ & $\begin{array}{l}7(10.8 \%) \\
58(89.2 \%) \\
28(43.1 \%) \\
37(56.9 \%) \\
\end{array}$ & 0.380 \\
\hline
\end{tabular}

All variables reported as $\mathrm{N}(\%)$

Note: $P$-values correspond to $\chi^{2}$ tests for all variables ART: Antiretroviral therapy. 
Table 3: Follow-up Health and Lifestyle Characteristics of PLWH by Caffeine Consumption Levels

\begin{tabular}{|c|c|c|c|c|}
\hline Variables & Total & $\begin{array}{l}\text { Low caffeine } \\
\text { intake } \\
(\leq 250 \mathrm{mg} / \mathrm{d})\end{array}$ & $\begin{array}{c}\text { High caffeine } \\
\text { intake } \\
(>250 \mathrm{mg} / \mathrm{d})\end{array}$ & $\begin{array}{c}P \text { - } \\
\text { value }\end{array}$ \\
\hline $\begin{array}{l}\text { Smoking } \\
\text { cigarettes }\end{array}$ & $\begin{array}{l}79(63.2 \%) \\
46(36.8 \%)\end{array}$ & $\begin{array}{l}41(68.3 \%) \\
19(31.7 \%)\end{array}$ & $\begin{array}{l}38(58.5 \%) \\
27(41.5 \%)\end{array}$ & 0.271 \\
\hline $\begin{array}{rr}\text { Alcohol use } & \\
& \text { Yes } \\
& \text { No } \\
\end{array}$ & $\begin{array}{l}76(60.3 \%) \\
50(39.7 \%)\end{array}$ & $\begin{array}{l}34(56.7 \%) \\
26(43.3 \%)\end{array}$ & $\begin{array}{l}42(63.6 \%) \\
24(36.4 \%)\end{array}$ & 0.469 \\
\hline Drug use & $\begin{array}{l}79(65.8 \%) \\
41(34.2 \%)\end{array}$ & $\begin{array}{l}45(75.0 \%) \\
15(25.0 \%)\end{array}$ & $\begin{array}{l}34(56.7 \%) \\
26(43.3 \%)\end{array}$ & 0.054 \\
\hline $\begin{array}{lr}\text { Marijuana } & \\
& \text { Yes } \\
\text { Cocaine } & \text { No } \\
& \text { Yes } \\
& \text { No } \\
\text { Other drugs } & \\
& \text { Yes } \\
& \text { No } \\
\end{array}$ & $\begin{array}{l}67(55.8 \%) \\
53(44.2 \%) \\
48(40.0 \%) \\
72(60.0 \%) \\
13(10.9 \%) \\
106(89.1 \%)\end{array}$ & $\begin{array}{l}38(63.3 \%) \\
22(36.7 \%) \\
29(48.3 \%) \\
31(51.7 \%) \\
6(10.0 \%) \\
54(90.0 \%)\end{array}$ & $\begin{array}{l}29(48.3 \%) \\
31(51.7 \%) \\
19(31.7 \%) \\
41(68.3 \%) \\
7(11.9 \%) \\
52(88.1 \%)\end{array}$ & $\begin{array}{l}0.141 \\
0.093\end{array}$ \\
\hline $\begin{array}{lr}\text { ART } & \\
\text { Multi- } & \\
\text { combination } & \\
& \text { Yes } \\
& \text { No }\end{array}$ & $\begin{array}{l}33(25.4 \%) \\
97(74.6 \%)\end{array}$ & $\begin{array}{l}20(31.7 \%) \\
43(68.3 \%)\end{array}$ & $\begin{array}{l}13(19.4 \%) \\
54(80.6 \%)\end{array}$ & 0.113 \\
\hline $\begin{array}{l}\text { Yes } \\
\text { No }\end{array}$ & $\begin{array}{l}83(63.8 \%) \\
47(36.2 \%)\end{array}$ & $\begin{array}{l}40(63.5 \%) \\
23(36.5 \%)\end{array}$ & $\begin{array}{l}43(64.2 \%) \\
24(35.8 \%)\end{array}$ & 1.000 \\
\hline $\begin{array}{r}\text { Yes } \\
\text { No } \\
\text { Yes } \\
\text { No }\end{array}$ & $\begin{array}{l}18(13.8 \%) \\
112(86.2 \%) \\
62(47.7 \%) \\
68(52.3 \%)\end{array}$ & $\begin{array}{l}9(14.3 \%) \\
54(85.7 \%) \\
28(44.4 \%) \\
35(55.6 \%)\end{array}$ & $\begin{array}{l}9(13.4 \%) \\
58(86.6 \%) \\
34(50.7 \%) \\
33(49.3 \%)\end{array}$ & 0.488 \\
\hline
\end{tabular}

All variables reported as $\mathrm{N}(\%)$

Note: $P$-values correspond to $\chi^{2}$ tests all variables.

ART: Antiretroviral therapy. 
Table 4: Mean Caffeine Intake: Baseline and Follow-up Visit

\begin{tabular}{|l|l|l|l|}
\hline Food source & \multicolumn{1}{|c|}{ Baseline } & \multicolumn{1}{c|}{ Follow-up } & \multicolumn{1}{c|}{ P-value } \\
\hline Coffee & $161.26 \pm 194.95$ & $190.40 \pm 205.03$ & 0.206 \\
\hline De-Caffeinated coffee & $0.83 \pm 9.21$ & $0.03 \pm 0.43$ & 0.329 \\
\hline Expresso & $14.40 \pm 64.35$ & $13.92 \pm 57.82$ & 0.942 \\
\hline Tea & $34.70 \pm 64.32$ & $31.58 \pm 59.36$ & 0.640 \\
\hline Green tea & $7.34 \pm 62.93$ & $4.20 \pm 21.62$ & 0.594 \\
\hline Energy drinks & $46.32 \pm 134.42$ & $9.61 \pm 65.32$ & $0.005^{*}$ \\
\hline Hot cocoa & $1.03 \pm 5.00$ & $0.00 \pm 0.00$ & $0.020^{*}$ \\
\hline Caffeinated soft drinks & $63.23 \pm 92.98$ & $29.66 \pm 83.78$ & $<0.0001^{*}$ \\
\hline Chocolate candy bars & $3.69 \pm 13.81$ & $2.00 \pm 17.93$ & 0.402 \\
\hline Anacin & $0.24 \pm 2.80$ & $0.00 \pm 0.00$ & 0.319 \\
\hline Appetite control pills & $4.61 \pm 39.10$ & $0.00 \pm 0.00$ & 0.181 \\
\hline Total & $337.63 \pm 304.97$ & $281.04 \pm 260.85$ & 0.890 \\
\hline
\end{tabular}

All variables reported as mean $\pm \mathrm{SD}$

Note: $P$-values correspond to t-tests for all variables

*Significant

Table 5: Baseline PIRS Variables by Caffeine Consumption Levels

\begin{tabular}{|l|l|l|l|}
\hline Variables & \multicolumn{1}{|c|}{$\begin{array}{c}\text { Low caffeine } \\
\text { intake } \\
(\leq \mathbf{2 5 0} \mathbf{~ m g} / \mathbf{d})\end{array}$} & $\begin{array}{c}\text { High caffeine } \\
\text { intake } \\
(\mathbf{2 5 0} \mathbf{~ m g} / \mathbf{d})\end{array}$ & P-value \\
\hline Distress Score & $31.44 \pm 23.92$ & $72.33 \pm 28.75$ & $0.002^{*}$ \\
\hline Sleep Parameter Score & $7.56 \pm 5.38$ & $17.96 \pm 7.28$ & $0.035^{*}$ \\
\hline Quality of Life Score & $6.87 \pm 5.41$ & $15.44 \pm 6.43$ & 0.588 \\
\hline The Global PIRS Score & $45.89 \pm 133.13$ & $105.75 \pm 41.12$ & $0.002^{*}$ \\
\hline
\end{tabular}

All variables reported as mean $\pm \mathrm{SD}$

Note: $P$-values correspond to t-tests for all variables

*Significant 
Table 6: Follow-Up PIRS Variables by Caffeine Consumption Levels

\begin{tabular}{|l|l|l|l|}
\hline Variables & \multicolumn{1}{|c|}{$\begin{array}{c}\text { Low caffeine } \\
\text { intake } \\
(\leq \mathbf{2 5 0} \mathbf{~ m g} / \mathbf{d})\end{array}$} & $\begin{array}{c}\text { High caffeine } \\
\text { intake } \\
(>\mathbf{2 5 0} \mathbf{~ m g} / \mathbf{d})\end{array}$ & $\boldsymbol{P}$-value \\
\hline Distress Score & $24.77 \pm 20.98$ & $85.70 \pm 22.52$ & 0.543 \\
\hline Sleep Parameter Score & $3.53 \pm 5.81$ & $20.34 \pm 6.14$ & $0.022^{*}$ \\
\hline Quality of Life Score & $4.50 \pm 5.30$ & $17.85 \pm 4.46$ & $0.001^{*}$ \\
\hline $\begin{array}{l}\text { The Global PIRS } \\
\text { Score }\end{array}$ & $32.82 \pm 30.10$ & $128.89 \pm 31.24$ & 0.449 \\
\hline
\end{tabular}

All variables reported as mean $\pm \mathrm{SD}$

Note: $P$-values correspond to t-tests for all variables

Table 7: Mean Scores of PIRS Variables: Baseline and Follow-Up Visit

\begin{tabular}{|l|l|l|l|}
\hline Variables & \multicolumn{1}{c|}{ BL } & \multicolumn{1}{c|}{ FU } & P-value \\
\hline PIRS SCORES & $51.89 \pm 33.39$ & $56.17 \pm 37.48$ & 0.331 \\
\hline Distress Score & $12.76 \pm 8.24$ & $12.20 \pm 10.32$ & 0.622 \\
\hline Sleep Parameter Score & $11.16 \pm 7.32$ & $11.38 \pm 8.27$ & 0.817 \\
\hline Quality of Life Sore & $75.82 \pm 47.81$ & $79.76 \pm 54.97$ & 0.537 \\
\hline The Global PIRS Score
\end{tabular}

All variables reported as mean $\pm \mathrm{SD}$

Note: $P$-values correspond to t-tests for all variables

Table 8: Baseline PSQI Variables by Caffeine Consumption Levels

\begin{tabular}{|c|c|c|c|}
\hline Variables & $\begin{array}{c}\text { Low caffeine } \\
\text { intake } \\
(\leq 250 \mathrm{mg} / \mathrm{d})\end{array}$ & $\begin{array}{c}\text { High caffeine } \\
\text { intake } \\
(>250 \mathrm{mg} / \mathrm{d})\end{array}$ & $P$-value \\
\hline Sleep Duration & $0.03 \pm 0.17$ & $1.14 \pm 0.98$ & 0.068 \\
\hline Sleep Disturbance & $1.08 \pm 0.32$ & $2.03 \pm 0.74$ & $0.039 *$ \\
\hline Sleep Latency & $0.72 \pm 0.62$ & $2.35 \pm 0.69$ & 0.059 \\
\hline $\begin{array}{l}\text { Days Dysfunction due to } \\
\text { Sleepiness }\end{array}$ & $0.60 \pm 0.63$ & $1.89 \pm 0.85$ & $0.002^{*}$ \\
\hline Sleep Efficiency & $0.22 \pm 0.57$ & $1.15 \pm 1.04$ & 0.568 \\
\hline Overall Sleep Quality & $0.58 \pm 0.63$ & $1.74 \pm 0.85$ & $0.002 *$ \\
\hline Need Meds to Sleep & $0.52 \pm 0.61$ & $1.89 \pm 0.86$ & 0.588 \\
\hline Global PSQI & $3.75 \pm 2.55$ & $12.20 \pm 4.51$ & $0.039 *$ \\
\hline
\end{tabular}

All variables reported as mean $\pm \mathrm{SD}$

Note: $P$-values correspond to t-tests for all variables

*Significant 
Table 9: Follow-Up PSQI Variables by Caffeine Consumption Levels

\begin{tabular}{|c|c|c|c|}
\hline Variables & $\begin{array}{c}\text { Low } \\
\text { caffeine } \\
\text { intake } \\
(\leq 250 \mathrm{mg} / \mathrm{d})\end{array}$ & $\begin{array}{c}\text { High } \\
\text { caffeine } \\
\text { intake } \\
(>250 \mathrm{mg} / \mathrm{d})\end{array}$ & $P$-value \\
\hline Sleep Duration & $0.19 \pm 0.56$ & $0.76 \pm 0.87$ & $0.046 *$ \\
\hline Sleep Disturbance & $0.68 \pm 0.66$ & $1.93 \pm 0.43$ & 0.532 \\
\hline Sleep Latency & $0.57 \pm 0.79$ & $1.72 \pm 0.57$ & 0.579 \\
\hline $\begin{array}{l}\text { Days Dysfunction due to } \\
\text { Sleepiness }\end{array}$ & $0.41 \pm 0.75$ & $1.99 \pm 0.53$ & $0.002 *$ \\
\hline Sleep Efficiency & $0.10 \pm 0.46$ & $0.28 \pm 0.57$ & $0.041 *$ \\
\hline Overall Sleep Quality & $0.29 \pm 0.60$ & $1.94 \pm 0.54$ & $0.002 *$ \\
\hline Need Meds to Sleep & $0.38 \pm 0.65$ & $1.75 \pm 0.53$ & 0.598 \\
\hline Global PSQI & $2.62 \pm 3.35$ & $10.36 \pm 2.53$ & $0.001^{*}$ \\
\hline
\end{tabular}

All variables reported as mean $\pm \mathrm{SD}$

Note: $P$-values correspond to t-tests for all variables

*Significant

Table 10: Mean Scores of PSQI Variables: Baseline and Follow-Up Visit

\begin{tabular}{|l|l|l|l|}
\hline Variables & \multicolumn{1}{|c|}{ BL } & FU & P-value \\
\hline PSQI SCORES & & & \\
\hline Sleep Duration & $0.58 \pm 0.89$ & $0.48 \pm 0.79$ & 0.292 \\
\hline Sleep Disturbance & $1.55 \pm 0.74$ & $1.32 \pm 0.83$ & $0.019^{*}$ \\
\hline Sleep Latency & $1.54 \pm 1.05$ & $1.16 \pm 0.89$ & $0.001^{*}$ \\
\hline $\begin{array}{l}\text { Days Dysfunction due to } \\
\text { Sleepiness }\end{array}$ & $1.25 \pm 0.98$ & $1.22 \pm 1.02$ & 0.852 \\
\hline Sleep Efficiency & $0.68 \pm 0.96$ & $0.19 \pm 0.53$ & $<0.0001^{*}$ \\
\hline Overall Sleep Quality & $1.16 \pm 0.94$ & $1.14 \pm 1.01$ & 0.851 \\
\hline Need Meds to Sleep & $1.21 \pm 1.01$ & $1.08 \pm 0.90$ & 0.299 \\
\hline Global PSQI & $7.98 \pm 5.59$ & $6.61 \pm 4.87$ & $0.031^{*}$ \\
\hline
\end{tabular}

All variables reported as mean $\pm \mathrm{SD}$

Note: $P$-values correspond to t-tests for all variables

*Significant

Table 11: Baseline GAD-7 Scores by Caffeine Consumption Levels

\begin{tabular}{|l|l|l|l|}
\hline Variables & $\begin{array}{c}\text { Low caffeine intake } \\
(\leq \mathbf{2 5 0} \mathbf{~ m g} / \mathbf{d})\end{array}$ & $\begin{array}{c}\text { High caffeine intake } \\
(>\mathbf{2 5 0} \mathbf{~ m g} / \mathbf{d})\end{array}$ & P-value \\
\hline GAD-7 scores & $4.42 \pm 3,441$ & $12.78 \pm 5.014$ & $0.024^{*}$ \\
\hline
\end{tabular}

All variables reported as mean $\pm \mathrm{SD}$

Note: $P$-values correspond to t-tests for all variables

*Significant 
Table 12: Follow-Up GAD-7 Scores by Caffeine Consumption Levels

\begin{tabular}{|l|c|c|c|}
\hline Variables & $\begin{array}{c}\text { Low caffeine } \\
\text { intake } \\
(\leq \mathbf{2 5 0} \mathbf{~ m g} / \mathbf{d})\end{array}$ & $\begin{array}{c}\text { High caffeine } \\
\text { intake } \\
(>\mathbf{2 5 0} \mathbf{~ m g} / \mathbf{d})\end{array}$ & P-value \\
\hline GAD-7 scores & $3.41 \pm 1.272$ & $14.03 \pm 0.361$ & $0.043^{*}$ \\
\hline
\end{tabular}

All variables reported as mean $\pm \mathrm{SD}$

Note: $P$-values correspond to t-tests for all variables

*Significant

Table 13: Mean GAD-7 Scores: Baseline and Follow-Up Visit

\begin{tabular}{|l|c|c|c|}
\hline Variables & BL & FU & $\boldsymbol{P}$-value \\
\hline GAD-7 Score & $8.60 \pm 5.999$ & $8.88 \pm 6.450$ & 0.711 \\
\hline
\end{tabular}

All variables reported as mean $\pm \mathrm{SD}$

Note: $P$-values correspond to t-tests for all variables

Table 14: Linear Regression of the Effect of Caffeine Consumption on PIRS Variables

\begin{tabular}{|l|l|l|l|l|l|l|}
\hline PIRS Varables & \multicolumn{3}{|c|}{ Unadjusted } & \multicolumn{3}{c|}{ Adjusted $^{\dagger}$} \\
\hline Distress Score & Beta & SE & P-value & Beta & SE & P-value \\
\hline $\begin{array}{l}\text { Sleep Parameter } \\
\text { Score }\end{array}$ & 1.088 & 1.006 & 0.239 & 1.506 & 1.103 & $0.048^{*}$ \\
\hline $\begin{array}{l}\text { Quality of Life } \\
\text { Score }\end{array}$ & 1.018 & 1.001 & 0.599 & 1.890 & 1.096 & 0.586 \\
\hline $\begin{array}{l}\text { The Global PIRS } \\
\text { Score }\end{array}$ & 1.128 & 1.057 & $0.048^{\text {a }}$ & 1.776 & 1.120 & $0.046^{*}$ \\
\hline
\end{tabular}

${ }^{\mathrm{a}}$ Model $\mathrm{R}^{2}=0.213$, F (16) $=28.367, P=0.042$.

${ }^{\dagger}$ Model adjusted for age, income, race ethnicity, time from diagnosis of HIV, drug, tobacco and alcohol use, sleep medications and types of ART medication.

*Significant 
Table 15: Linear Mixed Model (LMM) Analysis of Overtime Changes in PIRS Variables due to Caffeine Consumption

\begin{tabular}{|l|l|l|l|l|l|l|}
\hline PIRS variables & \multicolumn{3}{|c|}{ Unadjusted } & \multicolumn{3}{c|}{ Adjusted $^{\dagger}$} \\
\hline & Beta & SE & $\boldsymbol{P}$-value & Beta & SE & P-value $^{-}$ \\
\hline Distress Score & 1.095 & 1.004 & $0.045^{*}$ & 1.347 & 1.200 & $0.036^{*}$ \\
\hline $\begin{array}{l}\text { Sleep Parameter } \\
\text { Score }\end{array}$ & 1.256 & 1.127 & 0.587 & 1.304 & 1.183 & $0.045^{*}$ \\
\hline $\begin{array}{l}\text { Quality of Life } \\
\text { Score }\end{array}$ & 1.202 & 1.114 & 0.046 & 1.767 & 1.168 & $0.006^{*}$ \\
\hline $\begin{array}{l}\text { The Global PIRS } \\
\text { Score }\end{array}$ & 1.141 & 1.070 & $0.035^{*}$ & 1.678 & 1.010 & $0.047^{*}$ \\
\hline
\end{tabular}

àdel: -2 Restricted Log Likelihood = 1952.149; Akaike's Information Criteria (AIC) = 1956.149; Schwarz’s Bayesian Criteria $(B I C)=1962.725$.

${ }^{\dagger}$ Model adjusted for age, income, race ethnicity, time from diagnosis of HIV, drug, tobacco and alcohol use, sleep medications and types of ART medication.

*Significant

Table 16: Baseline Multinomial Logistic Regression of the Effect of Caffeine Consumption Levels on Global PIRS Score Categories

\begin{tabular}{|c|c|c|c|c|c|c|}
\hline & \multicolumn{3}{|c|}{ Unadjusted } & \multicolumn{3}{|c|}{ Adjusted $^{\dagger}$} \\
\hline $\begin{array}{l}\text { Caffeine } \\
\text { intake }\end{array}$ & OR & $95 \% \mathrm{CI}$ & $\begin{array}{c}P- \\
\text { value }\end{array}$ & OR & $95 \% \mathrm{CI}$ & $\begin{array}{c}P \text { - } \\
\text { value }\end{array}$ \\
\hline & \multicolumn{6}{|c|}{ PIRS $\leq 50$ (No Insomnia) versus PIRS 51-100 (Moderate Insomnia) } \\
\hline $\begin{array}{l}\text { Low } \\
\text { High }\end{array}$ & $\begin{array}{c}\text { Ref } \\
4.395\end{array}$ & $\begin{array}{r}\text { Ref } \\
(0.436-25\end{array}$ & 0.190 & $\begin{array}{c}\text { Ref } \\
9.321\end{array}$ & $\begin{array}{r}\text { Ref } \\
\text { (3.324-21.4 }\end{array}$ & 0.0 \\
\hline & \multicolumn{6}{|c|}{ PIRS $\leq 50$ (No Insomnia) versus PIRS >100 (Severe Insomnia) } \\
\hline $\begin{array}{l}\text { Low } \\
\text { High }\end{array}$ & $\begin{array}{c}\text { Ref } \\
9.314\end{array}$ & $\begin{array}{c}\text { Ref } \\
(0.928-35.245)\end{array}$ & 0.095 & $\begin{array}{c}\text { Ref } \\
17.958\end{array}$ & $\begin{array}{c}\text { Ref } \\
(10.153-94.512)\end{array}$ & $0.003 *$ \\
\hline
\end{tabular}

$\mathrm{R}^{2}=0.176$ (Cox and Snell), 0.188 (Nagelkerke). $\chi^{2}(32)=42.679, P=0.031$

${ }^{\dagger}$ Model adjusted for age, income, race ethnicity, time from diagnosis of HIV, drug, tobacco and alcohol use, sleep medications and types of ART medication.

*Significant 
Table 17: Over Time Multinomial Logistic Regression of the Effect of Caffeine Consumption Levels on Global PIRS Score Categories

\begin{tabular}{|c|c|c|c|c|c|c|}
\hline & \multicolumn{3}{|c|}{ Unadjusted } & \multicolumn{3}{|c|}{ Adjusted $^{\dagger}$} \\
\hline $\begin{array}{l}\text { Caffeine } \\
\text { intake }\end{array}$ & OR & $95 \% \mathrm{CI}$ & $\begin{array}{c}P \text { - } \\
\text { value }\end{array}$ & OR & $95 \% \mathrm{CI}$ & $\begin{array}{c}P \text { - } \\
\text { value }\end{array}$ \\
\hline & \multicolumn{6}{|c|}{ PIRS $\leq 50$ (No Insomnia) versus PIRS 51-100 (Moderate Insomnia) } \\
\hline $\begin{array}{l}\text { Low } \\
\text { High }\end{array}$ & $\begin{array}{c}\text { Ref } \\
3.469\end{array}$ & $\begin{array}{c}\text { Ref } \\
(0.369-13.535)\end{array}$ & 0.130 & $\begin{array}{c}\text { Ref } \\
15.550\end{array}$ & $\begin{array}{c}\text { Ref } \\
(4.982-96.042)\end{array}$ & $0.019 *$ \\
\hline & \multicolumn{6}{|c|}{ PIRS $\leq 50$ (No Insomnia) versus PIRS >100 (Severe Insomnia) } \\
\hline $\begin{array}{l}\text { Low } \\
\text { High }\end{array}$ & $\begin{array}{c}\text { Ref } \\
9.667\end{array}$ & $\begin{array}{c}\text { Ref } \\
(0.965-963.457)\end{array}$ & 0.110 & $\begin{array}{c}\text { Ref } \\
23.988\end{array}$ & $\begin{array}{c}\text { Ref } \\
(8.245-5.652)\end{array}$ & $0.013^{*}$ \\
\hline
\end{tabular}

$\mathrm{R}^{2}=0.170$ (Cox and Snell), 0.181 (Nagelkerke). $\chi^{2}(30)=37.654, P=0.034$

${ }^{\dagger}$ Model adjusted for age, income, race ethnicity, time from diagnosis of HIV, drug, tobacco and alcohol use, sleep medications and types of ART medication.

*Significant

Table 18: Linear Regression of the Effect of Caffeine Consumption on PSQI Variables

\begin{tabular}{|c|c|c|c|c|c|c|}
\hline PSQI Variables & \multicolumn{3}{|c|}{ Unadjusted } & \multicolumn{3}{|c|}{ Adjusted $^{\dagger}$} \\
\hline & Beta & SE & $P$-value & Beta & SE & $P$-value \\
\hline Sleep Duration & 1.194 & 1.220 & 0.568 & 1.199 & 1.228 & $0.049 *$ \\
\hline Sleep Disturbance & 1.201 & 1.124 & 0.564 & 1.932 & 1.380 & 0.540 \\
\hline Sleep Latency & 1.271 & 1.188 & 0.786 & 1.258 & 1.015 & 0.548 \\
\hline $\begin{array}{l}\text { Days Dysfunction } \\
\text { due to Sleepiness }\end{array}$ & 1.259 & 1.173 & 0.239 & 1.250 & 1.193 & $0.043 *$ \\
\hline Sleep Efficiency & 2.157 & 2.430 & 0.568 & 2.195 & 1.263 & $0.049 *$ \\
\hline $\begin{array}{l}\text { Overall Sleep } \\
\text { Quality }\end{array}$ & 2.239 & 2.175 & $0.002 *$ & 2.248 & 2.182 & $0.001^{*}$ \\
\hline $\begin{array}{l}\text { Need Meds to } \\
\text { Sleep }\end{array}$ & 1.268 & 1.176 & 0.987 & 1.274 & 1.197 & 0.589 \\
\hline Global PSQI $^{\mathrm{a}}$ & 2.159 & 1.812 & $0.048^{*}$ & 2.587 & 1.058 & $0.038 *$ \\
\hline
\end{tabular}

${ }^{a}$ Model $\mathrm{R}^{2}=0.191, \mathrm{~F}(15)=26.491, P=0.034$.

${ }^{\dagger}$ Model adjusted for age, income, race ethnicity, time from diagnosis of HIV, drug, tobacco and alcohol use, sleep medications and types of ART medication.

*Significant 
Table 19: Linear Mixed Model (LMM) Analysis of Overtime Changes in PSQI Variables due to Caffeine Consumption

\begin{tabular}{|l|l|l|l|l|l|l|}
\hline PSQI variables & \multicolumn{3}{|c|}{ Unadjusted } & \multicolumn{3}{c|}{ Adjusted $^{\dagger}$} \\
\hline & Beta & SE & P-value & Beta & SE & P-value \\
\hline Sleep Duration & 1.162 & 1.054 & 0.450 & 1.345 & 1.134 & $0.042^{*}$ \\
\hline Sleep Disturbance & 1.216 & 1.112 & 0.570 & 1.505 & 1.122 & $0.032^{*}$ \\
\hline Sleep Latency & 1.245 & 1.154 & 0.568 & 1.323 & 1.170 & $0.023^{*}$ \\
\hline $\begin{array}{l}\text { Days Dysfunction } \\
\text { due to Sleepiness }\end{array}$ & 1.263 & 1.146 & 0.460 & 1.353 & 1.161 & $0.036^{*}$ \\
\hline Sleep Efficiency & 1.104 & 1.016 & 0.450 & 1.212 & 1.178 & $0.025^{*}$ \\
\hline $\begin{array}{l}\text { Overall Sleep } \\
\text { Quality }\end{array}$ & 1.256 & 1.143 & 0.570 & 1.575 & 1.152 & 0.058 \\
\hline $\begin{array}{l}\text { Need Meds to } \\
\text { Sleep }\end{array}$ & 1.258 & 1.136 & 0.470 & 1.494 & 1.147 & $0.049^{*}$ \\
\hline Global PSQI $^{\mathrm{a}}$ & 2.150 & 1.067 & $0.048^{*}$ & 2.594 & 1.190 & $0.006^{*}$ \\
\hline
\end{tabular}

aModel: -2 Restricted Log Likelihood = 1074.021; Akaike's Information Criteria (AIC) = 1078.021; Schwarz’s Bayesian Criteria $(B I C)=1084.608$.

${ }^{\dagger}$ Model adjusted for age, income, race ethnicity, time from diagnosis of HIV, drug, tobacco and alcohol use, sleep medications and types of ART medication.

*Significant

Table 20: Baseline Multinomial Logistic Regression of the Effect of Caffeine Consumption Levels on Global PSQI Score Categories

\begin{tabular}{|c|c|c|c|c|c|c|}
\hline & \multicolumn{3}{|c|}{ Unadjusted } & \multicolumn{3}{|c|}{ Adjusted $^{\dagger}$} \\
\hline $\begin{array}{l}\text { Caffe- } \\
\text { ine } \\
\text { intake } \\
\end{array}$ & OR & $95 \% \mathrm{CI}$ & $P$-value & OR & $95 \% \mathrm{CI}$ & $\begin{array}{c}P \text { - } \\
\text { value }\end{array}$ \\
\hline & \multicolumn{6}{|c|}{ PSQI $\leq 5$ (Good Sleep Quality) versus PSQI 6-10 (Poor Sleep Quality) } \\
\hline $\begin{array}{l}\text { Low } \\
\text { High }\end{array}$ & $\begin{array}{c}\text { Ref } \\
2.585\end{array}$ & $\begin{array}{c}\text { Ref } \\
(0.625-93.988)\end{array}$ & 0.058 & $\begin{array}{c}\text { Ref } \\
18.659\end{array}$ & $\begin{array}{c}\text { Ref } \\
(8.016-165.741)\end{array}$ & $0.013^{*}$ \\
\hline & \multicolumn{6}{|c|}{ PSQI $\leq 5$ (Good Sleep Quality) versus PSQI >10 (Worst Sleep Quality) } \\
\hline $\begin{array}{l}\text { Low } \\
\text { High }\end{array}$ & $\begin{array}{c}\text { Ref } \\
3.899\end{array}$ & $\begin{array}{c}\text { Ref } \\
(1.609-193.863)\end{array}$ & $0.047 *$ & $\begin{array}{c}\text { Ref } \\
19.060\end{array}$ & $\begin{array}{c}\text { Ref } \\
(16.906-186.786)\end{array}$ & $0.008^{*}$ \\
\hline
\end{tabular}

$\mathrm{R}^{2}=0.218$ (Cox and Snell), 0.218 (Nagelkerke). $\chi^{2}(28)=44.688, P=0.038$

${ }^{\dagger}$ Model adjusted for age, income, race ethnicity, time from diagnosis of HIV, drug, tobacco and alcohol use, sleep medications and types of ART medication.

*Significant 
Table 21: Over Time Multinomial Logistic Regression of the Effect of Caffeine Consumption Levels on Global PSQI Score Categories

\begin{tabular}{|c|c|c|c|c|c|c|}
\hline & \multicolumn{3}{|c|}{ Unadjusted } & \multicolumn{3}{|c|}{ Adjusted $^{\dagger}$} \\
\hline $\begin{array}{l}\text { Caffeine } \\
\text { intake }\end{array}$ & OR & $95 \% \mathrm{CI}$ & $\begin{array}{c}P \text { - } \\
\text { value }\end{array}$ & OR & $95 \%$ CI & $\begin{array}{c}P- \\
\text { value }\end{array}$ \\
\hline & \multicolumn{6}{|c|}{ PSQI $\leq 5$ (Good Sleep Quality) versus PSQI 6-10 (Poor Sleep Quality) } \\
\hline $\begin{array}{l}\text { Low } \\
\text { High }\end{array}$ & $\begin{array}{c}\text { Ref } \\
2.994\end{array}$ & $\begin{array}{c}\text { Ref } \\
(0.382-7.067)\end{array}$ & 0.509 & $\begin{array}{c}\text { Ref } \\
33.577\end{array}$ & $\begin{array}{c}\text { Ref } \\
(24.695-82.962)\end{array}$ & 0.039* \\
\hline & \multicolumn{6}{|c|}{ PSQI $\leq 5$ (Good Sleep Quality) versus PSQI >10 (Worst Sleep Quality) } \\
\hline $\begin{array}{l}\text { Low } \\
\text { High }\end{array}$ & $\begin{array}{c}\text { Ref } \\
3.470\end{array}$ & $\begin{array}{c}\text { Ref } \\
(0.627-2.939)\end{array}$ & 0.870 & $\begin{array}{c}\text { Ref } \\
65.201\end{array}$ & $\begin{array}{c}\text { Ref } \\
(49.882-96.662)\end{array}$ & $0.015^{*}$ \\
\hline
\end{tabular}

$\mathrm{R}^{2}=0.165$ (Cox and Snell), 0.174 (Nagelkerke). $\chi^{2}(30)=29.596, P=0.042$

${ }^{\dagger}$ Model adjusted for age, income, race ethnicity, time from diagnosis of HIV, drug, tobacco and alcohol use, sleep medications and types of ART medication.

*Significant

Table 22: Linear Regression of the Effect of Caffeine Consumption on GAD-7 Scores

\begin{tabular}{|l|l|l|l|l|l|l|}
\hline $\begin{array}{l}\text { Generalized } \\
\text { Anxiety }\end{array}$ & \multicolumn{3}{|c|}{ Unadjusted } & \multicolumn{3}{c|}{ Adjusted $^{\dagger}$} \\
\hline & Beta & SE & P-value & Beta & SE & P-value \\
\hline GAD-7 Score $^{\text {a }}$ & 0.963 & 1.375 & 0.674 & 1.647 & 0.917 & $0.027^{*}$ \\
\hline
\end{tabular}

${ }^{a}$ Model $\mathrm{R}^{2}=0.182$, F (17) $=22.279, P=0.039$.

${ }^{\dagger}$ Model adjusted for age, income, time from diagnosis of HIV, drug use, alcohol consumption, smoking status and types of ART medications.

*Significant

Table 23: Linear Mixed Model (LMM) Analysis of Over Time Changes in GAD-7 Scores due to Caffeine Consumption

\begin{tabular}{|l|l|l|l|l|l|l|}
\hline $\begin{array}{l}\text { Generalized } \\
\text { Anxiety }\end{array}$ & \multicolumn{3}{|c|}{ Unadjusted } & \multicolumn{3}{c|}{ Adjusted $^{\dagger}$} \\
\hline & Beta & SE & P-value & Beta & SE & P-value \\
\hline GAD-7 Score $^{\text {a }}$ & 0.917 & 0.848 & 0.569 & 0.937 & 0.218 & $0.048^{*}$ \\
\hline
\end{tabular}

a Model: -2 Restricted Log Likelihood = 1096.531; Akaike’s Information Criteria (AIC) = 1100.531; Schwarz’s Bayesian Criteria $(\mathrm{BIC})=1107.087$.

${ }^{\dagger}$ Model adjusted for age, income, time from diagnosis of HIV, drug use, alcohol consumption, smoking status and types of ART medications.

*Significant 
Table 24: Baseline Multinomial Logistic Regression of the Effect of Caffeine Consumption Levels on GAD-7 Score Categories

\begin{tabular}{|c|c|c|c|c|c|c|}
\hline & \multicolumn{3}{|c|}{ Unadjusted } & \multicolumn{3}{|c|}{ Adjusted $^{\dagger}$} \\
\hline $\begin{array}{l}\text { Caffeine } \\
\text { intake }\end{array}$ & OR & $95 \% \mathrm{CI}$ & $\begin{array}{c}P \text { - } \\
\text { value }\end{array}$ & OR & $95 \%$ CI & $\begin{array}{c}P \text { - } \\
\text { value }\end{array}$ \\
\hline & \multicolumn{6}{|c|}{$\begin{array}{l}\text { GAD-7 Scores } \leq 5 \text { (Minimal Anxiety) versus GAD-7 Scores 6-10 (Mild } \\
\text { Anxiety) }\end{array}$} \\
\hline $\begin{array}{l}\text { Low } \\
\text { High }\end{array}$ & $\begin{array}{c}\text { Ref } \\
1.150\end{array}$ & $\begin{array}{c}\text { Ref } \\
(0.387-7.009)\end{array}$ & 0.482 & $\begin{array}{c}\text { Ref } \\
5.107\end{array}$ & $\begin{array}{c}\text { Ref } \\
(1.568-33.499)\end{array}$ & $0.027 *$ \\
\hline & \multicolumn{6}{|c|}{$\begin{array}{l}\text { GAD-7 Scores } \leq 5 \text { (Minimal Anxiety) versus GAD-7 Scores 11-15 } \\
\text { (Moderate Anxiety) }\end{array}$} \\
\hline $\begin{array}{l}\text { Low } \\
\text { High }\end{array}$ & $\begin{array}{c}\text { Ref } \\
4.714\end{array}$ & $\begin{array}{c}\text { Ref } \\
(0.578-8.734)\end{array}$ & 0.160 & $\begin{array}{c}\text { Ref } \\
6.091\end{array}$ & $\begin{array}{c}\text { Ref } \\
(2.333-35.841)\end{array}$ & $0.002 *$ \\
\hline & \multicolumn{6}{|c|}{$\begin{array}{l}\text { GAD-7 Scores } \leq 5 \text { (Minimal Anxiety) versus GAD-7 Scores 15-20 } \\
\text { (Severe Anxiety) }\end{array}$} \\
\hline $\begin{array}{l}\text { Low } \\
\text { High }\end{array}$ & $\begin{array}{c}\text { Ref } \\
5.904\end{array}$ & $\begin{array}{c}\text { Ref } \\
(0.714-9.150)\end{array}$ & 0.080 & $\begin{array}{c}\text { Ref } \\
17.185\end{array}$ & $\begin{array}{c}\text { Ref } \\
(5.185-88.185)\end{array}$ & $0.001 *$ \\
\hline
\end{tabular}

$\mathrm{R}^{2}=0.167$ (Cox and Snell), 0.172 (Nagelkerke). $\chi^{2}(48)=42.416, P=0.035$

${ }^{\dagger}$ Model adjusted for age, income, time from diagnosis of HIV, drug use, alcohol consumption, smoking status and types of ART medications.

*Significant 
Table 25: Over Time Multinomial Logistic Regression of the Effect of Caffeine Consumption Levels on GAD-7 Score Categories

\begin{tabular}{|c|c|c|c|c|c|c|}
\hline & \multicolumn{3}{|c|}{ Unadjusted } & \multicolumn{3}{|c|}{ Adjusted $^{\dagger}$} \\
\hline $\begin{array}{l}\text { Caffei- } \\
\text { ne } \\
\text { intake }\end{array}$ & OR & $95 \%$ CI & $\begin{array}{c}P \text { - } \\
\text { value }\end{array}$ & OR & $95 \%$ CI & $P$-value \\
\hline & \multicolumn{6}{|c|}{$\begin{array}{l}\text { GAD-7 } \leq 5 \text { Scores (Minimal Anxiety) versus GAD-7 Scores 6-10 (Mild } \\
\text { Anxiety) }\end{array}$} \\
\hline $\begin{array}{l}\text { Low } \\
\text { High }\end{array}$ & $\begin{array}{c}\text { Ref } \\
1.160\end{array}$ & $\begin{array}{c}\text { Ref } \\
(0.387-17.009)\end{array}$ & 0.482 & $\begin{array}{c}\text { Ref } \\
12.107\end{array}$ & $\begin{array}{c}\text { Ref } \\
(1.568-33.499)\end{array}$ & 0.037* \\
\hline & \multicolumn{6}{|c|}{$\begin{array}{l}\text { GAD-7 Scores } \leq 5 \text { (Minimal Anxiety) versus GAD-7 Scores 10-15 } \\
\text { (Moderate Anxiety) }\end{array}$} \\
\hline $\begin{array}{l}\text { Low } \\
\text { High }\end{array}$ & $\begin{array}{c}\text { Ref } \\
2.714\end{array}$ & $\begin{array}{c}\text { Ref } \\
(0.578-28.734)\end{array}$ & 0.316 & $\begin{array}{c}\text { Ref } \\
22.911\end{array}$ & $\begin{array}{c}\text { Ref } \\
(6.333-53.841)\end{array}$ & 0.033* \\
\hline & \multicolumn{6}{|c|}{$\begin{array}{l}\text { GAD-7 Scores } \leq 5 \text { (Minimal Anxiety) versus GAD-7 Scores 15-20 } \\
\text { (Severe Anxiety) }\end{array}$} \\
\hline $\begin{array}{l}\text { Low } \\
\text { High }\end{array}$ & $\begin{array}{c}\text { Ref } \\
3.222 \\
\end{array}$ & $\begin{array}{c}\text { Ref } \\
(0.906-29.063)\end{array}$ & 0.179 & $\begin{array}{c}\text { Ref } \\
32.185\end{array}$ & $\begin{array}{c}\text { Ref } \\
(7.185-87.185)\end{array}$ & $0.002 *$ \\
\hline
\end{tabular}

$\mathrm{R}^{2}=0.173$ (Cox and Snell), 0.180 (Nagelkerke). $\chi^{2}(42)=46.202, P=0.043$

${ }^{\dagger}$ Model adjusted for age, income, time from diagnosis of HIV, drug use, alcohol consumption, smoking status and types of ART medications.

*Significant

Table 26: Linear Regression Analysis of the Effect of Global PIRS, Global PSQI and GAD-7 Scores on Immunological and Virologic Markers of Disease Progression

\begin{tabular}{|c|c|c|c|c|c|c|}
\hline & \multicolumn{3}{|c|}{ Unadjusted } & \multicolumn{3}{|c|}{ Adjusted $^{\dagger}$} \\
\hline & Beta & SE & $P$-value & Beta & SE & $P$-value \\
\hline \multicolumn{7}{|l|}{ Global PIRS $^{\text {a }}$} \\
\hline CD4 square root & -0.913 & 0.128 & 0.316 & -1.202 & 0.649 & $0.015 *$ \\
\hline $\log _{10}$ Viral load & 1.659 & 0.735 & 0.698 & 1.949 & 0.933 & $0.045^{*}$ \\
\hline \multicolumn{7}{|l|}{ Global PSQI $^{\mathrm{b}}$} \\
\hline CD4 square root & -0.782 & 0.110 & 0.479 & -1.149 & 0.931 & 0.036* \\
\hline $\log _{10}$ Viral load & 1.176 & 0.924 & 0.741 & 1.988 & 0.828 & $0.031^{*}$ \\
\hline \multicolumn{7}{|l|}{ GAD-7 ${ }^{\mathrm{c}}$} \\
\hline CD4 square root & -0.476 & 0.239 & 0.643 & -1.122 & 0.964 & $0.031^{*}$ \\
\hline $\log _{10}$ Viral load & 1.508 & 1.219 & 0.417 & 1.269 & 0.425 & $0.029 *$ \\
\hline
\end{tabular}

${ }^{a}$ Model $\mathrm{R}^{2}=0.187, \mathrm{~F}(14)=32.390, P=0.041$.

${ }^{\mathrm{b}}$ Model $\mathrm{R}^{2}=0.188$, F (14) $=28.833, P=0.046$.

${ }^{\mathrm{c}}$ Model $\mathrm{R}^{2}=0.220$, F (14) $=20.862, P=0.014$.

${ }^{\dagger}$ Model adjusted for time from diagnosis of HIV, drug use, smoking status, alcohol use and different types of ART medications. *Significant 
Table 27: Linear Mixed Model Analysis of Over Time Changes in Immunological and Virologic Markers of Disease Progression due to Global PIRS, Global PSQI and GAD-7 Scores

\begin{tabular}{|c|c|c|c|c|c|c|}
\hline & \multicolumn{3}{|c|}{ Unadjusted } & \multicolumn{3}{|c|}{ Adjusted $^{\dagger}$} \\
\hline & Beta & SE & $P$-value & Beta & SE & $P$-value \\
\hline \multicolumn{7}{|l|}{ Global PIRS $^{\text {a }}$} \\
\hline CD4 square root & -0.643 & 0.126 & 0.817 & -0.923 & 0.680 & 0.732 \\
\hline $\log _{10}$ Viral load & 0.848 & 0.714 & 0.732 & 1.213 & 0.615 & 0.890 \\
\hline \multicolumn{7}{|l|}{ Global PSQI $^{\mathrm{b}}$} \\
\hline CD4 square root & -0.537 & 0.638 & 0.401 & -1.081 & 0.722 & 0.260 \\
\hline $\log _{10}$ Viral load & 0.918 & 0.814 & 0.201 & 1.013 & 0.716 & 0.429 \\
\hline \multicolumn{7}{|l|}{ GAD-7 ${ }^{\mathrm{c}}$} \\
\hline CD4 square root & -0.366 & 0.152 & 0.900 & -1.011 & 0.583 & 0.838 \\
\hline $\log _{10}$ Viral load & 0.960 & 0.811 & 0.608 & 0.984 & 0.213 & 0.880 \\
\hline
\end{tabular}

aModel: -2 Restricted Log Likelihood = 1146.722; Akaike's Information Criteria (AIC) = 1150.722; Schwarz’s Bayesian Criteria $(B I C)=1157.005$.

bModel: -2 Restricted Log Likelihood = 1140.831; Akaike's Information Criteria (AIC) =1144.831; Schwarz's Bayesian Criteria $($ BIC) = 1151.115.

'Model: -2 Restricted Log Likelihood = 1142.502; Akaike's Information Criteria (AIC) = 1146.502; Schwarz's Bayesian Criteria $(B I C)=1152.785$.

${ }^{\dagger}$ Model adjusted for time from diagnosis of HIV, drug use, smoking status, alcohol use and different types of ART medications. 


\section{References}

1. Federal Department of Health. HIV Disease: United States vs Florida. 2014; http://www.floridahealth.gov/diseases-andconditions/aids/surveillance/_documents/fact-sheet/2014/2014-us-vs-fl-factsheet.pdf. Accessed December 20, 2014.

2. Cohen FL, Ferrans CE, Vizgirda V, Kunkle V, Cloninger L. Sleep in men and women infected with human immunodeficiency virus. Holistic Nursing Practice. 1996;10(4):33-43.

3. Nokes KM, Kendrew J. Sleep quality in people with HIV disease. Journal of the Association of Nurses in AIDS Care. 1996;7(3):43-50.

4. Nokes KM, Chidekel JH, Kendrew J. Exploring the complexity of sleep disturbances in persons with HIV/AIDS. Journal of the Association of Nurses in AIDS Care. 1999;10(3):22-29.

5. Nokes KM, Kendrew J. Correlates of sleep quality in persons with HIV disease. Journal of the Association of Nurses in AIDS Care. 2001;12(1):17-22.

6. Gamaldo CE, Gamaldo A, Creighton J, et al. Evaluating sleep and cognition in HIV. JAIDS Journal of Acquired Immune Deficiency Syndromes. 2013;63(5):609616.

7. Motivala SJ, Hurwitz BE, Llabre MM, et al. Psychological distress is associated with decreased memory helper T-cell and B-cell counts in pre-AIDS HIV seropositive men and women but only in those with low viral load. Psychosomatic Medicine. 2003;65(4):627-635.

8. Vosvick M, Gore-Felton C, Ashton E, et al. Sleep disturbances among HIVpositive adults: the role of pain, stress, and social support. Journal of Psychosomatic Research. 2004;57(5):459-463.

9. Hindmarch I, Rigney U, Stanley N, Quinlan P, Rycroft J, Lane J. A naturalistic investigation of the effects of day-long consumption of tea, coffee and water on alertness, sleep onset and sleep quality. Psychopharmacology. 2000;149(3):203216.

10. Nardi AE, Lopes FL, Freire RC, et al. Panic disorder and social anxiety disorder subtypes in a caffeine challenge test. Psychiatry Research. 2009;169(2):149-153.

11. Dreher HM. The effect of caffeine reduction on sleep quality and well-being in persons with HIV. Journal of Psychosomatic Research. 2003;54(3):191-198. 
12. United States Food and Drug Administration. FDA to investigate added caffeine. 2013; http://www.fda.gov/downloads/ForConsumers/ConsumerUpdates/UCM350 740.pdf. Accessed October 20, 2014.

13. Moul D, Pilkonis P, Miewald J, Carey T, Buysse D. Preliminary study of the testretest reliability and concurrent validities of the Pittsburgh Insomnia Rating Scale (PIRS). Paper presented at: Sleep2002.

14. Buysse DJ, Reynolds CF, Monk TH, Berman SR, Kupfer DJ. The Pittsburgh Sleep Quality Index: a new instrument for psychiatric practice and research. Psychiatry Research. 1989;28(2):193-213.

15. Spitzer RL, Kroenke K, Williams JB, Löwe B. A brief measure for assessing generalized anxiety disorder: the GAD-7. Archives of Internal Medicine. 2006;166(10):1092-1097.

16. Preston JD, O'Neal JH, Talaga MC. Consumer's Guide to Psychiatric Drugs. New Harbinger Publications, Inc; 1998.

17. United States Food and Drug Administration. Database of Select Committee on GRAS Substances (SCOG) Reviews: Caffeine. 2006; http://www.accessdata.fda.gov/scripts/fcn/fcnDetailNavigation.cfm?rpt=sco gsListing\&id=42. Accessed Spetember 12, 2014.

18. United States Food and Drug Administration. FDA to investigate added caffeine. 2013; http://www.fda.gov/downloads/ForConsumers/ConsumerUpdates/UCM350 740.pdf. Accessed September 22013.

19. World Health Organization. Lexicon of alcohol and drug terms published by the World Health Organization. Accessed September 22013.

20. World Health Organization. Mental and behavioural disorders F15. International Statistical Classification of Diseases and Related Health Problems. 2010;Chapter 5(Mental and behavioural disorders due to use of other stimulants, including caffeine.).

21. American Psychiatric Association. Diagnostic and Statistical Manual of Mental Disorders. Vol Fifth ed2013.

22. Carpenter JS, Andrykowski MA. Psychometric evaluation of the Pittsburgh sleep quality index. Journal of Psychosomatic Research. 1998;45(1):5-13.

23. Fichtenberg NL, Putnam SH, Mann NR, Zafonte RD, Millard AE. Insomnia screening in postacute traumatic brain injury: utility and validity of the Pittsburgh 
Sleep Quality Index. American Journal of Physical Medicine \& Rehabilitation. 2001;80(5):339-345.

24. Backhaus J, Junghanns K, Broocks A, Riemann D, Hohagen F. Test-retest reliability and validity of the Pittsburgh Sleep Quality Index in primary insomnia. Journal of Psychosomatic Research. 2002;53(3):737-740.

25. Kroenke K, Spitzer RL, Williams JB, Monahan PO, Löwe B. Anxiety disorders in primary care: prevalence, impairment, comorbidity, and detection. Annals of Internal Medicine. 2007;146(5):317-325.

26. Moyle G, Fletcher C, Brown H, Mandalia S, Gazzard B. Changes in sleep quality and brain wave patterns following initiation of an efavirenz-containing triple antiretroviral regimen. HIV Medicine. 2006;7(4):243-247.

27. Dorey-Stein Z, Amorosa VK, Kostman JR, Lo Re V, Shannon RP. Severe Weight Gain, Lipodystrophy, Dyslipidemia, and Obstructive Sleep Apnea in a Human Immunodeficiency Virus-Infected Patient Following Highly Active Antiretroviral Therapy. Journal of the Cardiometabolic Syndrome. 2008;3(2):111-114.

28. Morrison MF, Petitto JM, Have TT, et al. Depressive and anxiety disorders in women with HIV infection. American Journal of Psychiatry. 2002;159(5):789796.

29. Moss T, Martin CW, Klausner JD, Brown BJ. Integration of Screening for Syphilis, Hepatitis C, and Other Sexually Transmitted Infections with HIV Testing in a Community-Based HIV Prevention Program in Miami, Florida. LGBT Health. 2014;1(2):82-85.

30. Wawrzyniak AJ, Rodríguez AE, Falcon AE, et al. Association of Individual and Systemic Barriers to Optimal Medical Care in People Living With HIV/AIDS in Miami-Dade County. JAIDS Journal of Acquired Immune Deficiency Syndromes. 2015;69:S63-S72.

31. Penetar D, McCann U, Thorne D, et al. Caffeine reversal of sleep deprivation effects on alertness and mood. Psychopharmacology. 1993;112(2-3):359-365.

32. Griffiths RR, Woodson PP. Reinforcing effects of caffeine in humans. Journal of Pharmacology and Experimental Therapeutics. 1988;246(1):21-29.

33. Wesensten N, Belenky G, Kautz MA, Thorne DR, Reichardt RM, Balkin TJ. Maintaining alertness and performance during sleep deprivation: modafinil versus caffeine. Psychopharmacology. 2002;159(3):238-247.

34. Wesensten NJ. Legitimacy of concerns about caffeine and energy drink consumption. Nutrition Reviews. 2014;72(suppl 1):78-86. 
35. Taibi DM. Sleep disturbances in persons living with HIV. Journal of the Association of Nurses in AIDS Care. 2013;24(1):S72-S85.

36. Lee KA, Gay C, Portillo CJ, et al. Types of sleep problems in adults living with HIV/AIDS. Journal of Clinical Sleep Medicine: JCSM: official publication of the American Academy of Sleep Medicine. 2012;8(1):67.

37. Taibi DM, Price C, Voss J. A pilot study of sleep quality and Rest-Activity patterns in persons living with HIV. Journal of the Association of Nurses in AIDS Care. 2013;24(5):411-421.

38. Webel AR, Moore SM, Hanson JE, Patel SR, Schmotzer B, Salata RA. Improving sleep hygiene behavior in adults living with HIV/AIDS: a randomized control pilot study of the SystemCHANGE TM-HIV intervention. Applied Nursing Research. 2013;26(2):85-91.

39. Gallego L, Barreiro P, del Río R, et al. Analyzing sleep abnormalities in HIVinfected patients treated with Efavirenz. Clinical Infectious Diseases. 2004;38(3):430-432.

40. Hudson AL, Portillo CJ, Lee KA. Sleep disturbances in women with HIV or AIDS: efficacy of a tailored sleep promotion intervention. Nursing Research. 2008;57(5):360-366.

41. Lee KA, Portillo CJ, Miramontes H. The influence of sleep and activity patterns on fatigue in women with HIV/AIDS. Journal of the Association of Nurses in AIDS Care. 2001;12:19-27.

42. Robbins JL, Phillips KD, Dudgeon WD, Hand GA. Physiological and psychological correlates of sleep in HIV infection. Clinical Nursing Research. 2004;13(1):33-52.

43. Cruess DG, Antoni MH, Gonzalez J, et al. Sleep disturbance mediates the association between psychological distress and immune status among HIVpositive men and women on combination antiretroviral therapy. Journal of Psychosomatic Research. 2003;54(3):185-189.

44. Patel NP, Grandner MA, Xie D, Branas CC, Gooneratne N. Sleep disparity" in the population: poor sleep quality is strongly associated with poverty and ethnicity. BMC Public Health. 2010;10(1):475-485.

45. Roehrs T, Burduvali E, Bonahoom A, Drake C, Roth T. Ethanol and sleep loss: a" dose" comparison of impairing effects. SLEEP-NEW YORK THEN WESTCHESTER-. 2003;26(8):981-985. 
46. Moldofsky H, Gilbert R, Lue FA, MacLean AW. Sleep-related violence. Sleep. 1995;18(9):731-739.

47. Christian J. Fatigue, sleep disturbance, disability, and indices of progression of HIV infection. Am J Psychiatry. 1992;1:49.

48. Schneider M, Chersich M, Neuman M, Parry C. Alcohol consumption and HIV/AIDS: the neglected interface. Addiction. 2012;107(8):1369-1371.

49. Darke S, Swift W, Hall W, Ross M. Drug use, HIV risk-taking and psychosocial correlates of benzodiazepine use among methadone maintenance clients. Drug and Alcohol Dependence. 1993;34(1):67-70.

50. Nieman RB, Fleming J, Coker RJ, Harris JW, Mitchell DM. The effect of cigarette smoking on the development of AIDS in HIV-1-seropositive individuals. Aids. 1993;7(5):705-710.

51. Lyles RH, Muñoz A, Yamashita TE, et al. Natural history of human immunodeficiency virus type 1 viremia after seroconversion and proximal to AIDS in a large cohort of homosexual men. Journal of Infectious Diseases. 2000;181(3):872-880.

52. Rosenthal R, Rubin DB. Interpersonal expectancy effects: The first 345 studies. Behavioral and Brain Sciences. 1978;1(03):377-386. 


\title{
CHAPTER-VI: CAFFEINE INTAKE AND ITS ASSOCIATION WITH NUTRITIONAL PARAMETERS IN MIAMI ADULT STUDIES OF HIV (MASH) COHORT-AN OBSERVATIONAL STUDY
}

\begin{abstract}
\end{abstract}
Introduction: In a number of studies, people living with HIV (PLWH) have reported inadequate dietary intakes and compromised body compositions measures even when they were on ART. Additionally, weight-loss and reduced body fat reserves were associated with accelerated HIV-disease progression. Although the literature abounds on studies on caffeine consumption and its relationship with changes in bodyweight and body composition in healthy populations, similar studies in PLWH are few.

Methods: We examined the impact of high caffeine consumption on dietary intake and body composition measures in a convenience sample of $130 \mathrm{HIV}+$ participants (65 consuming $\leq 250 \mathrm{mg} /$ day and 65 consuming $>250 \mathrm{mg}$ /day of caffeine) recruited from the Miami Adult Studies on HIV (MASH) cohort. This study included a baseline and a 3month follow-up visits. After obtaining written informed consent, caffeine consumption was estimated using Modified Caffeine Consumption Questionnaire (MCCQ). Information on demographics, anthropometries, body composition measures, substance use, 24-hour dietary recall, Food Security Scores and antiretroviral therapy (ART) were obtained from the MASH cohort database. T-tests and chi-square were used to describe demographics and health and lifestyle characteristics. Linear regressions were used to analyze baseline data for the effects of caffeine intake on the outcome variables. Linear Mixed Models were used to estimate the effect of caffeine consumption on these parameters over time. 
Results: The mean age of the cohort was $47.89 \pm 6.37$ years, $60.8 \%$ were males and 75.4\% were African-Americans. All participants were on antiretroviral treatment (ART) throughout the study. Mean caffeine intake at the baseline was $161.26 \pm 194.95 \mathrm{mg} /$ day (3-8 cups of coffee) (Range: $0 \mathrm{mg}-1498 \mathrm{mg} /$ day) and did not change significantly at the 3-month visit. Fat (93.43 \pm 48.484 vs $170.94 \pm 44.585, P=0.048)$, carbohydrate $(259.15$ \pm 132.242 vs $341.83 \pm 133.437, P=0.048)$ and protein $(85.24 \pm 40.866$ vs $94.82 \pm 54.556$, $P=0.046$ ) intakes were significantly lower in participants consuming $>250 \mathrm{mg}$ of caffeine/day, compared to those who consumed $\leq 250 \mathrm{mg}$ of caffeine/day. Higher caffeine consumption was also associated with lower fat mass $(\beta=-0.994, P=0.042)$, lower caloric intakes $(\beta=-1.643, P=0.042)$ and lower fat consumption $(\beta=-1.902$, $P=0.044$ ), in conjunction with the use of other anorexic agents such as cocaine use and amphetamine after adjusting for HIV viral load and ART medications.

Conclusion: Higher caffeine consumption was associated with lower dietary intakes of macronutrients and lower fat reserves. These associations also became weaker or disappeared when adjusting for, or excluding, the use of other anorexic and stimulant drugs such as cocaine and methamphetamine, suggesting that caffeine may worsen the action of these drugs. Future large scale studies are needed to understand the level of caffeine's influences on these health and nutritional outcomes.

Keywords: Modified Caffeine Consumption Questionnaire (MCCQ), HIV infection, Body Mass Index (BMI), Lean Body Mass (LBM). 


\section{INTRODUCTION}

With significant improvements in availability and accessibility of combination ART, HIV is currently a chronic disease with decreasing incidence, increasing prevalence and 97\% decrease in progression to AIDS and death, thereby increasing the number of people living with HIV (PLWH). ${ }^{1}$ According to CDC's estimates in 2013, there were about 1.2 million PLWH in the $\mathrm{US}^{2}$ and 26,760 of them were living in Miami. ${ }^{3}$

Most of the PLWH in Miami live in marginalized neighborhoods with limited resources. ${ }^{4}$ Many socioeconomic factors such as homelessness, illegal commercial sex, drug abuse, alcohol addiction, extreme tobacco use and criminalization act as barriers for access to nutritious foods and supplements and compliance with ART. ${ }^{5-10}$ Though the majority of the MASH cohort, from which our participants were recruited, received social security benefits and some forms of food assistance, many experience food insecurity. ${ }^{10}$ Food insecurity and decreased food intake are associated with uncontrolled HIV viral load and increased mortality even in participants on ART. ${ }^{11,12}$ Similarly weight loss and lower BMI are associated with faster disease progression as measured by lower CD4 cell counts and uncontrolled HIV viral load even in PLWH on ART. ${ }^{13-15}$

Caffeine shows anorexic, lipolytic and thermogenic effects due to its inhibitory action on cAMP degradation pathway, as well as increased cAMP generation via stimulation of beta-adrenergic receptors. ${ }^{16}$ In a double blind placebo controlled study on healthy volunteers, caffeine intake (100, 200 and $400 \mathrm{mg} /$ day) produced a positive and dose-dependent increase in resting energy expenditures (REE), $(r=0.86 ; P<0.001)$, after controlling for plasma lactate levels and plasma triglyceride levels. ${ }^{17}$ In another double blind placebo controlled study on the supplement Meltdown ${ }^{\circledR}$, containing caffeine (400 
mg/pill), participants who were administered the supplement once per day, recorded higher Area Under the Curve (AUC) for serum norepinephrine levels (NE), glycerol, free fatty acids (FFA), and basal metabolic rate (BMR) compared to placebo, indicating increased Resting Energy Expenditures (REE). ${ }^{18}$ Similar effects were reported in another study where $450 \mathrm{mg} /$ day of caffeine produced higher AUC for resting oxygen uptake (VO2), which is also a measure of REE. ${ }^{19}$ Caffeine at a dose of $700 \mathrm{mg} /$ day also produced 2-fold increase in lipid turnover $(P<0.005)$, increased thermic effect $(P<$ 0.001), and 2.3 times increased oxidative free fatty acid (FFA) disposal $(P<0.01)$ compared to placebo pills, indicating increased REE and lipid breakdown. ${ }^{16}$

Caffeine consumption (250 mg/day) was also associated with lower plasma levels of antioxidant trace elements such as Zinc And Selenium after controlling for dietary intakes, age, physical activity and substance use. ${ }^{20}$ This relationship also showed a dose-response pattern, with lower caffeine consumption associated with decreased depletion of antioxidant trace elements. ${ }^{20}$

In summary, the literature supports that caffeine acted as an anorexic agent, increased energy expenditure, precipitated weight loss, and depleted antioxidant nutrients. Such effects could be detrimental to PLWH, because many of them already experience food scarcity and insecurity. ${ }^{10}$ Our study evaluated the effects of caffeine consumption on nutrient intake, body composition and nutritional indicators in a group of PLWH who were recruited from the MASH cohort. This study also examined the relationship between food security scores and caffeine consumption levels. In addition, this study also examined the net effects of body composition measures and macronutrient intakes on markers of HIV disease progression (CD4 counts and viral load). 


\section{METHODS}

\section{Study Design and Setting}

The present study recruited a convenience sample of 130 participants (65 consuming $\leq$ $250 \mathrm{mg} /$ day and 65 consuming > $250 \mathrm{mg} /$ day of caffeine) from the MASH cohort, which consisted of 803 HIV positive and 78 uninfected participants, followed for more than 10 years at the FIU research clinic in the Borinquen Health Care Center (BHCC). The BHCC provides comprehensive range of health and social services to a culturally diverse low income community. The recruitment for the present study took place from February to July 2014. The present study included a baseline and a 3-month follow-up visit, and participants received \$5 as partial reimbursement for their time and efforts, for each of the two visits. The initial screening included detailed explanation of the study as well as obtaining informed voluntary written consent for participation. In order to obtain a study sample of 128 participants as estimated in our sample size calculations, we screened a total of 150 subjects, enrolled 130 participants and excluded 20 ineligible participants. The present study also included secondary analysis of relevant variables collected for the MASH cohort studies. Data collected during the baseline and 3-month visits were used for the analyses of descriptive and inferential statistics. The inclusion and exclusion criteria for the MASH cohort are presented in “Chapter 3: Methodology” and applicable to our current study. The additional inclusion criteria for participants in the present study were: enrollment in the MASH cohort; receiving ART; and willingness to participate in a study with two visits, a baseline and one follow-up visit at 3 months. The exclusion criteria were: cardiovascular abnormalities or implanted pacemakers; morbid medical conditions such as uncontrolled hypertension, anemia, chronic inflammatory diseases or 
mal-absorption syndromes. The Institutional Review Board at Florida International University approved the study protocol and research procedures.

\section{Survey Instruments, Outcome Measures and Variables}

The questionnaires used in the present study were previously field tested and validated in several large scale studies. ${ }^{21-24}$ However, we pre-tested these questionnaires on 15 participants from the MASH cohort to ascertain their applicability and we determined that revisions were not necessary for the questionnaires.

Caffeine consumption questionnaire: We used the Modified Caffeine Consumption Questionnaire (MCCQ) developed by Preston et al in the year $1998 .{ }^{25}$ This questionnaire is easy to understand, compact, organized and reports adequate compliance, validity and reliability. ${ }^{25}$ This questionnaire was field tested and validated in several large scale studies and adequately reflected average daily caffeine consumption levels. ${ }^{21}$ It includes a total of 21 sources of caffeine classified in to three groups, 'Beverages', 'Over the counter medications' and 'Prescription medications'. This questionnaire also included ‘Total caffeine consumption per day’ by adding these individual sources. Caffeine consumption was analyzed both as a continuous variable and a categorical variable.

For both naturally occurring and artificially added caffeine sources, FDA considers $400 \mathrm{mg} /$ day (6-7 cups of coffee) to be generally safe and not associated with any dangerous side effects. ${ }^{26,27}$ The World Health Organization (WHO) defines caffeine overuse as daily consumption beyond $500 \mathrm{mg} / \mathrm{d}^{28,29}$ Beyond this level caffeine produces visible adverse effects collectively known as ‘caffeinism'. The World Health Organization (WHO) has also cautioned that these adverse effects could be precipitated at much lower doses depending on the physiological profiles of individuals as well as the 
genetic makeup of the population. ${ }^{28,29}$ The International Classification of Diseases (ICD) manual considers caffeine consumption above $250 \mathrm{mg}$ /day to be associated with many mental and behavioral disorders though it is inconclusive whether such effects would be uniformly applicable in the general population. ${ }^{13}$ The Diagnostic and Statistical Manual of Mental Disorders (DSM-5) considers consumption below $250 \mathrm{mg} /$ day to be generally safe and above this level to be associated with many adverse effects such as withdrawal, addiction, irritability and craving. ${ }^{30}$ Summarizing these cutoffs, we concluded that caffeine consumption below $250 \mathrm{mg} /$ day that is equivalent to 4 cups of coffee, irrespective of the sources is generally safe and not associated with adverse effects. In this study, caffeine categories included low ( $\leq 250 \mathrm{mg} /$ day, within safe levels) and high (>250 mg/day, beyond safe levels) based on these recommendations.

\section{Nutritional Status Assessment}

Dietary intakes: All research personnel in the MASH cohort studies were trained to obtain 24-hour dietary recalls, which were used to estimate daily dietary and nutrient consumption by the participants. During each MASH cohort study visit, participants were queried about foods and beverages consumed on the day prior to the visit. All details including cooking methods, amount consumed, additional ingredients and seasonings and food brands were recorded to ensure comprehensiveness of the obtained information. We also used props like food models and measuring cups to ensure accuracy of the amounts and volumes consumed and to provide cues for better recall of consumed foods. We used Nutribase Professional Software Version 9 (Cybersoft Inc, 2011), into which all the collected information were entered to obtain a detailed estimation of kilocalories, macronutrients and micronutrients consumed by the participants. Adequacy of nutrient 
intakes were determined using the Daily Values (DV), developed by the FDA by combining two sets of reference values, the Daily Reference Values (DRV) and the Reference Daily Intakes (RDI), to include a comprehensive list of all essential nutrients, including the nutrients for which Recommended Dietary Allowances (RDA) are not established. ${ }^{31}$

Body composition measures: In the MASH cohort studies, after screening the participants, height was recorded immediately using a stadiometer, calibrated according to the instructions in the user's manual. Height was recorded to the nearest 0.5 inch after removing shoes, socks and other footwear. Height was recorded only once to ensure that it was uniform and there were no minor variations during every successive visit. Weight was measured every visit to the nearest $0.1 \mathrm{lbs}$. using a standard weighing machine which was calibrated and maintained throughout the study. Participants were requested to remove their watches, shoes, mobile phones or other heavy materials possessed by them. The data so obtained, along with age, were entered into the bio-impedance machine (Biodynamics-450) 32 $^{32}$ obtain several body composition measures, including body cell mass, extracellular mass, lean body mass (LBM), fat mass, body mass index (BMI) and intracellular and extracellular fluid levels. In addition, we also obtained the waist-to-hip ratio using a non-stretchable tape to measure the waist and hip circumferences at the narrowest levels of the waist and widest levels of the hip.

Biochemical indicators: Nutritional biomarkers which included serum albumin, hemoglobin and hematocrit were obtained at the semiannual MASH visits . In addition, participants provided their most recent laboratory reports from their regular treatment 
visits. The MASH cohort studies also collected other relevant laboratory and clinical data after the participants signed a medical release form.

Immunological and virologic variables: CD4 counts, viral loads and other clinical variables were obtained from participants' medical charts and collected by the MASH cohort study after appropriate medical release by the participants. In the current research, CD4 counts and viral loads were analyzed as continuous variables and transformed into CD4 square root and $\log _{10}$ viral load to ensure normal distribution and better model fit criteria.

\section{Control Variables}

Demographic and socioeconomic information: Demographic variables used for the current study included age, gender, race/ethnicity, education and income levels. A number of health and lifestyle related factors such as tobacco use, alcohol consumption, and illicit drug use were also obtained from the MASH data repository. All these variables were controlled in our analysis based on studies associating these variables with adverse health and nutritional outcomes in HIV. ${ }^{33-46}$

ART medications: We obtained information about types of the antiretroviral medications prescribed by their physicians during the MASH cohort visits. We controlled for these variables because some of the antiretroviral medications were associated with altered nutrition and body composition measures. ${ }^{47-49}$

\section{Statistical Analysis}

Field data were collected in paper based questionnaires and later entered into RedCap database, imported into SPSS version 21 for Windows (Armonk, NY: IBM Corp), and merged into a single dataset for analysis. Descriptive statistics used to understand the 
characteristics of the cohort were expressed in terms of means, standard deviations and percentages and were separated based on low and high intakes of caffeine using the cutoff points: $>250 \mathrm{mg} /$ day for high intake; and $\leq 250 \mathrm{mg} /$ day for low or no intake. Ttests and chi square tests were used to compare the differences in demographics, health and lifestyle characteristics, nutrient intakes and percentages of participants who were not meeting the Daily Values (DV) for the nutrients, between the low and high caffeine groups. Paired sample t-tests were used to understand the changes in caffeine and nutrient intakes between the baseline and 3-month visits. Linear regression analyses were used to estimate the strength of the association of caffeine intake as a continuous variable with body composition measures; nutritional status indicators, dietary intakes and food security scores. Assumptions of linear regression were followed prior to analyses. Linear mixed models (LMM) were used to determine the changes in these associations over time. For parameter estimation in LMM models, Restricted Maximum Likelihood (REML) was used. Multinomial logistic regressions were used to determine the strength of associations between different categories of caffeine intake (low and high) and different categories of food insecurity measured through FSQ scores. Linear Regression was also used to estimate the strength of association between body composition, dietary intakes and food security scores and the markers of HIV disease progression (CD4 counts and viral load). Linear Mixed Models were used to estimate the changes over time in the strength of these associations. For both liner and logistic regressions, as well as liner mixed model analysis, we initially used crude models and subsequently adjusted for covariates such as age, gender, race/ethnicity, grades of schooling, income, time from diagnosis of HIV, drug use, alcohol use, smoking and different types of antiretroviral 
medications, based on studies associating these risk factors with adverse health and nutritional outcomes in HIV. ${ }^{33-49}$ These covariates were also tested for significant associations with the outcome variables using bivariate analysis before being incorporated into the models. To increase the validity of the models, mutlicollinearity among covariates was tested prior to the analyses. Adjusted models included non-missing values for all independent variables included in the models. Statistical significance was set at $P<0.05$ for all the analyses.

\section{RESULTS}

\section{Demographic and Socio-economic Characteristics}

A total of 130 participants were included in the study and 79 (60.8\%) were men. The mean age of the sample was $47.89 \pm 6.37$ years. Most of the participants were African Americans (75.4\%), Hispanics constituted 16.9\%, Whites constituted 5.4\% and other races were 4.6 percent. Less than one fourth (23.8\%) of the participants had college education, while $45.4 \%$ were high school graduates and $30.8 \%$ has some form of primary education. All participants had incomes under the level of poverty and the mean income was $\$ 495.91 \pm 465.887$. There were no significant differences in any socio-demographic variables between low and high levels of caffeine consumption in both baseline and follow-up visits (Table-1A, 1B).

\section{Health/lifestyle Characteristics}

Sixty one percent of the participants reported smoking within the past six weeks of their scheduled baseline visits, $57.9 \%$ reported alcohol use and $48.2 \%$ tested positive for illicit drug use. Similarly, 63.2\% reported smoking, 60.3\% reported alcohol use and 65.8\% tested positive for illicit drug use during the follow-up visit. 
All participants were on ART during the entire duration of the study.

Antiretroviral therapy took many forms, 58.5\% were on NRTI, $13.1 \%$ were on NNRTI and $47.7 \%$ were on PI in several combinations, $26.2 \%$ of the participants were using a one-pill multi-drug combination such as Atripla, Truvada and Combivir during the baseline visit. At the 3-month visit, $63.8 \%$ were on NRTI, $13.8 \%$ were on NNRTI and 47.7\% were on PI, and $25.4 \%$ were on a one-pill multi-drug combination. There were no significant differences in the distribution of these variables between low and high levels of caffeine consumption in both baseline and follow-up visits, or in the distribution of these variables between baseline and follow-up visits (Tables 2 and 3).

\section{Caffeine Consumption from Different Sources}

The mean total caffeine consumption from all sources was $337.63 \pm 304.97 \mathrm{mg} / \mathrm{day}$ (Range: 0-1,498 mg/day) at baseline, and $281.04 \pm 260.85 \mathrm{mg} /$ day (Range: 0-1,175 mg/day) at follow-up. Coffee constituted the largest source of caffeine and mean consumption levels were $161.26 \pm 194.95 \mathrm{mg} /$ day at baseline, and $190.40 \pm 205.03$ mg/day at follow-up. Caffeinated soft drinks constituted the second largest source of caffeine and mean consumption levels were $63.23 \pm 92.98 \mathrm{mg} /$ day at baseline, and 29.66 $\pm 83.78 \mathrm{mg} /$ day at follow-up. There were no significant differences between baseline and follow-up visits with respect to total caffeine consumption or caffeine from most of the sources. However, there was significant decrease in consumption of caffeinated soft drinks (63.23 \pm 92.98 vs. $29.66 \pm 83.78, P<0.00001)$, energy drinks (46.32 \pm 134.42 vs. $9.61 \pm 65.32, P=0.005)$ and hot cocoa $(1.03 \pm 5.00$ vs. $0.00 \pm 0.00, P=0.020)$ from the baseline to the follow-up visits (Table 4). For all other sources of caffeine in the 
questionnaire, except the ones enlisted in Table 4, participants reported none to negligible levels of consumption at both the visits.

\section{Dietary Intakes by Caffeine Consumption Status}

During the baseline visit, total fat $(93.43 \pm 48.484$ vs $170.94 \pm 44.585, P=0.048)$, carbohydrate $(259.15 \pm 132.242$ vs $341.83 \pm 133.437, P=0.048)$ and protein intakes (85.24 \pm 40.866 vs $94.82 \pm 54.556, P=0.046)$ were significantly lower in participants consuming $>250 \mathrm{mg}$ of caffeine per day, compared to participants consuming $\leq 250 \mathrm{mg}$ of caffeine per day (Table 5). Similarly intakes of Sodium, Chloride, Potassium, Calcium, Magnesium, Phosphorus, Vitamin C, Thiamine, Riboflavin, Niacin, Vitamin B6, Vitamin $\mathrm{B}_{12}$, Iron, Zinc and Selenium were also significantly lower in high caffeine consumers compared to low caffeine consumers (Table 5). During the follow-up visits, total calories (1858.27 \pm 932.055 vs $2100.52 \pm 1127.868, P=0.017)$, carbohydrate $(151.32 \pm 116.795$ vs $255.27 \pm 152.914, P=0.042)$, protein $(43.48 \pm 37.841$ vs $86.49 \pm 42.173, P=0.017)$ and fat intake (77.52 \pm 56.469 vs $183.72 \pm 68.771, P=0.026)$ were significantly lower in high caffeine consumers compared to low caffeine consumers (Table 6). Total intakes of Cholesterol, Sodium, Potassium, Thiamine, Riboflavin, Niacin, and Vitamin B6 were also significantly lower in high caffeine group compared to low caffeine group (Table 6). However, there were no significant differences in any nutrient intakes between baseline and follow-up visit (Table 7). During the baseline visit, nutrient intakes were below Daily Values (DV), for many micronutrients (Table 8). All participants reported nutrient intakes below DV for chromium, molybdenum, and chloride. More than $90 \%$ of the participants reported consumption below DV for Potassium, Vitamin D, Vitamin E, Vitamin K, Pantothenic Acid, Iodine, Copper, and Manganese. For many of the 
remaining nutrients, $50.0 \%$ to $87.7 \%$ of the participants reported consumption below DV (Table 8). For total fat, Saturated Fat, Sodium, and protein, less than $50 \%$ of participants reported consumption below DV (Table 8). For most of the nutrients, there were no significant differences between low and high caffeine consumers with respect to the proportion of participants failing to meet the DV, except Sodium (24.6\% vs $10.8 \%$, $P=0.039$ ). Similar trends were observed in follow-up visit (Table 9). More than 99\% of the participants reported consumption below DV for Chromium, Molybdenum and Chloride. Similar to baseline findings, only for total fat, saturated fat, Sodium, and protein, less than $50 \%$ of participants reported consumption below DV. For many nutrients there were no significant differences between low and high caffeine consumers with respect to proportion of participants failing to meet the DV, except for total fat (38.1\% vs $56.7 \%, P=0.034$ ) which was higher in participants consuming $\leq 250 \mathrm{mg}$ of caffeine per day.

\section{Relationship between Caffeine Consumption and Body Composition Measures and Biochemical Indicators}

Mean BMI for this cohort was $26.81 \pm 7.82 \mathrm{~kg} / \mathrm{m}^{2}$ and mean waist to hip ratio was 0.93 . Higher caffeine consumption was associated with lower fat mass ( $\beta=-0.994, P=0.042)$ after adjusting for time from diagnosis of HIV, drug use, smoking status, alcohol use and different types of ART medications (Table 10). Linear mixed model analysis showed that this relationship increased overtime ( $\beta=-1.987, P=0.035$ ), after adjusting for the same covariates (Table 11). Though BMI was not significantly different between low and high caffeine consuming participants, when caffeine was combined with cocaine and amphetamine to form a composite measure of total anorectic agents, we found that BMI 
(27.70 \pm 7.332 vs $25.51 \pm 6.461, P=0.046$ ) was significantly lower and HIV viral load ( $3.23 \pm 1.465$ vs $2.09 \pm 1.137, P=0.000$ ) was significantly higher in those who consumed high caffeine, and reported cocaine and amphetamine use. Similarly linear regression analysis also showed that the effect of cocaine on BMI $(\beta=-2.502, P=0.013)$ decreased upon adjusting for caffeine ( $\beta=-2.352, P=0.046)$, thus justifying that caffeine compounded the weight loss effects of other powerful anorectic agents such as cocaine.

\section{Relationship between Dietary Intakes and Caffeine Consumption}

Higher caffeine intake was significantly associated with lower total caloric intake ( $\beta=-$ 1.643, $P=0.042$ ) and lower calories from fat ( $\beta=-1.902, P=0.044)$, after adjusting for time from diagnosis of HIV, drug use, smoking status, alcohol use and different types of ART medications (Table 12). Linear Mixed Models for the effects of caffeine on macronutrient consumption over time showed no associations (Table 13).

\section{Relationship between Body Composition and Macronutrient Intake and CD4 Count and Viral Load}

No associations were found between body composition measures or macronutrient intakes and CD4 counts and HIV viral load (Table 14, 16). Linear mixed models for the effects of body composition measures and macronutrient intakes on CD4 counts and viral load over time, also showed no associations (Table 15, 17).

\section{DISCUSSION}

During the baseline and follow-up visits, PLWH reported inadequate intakes for many nutrients, such as, total energy, carbohydrate, protein, fat, and many electrolytes, vitamins and minerals. All participants had incomes below the poverty level and more than half of them were consuming alcohol, smoking cigarettes, and had positive urine 
toxicology result for illicit drugs. Poverty, substance abuse and dependence could have adversely influenced their dietary intake and food purchasing potential, which is supported by previous reports. ${ }^{50} \mathrm{~A}$ study done among 459 men and 212 women, living with HIV, found that food insecurity was associated with poverty and substance use. One in four participants in this study reported alcohol and tobacco purchase with resources allocated for food..$^{50}$

In our study, caffeine consumption was associated with decreased dietary intakes for several nutrients and decreased fat mass. Caffeine also contributed to the weight loss effects of other powerful anorectic agents such as cocaine and amphetamine. These adverse associations of caffeine were superimposed on the already inadequate diet recorded for most participants. Adverse effects of caffeine on energy deficits and weight loss were observed in many non-HIV infected populations. ${ }^{51-54}$ In a long-term follow-up study of eighteen years, conducted in 1333 males and 4085 females with type-2 diabetes, there was a strong association between caffeine consumption ( $>4$ cups/day which is approximately >240 mg caffeine/day) and weight loss after controlling for age, baseline body weight, insulin and anti-diabetic drugs, physical activity and lifestyle factors. ${ }^{51}$ Further analysis of the same study found a dose-response relationship between caffeine intake and weight loss. ${ }^{51}$ In a systematic review of twenty studies on the protective effects of caffeine in diabetes, twelve studies reported weight loss due to caffeine consumption. ${ }^{52}$ This review also stated an estimated $100 \mathrm{kcal} /$ day increased energy deficits due to habitual consumption of 7 cups of coffee ( $400 \mathrm{mg}$ caffeine/day). ${ }^{52}$ Eight of these twenty studies also reported a dose-response relationship between caffeine intake and weight loss. ${ }^{52}$ 
Our study also reported that total fat mass was adversely affected by caffeine consumption. Probable mechanisms include increased basal energy expenditures (BEE) and the thermogenic effects of caffeine. ${ }^{54}$ Similar mechanisms were reported in a study done in young healthy women, where, caffeine increased BEE, even in the presence of genetic abnormalities predisposing to decreased BEE. The Arg allele in the beta-3 adrenergic receptor gene (beta-3-AR) is a marker for obesity-related traits, and mutations in this gene leads to decreased BEE. ${ }^{54}$ In a group of women showing beta-3-AR Trp64Arg abnormalities, and consequently decreased BEE, an average early morning dose of $250 \mathrm{mg} /$ day of caffeine, produced significant increase in BEE, measured by indirect open-circuit calorimeter at four intervals during the day, after controlling for age, physical activity, height, blood pressure, dietary intakes of fat, proteins, carbohydrates, cholesterol, fiber, BMI and lifestyle factors. ${ }^{54}$ This study showed that caffeine, independent of genetic predispositions to gain weight, increased resting energy expenditure leading to significant fat loss. ${ }^{54}$

Our study did not find any association between body composition measures, CD4 cell count and HIV viral load. However, higher total fat mass and higher BMI have been associated with better immunological and virologic profiles. Such beneficial effects were reported by Jones et al., ${ }^{13}$ in a study among 871 HIV positive women followed for three years. Cross sectional analysis, survival analysis and longitudinal analysis revealed that, all five HIV disease severity outcomes such as CD4 cell count and viral load; time to first occurrence of CD4 cell count $\leq 200$ cells $/ \mathrm{mm}^{3}$; first occurrence of CD4 cell count $\leq 100$ cells $/ \mathrm{mm}^{3}$; first occurrence of other infection/malignancy; and HIV-related deaths, were significantly delayed in women in the obese group $\left(\mathrm{BMI} \geq 35 \mathrm{~kg} / \mathrm{m}^{2}\right)$, after controlling for 
ART status, baseline BMI, baseline CD4 cell counts, attrition due to death and progression to AIDS, age and lifestyle factors. ${ }^{13}$ A longitudinal study conducted among 125 HIV-1 seropositive drug users on ART showed that non-obese individuals reported $25 \%$ decline in CD4 cell counts, compared to $18 \%$ decline in obese patients $(P<0.004)$, over a period of 18 months. ${ }^{55}$ This study also showed that BMI was inversely associated with time towards progression to AIDS and death, after controlling for covariates such as ART and drug use. This study states that HIV infection constitutes a chronic hypermetabolic state with increased demands on existing fat reserves, which if not replenished, would aggravate the process of wasting. ${ }^{55}$ Many other studies have also reported that resting metabolic rate (RMR) was significantly higher in HIV positive patients compared to healthy controls, leading to energy deficits and wasting. ${ }^{56-58}$ The importance of preserving healthy BMI in PLWH is adequately emphasized in a review by Langford et al., ${ }^{59}$ which summarized that BMI $<20.3 \mathrm{~kg} / \mathrm{m}^{2}$ in men and $<18.5 \mathrm{~kg} / \mathrm{m}^{2}$ in women were strong indicators of mortality due to HIV, in many racially diverse populations. This review also stated that BMI values $17-18 \mathrm{~kg} / \mathrm{m}^{2}$ and $<16 \mathrm{~kg} / \mathrm{m}^{2}$ increased the risk for progression to AIDS by twice and 5 times, respectively, and that BMI $<18.5 \mathrm{~kg} / \mathrm{m}^{2}$ was as useful as clinical staging and serological and immunological markers for decisions about ART initiations. ${ }^{59}$ All these studies justify the need to prevent weight loss; especially loss of fat mass in HIV positive patients. Therefore, high caffeine intake, a known anorectic, should be prevented in PLWH reporting decreased BMI, fat mass and signs of wasting.

Our study also found that caffeine consumption was associated with lower intakes of several micronutrients such as Vitamin C, Thiamin, Riboflavin, Niacin, Vitamin $\mathrm{B}_{6}$, Vitamin $B_{12}$, Iron, Zinc and Selenium. This is consistent with previous findings reported 
in a study of $225 \mathrm{HIV}$ positive participants, where caffeine at a level of $115 \mathrm{mg} /$ day was associated with decreased plasma levels of Zinc, after controlling for age, gender, CD4 count, viral load and ART. ${ }^{20}$ Though the mechanisms for such findings are unclear, decreased dietary intakes could have precipitated such events, as supported by our study. Future large studies should investigate such effects to understand the bio-chemical mechanisms for such micronutrient depletions. Similar to what we observed in our study, a study by Laurie et al., ${ }^{60}$ on 264 HIV positive and 127 un-infected participants, reported significantly lower intakes of Vitamin C and Vitamin E, in HIV positive participants, when compared to un-infected participants, after controlling for several dietary, behavioral and lifestyle factors. Furthermore, deficiencies of micronutrients such as Zinc and Selenium have been independently associated with accelerated HIV disease progression and mortality risks, ${ }^{61,62}$ and caffeine intake is one more factor that could affect this relationship.

In spite of the findings in this study, we have to acknowledge some of its limitations. The current study enrolled a consecutive convenient sample of $130 \mathrm{HIV}$ positive participants and the generalizability is weak. Participating in the baseline could also have influenced the outcomes in the follow-up visit, as the participants could have been affected by an "Interpersonal Expectancy Bias," 63 by which they would have responded what they believed the investigators wanted to hear or the investigators would have recorded what they wanted to report. In addition, the 24-hour dietary recall used for assessing nutrient consumption is a self-reported parameter and subject to memory and recall biases. 
Large scale studies should be conducted with controlled dietary and lifestyle factors, as well as controlled study settings, to overcome the limitations of our study. Though, our findings showed that caffeine intake adversely affected dietary intakes of several nutrients and body composition measures and, in turn, adversely affected HIV disease progression, these findings should be confirmed by such large scale studies.

\section{Acknowledgements}

I would like to thank Dr. Marianna Baum and their research group for their assistance in providing access to the MASH cohort data repository, as well as for their collaboration and advisement on the intellectual content of this article. I am grateful for the support provided by Florida International University Graduate School, in the form of Data and Evidence Acquisition Fellowship and Doctoral Year Fellowship. Overall, I am very grateful to the FIU-Borinquen team, who collaborated enthusiastically with this

project, and especially for the generosity of our participants who gave us their time and efforts. 
Table 1A: Baseline Demographic Characteristics of PLWH by Caffeine Consumption Levels

\begin{tabular}{|c|c|c|c|c|}
\hline \multirow[b]{2}{*}{ Variables } & \multicolumn{4}{|c|}{ Baseline } \\
\hline & Total & 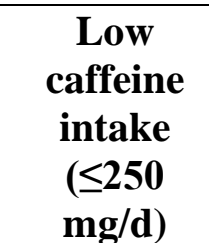 & $\begin{array}{c}\text { High } \\
\text { caffeine } \\
\text { intake } \\
(>250 \\
\text { mg/d) }\end{array}$ & $P$-value \\
\hline $\begin{array}{l}\text { Age in years } \\
\text { (Mean } \pm \text { SD) }\end{array}$ & $47.89 \pm 6.37$ & $47.57 \pm 6.81$ & $48.00 \pm 6.15$ & 0.706 \\
\hline $\begin{array}{r}\text { Gender, N (\%) } \\
\text { Male } \\
\text { Female } \\
\end{array}$ & $\begin{array}{l}79(60.8 \%) \\
51(39.2 \%)\end{array}$ & $\begin{array}{l}40(61.5 \%) \\
25(38.5 \%)\end{array}$ & $\begin{array}{l}39(60.0 \%) \\
26(40.0 \%)\end{array}$ & 0.857 \\
\hline $\begin{array}{r}\text { Ethnicity, } \mathrm{N}(\%) \\
\text { White } \\
\text { Hispanic } \\
\text { Black } \\
\text { Other } \\
\end{array}$ & $\begin{array}{l}7(5.4 \%) \\
22(16.9 \%) \\
98(75.4 \%) \\
3(2.3 \%) \\
\end{array}$ & $\begin{array}{l}3(4.6 \%) \\
7(10.8 \%) \\
55(84.6 \%) \\
0(0.0 \%)\end{array}$ & $\begin{array}{l}4(6.2 \%) \\
15(23.1 \%) \\
43(66.2 \%) \\
3(4.6 \%) \\
\end{array}$ & 0.057 \\
\hline $\begin{array}{l}\text { Education in years, } \\
\mathrm{N}(\%) \\
\\
<12 \\
12 \\
>12\end{array}$ & $\begin{array}{l}40(30.8 \%) \\
59(45.4 \%) \\
31(23.8 \%)\end{array}$ & $\begin{array}{l}24(36.9 \%) \\
29(44.6 \%) \\
12(18.5 \%)\end{array}$ & $\begin{array}{l}16(24.6 \%) \\
30(46.2 \%) \\
19(29.2 \%)\end{array}$ & 0.202 \\
\hline $\begin{array}{l}\text { Income in dollars } \\
\text { per month }\end{array}$ & $\begin{array}{l}495.91 \pm \\
465.887\end{array}$ & $\begin{array}{l}464.00 \pm \\
419.667\end{array}$ & $\begin{array}{l}527.34 \pm \\
508.637\end{array}$ & 0.442 \\
\hline
\end{tabular}

Note: $P$-values corresponds to $\chi^{2}$ tests for categorical variables and t-test for continuous variables 
Table 1B: Follow-up Demographic Characteristics of PLWH by Caffeine Consumption Levels

\begin{tabular}{|c|c|c|c|c|}
\hline \multirow[b]{2}{*}{ Variables } & \multicolumn{4}{|c|}{ Follow-up } \\
\hline & Total & $\begin{array}{c}\text { Low } \\
\text { caffeine } \\
\text { intake } \\
(\leq 250 \\
\mathbf{m g} / \mathbf{d})\end{array}$ & $\begin{array}{c}\text { High } \\
\text { caffeine } \\
\text { intake } \\
(>250 \\
\text { mg/d) }\end{array}$ & $P$-value \\
\hline $\begin{array}{l}\text { Age in years } \\
\text { (Mean } \pm \text { SD) }\end{array}$ & $47.89 \pm 6.37$ & $46.63 \pm 7.33$ & $48.87 \pm 5.38$ & 0.490 \\
\hline $\begin{array}{r}\text { Gender, N (\%) } \\
\text { Male } \\
\text { Female }\end{array}$ & $\begin{array}{l}79(60.8 \%) \\
51(39.2 \%)\end{array}$ & $\begin{array}{l}43(68.3 \%) \\
20(31.7 \%) \\
\end{array}$ & $\begin{array}{l}36(53.7 \%) \\
31(46.3 \%) \\
\end{array}$ & 0.090 \\
\hline $\begin{array}{r}\text { Ethnicity, } \mathrm{N}(\%) \\
\text { White } \\
\text { Hispanic } \\
\text { Black } \\
\text { Other }\end{array}$ & $\begin{array}{l}7(5.4 \%) \\
22(16.9 \%) \\
98(75.4 \%) \\
3(2.3 \%)\end{array}$ & $\begin{array}{l}4(6.3 \%) \\
9(14.3 \%) \\
50(79.4 \%) \\
0(0.0 \%)\end{array}$ & $\begin{array}{l}3(4.5 \%) \\
13(19.4 \%) \\
48(71.6 \%) \\
3(4.6 \%)\end{array}$ & 0.285 \\
\hline 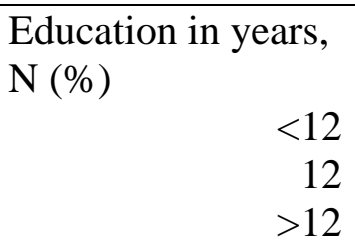 & $\begin{array}{l}40(30.8 \%) \\
59(45.4 \%) \\
31(23.8 \%)\end{array}$ & $\begin{array}{l}21(33.3 \%) \\
29(46.0 \%) \\
13(20.6 \%)\end{array}$ & $\begin{array}{l}19(28.4 \%) \\
30(44.8 \%) \\
18(26.9 \%)\end{array}$ & 0.670 \\
\hline $\begin{array}{l}\text { Income in dollars } \\
\text { per month }\end{array}$ & $\begin{array}{l}495.91 \pm \\
465.887\end{array}$ & $\begin{array}{l}498.80 \pm \\
511.708\end{array}$ & $\begin{array}{l}492.89 \pm \\
416.619\end{array}$ & 0.943 \\
\hline
\end{tabular}

Note: $P$-values corresponds to $\chi^{2}$ tests for categorical variables and t-test for continuous variables 
Table 2: Baseline Health and Lifestyle Characteristics of PLWH by Caffeine Consumption Levels

\begin{tabular}{|c|c|c|c|c|}
\hline Variables & Total & $\begin{array}{l}\text { Low caffeine } \\
\text { intake } \\
(\leq 250 \mathrm{mg} / \mathrm{d})\end{array}$ & $\begin{array}{l}\text { High caffeine } \\
\text { intake } \\
(>250 \mathrm{mg} / \mathrm{d})\end{array}$ & $\begin{array}{c}P \text { - } \\
\text { value }\end{array}$ \\
\hline $\begin{array}{r}\text { Smoking cigarettes } \\
\text { Yes } \\
\text { No }\end{array}$ & $\begin{array}{l}80(63.5 \%) \\
46(36.5 \%)\end{array}$ & $\begin{array}{l}39(60.9 \%) \\
25(39.1 \%)\end{array}$ & $\begin{array}{l}41(66.1 \%) \\
21(33.9 \%)\end{array}$ & 0.582 \\
\hline Alcohol use & $\begin{array}{l}73(57.9 \%) \\
53(42.1 \%)\end{array}$ & $\begin{array}{l}36(56.3 \%) \\
28(43.8 \%)\end{array}$ & $\begin{array}{l}37(59.7 \%) \\
25(40.3 \%)\end{array}$ & 0.721 \\
\hline Drug use & $\begin{array}{l}53(48.2 \%) \\
57(51.8 \%)\end{array}$ & $\begin{array}{l}25(43.9 \%) \\
32(56.1 \%)\end{array}$ & $\begin{array}{l}28(52.8 \%) \\
25(47.2 \%)\end{array}$ & 0.445 \\
\hline Marijuana & $\begin{array}{l}44(33.8 \%) \\
86(66.2 \%)\end{array}$ & $\begin{array}{l}21(32.3 \%) \\
44(67.7 \%)\end{array}$ & $\begin{array}{l}23(35.4 \%) \\
42(64.6 \%)\end{array}$ & 0.853 \\
\hline Cocaine & $\begin{array}{l}41(31.5 \%) \\
89(68.5 \%)\end{array}$ & $\begin{array}{l}19(29.2 \%) \\
46(70.8 \%)\end{array}$ & $\begin{array}{l}22(33.8 \%) \\
43(66.2 \%)\end{array}$ & 0.706 \\
\hline Other Drugs & $\begin{array}{l}10(9.1 \%) \\
100 \\
(90.9 \%)\end{array}$ & $\begin{array}{l}6(10.5 \%) \\
51(89.5 \%)\end{array}$ & $\begin{array}{l}4(7.5 \%) \\
49(92.5 \%)\end{array}$ & 0.744 \\
\hline $\begin{array}{l}\text { ART } \\
\text { Multi-combination } \\
\text { Yes } \\
\text { No }\end{array}$ & $\begin{array}{l}34(26.2 \%) \\
96(73.8 \%)\end{array}$ & $\begin{array}{l}22(33.8 \%) \\
43(66.2 \%)\end{array}$ & $\begin{array}{l}12(18.5 \%) \\
53(81.5 \%)\end{array}$ & 0.072 \\
\hline $\begin{array}{c}\text { Yes } \\
\text { No }\end{array}$ & $\begin{array}{l}76(58.5 \%) \\
54(41.5 \%)\end{array}$ & $\begin{array}{l}40(61.5 \%) \\
25(38.5 \%)\end{array}$ & $\begin{array}{l}36(55.4 \%) \\
29(44.6 \%)\end{array}$ & 0.594 \\
\hline NNRTI & $\begin{array}{l}17(13.1 \%) \\
113 \\
(86.9 \%)\end{array}$ & $\begin{array}{l}10(15.4 \%) \\
55(84.6 \%)\end{array}$ & $\begin{array}{l}7(10.8 \%) \\
58(89.2 \%)\end{array}$ & 0.604 \\
\hline $\begin{array}{l}\text { Yes } \\
\text { No }\end{array}$ & $\begin{array}{l}62(47.7 \%) \\
68(52.3 \%)\end{array}$ & $\begin{array}{l}34(52.3) \\
31(47.7 \%)\end{array}$ & $\begin{array}{l}28(43.1 \%) \\
37(56.9 \%)\end{array}$ & 0.380 \\
\hline
\end{tabular}

All variables reported as $\mathrm{N}(\%)$

Note: $P$-values correspond to $\chi^{2}$ tests for all variables

ART: Antiretroviral therapy. 
Table 3: Follow-up Health and Lifestyle Characteristics of PLWH by Caffeine Consumption Levels

\begin{tabular}{|c|c|c|c|c|}
\hline Variables & Total & $\begin{array}{l}\text { Low caffeine } \\
\text { intake } \\
(\leq 250 \mathrm{mg} / \mathrm{d})\end{array}$ & $\begin{array}{c}\text { High caffeine } \\
\text { intake } \\
(>250 \mathrm{mg} / \mathrm{d})\end{array}$ & $\begin{array}{c}P \text { - } \\
\text { value }\end{array}$ \\
\hline $\begin{array}{l}\text { Smoking } \\
\text { cigarettes }\end{array}$ & $\begin{array}{l}79(63.2 \%) \\
46(36.8 \%)\end{array}$ & $\begin{array}{l}41(68.3 \%) \\
19(31.7 \%)\end{array}$ & $\begin{array}{l}38(58.5 \%) \\
27(41.5 \%)\end{array}$ & 0.271 \\
\hline Alcohol use & $\begin{array}{l}76(60.3 \%) \\
50(39.7 \%)\end{array}$ & $\begin{array}{l}34(56.7 \%) \\
26(43.3 \%)\end{array}$ & $\begin{array}{l}42(63.6 \%) \\
24(36.4 \%)\end{array}$ & 0.469 \\
\hline Drug use & $\begin{array}{l}79(65.8 \%) \\
41(34.2 \%)\end{array}$ & $\begin{array}{l}45(75.0 \%) \\
15(25.0 \%)\end{array}$ & $\begin{array}{l}34(56.7 \%) \\
26(43.3 \%)\end{array}$ & 0.054 \\
\hline $\begin{array}{lr}\text { Marijuana } & \\
& \text { Yes } \\
\text { Cocaine } & \text { No } \\
& \text { Yes } \\
& \text { No } \\
\text { Other drugs } & \\
& \text { Yes } \\
& \text { No }\end{array}$ & $\begin{array}{l}67(55.8 \%) \\
53(44.2 \%) \\
48(40.0 \%) \\
72(60.0 \%) \\
13(10.9 \%) \\
106 \\
(89.1 \%) \\
\end{array}$ & $\begin{array}{l}38(63.3 \%) \\
22(36.7 \%) \\
29(48.3 \%) \\
31(51.7 \%) \\
6(10.0 \%) \\
54(90.0 \%)\end{array}$ & $\begin{array}{l}29(48.3 \%) \\
31(51.7 \%) \\
19(31.7 \%) \\
41(68.3 \%) \\
7(11.9 \%) \\
52(88.1 \%)\end{array}$ & $\begin{array}{l}0.141 \\
0.093\end{array}$ \\
\hline $\begin{array}{l}\text { ART } \\
\text { Multi-combination } \\
\text { Yes } \\
\text { No }\end{array}$ & $\begin{array}{l}33(25.4 \%) \\
97(74.6 \%)\end{array}$ & $\begin{array}{l}20(31.7 \%) \\
43(68.3 \%)\end{array}$ & $\begin{array}{l}13(19.4 \%) \\
54(80.6 \%)\end{array}$ & 0.113 \\
\hline $\begin{array}{c}\text { Yes } \\
\text { No }\end{array}$ & $\begin{array}{l}83(63.8 \%) \\
47(36.2 \%)\end{array}$ & $\begin{array}{l}40(63.5 \%) \\
23(36.5 \%)\end{array}$ & $\begin{array}{l}43(64.2 \%) \\
24(35.8 \%)\end{array}$ & 1.000 \\
\hline $\begin{array}{r}\text { Yes } \\
\text { No }\end{array}$ & $\begin{array}{l}18(13.8 \%) \\
112 \\
(86.2 \%)\end{array}$ & $\begin{array}{l}9(14.3 \%) \\
54(85.7 \%)\end{array}$ & $\begin{array}{l}9(13.4 \%) \\
58(86.6 \%)\end{array}$ & 1.000 \\
\hline $\begin{array}{c}\text { Yes } \\
\text { No }\end{array}$ & $\begin{array}{l}62(47.7 \%) \\
68(52.3 \%)\end{array}$ & $\begin{array}{l}28(44.4 \%) \\
35(55.6 \%)\end{array}$ & $\begin{array}{l}34(50.7 \%) \\
33(49.3 \%)\end{array}$ & 0.488 \\
\hline
\end{tabular}

All variables reported as $\mathrm{N}(\%)$

Note: $P$-values correspond to $\chi^{2}$ tests all variables.

ART: Antiretroviral therapy. 
Table 4: Mean Caffeine Intake: Baseline and Follow-up Visit

\begin{tabular}{|l|l|l|l|}
\hline Food source & \multicolumn{1}{|c|}{ Baseline } & \multicolumn{1}{c|}{ Follow-up } & \multicolumn{1}{|c|}{ P-value } \\
\hline Coffee & $161.26 \pm 194.95$ & $190.40 \pm 205.03$ & 0.206 \\
\hline De-Caffeinated coffee & $0.83 \pm 9.21$ & $0.03 \pm 0.43$ & 0.329 \\
\hline Expresso & $14.40 \pm 64.35$ & $13.92 \pm 57.82$ & 0.942 \\
\hline Tea & $34.70 \pm 64.32$ & $31.58 \pm 59.36$ & 0.640 \\
\hline Green tea & $7.34 \pm 62.93$ & $4.20 \pm 21.62$ & 0.594 \\
\hline Energy drinks & $46.32 \pm 134.42$ & $9.61 \pm 65.32$ & $0.005^{*}$ \\
\hline Hot cocoa & $1.03 \pm 5.00$ & $0.00 \pm 0.00$ & $0.020^{*}$ \\
\hline Caffeinated soft drinks & $63.23 \pm 92.98$ & $29.66 \pm 83.78$ & $<0.0001^{*}$ \\
\hline Chocolate candy bars & $3.69 \pm 13.81$ & $2.00 \pm 17.93$ & 0.402 \\
\hline Anacin & $0.24 \pm 2.80$ & $0.00 \pm 0.00$ & 0.319 \\
\hline Appetite control pills & $4.61 \pm 39.10$ & $0.00 \pm 0.00$ & 0.181 \\
\hline Total & $337.63 \pm 304.97$ & $281.04 \pm 260.85$ & 0.890 \\
\hline
\end{tabular}

All variables reported as mean $\pm \mathrm{SD}$

Note: $P$-values correspond to t-tests for all variables

*Significant 
Table 5: Baseline: Mean Nutrient Intakes by Levels of Caffeine Consumption

\begin{tabular}{|c|c|c|c|}
\hline \multirow[t]{2}{*}{ Nutrient } & \multicolumn{2}{|c|}{ Caffeine intake } & \multirow[t]{2}{*}{$P$-value } \\
\hline & Low & High & \\
\hline Total Calorie & $1911.84 \pm 1045.674$ & $2038.36 \pm 945.830$ & 0.791 \\
\hline $\begin{array}{c}\text { Total } \\
\text { Carbohydrate }\end{array}$ & $341.83 \pm 133.437$ & $259.15 \pm 132.242$ & $0.048 *$ \\
\hline Protein & $94.82 \pm 54.556$ & $85.24 \pm 40.866$ & 0.046* \\
\hline Total Fat & $170.94 \pm 44.585$ & $93.43 \pm 48.484$ & $0.048 *$ \\
\hline Saturated Fat & $23.02 \pm 15.899$ & $24.51 \pm 16.667$ & 0.602 \\
\hline Cholesterol & $359.27 \pm 286.033$ & $374.97 \pm 304.754$ & 0.762 \\
\hline Dietary Fiber & $12.18 \pm 9.783$ & $13.06 \pm 9.346$ & 0.599 \\
\hline Sodium & $3932.89 \pm 2666.521$ & $3177.54 \pm 1756.021$ & $0.016 *$ \\
\hline Chloride & $8.93 \pm 4.000$ & $5.23 \pm 4.172$ & $0.032 *$ \\
\hline Potassium & $1751.09 \pm 1245.598$ & $1437.63 \pm 999.103$ & $0.018 *$ \\
\hline Calcium & $999.60 \pm 466.681$ & $651.53 \pm 448.444$ & $0.049 *$ \\
\hline Magnesium & $177.62 \pm 38.055$ & $144.61 \pm 84.679$ & $0.010 *$ \\
\hline Phosphorus & $856.29 \pm 549.057$ & $760.73 \pm 491.577$ & $0.030 *$ \\
\hline Vitamin $\mathrm{A}^{\dagger}$ & $6259.44 \pm 10687.908$ & $5503.70 \pm 10197.283$ & 0.475 \\
\hline Vitamin $\mathrm{C}^{\dagger}$ & $110.38 \pm 141.475$ & $61.68 \pm 71.914$ & 0.029* \\
\hline Vitamin $\mathrm{D}^{\dagger}$ & $77.13 \pm 92.950$ & $75.54 \pm 93.053$ & 0.659 \\
\hline Vitamin $\mathrm{E}^{\dagger}$ & $1.12 \pm 5.307$ & $1.53 \pm 4.980$ & 0.266 \\
\hline Vitamin $\mathrm{K}^{\dagger}$ & $23.67 \pm 29.992$ & $30.22 \pm 69.443$ & 0.631 \\
\hline Thiamin & $2.33 \pm 1.762$ & $1.08 \pm 0.714$ & $0.028^{*}$ \\
\hline Riboflavin & $2.47 \pm 1.037$ & $1.29 \pm 1.286$ & $0.037 *$ \\
\hline Niacin & $26.95 \pm 13.737$ & $17.14 \pm 13.124$ & $0.044^{*}$ \\
\hline Vitamin B6 & $1.44 \pm 1.168$ & $1.01 \pm 0.904$ & $0.022 *$ \\
\hline Folate & $268.90 \pm 226.207$ & $258.16 \pm 207.074$ & 0.778 \\
\hline Vitamin B12 & $13.91 \pm 4.189$ & $5.75 \pm 2.452$ & $0.046 *$ \\
\hline $\begin{array}{c}\text { Pantothenic } \\
\text { Acid }\end{array}$ & $3.57 \pm 2.192$ & $3.57 \pm 2.985$ & 0.994 \\
\hline Iodine $^{\dagger}$ & $4.39 \pm 7.979$ & $4.74 \pm 33.746$ & 0.994 \\
\hline Iron & $34.46 \pm 9.319$ & $25.80 \pm 11.356$ & $0.046 *$ \\
\hline Zinc & $9.13 \pm 1.774$ & $4.64 \pm 1.753$ & $0.027 *$ \\
\hline Selenium & $76.61 \pm 5.797$ & $45.27 \pm 5.837$ & 0.029* \\
\hline Copper $^{\dagger}$ & $0.77 \pm 0.688$ & $1.19 \pm 4.261$ & 0.426 \\
\hline Manganese & $1.42 \pm 1.419$ & $1.59 \pm 1.343$ & 0.487 \\
\hline Chromium $^{\dagger}$ & $1.11 \pm 6.354$ & $0.41 \pm 2.603$ & 0.975 \\
\hline Molybdenum $^{\dagger}$ & $0.65 \pm 3.705$ & $0.31 \pm 2.481$ & 0.555 \\
\hline
\end{tabular}

All variables reported as mean \pm SD

${ }^{\text {a }} P$-values correspond to t- tests for all variables

${ }^{\dagger}$ Mann-Whitney U test was used for comparison because the variables were not normally distributed.

*Significant 
Table 6: Follow-up: Mean Nutrient Intakes by Levels of Caffeine Consumption

\begin{tabular}{|c|c|c|c|}
\hline \multirow[t]{2}{*}{ Nutrient } & \multicolumn{2}{|c|}{ Caffeine intake } & \multirow[t]{2}{*}{$P$-value } \\
\hline & Low & High & \\
\hline Total Calorie & $2100.52 \pm 1127.868$ & $1858.27 \pm 932.055$ & $0.017^{*}$ \\
\hline $\begin{array}{c}\text { Total } \\
\text { Carbohydrate }\end{array}$ & $255.27 \pm 152.914$ & $151.32 \pm 116.795$ & $0.042^{*}$ \\
\hline Protein & $86.49 \pm 42.173$ & $43.48 \pm 37.841$ & $0.017 *$ \\
\hline Total Fat & $183.72 \pm 68.771$ & $77.52 \pm 56.469$ & $0.026^{*}$ \\
\hline Saturated Fat $^{\dagger}$ & $30.45 \pm 35.212$ & $44.84 \pm 178.663$ & 0.121 \\
\hline Cholesterol & $419.85 \pm 347.931$ & $300.71 \pm 227.419$ & $0.024 *$ \\
\hline Dietary Fiber $^{\dagger}$ & $13.45 \pm 18.933$ & $13.06 \pm 7.673$ & 0.163 \\
\hline Sodium & $3911.67 \pm 1857.343$ & $3239.20 \pm 2049.984$ & $0.018^{*}$ \\
\hline Chloride $^{\dagger}$ & $42.54 \pm 212.929$ & $15.22 \pm 70.847$ & 0.638 \\
\hline Potassium & $1482.16 \pm 1264.208$ & $666.63 \pm 598.147$ & $0.036 *$ \\
\hline Calcium & $689.22 \pm 480.232$ & $705.43 \pm 37.815$ & 0.857 \\
\hline Magnesium & $165.88 \pm 109.738$ & $169.48 \pm 122.184$ & 0.897 \\
\hline Phosphorus & $818.62 \pm 587.809$ & $771.74 \pm 508.395$ & 0.627 \\
\hline Vitamin $\mathrm{A}^{\dagger}$ & $5285.28 \pm 13851.995$ & $5153.94 \pm 12370.864$ & 0.334 \\
\hline Vitamin $\mathrm{C}^{\dagger}$ & $65.42 \pm 91.662$ & $79.52 \pm 84.668$ & 0.150 \\
\hline Vitamin $\mathrm{D}^{\dagger}$ & $96.57 \pm 107.881$ & $75.12 \pm 91.308$ & 0.293 \\
\hline Vitamin $\mathrm{E}^{\dagger}$ & $4.58 \pm 19.808$ & $2.00 \pm 8.892$ & 0.241 \\
\hline Vitamin $\mathrm{K}^{\dagger}$ & $24.76 \pm 36.634$ & $31.95 \pm 56.458$ & 0.993 \\
\hline Thiamin & $2.16 \pm 1.055$ & $1.05 \pm 0.681$ & $0.044 *$ \\
\hline Riboflavin & $12.54 \pm 1.755$ & $8.24 \pm 2.521$ & $0.036 *$ \\
\hline Niacin & $18.69 \pm 5.191$ & $5.61 \pm 1.769$ & $0.034 *$ \\
\hline Vitamin B6 & $2.34 \pm 1.446$ & $1.38 \pm 0.875$ & $0.048 *$ \\
\hline Folate $^{\dagger}$ & $288.24 \pm 297.962$ & $286.71 \pm 178.391$ & 0.180 \\
\hline Vitamin B12 $^{\dagger}$ & $6.84 \pm 30.140$ & $4.04 \pm 9.221$ & 0.672 \\
\hline Pantothenic acid & $3.99 \pm 3.748$ & $3.27 \pm 1.868$ & 0.176 \\
\hline Iodine $^{\dagger}$ & $6.06 \pm 25.970$ & $2.27 \pm 11.227$ & 0.402 \\
\hline Iron & $17.31 \pm 7.898$ & $14.67 \pm 8.972$ & 0.285 \\
\hline Zinc & $9.61 \pm 3.021$ & $7.91 \pm 5.847$ & 0.244 \\
\hline Selenium & $71.57 \pm 52.860$ & $69.47 \pm 59.698$ & 0.833 \\
\hline Copper $^{\dagger}$ & $1.63 \pm 6.081$ & $20.54 \pm 161.78$ & 0.958 \\
\hline Manganese $^{\dagger}$ & $1.97 \pm 5.313$ & $23.98 \pm 184.300$ & 0.212 \\
\hline Chromium $^{\dagger}$ & $3.51 \pm 14.574$ & $11.52 \pm 83.442$ & 0.668 \\
\hline Molybdenum $^{\dagger}$ & $3.48 \pm 13.972$ & $1.18 \pm 5.810$ & 0.392 \\
\hline
\end{tabular}

All variables reported as mean \pm SD

${ }^{\text {a }} \mathrm{P}$-values correspond to t- tests for all variables

${ }^{\dagger}$ Mann-Whitney U test was used for comparison because the variables were not normally distributed

*Significant 
Table 7: Differences in Mean Nutrient Intake between Baseline and Follow-Up Visit

\begin{tabular}{|c|c|c|c|}
\hline \multirow[t]{2}{*}{ Nutrient } & & & \multirow{2}{*}{$\begin{array}{c}P- \\
\text { value }\end{array}$} \\
\hline & BL & $\mathbf{F U}$ & \\
\hline Total Calorie & $1981.84 \pm 1024.674$ & $2098.84 \pm 1032.674$ & 0.838 \\
\hline Total Carbohydrate & $250.49 \pm 132.610$ & $253.23 \pm 134.986$ & 0.835 \\
\hline Protein & $84.72 \pm 48.069$ & $84.95 \pm 39.887$ & 0.962 \\
\hline Total Fat & $72.18 \pm 46.411$ & $80.52 \pm 62.563$ & 0.143 \\
\hline Saturated Fat & $23.77 \pm 16.242$ & $37.87 \pm 13.305$ & 0.214 \\
\hline Cholesterol & $367.12 \pm 94.499$ & $358.45 \pm 97.012$ & 0.788 \\
\hline Dietary Fiber & $12.62 \pm 9.540$ & $13.25 \pm 4.228$ & 0.671 \\
\hline Sodium & $3105.22 \pm 2250.051$ & $3274.32 \pm 1951.772$ & 0.401 \\
\hline Chloride & $120.62 \pm 29.820$ & $128.46 \pm 56.673$ & 0.058 \\
\hline Potassium & $1594.36 \pm 1135.664$ & $1577.23 \pm 1134.212$ & 0.889 \\
\hline Calcium & $625.57 \pm 456.621$ & $697.58 \pm 408.816$ & 0.183 \\
\hline Magnesium & $161.11 \pm 115.273$ & $167.73 \pm 117.936$ & 0.674 \\
\hline Phosphorus & $808.51 \pm 521.298$ & $794.46 \pm 546.676$ & 0.810 \\
\hline Vitamin A & $5881.57 \pm 1411.824$ & $5217.59 \pm 1058.457$ & 0.656 \\
\hline Vitamin C & $86.03 \pm 14.427$ & $72.69 \pm 18.067$ & 0.247 \\
\hline Vitamin D & $76.34 \pm 42.644$ & $85.52 \pm 49.874$ & 0.419 \\
\hline Vitamin E & $1.32 \pm 0.130$ & $3.25 \pm 1.189$ & 0.168 \\
\hline Vitamin $\mathrm{K}$ & $26.95 \pm 5.381$ & $28.46 \pm 4.842$ & 0.808 \\
\hline Thiamin & $1.21 \pm 0.345$ & $1.11 \pm 0.880$ & 0.462 \\
\hline Riboflavin & $1.38 \pm 0.167$ & $4.99 \pm 1.299$ & 0.320 \\
\hline Niacin & $18.04 \pm 13.413$ & $27.41 \pm 11.594$ & 0.296 \\
\hline Vitamin B6 & $1.22 \pm 0.062$ & $1.36 \pm 0.182$ & 0.298 \\
\hline Folate & $263.53 \pm 216.077$ & $287.45 \pm 242.801$ & 0.371 \\
\hline Vitamin B12 & $4.83 \pm 1.192$ & $5.40 \pm 1.957$ & 0.811 \\
\hline Pantothenic acid & $3.57 \pm 2.608$ & $3.62 \pm 2.944$ & 0.880 \\
\hline Iodine & $3.07 \pm 2.483$ & $4.11 \pm 1.805$ & 0.707 \\
\hline Iron & $15.13 \pm 10.369$ & $15.95 \pm 10.032$ & 0.588 \\
\hline Zinc & $8.88 \pm 2.737$ & $8.73 \pm 2.154$ & 0.868 \\
\hline Selenium & $75.94 \pm 56.600$ & $70.49 \pm 56.280$ & 0.360 \\
\hline Copper & $9.98 \pm 3.048$ & $11.38 \pm 6.183$ & 0.309 \\
\hline Manganese & $1.50 \pm 0.379$ & $3.31 \pm 2.339$ & 0.311 \\
\hline Chromium & $8.76 \pm 4.849$ & $7.64 \pm 3.667$ & 0.200 \\
\hline Molybdenum & $6.48 \pm 3.145$ & $12.29 \pm 8.603$ & 0.060 \\
\hline
\end{tabular}

All variables reported as mean $\pm \mathrm{SD}$.

Note: $P$-values correspond to t- tests for all variables 
Table 8: Baseline, PLWH with Nutrient Intakes below Daily Values (DV) by Levels of Caffeine Consumption

\begin{tabular}{|c|c|c|c|c|}
\hline \multirow[t]{2}{*}{ Nutrient } & \multirow[t]{2}{*}{ Total } & \multicolumn{2}{|c|}{ Caffeine intake } & \multirow[t]{2}{*}{$P$-value } \\
\hline & & Low & High & \\
\hline Total Calorie & $70(53.8 \%)$ & $36(55.4 \%)$ & $34(52.3 \%)$ & 0.860 \\
\hline Total Carbohydrate & $92(70.8 \%)$ & $45(69.2 \%)$ & $47(72.3 \%)$ & 0.700 \\
\hline Protein & $29(22.7 \%)$ & $18(28.1 \%)$ & $11(17.2 \%)$ & 0.139 \\
\hline Total Fat & $61(47.3 \%)$ & $33(50.8 \%)$ & $28(43.8 \%)$ & 0.425 \\
\hline Saturated Fat & $58(46.4 \%)$ & $32(50.8 \%)$ & $26(41.9 \%)$ & 0.321 \\
\hline Cholesterol & $71(54.6 \%)$ & $36(55.4 \%)$ & $35(53.8 \%)$ & 0.860 \\
\hline Dietary Fiber & $114(87.7 \%)$ & $56(86.2 \%)$ & $58(89.2 \%)$ & 0.593 \\
\hline Sodium & $23(17.7 \%)$ & $16(24.6 \%)$ & $7(10.8 \%)$ & $0.039 *$ \\
\hline Chloride $^{\dagger}$ & $130(100 \%)$ & $65(100 \%)$ & $65(100 \%)$ & N/A \\
\hline Potassium & $119(91.5 \%)$ & $57(87.7 \%)$ & $62(95.4 \%)$ & 0.115 \\
\hline Calcium & $106(81.5 \%)$ & $54(83.1 \%)$ & $52(80.0 \%)$ & 0.651 \\
\hline Magnesium & $126(96.9 \%)$ & $62(95.4 \%)$ & $64(98.5 \%)$ & 0.310 \\
\hline Phosphorus & $93(71.5 \%)$ & $43(66.2 \%)$ & $50(76.9 \%)$ & 0.174 \\
\hline Vitamin A & $95(73.1 \%)$ & $45(69.2 \%)$ & $50(76.9 \%)$ & 0.323 \\
\hline Vitamin C & $73(56.2 \%)$ & $31(47.7 \%)$ & $42(64.6 \%)$ & 0.052 \\
\hline Vitamin D & $127(97.7 \%)$ & 64 (98.5\%) & $63(96.9 \%)$ & 0.559 \\
\hline Vitamin E & $127(97.7 \%)$ & $63(96.9 \%)$ & $64(98.5 \%)$ & 0.599 \\
\hline Vitamin K & $119(91.5 \%)$ & $59(90.8 \%)$ & $60(92.3 \%)$ & 0.753 \\
\hline Thiamin & $96(73.8 \%)$ & $46(70.8 \%)$ & $50(76.9 \%)$ & 0.425 \\
\hline Riboflavin & $88(68.8 \%)$ & $41(63.1 \%)$ & $47(74.6 \%)$ & 0.160 \\
\hline Niacin & $81(62.8 \%)$ & $39(60.9 \%)$ & $42(64.6 \%)$ & 0.666 \\
\hline Vitamin B6 & $102(78.5 \%)$ & 47 (72.3\%) & $55(84.6 \%)$ & 0.088 \\
\hline Folate & $106(81.5 \%)$ & $53(81.5 \%)$ & $53(81.5 \%)$ & 1.000 \\
\hline Vitamin B12 & $108(84.4 \%)$ & $52(81.3 \%)$ & $56(87.5 \%)$ & 0.330 \\
\hline Pantothenic acid & $127(98.4 \%)$ & $64(98.5 \%)$ & $63(98.4 \%)$ & 0.991 \\
\hline Iodine & $129(00.2 \%)$ & $65(100 \%)$ & $64(98.5 \%)$ & 0.315 \\
\hline Iron & $87(68.0 \%)$ & $46(70.8 \%)$ & $41(65.1 \%)$ & 0.490 \\
\hline Zinc & $106(82.8 \%)$ & $51(81.0 \%)$ & $55(84.6 \%)$ & 0.583 \\
\hline Selenium & $66(50.8 \%)$ & $33(50.8 \%)$ & $33(50.8 \%)$ & 1.000 \\
\hline Copper & $126(96.9 \%)$ & $63(96.9 \%)$ & $63(96.9 \%)$ & 1.000 \\
\hline Manganese & $86(66.2 \%)$ & $47(72.3 \%)$ & $39(60.0 \%)$ & 0.138 \\
\hline Chromium $^{\dagger}$ & $130(100 \%)$ & $65(100 \%)$ & $65(100 \%)$ & N/A \\
\hline Molybdenum $^{\dagger}$ & $130(100 \%)$ & $65(100 \%)$ & $65(100 \%)$ & N/A \\
\hline
\end{tabular}

All variables reported as $\mathrm{N}(\%)$

Note: $P$-values correspond to $\chi^{2}$ tests for all variables

† Pearson's Chi-Square test could not be done because all participants reported consumption below Daily Values (DV) for the nutrient.

*Significant 
Table 9: Follow-Up, PLWH with Nutrient Intakes below Daily Values (DV) by Levels of Caffeine Consumption

\begin{tabular}{|c|c|c|c|c|}
\hline \multirow{2}{*}{ Nutrient } & Total & \multicolumn{2}{|c|}{ Caffeine intake } & \multirow{2}{*}{ P-value } \\
\cline { 2 - 4 } & & Low & High & \\
\hline Total Calorie & $72(55.8 \%)$ & $33(52.4 \%)$ & $39(59.1 \%)$ & 0.481 \\
\hline Total Fat & $62(47.7 \%)$ & $24(38.1 \%)$ & $38(56.7 \%)$ & 0.034 \\
\hline Saturated Fat & $56(43.1 \%)$ & $25(39.7 \%)$ & $31(46.3 \%)$ & 0.449 \\
\hline Cholesterol & $72(55.4 \%)$ & $31(49.2 \%)$ & $41(61.2 \%)$ & 0.169 \\
\hline Sodium & $14(10.8 \%)$ & $6(9.5 \%)$ & $8(11.9 \%)$ & 0.657 \\
\hline Potassium & $121(93.1 \%)$ & $57(90.5 \%)$ & $64(95.5 \%)$ & 0.257 \\
\hline Total & $95(73.1 \%)$ & $43(68.3 \%)$ & $52(77.6 \%)$ & 0.229 \\
\hline Carbohydrate & & & & \\
\hline Dietary Fiber & $119(92.2 \%)$ & $58(92.1 \%)$ & $61(92.4 \%)$ & 0.939 \\
\hline Protein & $19(14.7 \%)$ & $11(17.5 \%)$ & $8(12.1 \%)$ & 0.392 \\
\hline Vitamin A & $102(78.5 \%)$ & $52(82.5 \%)$ & $50(74.6 \%)$ & 0.273 \\
\hline Vitamin C & $76(58.9 \%)$ & $39(62.9 \%)$ & $37(55.2 \%)$ & 0.376 \\
\hline Calcium & $100(76.9 \%)$ & $48(76.2 \%)$ & $52(77.6 \%)$ & 0.848 \\
\hline Iron & $87(66.9 \%)$ & $40(63.5 \%)$ & $47(70.1 \%)$ & 0.420 \\
\hline Vitamin D & $129(99.2 \%)$ & $62(98.4 \%)$ & $67(100 \%)$ & 0.301 \\
\hline Vitamin E & $124(95.4 \%)$ & $60(95.2 \%)$ & $64(95.5 \%)$ & 0.938 \\
\hline Vitamin K & $119(91.5 \%)$ & $60(95.2 \%)$ & $59(88.1 \%)$ & 0.142 \\
\hline Thiamin & $100(78.1 \%)$ & $49(79.0 \%)$ & $51(77.3 \%)$ & 0.810 \\
\hline Riboflavin & $91(71.7 \%)$ & $43(70.5 \%)$ & $48(72.7 \%)$ & 0.780 \\
\hline Niacin & $78(61.9 \%)$ & $39(65.0 \%)$ & $39(59.1 \%)$ & 0.495 \\
\hline Vitamin B6 & $95(73.1 \%)$ & $49(77.8 \%)$ & $46(68.7 \%)$ & 0.241 \\
\hline Folate & $104(80 \%)$ & $52(82.5 \%)$ & $52(77.6 \%)$ & 0.483 \\
\hline Vitamin B12 & $109(84.5 \%)$ & $55(87.3 \%)$ & $54(81.8 \%)$ & 0.390 \\
\hline Pantothenic acid & $126(97.7 \%)$ & $59(95.2 \%)$ & $67(100 \%)$ & 0.068 \\
\hline Phosphorus & $91(70.0 \%)$ & $43(68.3 \%)$ & $48(71.6 \%)$ & 0.674 \\
\hline Iodine & $129(99.2 \%)$ & $62(98.4 \%)$ & $67(100 \%)$ & 0.301 \\
\hline Magnesium & $123(94.6 \%)$ & $59(93.7 \%)$ & $64(95.5 \%)$ & 0.637 \\
\hline Zinc & $109(83.8 \%)$ & $51(81.0 \%)$ & $58(86.6 \%)$ & 0.385 \\
\hline Selenium & $75(57.7 \%)$ & $35(55.6 \%)$ & $40(59.7 \%)$ & 0.633 \\
\hline Copper & $116(89.2 \%)$ & $54(85.7 \%)$ & $62(92.5 \%)$ & 0.210 \\
\hline Manganese & $81(62.3 \%)$ & $43(68.3 \%)$ & $38(56.7 \%)$ & 0.175 \\
\hline Chromium & $129(99.2 \%)$ & $63(100 \%)$ & $66(98.5 \%)$ & 0.330 \\
\hline Molybdenum & $129(99.2 \%)$ & $62(98.4 \%)$ & $67(100 \%)$ & 0.301 \\
\hline Chloride ${ }^{\dagger}$ & $130(100 \%)$ & $63(100 \%)$ & $67(100 \%)$ & N/A \\
\hline
\end{tabular}

All variables reported as $\mathrm{N}(\%)$

Note: $P$-values correspond to $\chi^{2}$ tests for all variables

${ }^{\dagger}$ Pearson's Chi-Square test could not be done because all participants reported consumption below recommended daily values for the nutrient.

*Significance 
Table 10: Linear Regression of the Effect of Caffeine Consumption on Body Composition Measures and Nutritional Indicators

\begin{tabular}{|c|c|c|c|c|c|c|}
\hline \multirow{2}{*}{$\begin{array}{c}\text { Body } \\
\text { Composition } \\
\text { Variables } \\
\end{array}$} & \multicolumn{3}{|c|}{ Unadjusted } & \multicolumn{3}{|c|}{ Adjusted $^{\dagger}$} \\
\hline & $\boldsymbol{\beta}$ & SE & $P$-value & $\boldsymbol{\beta}$ & SE & $P$-value \\
\hline Waist/Hip ratio & -2.200 & 1.042 & 0.920 & -2.345 & 1.190 & 0.573 \\
\hline BMI lbs/in ${ }^{2}$ & -0.001 & 0.002 & 0.648 & -0.002 & 0.002 & 0.064 \\
\hline LBM lbs & -0.001 & 0.007 & 0.885 & 0.002 & 0.007 & 0.761 \\
\hline Fat mass $l b s^{\mathrm{b}}$ & -0.449 & 0.774 & 0.058 & -0.994 & 0.737 & $0.042 *$ \\
\hline Hemoglobin $g / d l$ & 0.027 & 0.007 & 0.706 & -0.029 & 0.008 & 0.503 \\
\hline Hematocrit \% & 0.001 & 0.002 & 0.708 & -0.001 & 0.001 & 0.667 \\
\hline Albumin $g / d l$ & 0.001 & 0.001 & 0.361 & 0.004 & 0.001 & 0.604 \\
\hline
\end{tabular}

${ }^{a}$ Model $\mathrm{R}^{2}=0.187, \mathrm{~F}(16)=25.075, P=.039$.

${ }^{\mathrm{b}}$ Model $\mathrm{R}^{2}=0.155$, F (16) $=24.292, P=.034$.

${ }^{\dagger}$ Model adjusted for age, gender, income, time from diagnosis of HIV, drug use, alcohol consumption, smoking status and types of ART medications.

*Significant 
Table 11: Linear Mixed Model (LMM) Analysis of Over Time Changes in Body Composition Measures and Nutritional Indicators due to Caffeine Consumption

\begin{tabular}{|c|c|c|c|c|c|c|}
\hline $\begin{array}{c}\text { Body } \\
\begin{array}{c}\text { Composition } \\
\text { Variables }\end{array}\end{array}$ & \multicolumn{3}{|c|}{ Unadjusted } & \multicolumn{3}{c|}{ Adjusted $^{\dagger}$} \\
\hline & $\beta$ & SE & P-value & $\beta$ & SE & P-value \\
\hline $\begin{array}{c}\text { Waist/Hip } \\
\text { ratio }\end{array}$ & 0.268 & 0.875 & 0.113 & 0.389 & 0.987 & 0.095 \\
\hline BMI $l b s /$ in $^{2 b}$ & -1.310 & 0.870 & 0.647 & 0.987 & 0.910 & 0.532 \\
\hline LBM $l b s$ & -0.477 & 0.332 & 0.815 & -0.363 & 0.377 & 0.338 \\
\hline Fat mass $l b s$ & -0.001 & 0.003 & 0.958 & -1.987 & 0.910 & $0.035^{*}$ \\
\hline $\begin{array}{c}\text { Hemoglobin } \\
\text { g/dl }\end{array}$ & -0.003 & 0.004 & 0.425 & 0.002 & 0.002 & 0.265 \\
\hline Hematocrit \% & 0.0007 & 0.001 & 0.463 & 0.0004 & 0.0006 & 0.532 \\
\hline Albumin $g / d l$ & 0.0002 & 0.0003 & 0.571 & 0.00020 & 0.0004 & 0.533 \\
\hline
\end{tabular}

a Model: -2 Restricted Log Likelihood = 1832.170; Akaike's Information Criteria (AIC) = 1836.170; Schwarz’s Bayesian Criteria $(B I C)=1842.716$.

bModel: -2 Restricted Log Likelihood = 1252.041; Akaike's Information Criteria (AIC) = 1256.014; Schwarz's Bayesian Criteria $(\mathrm{BIC})=1262.539$.

${ }^{\dagger}$ Model adjusted for age, gender, income, time from diagnosis of HIV, drug use, alcohol consumption, smoking status and types of ART medications.

*Significant

Table 12: Linear Regression of the Effect of Caffeine Consumption on Macronutrient Consumption

\begin{tabular}{|c|c|c|c|c|c|c|}
\hline \multirow{2}{*}{$\begin{array}{l}\text { Macronutrient } \\
\text { Intake }\end{array}$} & \multicolumn{3}{|c|}{ Unadjusted } & \multicolumn{3}{|c|}{ Adjusted $^{\dagger}$} \\
\hline & $\boldsymbol{\beta}$ & SE & $\begin{array}{c}P- \\
\text { value }\end{array}$ & $\boldsymbol{\beta}$ & SE & $P$-value \\
\hline Total Kcal $^{\mathrm{a}}$ & -1.071 & 1.208 & 0.644 & -1.643 & 1.491 & $0.042 *$ \\
\hline Kcal from Protein & -0.065 & 0.056 & 0.247 & -0.078 & 0.072 & 0.277 \\
\hline Kcal from Carbs & 0.604 & 0.152 & 0.692 & -0.972 & 0.178 & 0.956 \\
\hline Kcal from Fats ${ }^{b}$ & -1.043 & 0.121 & 0.647 & -1.902 & 0.155 & $0.044^{*}$ \\
\hline
\end{tabular}

${ }^{a}$ Model $\mathrm{R}^{2}=0.213, \mathrm{~F}(16)=35.707, P=0.038$.

${ }^{\mathrm{b}}$ Model $\mathrm{R}^{2}=0.185, \mathrm{~F}(16)=30.681, P=.0 .008$.

${ }^{\mathrm{c}}$ Model $\mathrm{R}^{2}=0.185, \mathrm{~F}(16)=16.300, P=0.022$.

${ }^{\dagger}$ Model adjusted for age, gender, income, time from diagnosis of HIV, drug use, alcohol consumption, smoking status and types of ART medications.

*Significant 
Table 13: Linear Mixed Model (LMM) Analysis of Over Time Changes in Macronutrient Consumption due to Caffeine Consumption

\begin{tabular}{|c|c|c|c|c|c|c|}
\hline $\begin{array}{c}\text { Food Intake and } \\
\begin{array}{c}\text { Food Security } \\
\text { Variables }\end{array}\end{array}$ & \multicolumn{3}{|c|}{ Unadjusted } & \multicolumn{3}{c|}{ Adjusted $^{\dagger}$} \\
\cline { 2 - 7 } & $\boldsymbol{\beta}$ & SE & $\begin{array}{c}\boldsymbol{P} \text { - } \\
\text { value }\end{array}$ & $\boldsymbol{\beta}$ & SE & $\begin{array}{c}\boldsymbol{P} \text { - } \\
\text { value }\end{array}$ \\
\hline Total Kcal & -0.933 & 0.821 & 0.257 & -0.402 & 0.942 & 0.670 \\
\hline Kcal from Protein & 0.013 & 0.049 & 0.784 & 0.039 & 0.058 & 0.506 \\
\hline Kcal from Carbs & -0.099 & 0.108 & 0.361 & -0.079 & 0.116 & 0.497 \\
\hline Kcal from Fats & -0.895 & 0.991 & 0.367 & -0.317 & 0.118 & 0.789 \\
\hline
\end{tabular}

aModel: -2 Restricted Log Likelihood = 1761.542; Akaike’s Information Criteria (AIC) = 1765.542; Schwarz’s Bayesian Criteria $(\mathrm{BIC})=1772.088$.

${ }^{\dagger}$ Model adjusted for age, gender, income, time from diagnosis of HIV, drug use, alcohol consumption, smoking status and types of ART medications.

*Significant

Table 14: Linear Regression of the Effect of Body Composition Measures and Macronutrient Intake on CD4 Cell Count

\begin{tabular}{|c|c|c|c|c|c|c|}
\hline $\begin{array}{c}\text { Body } \\
\text { Composition, and } \\
\text { Macronutrient } \\
\text { consumption }\end{array}$ & \multicolumn{3}{|c|}{ Unadjusted } & \multicolumn{3}{c|}{ Adjusted $^{\dagger}$} \\
\cline { 3 - 7 } & $\boldsymbol{\beta}$ & SE & $\begin{array}{c}\boldsymbol{P} \text { - } \\
\text { value }\end{array}$ & $\boldsymbol{\beta}$ & SE & $\begin{array}{c}\boldsymbol{P} \text { - } \\
\text { value }\end{array}$ \\
\hline BMI $l b s /$ in $^{2 \mathrm{a}}$ & 1.225 & 1.010 & 0.643 & 1.568 & 1.149 & 0.325 \\
\hline Fat mass $l b s^{\mathrm{b}}$ & 1.653 & 1.226 & 0.085 & 2.028 & 1.034 & 0.404 \\
\hline Total Kcal & 1.209 & 0.147 & 0.158 & 0.137 & 0.169 & 0.422 \\
\hline Kcal from Protein & -1.658 & 1.344 & 0.058 & -0.005 & 0.004 & 0.202 \\
\hline Kcal from Carbs & -1.103 & 1.012 & 0.391 & -0.001 & 0.001 & 0.485 \\
\hline Kcal from Fats & 1.267 & 1.001 & 0.485 & 1.185 & 1.016 & 0.262 \\
\hline
\end{tabular}

${ }^{a}$ Model $\mathrm{R}^{2}=0.159, \mathrm{~F}(14)=23.773, P=.047$.

${ }^{\mathrm{b}}$ Model $\mathrm{R}^{2}=0.174$, F (14) $=16.379, P=.042$.

${ }^{\dagger}$ Model adjusted for time from diagnosis of HIV, Cocaine and Methamphetamine use, HIV viral load. 
Table 15: Linear Regression of the Effect of Body Composition Measures and Macronutrient Intake on HIV Viral Load

\begin{tabular}{|c|c|c|c|c|c|c|}
\hline Body Composition, & \multicolumn{4}{|c|}{ Unadjusted } & \multicolumn{3}{c|}{ Adjusted $^{\dagger}$} \\
\cline { 2 - 7 } $\begin{array}{c}\text { and Macronutrient } \\
\text { consumption }\end{array}$ & $\boldsymbol{\beta}$ & SE & $\begin{array}{c}\boldsymbol{P} \text { - } \\
\text { value }\end{array}$ & $\boldsymbol{\beta}$ & SE & $\boldsymbol{P}$-value \\
\hline BMI $l b s /$ in $^{2 \mathrm{a}}$ & 0.151 & 0.076 & 0.068 & 0.972 & 0.486 & 0.567 \\
\hline Fat mass $l b s^{\mathrm{b}}$ & 0.592 & 0.176 & 0.052 & 0.936 & 0.223 & 0.056 \\
\hline Total Kcal & 0.219 & 0.097 & 0.625 & 0.901 & 0.710 & 0.624 \\
\hline Kcal from Protein & -0.786 & 0.153 & 0.609 & -0.987 & 0.155 & 0.994 \\
\hline Kcal from Carbs & -0.915 & 0.757 & 0.347 & -0.934 & 0.857 & 0.517 \\
\hline Kcal from Fats & 0.930 & 0.765 & 0.226 & 0.965 & 0.794 & 0.827 \\
\hline
\end{tabular}

aModel: -2 Restricted Log Likelihood = 1129.609; Akaike’s Information Criteria (AIC) = 1133.609; Schwarz's Bayesian Criteria $(\mathrm{BIC})=1139.868$.

'Model: -2 Restricted Log Likelihood = 1136.666; Akaike's Information Criteria (AIC) = 1140.666; Schwarz’s Bayesian Criteria $(B I C)=1146.937$.

${ }^{\dagger}$ Model adjusted for time from diagnosis of HIV, Cocaine and Methamphetamine use, HIV viral load.

Table 16: . Linear Mixed Model (LMM) Analysis of Over Time Changes in CD4 Cell Counts due to changes in Body Composition Measures and Macronutrient intakes

\begin{tabular}{|c|c|c|c|c|c|c|}
\hline \multirow{2}{*}{$\begin{array}{c}\text { Body Composition, } \\
\text { and Macronutrient } \\
\text { consumption }\end{array}$} & \multicolumn{3}{|c|}{ Unadjusted } & \multicolumn{3}{|c|}{ Adjusted $^{\dagger}$} \\
\hline & $\boldsymbol{\beta}$ & SE & $\begin{array}{c}P \text { - } \\
\text { value }\end{array}$ & $\beta$ & SE & $\begin{array}{c}P \text { - } \\
\text { value }\end{array}$ \\
\hline BMI lbs/inn & -0.048 & 0.023 & 0.142 & -0.033 & 0.031 & 0.430 \\
\hline Fat mass $l b s^{\mathrm{d}}$ & -0.010 & 0.005 & 0.248 & -0.053 & 0.007 & 0.347 \\
\hline Total Kcal & 0.988 & 0.346 & 0.858 & 1.032 & 0.360 & 0.389 \\
\hline Kcal from Protein & 0.420 & 0.075 & 0.956 & 0.800 & 0.084 & 0.344 \\
\hline Kcal from Carbs & 0.780 & 0.258 & 0.764 & 0.835 & 0.308 & 0.257 \\
\hline Kcal from Fats & -0.924 & 0.032 & 0.939 & -0.930 & 0.035 & 0.390 \\
\hline
\end{tabular}

${ }^{\mathrm{c}}$ Model $\mathrm{R}^{2}=0.189, \mathrm{~F}(14)=19.612, P=.036$.

${ }^{\mathrm{d}}$ Model $\mathrm{R}^{2}=0.182$, $\mathrm{F}(14)=18.560, P=.048$.

${ }^{\dagger}$ Model adjusted for time from diagnosis of HIV, Cocaine and Methamphetamine use and CD4 cell counts. 
Table 17: . Linear Mixed Model (LMM) Analysis of Over Time Changes in HIV Viral Load due to changes in Body Composition Measures and Macronutrient intakes

\begin{tabular}{|c|c|c|c|c|c|c|}
\hline $\begin{array}{c}\text { Body Composition, } \\
\begin{array}{c}\text { and } \\
\text { Macronutrient } \\
\text { consumption }\end{array}\end{array}$ & \multicolumn{4}{|c|}{ Unadjusted } & \multicolumn{3}{c|}{ Adjusted $^{\dagger}$} \\
\cline { 2 - 7 } & $\boldsymbol{\beta}$ & SE & $\boldsymbol{P}$-value & $\boldsymbol{\beta}$ & SE & $\boldsymbol{P}$-value \\
\hline BMI $l b s /$ in $^{2 \mathrm{c}}$ & -0.463 & 0.026 & 0.324 & -0.013 & 0.018 & 0.322 \\
\hline LBM $l b s$ & -0.304 & 0.380 & 0.793 & -0.532 & 0.483 & 0.261 \\
\hline Fat mass $l b s^{\mathrm{d}}$ & -0.810 & 0.472 & 0.456 & -0.724 & 0.485 & 0.314 \\
\hline Total Kcal & -0.158 & 0.121 & 0.253 & -0.586 & 0.123 & 0.845 \\
\hline Kcal from Protein & -0.214 & 0.134 & 0.740 & -0.189 & 0.035 & 0.922 \\
\hline Kcal from Carbs & 0.218 & 0.137 & 0.155 & 0.515 & 0.192 & 0.421 \\
\hline Kcal from Fats & 0.974 & 0.547 & 0.622 & -0.834 & 0.851 & 0.851 \\
\hline
\end{tabular}

'Model: -2 Restricted Log Likelihood = 1605.359; Akaike’s Information Criteria (AIC) = 1609.359; Schwarz’s Bayesian Criteria (BIC) = 1615.595.

dModel: -2 Restricted Log Likelihood = 1609.316; Akaike’s Information Criteria (AIC) = 1613.316; Schwarz’s Bayesian Criteria $(B I C)=1619.564$.

${ }^{\dagger}$ Model adjusted for time from diagnosis of HIV, Cocaine and Methamphetamine use and CD4 cell counts. 


\section{References}

1. Passaes CP, Sáez-Cirión A. HIV cure research: Advances and prospects. Virology. 2014;454:340-352.

2. Center for Disease Control. HIV/AIDS Fact Sheet. 2014; http://www.cdc.gov/hiv/statistics/basics/ataglance.html. Accessed December 12, 2014.

3. Care Resources. HIV/AIDS Fact sheet. 2014; http://www.careresource.org/hivaids/statistics/. Accessed December 25, 2014.

4. Rukmana D. Comparing the residential origins of homeless families and homeless individuals in Miami-Dade County, Florida. Area. 2011;43(1):96-109.

5. Metsch LR, Pereyra M, Brewer TH. Use of HIV health care in HIV-seropositive crack cocaine smokers and other active drug users. Journal of substance abuse. 2001;13(1):155-167.

6. Page JB, Chitwood DD, Smith PC, Kane N, McBride DC. Intravenous drug use and HIV infection in Miami. Medical Anthropology Quarterly. 1990;4(1):56-71.

7. Fernández MI, Bowen GS, Varga LM, et al. High rates of club drug use and risky sexual practices among Hispanic men who have sex with men in Miami, Florida. Substance Use \& Misuse. 2005;40(9-10):1347-1362.

8. Brewer TH, Metsch LR, Zenilman JM. Use of a public sexually transmitted disease clinic by known HIV-positive adults: decreased self-reported risk behavior and increased disease incidence. Journal of Acquired Immune Deficiency Syndromes (1999). 2002;29(3):289-294.

9. Brooks R, Rotheram-Borus MJ, Bing EG, Ayala G, Henry CL. HIV and AIDS among men of color who have sex with men and men of color who have sex with men and women: an epidemiological profile. AIDS Education and Prevention. 2003;15(1 Supplement):1-6.

10. Hatsu I, Huffman F, Johnson P, Baum M, Thomlison B, Campa A. Association of Supplemental Nutrition Assistance Program (SNAP) with food security and nutrition status among persons living with HIV. European Journal of Nutrition and Food Safety. 2015;5(4):229-241.

11. Weiser SD, Fernandes KA, Brandson EK, et al. The association between food insecurity and mortality among HIV-infected individuals on HAART. Journal of Acquired Immune Deficiency Syndromes (1999). 2009;52(3):342. 
12. Wang EA, McGinnis KA, Fiellin DA, et al. Food insecurity is associated with poor virologic response among HIV-infected patients receiving antiretroviral medications. Journal of General Internal Medicine. 2011;26(9):1012-1018.

13. Jones CY, Hogan JW, Snyder B, et al. Overweight and human immunodeficiency virus (HIV) progression in women: associations HIV disease progression and changes in body mass index in women in the HIV epidemiology research study cohort. Clinical Infectious Diseases. 2003;37(Supplement 2):S69-S80.

14. Blashill AJ, Mayer KH, Crane HM, Grasso C, Safren SA. Body mass index, immune status, and virological control in HIV-infected men who have sex with men. Journal of the International Association of Providers of AIDS Care (JIAPAC). 2013;12(5):319-324.

15. Koethe JR, Jenkins CA, Shepherd BE, Stinnette SE, Sterling TR. An optimal body mass index range associated with improved immune reconstitution among HIV-infected adults initiating antiretroviral therapy. Clinical Infectious Diseases. 2011;53(9):952-960.

16. Acheson KJ, Gremaud G, Meirim I, et al. Metabolic effects of caffeine in humans: lipid oxidation or futile cycling? The American Journal of Clinical Nutrition. 2004;79(1):40-46.

17. Astrup A, Toubro S, Cannon S, Hein P, Breum L, Madsen J. Caffeine: a doubleblind, placebo-controlled study of its thermogenic, metabolic, and cardiovascular effects in healthy volunteers. The American Journal of Clinical Nutrition. 1990;51(5):759-767.

18. Bloomer RJ, Canale RE, Blankenship MM, Hammond KG, Fisher-Wellman KH, Schilling BK. Effect of the dietary supplement Meltdown on catecholamine secretion, markers of lipolysis, and metabolic rate in men and women: a randomized, placebo controlled, cross-over study. Lipids Health Dis. 2009;8:32.

19. Hoffman JR, Kang J, Ratamess NA, Jennings PF, Mangine G, Faigenbaum AD. Thermogenic effect from nutritionally enriched coffee consumption. J Int Soc Sports Nutr. 2006;3:35-41.

20. Campa A LK, Rafie C, Sales S, Baum MK. Caffeine intake and plasma zinc levels among HIV+ adult drug users in Miami. Experimental Biology 2008 FASEB Conference, San Diego, CA, April 5-9, 2008.; 2008.

21. United States Food and Drug Administration. FDA to investigate added caffeine. 2013; http://www.fda.gov/downloads/ForConsumers/ConsumerUpdates/UCM350 740.pdf. Accessed October 20, 2014. 
22. Moul D, Pilkonis P, Miewald J, Carey T, Buysse D. Preliminary study of the testretest reliability and concurrent validities of the Pittsburgh Insomnia Rating Scale (PIRS). Paper presented at: Sleep2002.

23. Buysse DJ, Reynolds CF, Monk TH, Berman SR, Kupfer DJ. The Pittsburgh Sleep Quality Index: a new instrument for psychiatric practice and research. Psychiatry Research. 1989;28(2):193-213.

24. Spitzer RL, Kroenke K, Williams JB, Löwe B. A brief measure for assessing generalized anxiety disorder: the GAD-7. Archives of Internal Medicine. 2006;166(10):1092-1097.

25. Preston JD, O'Neal JH, Talaga MC. Consumer's Guide to Psychiatric Drugs. New Harbinger Publications, Inc; 1998.

26. United States Food and Drug Administration. Database of Select Committee on GRAS Substances (SCOG) Reviews: Caffeine.

2006; http://www.accessdata.fda.gov/scripts/fcn/fcnDetailNavigation.cfm?rpt=sco gsListing\&id=42. Accessed Spetember 12, 2014.

27. Flaghorn FH, Johnson RK, Ying LF. Food sources and intakes of caffeine in the diets of persons in the United States. Journal of the American Dietetic Association. 2014;115(1):110-113.

28. World Health Organization. Lexicon of alcohol and drug terms published by the World Health Organization. September 2013.

29. World Health Organization. Mental and behavioural disorders F15. International Statistical Classification of Diseases and Related Health Problems. 2010; Chapter 5(Mental and behavioural disorders due to use of other stimulants, including caffeine.).

30. Amerian Psychiatric Association. Diagnostic and Statistical Manual of Mental Disorders. Vol Fifth ed2013.

31. United States Food and Drug Administration. Guidance for Industry: A Food Labeling Guide. Calculate the Percent Daily Value for the Appropriate Nutrients. 2013; http://www.fda.gov/Food/GuidanceRegulation/GuidanceDocumentsRegulat oryInformation/LabelingNutrition/ucm064928.htm, June 2015.

32. Biodynamic Corporation. BIA 450 bioimpedance analyzer.

2010; http://www.biodyncorp.com/product/450/450.html, May, 2015. 
33. Ezeamama AE, Mupere E, Oloya J, et al. Age, sex, and nutritional status modify the CD4+ T-cell recovery rate in HIV-tuberculosis co-infected patients on combination antiretroviral therapy. International Journal of Infectious Diseases. 2015;35:73-79.

34. Feldman MB, Alexy ER, Thomas JA, Gambone GF, Irvine MK. The association between food insufficiency and HIV treatment outcomes in a longitudinal analysis of HIV-infected individuals in New York City. Journal of Acquired Immune Deficiency Syndromes (1999). 2015.

35. Nunn A, Sanders J, Carson L, et al. African American Community Leaders' Policy Recommendations for Reducing Racial Disparities in HIV Infection, Treatment, and Care Results From a Community-Based Participatory Research Project in Philadelphia, Pennsylvania. Health Promotion Practice. 2015;16(1):91100.

36. Behrman JA. The effect of increased primary schooling on adult women's HIV status in Malawi and Uganda: Universal Primary Education as a natural experiment. Social Science \& Medicine. 2015;127:108-115.

37. Dellar R, Karim QA. HIV/AIDS, food insecurity, and undernourishment: amplifying cycles of risk in vulnerable populations. Journal of Acquired Immune Deficiency Syndromes (2013). 2015.

38. Quach LA, Wanke CA, Schmid CH, et al. Drug use and other risk factors related to lower body mass index among HIV-infected individuals. Drug and Alcohol Dependence. 2008;95(1):30-36.

39. Calvo M, Laguno M, Martínez M, Martínez E. Effects of Tobacco Smoking on HIV-Infected Individuals. AIDS Reviews. 2015;17:47-55.

40. Chen Y, Kalichman SC. Synergistic effects of food insecurity and drug use on medication adherence among people living with HIV infection. Journal of Behavioral Medicine. 2015;38(3):397-406.

41. Abioye AI, Isanaka S, Liu E, et al. Gender differences in diet and nutrition among adults initiating antiretroviral therapy in Dar es Salaam, Tanzania. AIDS Care. 2015(ahead-of-print):1-10.

42. Salomon J, De Truchis P, Melchior J-C. Nutrition and HIV infection. British Journal of Nutrition. 2002;87(S1):S111-S119.

43. Alvarado G, Ceballos L, Baum M, et al. Alcohol Use and Zinc Status in HIV+ Adults in Miami, Florida. The FASEB Journal. 2015;29(1 Supplement):736.715. 
44. Sackey J, Chui K, Tang A. Food Insecurity and its Association with Depression among Injection Drug Users (IDUs) with or without HIV in Chennai, India. The FASEB Journal. 2015;29(1 Supplement):585.581.

45. Thapa R, Amatya A, Pahari DP, Bam K, Newman MS. Nutritional status and its association with quality of life among people living with HIV attending public anti-retroviral therapy sites of Kathmandu Valley, Nepal. AIDS Research and Therapy. 2015;12(1):14.

46. Li M, McDermott R. Smoking, poor nutrition, and sexually transmitted infections associated with pelvic inflammatory disease in remote North Queensland Indigenous communities, 1998-2005. BMC Women's Health. 2015;15(1):31.

47. Grenha I, Oliveira J, Lau E, et al. Body composition in HIV-infected patients under combined antiretroviral therapy over 5 years. 2015.

48. Soares LR, SILVA DCd, Gonsalez CR, et al. Discordance between body mass index and anthropometric measurements among hiv-1-infected patients on antiretroviral therapy and with lipoatrophy/lipohypertrophy syndrome. Revista Do Instituto De Medicina Tropical De São Paulo. 2015;57(2):105-110.

49. Moyle GJ, Hardy H, Farajallah A, DeGrosky M, McGrath D. Comparison of Body Composition Changes Between Atazanavir/Ritonavir and Lopinavir/Ritonavir Each in Combination with Tenofovir/Emtricitabine in Antiretroviral-Naïve Patients with HIV-1 Infection. Clinical Drug Investigation. 2014;34(4):287-296.

50. Kalichman SC, Hernandez D, Kegler C, Cherry C, Kalichman MO, Grebler T. Dimensions of Poverty and Health Outcomes Among People Living with HIV Infection: Limited Resources and Competing Needs. Journal of Community Health. 2015:1-7.

51. Salazar-Martinez E, Willett WC, Ascherio A, et al. Coffee consumption and risk for type 2 diabetes mellitus. Annals of Internal Medicine. 2004;140(1):1-8.

52. Greenberg JA, Boozer CN, Geliebter A. Coffee, diabetes, and weight control. The American Journal of Clinical Nutrition. 2006;84(4):682-693.

53. Pettenuzzo LF, Noschang C, von Pozzer Toigo E, Fachin A, Vendite D, Dalmaz C. Effects of chronic administration of caffeine and stress on feeding behavior of rats. Physiology \& Behavior. 2008;95(3):295-301.

54. Hamada T, Kotani K, Higashi A, et al. Lack of Association of the Trp64Arg Polymorphism of $\beta$ 3-Adrenergic Receptor Gene with Energy Expenditure in 
Response to Caffeine Among Young Healthy Women. The Tohoku Journal of Experimental Medicine. 2008;214(4):365-370.

55. Shor-Posner G, Campa A, Zhang G, et al. When obesity is desirable: a longitudinal study of the Miami HIV-1-infected drug abusers (MIDAS) cohort. Journal of Acquired Immune Deficiency Syndromes (1999). 2000;23(1):81-88.

56. Kosmiski L. Energy expenditure in HIV infection. The American Journal of Clinical Nutrition. 2011;94(6):1677S-1682S.

57. Melchior J-C, Salmon D, Rigaud D, et al. Resting energy expenditure is increased in stable, malnourished HIV-infected patients. The American Journal of Clinical Nutrition.1991;53(2):437-441.

58. Hommes M, Romijn JA, Endert E, Sauerwein HP. Resting energy expenditure and substrate oxidation in human immunodeficiency virus (HIV)-infected asymptomatic men: HIV affects host metabolism in the early asymptomatic stage. The American Journal of Clinical Nutrition. 1991;54(2):311-315.

59. Langford SE, Ananworanich J, Cooper DA. Predictors of disease progression in HIV infection: a review. AIDS Research and Therapy. 2007;4(1):11.

60. Kruzich LA, Marquis GS, Carriquiry AL, Wilson CM, Stephensen CB. US youths in the early stages of HIV disease have low intakes of some micronutrients important for optimal immune function. Journal of the American Dietetic Association. 2004;104(7):1095-1101.

61. Baum MK, Shor-Posner G, Campa A. Zinc status in human immunodeficiency virus infection. The Journal of Nutrition. 2000;130(5):1421S-1423S.

62. Baum MK, Shor-Posner G, Lai S, et al. High risk of HIV-related mortality is associated with selenium deficiency. JAIDS Journal of Acquired Immune Deficiency Syndromes. 1997;15(5):370-374.

63. Rosenthal R, Rubin DB. Interpersonal expectancy effects: The first 345 studies. Behavioral and Brain Sciences. 1978;1(03):377-386. 


\section{CHAPTER-VII: SUMMARY AND CONCLUSIONS}

The present study characterized a consecutive convenience sample of 130 PLWH (65 consuming $\leq 250 \mathrm{mg} /$ day and 65 consuming $>250 \mathrm{mg} /$ day of caffeine), recruited from the MASH cohort, and investigated for the effects of caffeine consumption on parameters of HIV disease progression crosssectionally and over time. Additionally, this study examined the effects of caffeine consumption on behavioral and nutritional parameters. The behavioral outcomes evaluated included sleep quality, insomnia levels and generalized anxiety symptoms. The nutritional parameters examined were nutrient intake, anthropometrics and body composition measures. Finally, this study explored the net combined impact of the behavioral and nutritional variables on HIV disease progression both crosssectionally and over time.

The mean caffeine consumption for our cohort was $338 \mathrm{mg} /$ day during the baseline visit and $281 \mathrm{mg} /$ day during the 3-month follow-up visit, and was higher than US average of $200 \mathrm{mg} /$ day during both the visits. ${ }^{1-3}$ Caffeine intake from coffee was also higher than the US average of $135 \mathrm{mg}$ /day during both visits. The Diagnostic and Statistical Manual of Mental Disorders (DSM-5) considers consumption below $250 \mathrm{mg}$ /day to be generally safe and not associated with any adverse effect. ${ }^{4}$ Considering this recommendation, it is concerning that our cohort reported a higher than safe, mean levels of caffeine consumption during both the study visits.

The majority of the demographic findings of the current study were epidemiologically similar to those described by others in Miami-Dade County., 5,6 
Most of the participants were African Americans (75.4\%). All participants had incomes under the level of poverty and the mean income was $\$ 495.91 \pm 465.887$ per month. More than half of the participants in our cohort were consuming alcohol and smoking cigarettes, and slightly less than half had a positive urine toxicology result for illicit drugs. Our results suggested that higher caffeine was associated with higher CD4 cell counts and lower viral load cross-sectionally, adjusting for co-variates such as age, gender, education, income, time from diagnosis of HIV, substance use, different types of ART medications, BMI and total fat mass. Higher caffeine consumption was also associated with higher CD4 cell counts and better control over viral loads, when observed over time after 3months, adjusting for the same covariates. Higher caffeine consumption was also associated with lower sleep quality, higher insomnia levels and higher generalized anxiety symptoms, both crosssectionally and over time, adjusting for the covariates. Approximately half of all participants reported inadequate dietary intakes for many micronutrients during both the visits, independent of the effects of caffeine. Higher caffeine intake was additionally associated with lower dietary intakes of many nutrients and lower fat mass. Our results were paradoxical because higher caffeine intakes were associated with improvements in parameters of disease progression, but indirectly also precipitated adverse outcomes, since higher caffeine intakes were associated with worsening behavioral and nutrition measures. High caffeine intakes seemed to improve the recuperation of CD4 cells and facilitated control over HIV viral load, whereas, caffeine also precipitated many adverse outcomes associated with HIV disease progression such as 
worsening sleep quality, increased insomnia and generalized anxiety levels, and compromised dietary intakes and body composition measures and consequently worsening HIV disease progression. These paradoxical and inconsistent findings open new hypotheses for future large scale studies to shed light on other behavioral and bio-chemical mechanisms responsible for these findings.

The majority of the adverse effects of caffeine became apparent, only after controlling for covariates associated with HIV disease progression, suggesting a mild but complex effects of caffeine on the adverse outcomes observed in this study. Caffeine can only be implicated in mediating and moderating the adverse and beneficial effects of other co-variates (with higher $\beta$ coefficients) such as cocaine and methamphetamine use and antiretroviral medications which have greater effects on HIV disease progression parameters.

Our study reported decrease in mean caffeine consumption from 338 $\mathrm{mg} /$ day during baseline visit, to $281 \mathrm{mg}$ /day during follow-up visit, though not statistically significant. Caffeine intakes from caffeinated soft drinks and energy drinks also decreased significantly, from $63 \mathrm{mg} /$ day to $30 \mathrm{mg} /$ day and $46 \mathrm{mg} /$ day to $10 \mathrm{mg} /$ day, respectively, from the baseline to the 3-month follow-up visit. Over three months, the effects of behavioral outcomes such as poor sleep quality, insomnia, and generalized anxiety symptoms, on CD4 counts and viral load diminished and lost statistical significance, thereby indicating decreasing effects of these behavioral outcomes on HIV disease progression. These observations could have been incidental findings or due to self-motivated changes in dietary and lifestyle factors, and better compliance to medications, ascribable to the 
stimulant effect of caffeine, the free nutritional advice and counselling provided during the visits, which would have facilitated better immune recuperation and decreased disease progression. There is a possibility that such changes could also be due to the 'Hawthorn Effect', where participants improved their behaviors in response to the awareness of being observed by our study. ${ }^{7}$ These findings suggest other approaches for improving the health and nutritional outcomes in PLWH. In addition to restricted consumption of anorectic agents such as caffeine, improved nutritional advice, dietary counseling and lifestyle-modifications could be associated with alleviating some of the adverse outcomes reported in our study.

Since almost half of the participants reported illicit drugs use and more than half of the participants reported alcohol use and smoking, the combined effects of these substances could far outweigh the adverse effects of caffeine, because many studies have associated substance use with adverse health and nutritional consequences in HIV.-11 Alcohol, drug and smoking cessation interventions should accompany nutritional and dietary counseling initiatives in order to achieve better immunologic and virologic profiles and thereby adequate control over disease progression in this vulnerable population of PLWH. 


\section{References}

1. Wesensten NJ. Legitimacy of concerns about caffeine and energy drink consumption. Nutrition Reviews. 2014;72(suppl 1):78-86.

2. Heckman MA, Weil J, Mejia D, Gonzalez E. Caffeine (1, 3, 7trimethylxanthine) in Foods: A Comprehensive Review on Consumption, Functionality, Safety, and Regulatory Matters. Journal of Food Science. 2010;75(3):R77-R87.

3. Pankevich D, Pray L, Yaktine AL. Caffeine in Food and Dietary Supplements: Examining Safety:Workshop Summary. National Academies Press; 2014.

4. American Psychiatric Association. Diagnostic and Statistical Manual of Mental Disorders. Vol Fifth ed2013.

5. Moss T, Martin CW, Klausner JD, Brown BJ. Integration of Screening for Syphilis, Hepatitis C, and Other Sexually Transmitted Infections with HIV Testing in a Community-Based HIV Prevention Program in Miami, Florida. LGBT Health. 2014;1(2):82-85.

6. Wawrzyniak AJ, Rodríguez AE, Falcon AE, et al. Association of Individual and Systemic Barriers to Optimal Medical Care in People Living With HIV/AIDS in Miami-Dade County. JAIDS Journal of Acquired Immune Deficiency Syndromes. 2015;69:S63-S72.

7. McCarney R, Warner J, Iliffe S, van Haselen R, Griffin M, Fisher P. The Hawthorne Effect: a randomised, controlled trial. BMC Medical Research Methodology. 2007;7(1):30.

8. Miguez MJ, Shor-Posner G, Morales G, Rodriguez A, Burbano X. HIV treatment in drug abusers: impact of alcohol use. Addiction Biology. 2003;8(1):33-37.

9. Schneider M, Chersich M, Neuman M, Parry C. Alcohol consumption and HIV/AIDS: the neglected interface. Addiction. 2012;107(8):1369-1371.

10. Darke S, Swift W, Hall W, Ross M. Drug use, HIV risk-taking and psychosocial correlates of benzodiazepine use among methadone maintenance clients. Drug and Alcohol Dependence. 1993;34(1):67-70.

11. Nieman RB, Fleming J, Coker RJ, Harris JW, Mitchell DM. The effect of cigarette smoking on the development of AIDS in HIV-1-seropositive individuals. Aids. 1993;7(5):705-710. 


\section{CHAPTER VIII: STRENGTHS AND LIMITATIONS}

The greatest strength of our study is filling the gap in the literature on the health effects of caffeine in PLWH, by examining the relationship of caffeine consumption with parameters of disease progression, and with behavioral and nutritional outcomes in this vulnerable population. For the first time, we identified paradoxical findings in the relationship of caffeine intake with HIV disease progression.

The current study followed a quasi-experimental design and gathered data from a baseline and 3-month follow-up visit, and two MASH cohort study visits. Because of the prospective observational characteristic of this study, changes in associations over time could be measured and a number of causal associations could be determined, controlling for the pertinent covariates. This greatly contributed to the strengths of the study, because, not only cross-sectional associations but also the causal effects with dose-response relationships were reported for many outcome variables. Large scale experimental and interventional studies planned in the future could benefit from our understandings on the effects of caffeine on the outcome variables researched in our study.

Our study recorded one hundred percent response rates to all components and questionnaires for both the study visits, thereby eliminating non-response and attrition biases. All the questionnaires used in the current study were field tested and validated in large scale studies. ${ }^{1-5}$ Our participants were recruited from the MASH cohort and comprehensive protocols were already developed and instituted for the MASH studies, thereby greatly facilitating precise data 
collecting procedures for the current study. All the data were collected and quality assured by trained dietitians, nutritionists and registered nurses with substantial experience in health-science research. Moreover, there were no adverse events or compromised participant compliance with the visits, during the entire duration of the current study. All these factors added to the validity and reliability of the data gathered during the study.

In spite of the planned research design and implementation, there were some limitations. The current study enrolled a consecutive convenient sample of 130 HIV positive participants from the MASH cohort, attending their treatment visits at BHCC. This sample of frequent health care utilizers would have been different form the population of PLWH in the United States. As this was not a random sample from the total population of PLWH, our findings are not generalizable, thus limiting the external validity of our study. In addition, many un-accounted confounders beyond the ones controlled in the current study and gathered in the MASH cohort studies, could have affected our results, thereby limiting the internal validity of our findings. Experimental designs such as randomized controlled trials, which have complete control over the study variables, a comparable control arm, and high internal validity, should be planned in the future to overcome these limitations and ascertain the findings of our study.

In the current study, there were two time points when the data was gathered, and carryover effects from the initial baseline visit could have affected the outcomes during the follow-up visit. Since these participants were followed for a long time (2002 - 2014) for MASH cohort study visits, some carry-over 
effects from the MASH cohort studies could have also affected the findings in our study. Biases such as the Pygmalion effect and the Golem effect, ${ }^{6}$ by which participants tend to improve or moderate their responses to the outcome measures, after learning about the expectations of the research and the research personnel, could have affected our study. Biases such as the Hawthorne effect, ${ }^{7}$ by which, participants could have modified their health and nutritional outcomes, because of being monitored by the studies, could have also affected our study findings. In addition, the participants could have been affected by an Interpersonal Expectancy Bias, ${ }^{8}$ by which, they would have responded what they believed the investigators wanted to hear, or the investigators would have recorded what they wanted to report. Such biases get adequately balanced and controlled in randomized control studies, due to the presence of a comparable control arm, and should be planned in the future to retest and establish the findings of our study. 


\section{References}

1. United States Food and Drug Association. FDA to investigate added caffeine.

2013; http://www.fda.gov/downloads/ForConsumers/ConsumerUpdates/U CM350740.pdf. Accessed October 20, 2014.

2. Moul D, Pilkonis P, Miewald J, Carey T, Buysse D. Preliminary study of the test-retest reliability and concurrent validities of the Pittsburgh Insomnia Rating Scale (PIRS). Paper presented at: Sleep2002.

3. Buysse DJ, Reynolds CF, Monk TH, Berman SR, Kupfer DJ. The Pittsburgh Sleep Quality Index: a new instrument for psychiatric practice and research. Psychiatry Research. 1989;28(2):193-213.

4. Spitzer RL, Kroenke K, Williams JB, Löwe B. A brief measure for assessing generalized anxiety disorder: the GAD-7. Archives of Internal Medicine. 2006;166(10):1092-1097.

5. Bickel G, Nord M, Price C, Hamilton W, Cook J. Guide to measuring household food security. US Department of Agriculture, Food and Nutrition Service, Office of Analysis, Nutrition, and Evaluation. http://www.fns. usda. gov/fsec/FILES/Guide\% 20to\% 20Measuring\% 20Household\% 20Food\% 20Security (3-23-00). pdf. 2000.

6. Babad EY, Inbar J, Rosenthal R. Pygmalion, Galatea, and the Golem: Investigations of biased and unbiased teachers. Journal of Educational Psychology. 1982;74(4):459.

7. Franke RH, Kaul JD. The Hawthorne experiments: First statistical interpretation. American Sociological Review. 1978:623-643.

8. Rosenthal R, Rubin DB. Interpersonal expectancy effects: The first 345 studies. Behavioral and Brain Sciences. 1978;1(03):377-386. 


\section{CHAPTER IX: FUTURE RESEARCH}

Our study findings will serve as a preface for further investigations on the paradoxical effects of caffeine consumption in PLWH. Organizations such as United States Food and Drug Administration (USFDA) and Food and Agriculture Department (FAO), can plan and accomplish future large scale studies on the effects of caffeine consumption in PLWH and regulate caffeine consumption in this population of PLWH.

Though caffeine and its health effects have been widely researched in several vulnerable populations such as students, business personnel, athletes, night shift workers, military personnel, geriatric population, frequent travelers and college and university professionals, ${ }^{1}$ similar studies are lacking in PLWH. Large scale studies should be planned in the future with greater sample size, better sample selection methods, other pertinent outcomes, and longer study durations for confirming and explaining the findings of our study.

We had primarily focused on HIV disease progression, sleep and generalized anxiety, and nutritional and body composition outcomes but did not consider other potential domains such neuro-hormonal changes, nerve conduction velocities, loco-motor stimulatory effects, simple reaction time, choice reaction time, state and trait anxiety, Critical Flicker Fusion Threshold (CFFT) and muscle sympathetic activity scores which are sleep and stress related variables affected by caffeine consumption. ${ }^{2-7}$ These are open areas for research because they are extensions of our study findings, where caffeine produced sleep loss and heightened anxiety states. Though dependence, tolerance and withdrawal effects 
of caffeine have been researched in healthy populations, ${ }^{8-11}$ similar studies are non-existent in PLWH and are open areas for future research.

There are very few studies on the effect of caffeine consumption on parameters of disease progression and hence there is no scientific consensus on this topic. Our study included CD4 counts and viral loads as markers of disease progression and found conflicting evidences of caffeine being both beneficial and detrimental to these variables. Several other markers such as time to first occurrence of CD4 cell count $\leq 100$ cells $/ \mathrm{mm}^{3}$; first occurrence of other infection/malignancy; and HIV-related deaths, ${ }^{12}$ could not be considered due to the short duration of the study. These additional parameters could have aided a better understanding about the effects of caffeine on HIV disease progression and should be considered by future large scale studies. Other behavioral markers such as the effect of caffeine consumption on mood, physical activity, routine physical functioning and performance, should also be considered in future studies.

Future bio-chemical investigations are also critical to explain the dose response relationship between increased caffeine consumption and increased CD4 cells and more controlled viral load observed in the current study. Caffeine has been associated with changes in plasma levels of hormones such as norepinephrine, epinephrine, prostaglandins, cortisol, testosterone, and insulin, and cytokines such as interleukins-6, interleukin-8, interleukin-18, 8-isoprostane, interferons, tumor necrosis factors, E-selectins, Hypoxia-Inducible Factor-1 $\alpha$, and Vascular Endothelial Growth Factor in many studies. ${ }^{13-22}$ To fully understand the relationship of caffeine with parameters of disease progression, behavioral and 
nutritional factors and their inter-relationships, these biomarkers should be measured and controlled, because they could explain the detrimental and beneficial outcomes observed in our study. Future large scale studies with sufficient resources should be planned to answer the questions raised by the paradoxical outcomes of our study. Additionally caffeine consumption should be considered for both the beneficial and the adverse effects in PLWH, in order to derive recommendations on safe levels of consumption for this population. 


\section{References}

1. Wesensten NJ. Legitimacy of concerns about caffeine and energy drink consumption. Nutrition Reviews. 2014;72(1):78-86.

2. Daly JW, Fredholm BB. Caffeine-an atypical drug of dependence. Drug and Alcohol Dependence. 1998;51(1):199-206.

3. Klotz K-N, Hessling J, Hegler J, et al. Comparative pharmacology of human adenosine receptor subtypes-characterization of stably transfected receptors in CHO cells. Naunyn-Schmiedeberg's Archives of Pharmacology. 1997;357(1):1-9.

4. Garrett BE, Griffiths RR. The role of dopamine in the behavioral effects of caffeine in animals and humans. Pharmacology Biochemistry and Behavior. 1997;57(3):533-541.

5. Svenningsson P, Le Moine C, Kull B, Sunahara R, Bloch B, Fredholm B. Cellular expression of adenosine $\mathrm{A}$ and 2A receptor messenger RNA in the rat central nervous system with special reference to dopamine innervated areas. Neuroscience. 1997;80(4):1171-1185.

6. Hettinger BD, Lee A, Linden J, Rosin DL. Ultrastructural localization of adenosine A2A receptors suggests multiple cellular sites for modulation of GABAergic neurons in rat striatum. Journal of Comparative Neurology. 2001;431(3):331-346.

7. Lieberman HR, Wurtman RJ, Emde GG, Coviella IG. The effects of caffeine and aspirin on mood and performance. Journal of Clinical Psychopharmacology. 1987;7(5):315-320.

8. Bruce M, Scott N, Shine P, Lader M. Anxiogenic effects of caffeine in patients with anxiety disorders. Archives of General Psychiatry. 1992;49(11):867-869.

9. Griffiths R, Mumford G. Caffeine reinforcement, discrimination, tolerance and physical dependence in laboratory animals and humans.

Pharmacological Aspects of Drug Dependence: Springer; 1996:315-341.

10. Silverman K, Evans SM, Strain EC, Griffiths RR. Withdrawal syndrome after the double-blind cessation of caffeine consumption. New England Journal of Medicine. 1992;327(16):1109-1114. 
11. Goldstein A, Kaizer S, Whitby O. Psychotropic effects of caffeine in man. IV. Quantitative and qualitative differences associated with habituation to coffee. Clin Pharmacol Ther. 1969;10(4):489-497.

12. Jones CY, Hogan JW, Snyder B, et al. Overweight and human immunodeficiency virus (HIV) progression in women: associations HIV disease progression and changes in body mass index in women in the HIV epidemiology research study cohort. Clinical Infectious Diseases. 2003;37(Supplement 2):S69-S80.

13. Merighi S, Benini A, Mirandola P, et al. Caffeine inhibits adenosineinduced accumulation of hypoxia-inducible factor- $1 \alpha$, vascular endothelial growth factor, and interleukin-8 expression in hypoxic human colon cancer cells. Molecular Pharmacology. 2007;72(2):395-406.

14. Kempf K, Herder C, Erlund I, et al. Effects of coffee consumption on subclinical inflammation and other risk factors for type 2 diabetes: a clinical trial. The American Journal of Clinical Nutrition. 2010;91(4):950957.

15. Geber W, Lefkowitz S, Hung C. Effect of morphine, hydromorphone, methadone, mescaline, trypan blue, vitamin A, sodium salicylate, and caffeine on the serum interferon level in response to viral infection. Archives Internationales de Pharmacodynamie et de Therapie. 1975;214(2):322-327.

16. Graham T, Spriet L. Metabolic, catecholamine, and exercise performance responses to various doses of caffeine. Journal of Applied Physiology. 1995;78(3):867-874.

17. Van Soeren M, Graham T. Effect of caffeine on metabolism, exercise endurance, and catecholamine responses after withdrawal. Journal of Applied Physiology. 1998;85(4):1493-1501.

18. Lovallo WR, Whitsett TL, al'Absi M, Sung BH, Vincent AS, Wilson MF. Caffeine stimulation of cortisol secretion across the waking hours in relation to caffeine intake levels. Psychosomatic Medicine. 2005;67(5):734.

19. Beaven CM, Hopkins WG, Hansen KT, Wood MR, Cronin JB, Lowe TE. Dose effect of caffeine on testosterone and cortisol responses to resistance exercise. International Journal of Sport Nutrition and Exercise Metabolism. 2008;18(2):131. 
20. Graham TE, Sathasivam P, Rowland M, Marko N, Greer F, Battram D. Caffeine ingestion elevates plasma insulin response in humans during an oral glucose tolerance test. Canadian Journal of Physiology and Pharmacology. 2001;79(7):559-565.

21. Lopez-Garcia E, van Dam RM, Qi L, Hu FB. Coffee consumption and markers of inflammation and endothelial dysfunction in healthy and diabetic women. The American Journal of Clinical Nutrition. 2006;84(4):888-893.

22. Snyder SH, Sklar P. Psychiatric progress: Behavioral and molecular actions of caffeine: Focus on adenosine. Journal of Psychiatric Research. 1984;18(2):91-106. 
APPENDIX - I 


\section{Caffeine Consumption Questionnaire}

\begin{tabular}{|c|c|c|c|c|}
\hline & & & $\begin{array}{c}\text { Average number of } \\
\text { ounces/doses/tablets } \\
\text { per day }\end{array}$ & $\begin{array}{l}\text { Average } \\
\text { total } \\
\text { per day }\end{array}$ \\
\hline \multicolumn{5}{|l|}{ Beverages } \\
\hline Coffee $(6$ oz.) & $125 \mathrm{mg}$ & $\mathrm{X}$ & & \\
\hline Decaf Coffee (6 oz.) & $5 \mathrm{mg}$ & $\mathrm{x}$ & & \\
\hline Espresso (1 oz.) & $50 \mathrm{mg}$ & $\mathrm{x}$ & & \\
\hline Tea $(6$ oz.) Green & $50 \mathrm{mg}$ & $\mathrm{x}$ & & \\
\hline Tea $(6 \mathrm{oz})$ Black & $50 \mathrm{mg}$ & $\mathrm{X}$ & & \\
\hline Cocoa (6 oz.) & $15 \mathrm{mg}$ & $\mathrm{x}$ & & \\
\hline Energy drinks (12 oz.) & *equivalent $200 \mathrm{mg}$ & $\mathrm{X}$ & & \\
\hline Caffeinated Soft Drinks (12 oz.) & $40-60 \mathrm{mg}$ & $\mathrm{X}$ & & \\
\hline Chocolate candy bar & $20 \mathrm{mg}$ & $\mathrm{x}$ & & \\
\hline \multicolumn{5}{|c|}{ Over-the-Counter Medications } \\
\hline Anacin & $32 \mathrm{mg}$ & $\mathrm{X}$ & 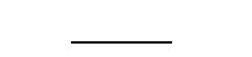 & \\
\hline Appetite-control pills & $100-200 \mathrm{mg}$ & $\mathrm{x}$ & & \\
\hline Dristan & $16 \mathrm{mg}$ & $\mathrm{X}$ & & \\
\hline Excedrine & $65 \mathrm{mg}$ & $\mathrm{x}$ & & \\
\hline Midol & $132 \mathrm{mg}$ & $\mathrm{X}$ & & \\
\hline NoDoz & $200 \mathrm{mg}$ & $\mathrm{X}$ & & \\
\hline Triaminicin & $30 \mathrm{mg}$ & $\mathrm{X}$ & & \\
\hline Vanquish & $33 \mathrm{mg}$ & $\mathrm{X}$ & & \\
\hline Vivarin & $200 \mathrm{mg}$ & $\mathrm{X}$ & & \\
\hline \multicolumn{5}{|l|}{ Prescription Medications } \\
\hline Fiorinal & $40 \mathrm{mg}$ & $\mathrm{X}$ & 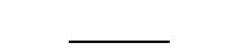 & \\
\hline
\end{tabular}

TOTAL MG. CAFFEINE PER DAY

*Caffeine content of energy drinks vary. They also include a number of stimulating herbs.

$>250$ milligrams a day, if taken after noon, may interfere with deep sleep

(B) John Preston (2014) 


\section{PIRS}

ID

Date $\frac{}{m} \bar{m}^{\prime} \frac{}{d} \bar{d}^{\prime} \frac{}{y} \bar{y}$

A. Overall sleep quality: Consider the quality of your sleep in the past 7 days. Then mark that point along the line that best describes your sleep quality in the past 7 days:

Horrible

The following questions ask about your sleep in the past 7 days and nights. Please circle the one best answer for each question.

B. In the past week, how much were you bothered by:

\begin{tabular}{|c|c|c|c|}
\hline $\begin{array}{l}\text { Not at all } \\
\text { bothered }\end{array}$ & $\begin{array}{l}\text { Slightly } \\
\text { bothered }\end{array}$ & $\begin{array}{l}\text { Moderately } \\
\text { bothered }\end{array}$ & $\begin{array}{l}\text { Severely } \\
\text { bothered }\end{array}$ \\
\hline 0 & 1 & 2 & 3 \\
\hline 0 & 1 & 2 & 3 \\
\hline 0 & 1 & 2 & 3 \\
\hline 0 & 1 & 2 & 3 \\
\hline 0 & 1 & 2 & 3 \\
\hline 0 & 1 & 2 & 3 \\
\hline 0 & 1 & 2 & 3 \\
\hline 0 & 1 & 2 & 3 \\
\hline 0 & 1 & 2 & 3 \\
\hline 0 & 1 & 2 & 3 \\
\hline 0 & $\mathrm{~A}^{\prime}$ & 2 & 3 \\
\hline 0 & 1 & 2 & 3 \\
\hline 0 & 1 & 2 & 3 \\
\hline 0 & 1 & 2 & 3 \\
\hline 0 . & 1 & 2 & 3 \\
\hline 0 & 1 & 2 & 3 \\
\hline 0 & 1 & 2 & 3 \\
\hline 0 & 1 & 2 & 3 \\
\hline 0 & 1 & 2 & 3 \\
\hline 0 & 1 & 2 & 3 \\
\hline 0 & & & \\
\hline 0 & 1 & 2 & 3 \\
\hline
\end{tabular}

Page 1 of 5 


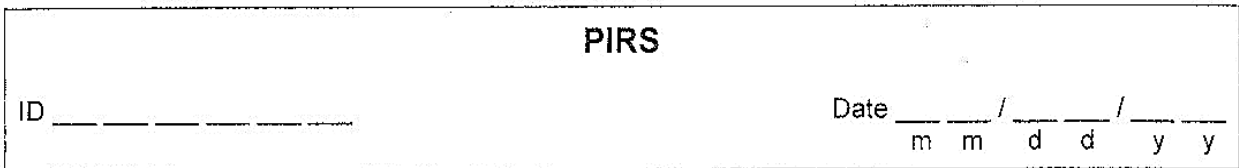

In the past week, how much were you bothered by:

\begin{tabular}{|c|c|c|c|c|}
\hline$e p$ & $\begin{array}{l}\text { Not at all } \\
\text { bothered }\end{array}$ & $\begin{array}{l}\text { Slightly } \\
\text { bothered }\end{array}$ & $\begin{array}{l}\text { Moderately } \\
\text { bothered }\end{array}$ & $\begin{array}{l}\text { Severely } \\
\text { bothered }\end{array}$ \\
\hline ind never slowing down during the & 0. & 1 & 2 & 3 \\
\hline 24. Difficulty remembering things & 0 & 1 & 2 & 3 \\
\hline $\begin{array}{l}\text { 25. Difficulty thinking cleally and making } \\
\text { decisions }\end{array}$ & & 1 & 2 & 3 \\
\hline 26. Tiredness or fatigue & 0 & $i$ & 2 & 3 \\
\hline $\begin{array}{l}27 \text { Dozing off or napping when you really } \\
\text { didn't want to }\end{array}$ & 0 & 1 & 2 & 3 \\
\hline $\begin{array}{l}\text { 28. Others noticing you appeared tired or } \\
\text { fatigued }\end{array}$ & 0 & 1 & 2 & 3 \\
\hline 29 Too many difficulties to overcome & 0 & & 2 & 3 \\
\hline $\begin{array}{l}\text { 30. Being unsure about handling your personal } \\
\text { problems }\end{array}$ & 0 & 1 & 2 & 3 \\
\hline $\begin{array}{l}\text { 31. Being unsure about dealing with day-to-day } \\
\text { problems }\end{array}$ & 0 & 1 & 2 & 3 \\
\hline $\begin{array}{l}\text { 32. Irritati } \\
\text { during }\end{array}$ & 0 & 1 & 2 & 3 \\
\hline 33 Bad mood(s) because you had poor sleep & 0 & $1 \%$ & 2 & 3 \\
\hline $\begin{array}{l}\text { 34. Irritation W } \\
\text { polite }\end{array}$ & 0 & 1 & 2 & 3 \\
\hline 35. Difficuly controlling your emotions & 0 & 1 & 2 & 3 \\
\hline 36. Needing to keep quiet around other people & 0 & 1 & 2 & 3 \\
\hline 37 Lack of energy because of poor sleep & 0 & 1 & 2 & 3 \\
\hline $\begin{array}{l}\text { 38. Poor sleep that interfe } \\
\text { relationships }\end{array}$ & 0 & 1 & 2 & 3 \\
\hline 39 Feeling sleepy & 0 & 1 & 2 & 3 \\
\hline 40. Being unable to sleep & 0 & 1 & 2 & 3 \\
\hline 41. Feeling that time itself slowed down & 0 & & 2 & 3 \\
\hline 42. Being able to do only enough to get by & 0 & 1 & 2 & 3 \\
\hline 43. Difficulty getting & 0 & 1 & 2 & 3 \\
\hline 44. Physical ciumsiness & 0 & 1 & 2 & 3 \\
\hline 45. Feeling physically ill or prone to infections. & 0 & 1. & 2 & 3 \\
\hline $\begin{array}{l}\text { 46. Being forced to pay special attention to } \\
\text { what you eat or what you do so that you } \\
\text { can sleep better }\end{array}$ & 0 & 1 & 2 & 3 \\
\hline
\end{tabular}




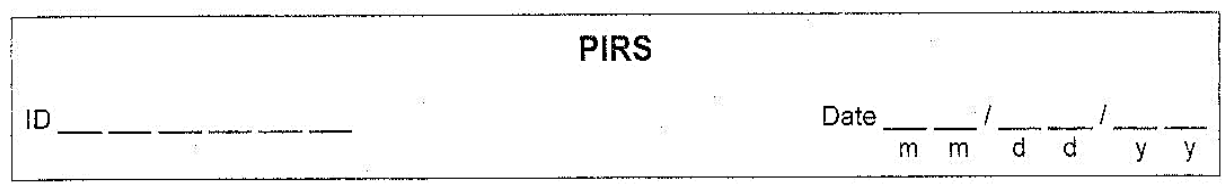

C. Please circle the best answer for each question about the past week:

47. From the time you tried to go to sleep, how long did it take to fall asleep on the worst night?

0 Less than $1 / 2$ hour

1 Between $1 / 2$ to 1 hour

2 Between 1 to 3 hours

3 More than 3 hours or I didn't sleep

48. From the time you tried to go to sleep, how long did it take to fall asleep on most nights?

0 Less than $1 / 2$ hour

1 Between $1 / 2$ to 1 hour

2 Between 1 to 3 hours

3 More than 3 hours or I didn't sleep

49. If you woke up during the night, how long did it take to fall back to sleep on the worst night?

0 Less than $1 / 2$ hour or I didn't wake up

1 Between $1 / 2$ to 1 hour

2 Between 1 to 3 hours

3 More than 3 hours or I didn't fall back to sleep

50. If you woke up during the night, how long did it take to fall back to sieep on most nights?

0 Less than $1 / 2$ hour or I didn't wake up

1 Between $1 / 2$ to 1 hour

2 Between 1 to 3 hours

3 More than 3 hours or I didn't fall back to sieep

51. Not counting times when you were awake in bed, how many hours of actual sleep did you get during the worst night?

0 More than 7 hours

1 Between 4 to 7 hours

2 Between 2 to 4 hours

3 Less than 2 hours or I didn't sleep

52. Not counting times when you were awake in bed, how many hours of actual sleep did you get during most nights?

0 More than 7 hours

1 Between 4 to 7 hours

2 Between 2 to 4 hours

3 Less than 2 hours or I didn't sleep 


\section{PIRS}

ID

Date $\frac{}{m}-\frac{1}{m} \frac{}{d} \frac{1}{d} \frac{}{y}-\frac{}{y}$

53. On how many nights did it take longer than 30 minutes to fall to sleep?

0 None or 1 night

1 On 2 or 3 nights

2 On 4 or 5 nights

3 On 6 or all nights

54 . On how many nights did you wake up and have trouble falling back to sleep?
0 None or 1 night
1 On 2 or 3 nights
2 On 4 or 5 nights
3 On 6 or all nights

55. On how many mornings did you wake up not fuliy rested?
0 None or 1 morning
1 On 2 or 3 mornings
2 On 4 or 5 mornings
3 On 6 or all mornings

56. On how many days did you have trouble coping because of poor sleep?
O None or 1 day
1 On 2 or 3 days
2 On 4 or 5 days
3 On 6 or all days

\begin{tabular}{|c|c|c|c|c|}
\hline D. Over the past week, how would you rate: & Excellent & Good & Fair & Poor \\
\hline 57 Your sleep quality, compared to most people & 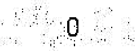 & $1:$ & 2 & 3 \\
\hline 58. Your satisfaction with your sleep & 0 & 1 & 2 & 3 \\
\hline $\begin{array}{l}59 \text { Your abity to get things done, compared to your } \\
\text { best }\end{array}$ & 0 & 1 & 2 & 3 \\
\hline 60. Your satisfaction with how you got things done & 0 & 1 & 2 & 3 \\
\hline 61. The regularity of your sleep & 0 & 1 & 2 & 3 \\
\hline 62. The soundness of your sleep & 0 & 1 & 2 & 3 \\
\hline $\begin{array}{l}\text { 63. How well you talked and communicated with } \\
\text { others }\end{array}$ & 0 & 1 & 2 & 3 \\
\hline 64. Your sense of humor & 0 & 1 & 2 & 3 \\
\hline 65 Your quality of life & 0 & 1 & 2 & 3 \\
\hline
\end{tabular}

Page 4 of 5 


\begin{tabular}{|c|c|c|c|c|c|}
\hline \multirow{3}{*}{ ID -----} & \multirow{3}{*}{ Date $\bar{m}$} & \multirow{3}{*}{\multicolumn{2}{|c|}{$\mathrm{m}^{\prime} \frac{\mathrm{d}}{\mathrm{d}}-\overline{\mathrm{d}}^{\prime}-$}} & & \\
\hline & & & & 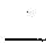 & \\
\hline & & & & $y$ & $\bar{y}$ \\
\hline
\end{tabular}

E. Thank you for completing this rating scale. We weicome your comments.

66. Please feel free to tell us about any aspects of your sleep or wakefulness we may have missed. Also feel free to tell us your opinion about this insomnia rating scale. (9) 2002, University of Pittspurgh. All rights reserved. Mage 50 of 5
Buysse,D.J., Pilkonis, P.A., Miewald,J.M., Carey,T.J., and
(the University of Pittsburgh. 
Page 1 of 4

Subject's Initials

ID\#

Date Time

\section{PITTSBURGH SLEEP QUALITY INDEX}

INSTRUCTIONS:

The following questions relate to your usual sleep habits during the past month only. Your answers should indicate the most accurate reply for the majority of days and nights in the past month.

Please answer all questions.

1. During the past month, what time have you usually gone to bed at night?

BED TIME

2. During the past month, how long (in minutes) has it usually taken you to fall asleep each night?

\section{NUMBER OF MINUTES}

3. During the past month, what time have you usually gotten up in the morning?

GETTING UP TIME

4. During the past month, how many hours of actual sleep did you get at night? (This may be different than the number of hours you spent in bed.)

\section{HOURS OF SLEEP PER NIGHT}

\section{For each of the remaining questions, check the one best response. Please answer all questions.}

5. During the past month, how often have you had trouble sleeping because you ...

a) Cannot get to sleep within 30 minutes

$\begin{array}{llll}\begin{array}{l}\text { Not during the } \\ \text { past month }\end{array} & \text { Less than } & \text { Once or twice } & \text { Three or more } \\ \text { once a week } & \text { a week } & \text { times a week }\end{array}$

b) Wake up in the middle of the night or early morning

Not during the
past month

Less than once a week

Once or twice a week

Three or more times a week

c) Have to get up to use the bathroom

$$
\text { Not during the }
$$
past month

Less than once a week
Once or twice a week
Three or more times a week 
d) Cannot breathe comfortably

\begin{tabular}{|c|c|}
\hline $\begin{array}{l}\text { Not during the } \\
\text { past month }\end{array}$ & $\begin{array}{l}\text { Less than } \\
\text { once a week }\end{array}$ \\
\hline
\end{tabular}

e) Cough or snore loudly

Not during the
past month

Less than once a week

Once or twice a week

Three or more times a week

f) Feel too cold

Not during the past month

Less than once a week

Once or twice a week

Three or more times a week

g) Feel too hot

Not during the past month

Less than once a week

Once or twice a week

Three or more times a week

h) Had bad dreams

Not during the past month

Less than once a week

Once or twice a week

Three or more times a week

i) Have pain Not during the past month

Less than once a week

Once or twice a week

Three or more times a week

j) Other reason(s), please describe

How often during the past month have you had trouble sleeping because of this?

Not during the past month

Less than once a week
Once or twice a week
Three or more times a week

6. During the past month, how would you rate your sleep quality overall?

Very good

Fairly good

Fairly bad

Very bad 
Page 3 of 4

7. During the past month, how often have you taken medicine to help you sleep (prescribed or "over the counter")?

Not during the Less than Once or twice Three or more

past month

once a week

a week

times a week

8. During the past month, how often have you had trouble staying awake while driving, eating meals, or engaging in social activity?

$\begin{array}{llll}\text { Not during the } & \text { Less than } & \text { Once or twice } & \text { Three or more } \\ \text { past month } & \text { once a week } & \text { a week } & \text { times a week }\end{array}$

9. During the past month, how much of a problem has it been for you to keep up enough enthusiasm to get things done?

No problem at all

Only a very slight problem

Somewhat of a problem

A very big problem

10. Do you have a bed partner or room mate?

No bed partner or room mate
Partner/room mate in other room
Partner in same room, but not same bed
Partner in same bed

If you have a room mate or bed partner, ask him/her how often in the past month you have had...

a) Loud snoring

Not during the past month

Less than once a week

Once or twice

Three or more

times a week

b) Long pauses between breaths while asleep

\section{Not during the} past month
Once or twice a week

Three or more times a week

c) Legs twitching or jerking while you sleep

Not during the past month
Less than once a week
Once or twice a week
Three or more times a week 
Page 4 of 4

d) Episodes of disorientation or confusion during sleep

$\begin{array}{llll}\begin{array}{l}\text { Not during the } \\ \text { past month__ }\end{array} & \begin{array}{l}\text { Less than } \\ \text { once a week }\end{array} & \begin{array}{l}\text { Once or twice } \\ \text { a week }\end{array} & \begin{array}{l}\text { Three or more } \\ \text { times a week }\end{array}\end{array}$

e) Other restlessness while you sleep; please describe

\begin{tabular}{llll}
\hline $\begin{array}{l}\text { Not during the } \\
\text { past month }\end{array}$ & Less than \\
once a week & Once or twice & $\begin{array}{l}\text { Three or more } \\
\text { a week }\end{array}$
\end{tabular}

(C) 1989, University of Pittsburgh. All rights reserved. Developed by Buysse,D.J., Reynolds,C.F., Monk,T.H., Berman,S.R., and Kupfer,D.J. of the University of Pittsburgh using National Institute of Mental Health Funding.

Buysse DJ, Reynolds CF, Monk TH, Berman SR, Kupfer DJ:Psychiatry Research, 28:193-213, 1989. 


\section{GAD-7}

Over the last 2 weeks, how often have you been bothered by the following problems?

Not Several More than Nearly

at all days half the every day

(Use " $\boldsymbol{V}$ " to indicate your answer)

\begin{tabular}{llll}
\hline 1. Feeling nervous, anxious or on edge & 0 & 1 & 2 \\
\hline 2. Not being able to stop or control worrying & 0 & 1 & 3 \\
\hline 3. Worrying too much about different things & 0 & 1 & 3 \\
\hline 4. Trouble relaxing & 0 & 1 & 3 \\
\hline $\begin{array}{l}\text { 5. Being so restless that it is hard to sit still } \\
\text { 6. Becoming easily annoyed or irritable }\end{array}$ & 0 & 1 & 3 \\
\hline 7. Feeling afraid as if something awful & 0 & 1 & 3 \\
\hline
\end{tabular}

Developed by Drs. Robert L. Spitzer, Janet B.W. Williams, Kurt Kroenke and colleagues, with an educational grant from Pfizer Inc. No permission required to reproduce, translate, display or distribute. 
VITA

\section{VENKATARAGHAVAN RAMAMOORTHY}

2000-2005

2005-2006

2006-2008

2008-2009

2009-2011

2011-2015
Medical Doctorate

Maharashtra University of Health Sciences

Mumbai, India

Medical Intern

Grant Medical College

Mumbai, India

Medical Officer

District Health Office

Thane, India

Graduate Certificate in Epidemiology

Florida International University

Miami, Florida

Master of Science in Dietetics \& Nutrition

Florida International University

Miami, Florida

Doctoral Candidate in Dietetics \& Nutrition

Florida International University

Miami, Florida

\section{PUBLICATIONS AND PRESENTATIONS}

Ramamoorthy V, Rubens M, Saxena A, Shehadeh N. Selenium and Vitamin E for Prostate Cancer-Justifications for the SELECT Study. Asian Pacific Journal of Cancer Prevention: APJCP. 2014;16(7):2619-2627.

Rubens M, Ramamoorthy V, Saxena A, Shehadeh N. Public health in the twenty-first century: the role of advanced technologies. Frontiers in Public Health. 2014;2.

Rubens M, Ramamoorthy V, Attonito J, Saxena A, Nair RR, Shehadeh N. Health Promotion and Disease Prevention Strategies for Today's Physicians. The American Journal of the Medical Sciences. 2015;349(1):73-79.

Rubens M, Ramamoorthy V. HIV Vaccine: Recent Advances Current Roadblocks and Future Directions. Vaccine. 2013;31(35):3502-3518. 
Rubens M, Ramamoorthy V, Attonito J, et al. A review of 5-HT transporter linked promoter region (5-HTTLPR) polymorphism and associations with alcohol use problems and sexual risk behaviors. Journal of Community Genetics. 2015:1-10.

Saxena A, Rubens M, Ramamoorthy V, Khan H. Risk of second cancers in merkel cell carcinoma: a meta-analysis of population based cohort studies. Journal of Skin Cancer. 2014;2014.

Khan HM, Saxena A, Ross E, Ramamoorthy V, Sheehan D. Inferential Statistics from Black Hispanic Breast Cancer Survival Data. The Scientific World Journal. 2014;2014.

Khan H, Ibrahimou B, Saxena A, Ramamoorthy V. Statistical estimates from black nonHispanic female breast cancer data. Asian Pacific Journal of Cancer Prevention: APJCP. 2013;15(19):8371-8376.

Khan HMR, Saxena A, Vera V, Ramamoorthy V. Black Hispanic and Black NonHispanic Breast Cancer Survival Data Analysis with Half-normal Model Application. Asian Pacific Journal of Cancer Prevention: APJCP. 2014;15(21):9453. 